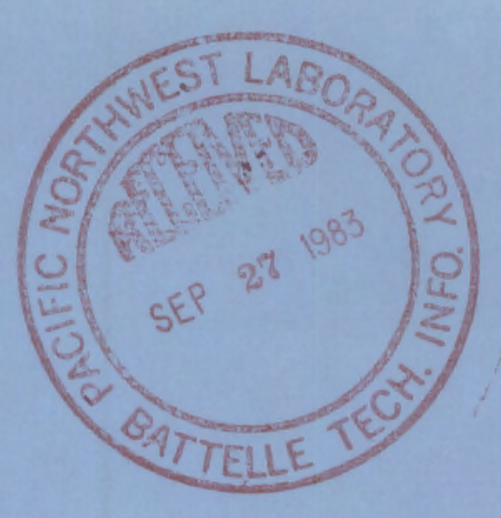

PNL-4728

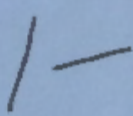

\title{
Valmet-A Valley Air Pollution Model
}

\author{
C. D. Whiteman \\ K. J. Allwine
}

September 1983

Prepared for the U.S. Environmental Protection Agency under Interagency Agreement AD-89-F-2-097-0

Pacific Northwest Laboratory Operated for the U.S. Department of Energy by Battelle Memorial institute

\section{Battelle}




\section{DISCLAIMER}

This report was prepared as an account of work sponsored by an agency of the United States Government. Neither the United States Government nor any agency thereof, nor any of their employees, makes any warranty, express or implied, or assumes any legal liability or responsibility for the accuracy, completeness, or usefulness of any information, apparatus, product, or process disclosed, or represents that its use would not infringe privately owned rights. Reference herein to any specific commercial product, process, or service by trade name, trademark, manufacturer, or otherwise, does not necessarily constitute or imply its endorsement, recommendation, or favoring by the United States Government or any agency thereof. The views and opinions of authors expressed herein do not necessarily state or reflect those of the United States Government or any agency thereof.

\section{PACIFIC NORTHWEST LABORATORY}

operated by

BATTELLE

for the

UNITED STATES DEPARTMENT OF ENERGY

under Contract DE-AC06-76RLO 1830 
PNL -4728

VALMET-A VALLEY AIR POLLUTION MODEL

C. D. Whiteman

K. J. Allwine

September 1983

Prepared for the U. S. Environmental Protection Agency under Interagency Agreement AD-89-F-2-097-0

Project Officer: Alan H. Huber Meteorology and Assessment Division Environmental Sciences Research Laboratory Research Triangle Park, NC 27711

Pacific Northwest Laboratory Richland, Washington 99352 


\section{DISCLAIMER}

Although the research described in this report has been funded wholly or in part by the United States Environmental Protection Agency through interagency agreement $A D-89-F-2-097-0$ to the Pacific Northwest Laboratory, it has not been subjected to agency review and therefore does not necessarily reflect the views of the agency and no official endorsement should be inferred. Mention of trade names or commercial products does not constitute endorsement or recommendation for use. 
PROLOGUE

This report is submitted as part of the Green River Ambient Model Assessment (GRAMA) project being conducted at the U.S. Department of Energy's Pacific Northwest Laboratory for the U.S. Environmental Protection Agency. The GRAMA Program has, as its ultimate goal, the development of validated air quality models that can be applied to the complex terrain of the Green River Formation of western Colorado, eastern Utah and southern Wyoming. The Green River Formation is a geological formation containing large reserves of oil shale, coal and other natural resources. Development of these resources may lead to a degradation of the air quality of the region. Air quality models are needed immediately for planning and regulatory purposes to assess the magnitude of these regional impacts. This report documents one of the models being developed for this purpose within GRAMA - specifically a model developed to predict worst case air pollutant concentrations due to elevated continuous point sources of pollution located in deep valley terrain. Model testing, evaluation, and revision are planned prior to completion of the final project report and user's guides in the spring of 1985 . 


\section{ABSTRACT}

An air quality model is described for predicting air pollution concentrations in deep mountain valleys arising from nocturnal downvalley transport and diffusion of an elevated pollutant plume, and the fumigation of the plume on the valley floor and sidewalls after sunrise. Included is a technical description of the model, a discussion of the model's applications, the required model inputs, sample calculations and model outputs, and a full listing of the FORTRAN computer program. 


\section{CONTENTS}

Prologue............................................. $i j i$

Abstract............................................ iv

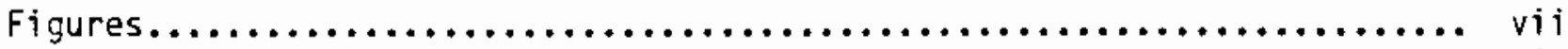

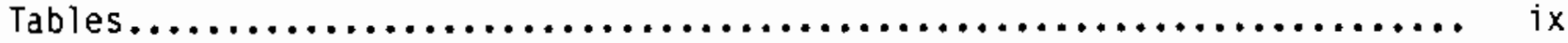

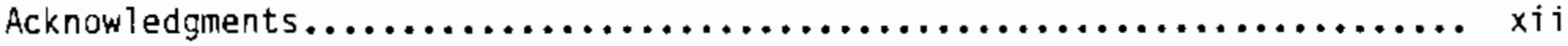

1. Introduction $\ldots \ldots \ldots \ldots \ldots \ldots \ldots \ldots \ldots \ldots \ldots \ldots \ldots \ldots \ldots \ldots \ldots \ldots \ldots$

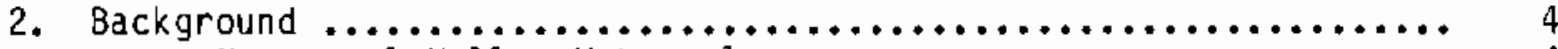

Nocturnal Valley Meteorology....................... 4

Valley Meteorology During the Temperature Inversion

Breakup Period.................................. 5

3. Technical Discussion............................... 14

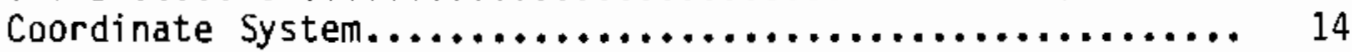

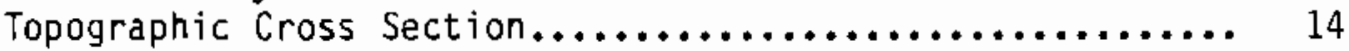

Nocturnal Model................................ 17

Pollutant Source............................ 17

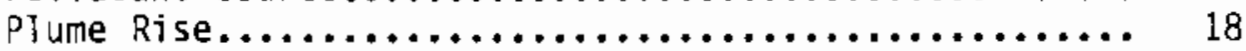

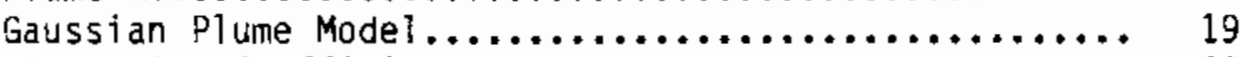

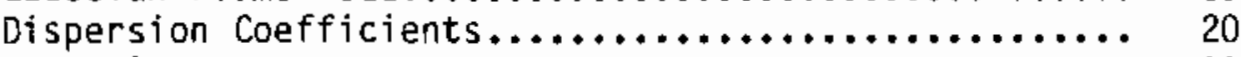

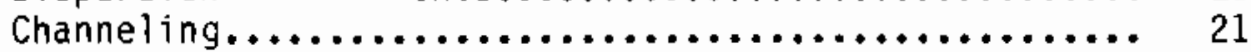

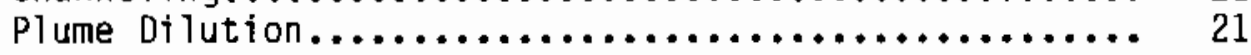

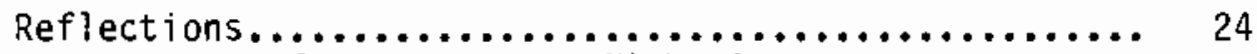

Calculation of Steady-State Nighttime

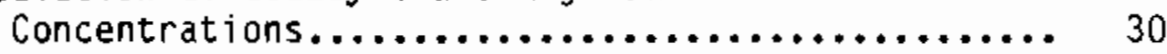

Daytime Model................................... 30

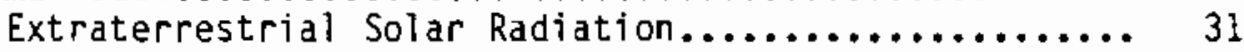

Parameterization of Sensible Heat Flux............. 35

Model Grid.................................. 35

Thermodynamic Equations for CBL Ascent and

Inversion Descent........................ 37

Advection in the Slope Flows.................... 41

Pollution Concentration Calculation Method............ 43

Exponential Decay of Concentration............... 46

Maximum 1- and 3-Hour Average Concentrations......... 47

4. Overview of Modular VALMET Mode $\ldots \ldots \ldots \ldots \ldots \ldots \ldots \ldots \ldots \ldots \ldots \ldots \ldots . \ldots . \ldots . \ldots$

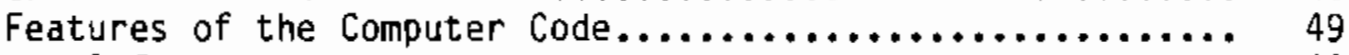

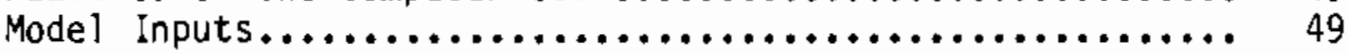

Specification of the Model Inputs by the User............ 52

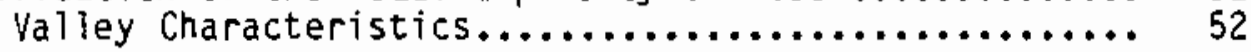

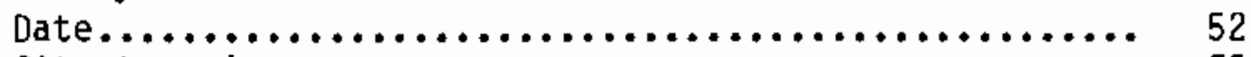

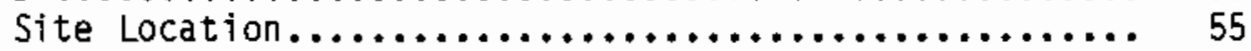




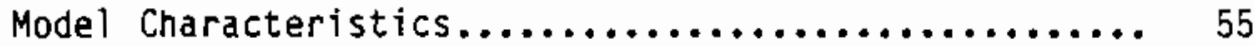

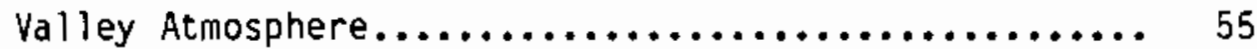

Stack Characteristics........................ 55

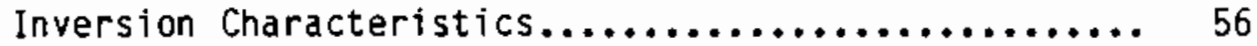

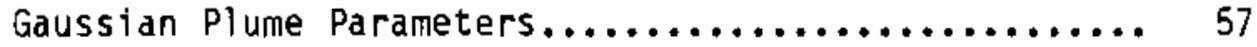

Sensible Heat Flux........................... 58

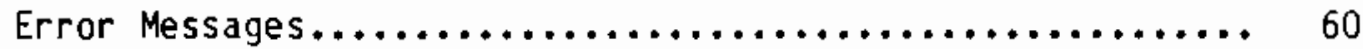

5. Technical Description of Individual Modules................ 62

VALMET-Main Program.............................. 62

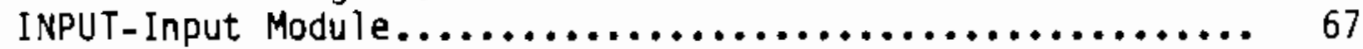

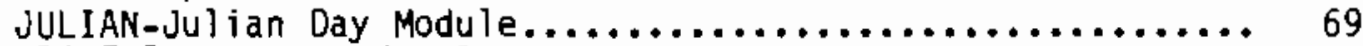

PRISE-Plume Rise Module........................... 70

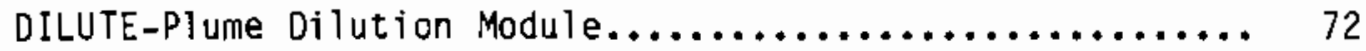

INGRAT-Valley Plume Reflection Module................ 73

NORMAL-Normal or Gaussian Curve Integration ModuTe....... 75

GAUSS-Gaussian Plume Module........................ 76

SOLAR-Extraterrestrial Solar Radiation Module........... 78

EBDGT-Surface Energy Budget Module.................. 80

DESCNT-Inversion Descent and CBL. Growth Module........... 81

PRDFIL-Concentration Profile Module.................. 83

VELOCY-Ups]ope Flow Velocity Module.................. 85

BRKUP-Pollutant Mass Budget Module................... 87

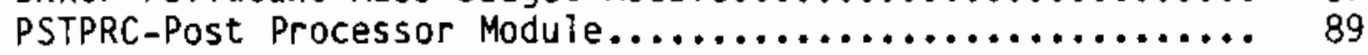

6. Sample Model Runs.................................. 91

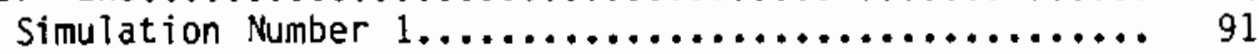

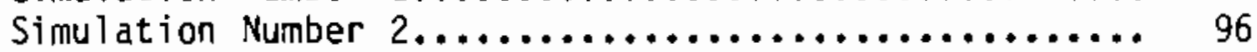

7. Further Work ................................... 99

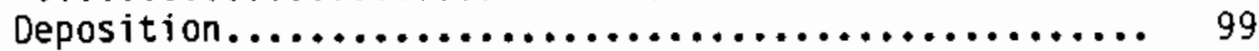

Emission Above or Below Stable Core................ 99

Energy Budget................................. 100

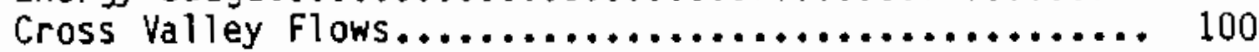

Turbulent Erosion of the Valley Inversion by

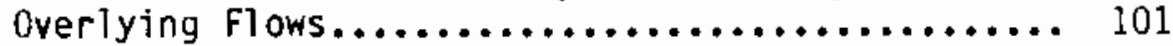

Effect of Tributary Flows on the Enhancement of

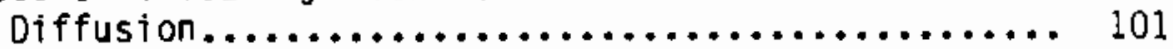

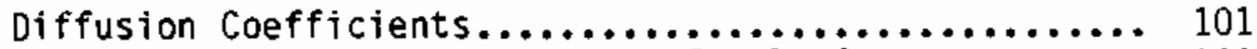

Time-Varying Wind Speeds in the Stable Core.......... 101

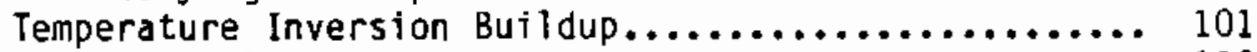

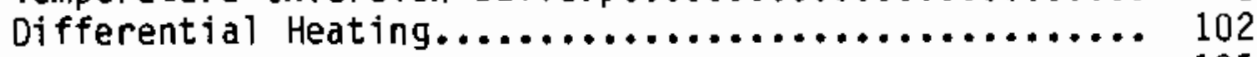

8. Sumary........................................ 105

References........................................ 107

Appendix A - FORTRAN Listing of VALMET .................... 112

AppendiX $B$ - FORTRAN Lising of VALMET Output Plotting

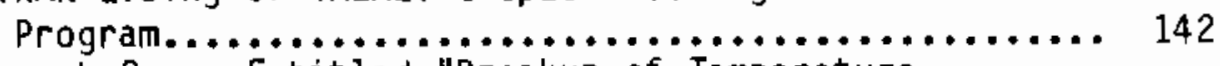

Appendix C - Research Paper Entitled "Breakup of Temperature

Inversions in Deep Mountain Valleys:

Part II. Thermodynamic Model".................. 


\section{FIGURES}

Number

Page

1 Three patterns of temperature structure evolution during the inversion breakup period. Potential temperature profiles are on the left, and time-height analyses of CBL height and

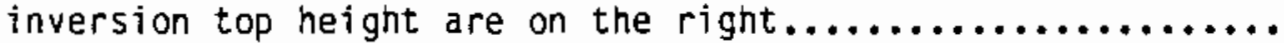

2 Typical mid-morning wind structure over and within a deep valley on the western slope of the Rockies, illustrating the five interrelated wind systems identified in field studies.

3 Relationship between temperature structure layers and wind systems. The temperature profile is a typical mid-morning

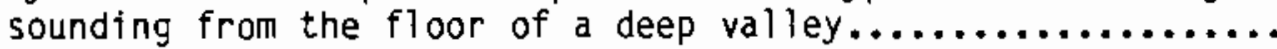

4 Dual soundings from a valley floor and a valley sidewall illustrating the up-slope flow found within the CBL over the sidewali

5 Illustration of the hypothes is of inversion destruction. In the center of the diagram cross sections of a valley are shown at times $t_{1}, t_{2}, t_{3}, t_{4}$, and $t_{0}$. On the left are corresponding potential temperature profiles as taken from the valley center. On the right are corresponding up-valley wind components as a function of height. At sunrise, $t_{i}$, an inversion is present in the valley. At $t_{2}$, a time after suniight has illuminated the valley floor and slopes, a growing CBL is present over the valley surfaces. Mass and heat are entrained into the CBLs from the stable core above and carried up the sidewalis in the upslope flows. This results in a sinking of the stable core and growth of the CBLs ( $t_{3}$ and $t_{4}$ ) until the inversion is broken $\left(t_{0}\right)$ and $a$ turbulent well-mixed neutral atmosphere prevails through the valley depth. Down-valley winds continue to blow in the stable core during the inversion breakup period. Winds in the CBL below, and in the region above the stable core often blow

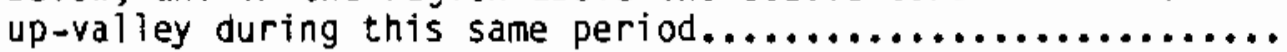

6 Air pollution implications of CBL growth and inversion top descent..................................... 
7 Illustration of the nocturnal down-valley transport and dispersion of a pollutant plume. The terrain following coordinate system, with cross valley section an arbitrary down-valley distance $x$, is illustrated.................. 15

8 Illustration of the local coordinate system on a cross valley section.................................. 16

9 Parameters used in the VALMET model to approximate a valley topographic cross section. The three parameters include the valley width and the two sidewall inclination angles.......................................... 16

10 Illustration of the definitions of secondary topographic variables used in the model......................... 16

11 Cross section of pollutant plume and valley topography illustrating the integral method of calculation for plume reflection, and diffusion out the top of the

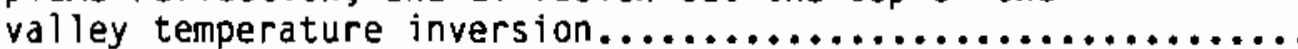

12 VALMET grid configuration on a valley cross section illustrating the nomenclature used in the model. The cross section is representative of the model configuration at sunrise, when the initial CBL height, inversion top height and plume centerline height are as shown. The $x$ 's on the figure illustrate the locations where nocturnal pollutant concentrations are determined.

13 Extraterrestrial solar heat flux as a function of time, showing solar model nomenclature. The figure illustrates how the sensible heat flux $F$ is parameterized as a fraction $A_{0}$ of the extraterrestrial solar heat flux on a horizontal surface above the site. The times of sunrise and sunset are shown. The daylength $\tau$ is defined in the model as the time difference between sunset and sunrise....................

14 Cross section of the valley floor and sidewalls illustrating the grid elements whose height corresponds to the CBL height. The rate of sinking of the top of the inversion (arrow) is related to the upslope transport of mass (other

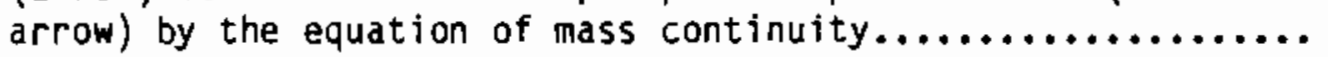

15 Illustration of the effect of topography in controlling the heating rates of the air within a valley temperature inversion versus the air within an inversion over the plains. The same incoming energy heats a smaller volume of air in the valley case.............................. 
16 Diagram showing the changes in CBL and inversion depth at a given time step above a valley floor grid element. The amount of air volume incorporated into the growing CBL at each time step is seen to be represented by $\left(y_{2}-y_{1}\right)$.

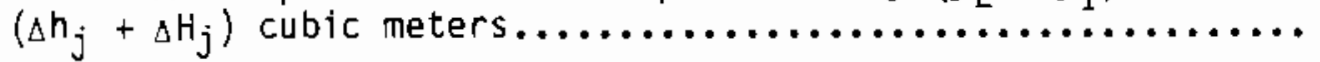

17 Representation of the volumetric element of mass incorporated into the growing CBL above a valley floor grid element at each model time step. The $x$ 's in the figure represent the positions where pollutant calculations are performed at each time step to estimate the average pollutant concentration carried within the volumetric element during the time step....

18 Schematic diagram of an individual model grid element

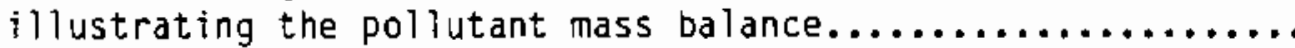

19 Flow diagram of VALMET model, showing the modular structure of the model and the physical processes parameterized in the modules. The modules indicated between the two-horizontal dashed lines constitute the nocturnal portion of the model. The daytime portion of the model follows the second dashed line.

20 Illustration of the VALMET model input table as it appears on the user's interactive terminal screen................. 53

21 Listing of summary output file generated by Sample

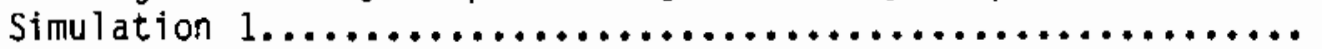

22 Plots of Sample Simulation 1: (a) nocturnal vertical concentration profile through plume centerline, (b) CBL height (long dashes) and inversion height (short dashes) as a function of time, and (c) nocturnal cross valiey concentration profile through plume centerline..............

23 Pollutant concentration versus time for selected grid elements for Sample Simulation 1 . The downvalley distance, centerline concentration and fraction of mass diffusing out the top of the valley inversion during the plume's nocturnal transport are indicated on the figure...................... 95

24 Same as Figure 22, for Sample Simulation $2 \ldots \ldots \ldots \ldots \ldots \ldots \ldots . . . . .97$

25 Same as Figure 23, for Sample Simulation $2 \ldots \ldots \ldots \ldots \ldots \ldots \ldots$......... 98 
26 Illustration of differential solar flux on opposing sidewalls for Brush Creek Colorado on August 1, 1982. The Brush Creek Valley drains from NW to SE. The curves represent extraterrestrial solar flux (i.e., they assume no atmosphere) and were determined using a solar radiation model.............. 10

27 Brehm's (1981) conceptual model of temperature inversion destruction in Austria's Inn Valley, showing differential CBL growth over the opposite sidewalls and continued downvalley flow in the elevated stable core................. 104 


\section{TABLES}

Number

Page

1 Values of the Constants I, J, $K$ for $\sigma_{y}$ as a Function of Downwind Distance for Six Stability Categories [28]......... 22

2 Values of the Constants I, J, $K$ for $\sigma_{z}$ as a Function of Downwind Distance for Six Stability Categories [28]......... 22

3 Relationship Between weather Conditions and Stability

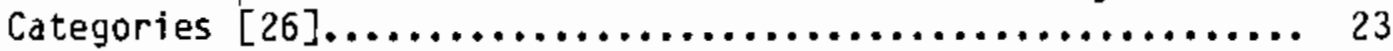

4 Equation of Time Correction........................ 34

5 Default values of VALMET Input Parameters.............. 54 


\section{ACKNOWLEDGMENTS}

The work reported here had its origins in research conducted at the Department of Atmospheric Science at Colorado State University while one of the authors (COW) was a student there. Dr. Thomas B. McKee's contributions to the work at that time, as a thesis advisor, are greatly appreciated.

The authors' colleagues at PNL contributed suggestions and criticisms as the work progressed that led to significant improvements in the model's design and in the clarity of the text. Dr. Thomas $W$. Horst and Dr. J. Christopher Doran are especially thanked for their help in that regard.

Mr. Alan Huber, the EPA Project Officer, and Mr. Rich Fisher, EPA Region VIII meteorologist, are thanked for their support and encouragement of the work. Mr. Fisher tested early versions of the model and provided a number of very useful suggestions from the viewpoint of a model user that resulted in improvements of the model code.

The work was funded by the Energy Air Division, Office of Environmental Processes and Effects Research, Office of Research and Development, U.S. Environmental Protection Agency under Interagency Agreement No. AD-B9-F-2-097-0 with the U.S. Department of Energy. 
SECTION 1

INTRODUCTION

This report documents an air quality model that was developed to predict concentrations of nonreactive pollutants arising from elevated continuous point sources that emit pollutants within well-defined deep mountain valleys. The model, termed VALMET, is intended to simulate the effects on pollutant transport and diffusion of various meteorological processes that are thought to result in worst-case pollutant concentrations. The model is run for situations when pollutants are carried in locally developed circulations within a valley when these circulations are "decoupled" from prevailing circulations above the valley. The primary physical processes included in the model are:

Nocturnal Simulation:

- Transport by down-valley drainage flows

- Plume channeling within the valley

- Enhanced horizontal and vertical diffusion due to topography

- Plume reflections off valley floor and sidewalls

- Pollutant diffusion out the top of the valley

- Dilution of the plume due to clean air inflow from tributaries.

Post-Sunrise Simulation During Temperature Inversion Breakup Period:

- Convective boundary layer growth

- Plume subsidence in the valiey inversion

- Fumigation into growing convective boundary layers

- Transport and diffusion in upslope flows over the sidewalis.

The model, while including a variety of meteorological processes, is highly parameterized so that it is simple in concept and easy to run. The model is composed of 13 modules, or subroutines, arranged in such a way that an improved understanding of individual valley meteorological phenomena can be easily incorporated in future versions of the model. The modules within the model can be replaced by data if they are available. Thus, the model can be used in one of two modes. It can be used in a "screening" mode to calculate pollutant concentrations within a valley when itttle site specific data is available, or the model can be "calibrated" with site specific data so that it can be used as a site-specific model. 
The two-dimensional model was developed primarily to predict pollutant concentrations on the valley floor and sidewalls on a valley cross section an arbitrary distance downvalley from a pollutant source during the postsunrise temperature inversion breakup period. It is necessary, however, to know the air pollution concentration within the valley cross section at sunrise, as an initial condition for the post-sunrise simulation. The model is therefore comprised of two parts--a nighttime part whose purpose is to predict concentrations on the valley cross-section at sunrise, and the daytime part which predicts concentrations on the valley floor and sidewalls during the post-sunrise temperature inversion breakup period. The temperature inversion breakup period has been identified by previous investigators [1] as a period when diurnal fumigations [2] can produce high pollutant concentrations in valleys.

The nighttime simulation, which applies during the steady-state period after valley temperature inversions and drainage wind systems have become established, uses a modified valley-following Gaussian plume algorithm to calculate air pollution concentrations for points on the valley floor and sidewalis. A plume rise formulation is used to simulate the initial rise of a pollutant plume at the stack due to momentum and buoyancy of the effiuent. Pasquill-Gifford diffusion coefficients are modified to account for enhanced nocturnal diffusion caused by rough terrain. The Gaussian plume is also modified to allow for dilution of the plume during its down-valley transport caused by clean air flowing into the plume from valley tributaries or by converging downslope drainage flows. An integral constraint on pol. lutant mass is applied to ensure that pollutant mass is conserved during the plume's transport down the valley and within any valley cross section downvailey from the emission source, except for pollution diffusion out the top of the valley.

The daytime simulation uses numerical techniques that simulate the fumigation of the nocturnal plume onto the valley floor and sidewalls as a convective boundary layer grows upwards from the heated valley surfaces and as subsiding motions occur over the valley center after sunrise. The rate of growth of convective boundary layers and subsidence within the valley temperature inversion are simulated using the bulk thermodynamic model of Whiteman and Mckee [3]. This model is driven by sensible heat flux, estimated as a fraction of the solar radiation using a highly parameterized surface energy budget. The effects of such factors as snow cover, soil moisture, cloud cover, or surface albedo are not explicitly included in the model but can be incorporated into the model in the future through an expanded energy budget module. The shape of the topographic cross section of the valley is explicitly included in the model through the specification of valley floor width and sidewall inclination angles at the valley cross section of interest. The retarding effect on temperature inversion breakup and pollution dispersion due to warm air advection above the inversion is also included in the model. Fumigated pollutants are transported from the valley cross section in upslope flows that develop within the convective boundary layers over the slopes. Pollutants are diffused through model grid elements during this transport up the slopes in the growing convective 
boundary layer. Pollutant concentrations decay exponentially within individual grid elements high on the sidewall as they are dropped from the simulation as the inversion top subsides below them.

The output from the nighttime simulation includes the steady-state pollutant concentration at valley floor and sidewall grid elements on the valley cross section of interest. The fraction of plume mass that has diffused out the top of the valley during the plume's travel is also an output of the model. Since an analytical formula describes the concentrations within a valley cross section, cross valley and vertical profiles of pollutant concentration can be calculated and plotted. The plume centerline concentration is an output of the model.

The primary output of the daytime simulation is the maximum 1- and 3-hr average pollutant concentrations in each of the model grid elements on the valley floor and sidewalls. The time varying 5-min-average concentrations for each of the grid elements between sunrise and the time of inversion destruction is also an output of the model. In addition to these primary outputs, intermediate model outputs come from individual modules in the program. The local standard time of sunrise, the duration of the daylight period, and the solar flux on a horizontal surface at solar noon come from the solar module. The convective boundary layer height and inversion top height as a function of time come from the temperature inversion breakup module.

Twenty-seven input parameters are necessary to drive the model. These input parameters include the date, site location, topographic characteristics of the valley cross section, temperature inversion characteristics at sunrise, emission and stack characteristics, down-valley windspeed(s), atmospheric stability, grid element length, and sensible heat flux parameters. If known, the rate of warm air advection above the valley can be input. The necessary model inputs can be obtained from topographic maps, engineering information on the pollutant source, and one or more seasonal meteorological data collection campaigns in the valley of interest using tethered balloon data collection systems and/or doppler acoustic sounders.

This report is written following EPA reporting guidelines $[4,5]$ and is organized in the following way. First, meteorological observations taken in a number of deep valleys in Western Colorado are summarized in order to provide a brief description of the salient meteorological features that must be included in a realistic air quality model. Second, a technical discussion is given of the mathematical representation of these processes used in VALMET. Third, a brief overview is given of the air quality model's structure. Fourth, the individual modules of the model are described in detail, including the FORTRAN code, inputs, outputs, etc. Fifth, sample runs of the model are presented. Finally, the need for further data and verification studies is indicated and an overall sumnary of the modeling approach is presented. Appendices include a complete listing of the VALMET source code, a listing of a sample plotting program for depicting model outputs, and a reprint of a scientific paper which describes the theoretical basis of one of the major components of the modeling approach. 


\title{
SECTION 2
}

\author{
BACKGROUND
}

The VALMET model is a further development of ideas that were published in research papers and reports over the last 5 years, based on a comprehensive set of valiey meteorological field experiments conducted in western colorado. These earlier papers summarize a case study of temperature inversion buildup [6], describe the data analysis, hypothesis and mathematicai foundation of the temperature inversion destruction part of the model [3,7-10]; describe the initial idea of an air pollution model framework abie to incorporate upslope winds and fumigations arising after sunrise [11]; and present a general summary of Colorado valley meteorology based on data analyses [12]. Progress in the development of VALMET has been described in two progress reports submitted to EPA in 1981 and $1982[13,14]$.

The present version of VALMET, as described in this report, must be considered as an initial or preliminary version of the model. This report is written to facilitate the limited distribution of the modei to users who will provide comments and suggestions regarding the further development of the model. The present version has not yet undergone sensitivity tests, has not been evaluated with respect to its performance in simulating air pollution concentrations in actual valleys, and contains modules which have not yet been fully deveìoped.

The user is cautioned against applying the air quality model for meteorological or topographical conditions that are contrary to assumptions made in the model. In order for the user to understand fully the assumptions and hypotheses used in the model, it is necessary to summarize briefly the results and hypotheses that arose from the observational program and the work of previous investigators. In this section we present a condensed summary of this material for both the nocturnal and temperature inversion breakup periods, emphasizing the physical mechanisms in the valley that are responsible for the transport and diffusion of pollutants. It is these individual mechanisms that are parameterized in the air pollution model.

\section{NOCTURNAL VALLEY METEOROLOGY}

The most universal features of nighttime valley meteorology, reported in valleys all over the globe [15-19, and others], is the drainage of cooled air down the valley sidewalls and valley axes. The initiation of these flows, which is closely related to changes in the temperature structure above valley surfaces, has received inadequate study to date and cannot be adequately parameterized for inclusion in the model. After the short ( 2 to 
$4 \mathrm{hr}$ ) initiation period the down-valley flows become well-established through the valley depth, and attain a speed that is characteristic of the valley and is reasonably steady-state. Observations $[9,12]$ show that the strength of the down-valley flows is quite variable from valley to valley, and no model is yet available which can accurately predict their strengths in individual valleys. In Colorado's valleys, however, observations show that windspeeds on a clear undisturbed night in one season are typical of windspeeds on similar nights in other seasons. Observations thus seem to be the best way of specifying down-valley wind system strength.

Down-slope flows on the valley sidewalls become weaker and less organized after the valley inversion develops, since air flowing down the slopes must work against a very stable ambient stratification. Slope flows can more easily become detached from the sidewalis during this period, providing an important stirring mechanisin which causes enhanced horizontal diffusion of pollutant plumes within the valley inversion. The effects of terrain roughness and mechanically generated turbulence also play an important role in enhancing dispersion in the down-valley flows.

Pollutant concentrations can be strongly affected by dilution of the plume due to clean air flowing in from valley tributaries. This feature of meteorology, unique to valleys, can make substantial changes in pollutant concentrations, especially where high volume fluxes of clean air are involved, as when a pollutant plume originates in a small tributary and emerges into a major valley.

\section{VALLEY METEOROLOGY DURING THE TEMPERATURE INVERSION BREAKUP PERIOD}

Observation in Colorado's deep valleys $[9,10]$ have provided detail on the changes in atmospheric structure during the morning transition period when the nocturnal down-valley flows are reversed to daytime up-valley flows. The transition period is much longer than expected in these deep valleys and the physical processes leading to the transition are expected to be of great importance for air pollution transport and dispersion. In this section, we will summarize the observations of inversion destruction, pointing out typical characteristics of the meteorology of these valleys, and the physical processes that must be included in realistic air pollution models simulating the inversion destruction period.

At sunrise nocturnal inversions in most of the valleys were built up to about the level of the surrounding ridgetops. The average depth, based on 21 cases studies, was 604-m. Vertical potential temperature gradients within the jnversions averaged $0.0295^{\circ} \mathrm{K} \mathrm{m}^{-1}$, but ranged from 0.0187 to $0.0566^{\circ} \mathrm{K} \mathrm{m}^{-1}$. The strength and direction of prevailing winds aloft, as determined from the Grand Junction, Colorado, morning rawinsonde sounding, had no demonstratable effect on the characteristics of valley inversions. The valley inversions showed much less variability from day to day and from season to season than inversions over Grand Junction. This suggests that at least for a narrow range of synoptic conditions, valley topography produces more consistent inversions, perhaps by protecting them from winds aloft. 
When the along-valley winds were weak, the valley vertical potential temperature profiles frequently were nyperbolic, especially near the ground. In most valleys where along-valley winds were of at least moderate strength, the inversion profiles were nearly linear with height.

Temperature inversions in all of the valieys investigated were destroyed after sunrise following one of three patterns of temperature structure evolution (Figure 1). The first pattern, observed in the widest valley studied, approximates inversion destruction over flat terrain, in which the nocturnal inversion is destroyed after sunrise by the upward growth from the ground of a warming convective boundary layer. The second pattern, observed in snow covered valleys, differs significantly from the first. Here the growth of the CBL, which begins after sunrise, is arrested once the CBL has attained a depth of 25 - to $50-\mathrm{m}$. The inversion is then destroyed as the top of the nocturnal inversion descends into the valley. Successive profiles of the valley atmosphere show a warming consistent with a simple subsidence of the previous profiles. The third pattern of temperature structure evolution was observed in all the valleys when snow cover was not present and describes the majority of case studies observed in field experiments. Following this pattern, inversions are destroyed by two processes: the continuous upward growth from the valley floor of a warming CBL and the continuous descent of the top of the nocturnal temperature inversion. Warming of the elevated inversion layer above the CBL is consistent with a simple subsidence of the previous profiles. In the Colorado valleys studied, the time required to break an inversion and establish a neutral atmosphere within the valley was typically $3-1 / 2$ to $5 \mathrm{hr}$ after sunrise. Temperature structure evolution during clear, undisturbed weather was surprisingly uniform from day to day and season to season. Thus, in future work, one may be fairly confident of observing typical inversion breakup during short field studies in undisturbed weather.

The common element of all three patterns of temperature structure evolution is the development of a CBL over the valley floor after it is illuminated by direct sunlight. Observations taken from the sidewall of one valley also show the development of a CBL after direct sunlight illuminates the sidewall. Due to the shading effects of surrounding topography, the different valley surfaces can be illuminated at significantly different times, thus affecting the initiation of CBL growth. The temperature structure of the sidewall CBL is similar to that of the CBL over the valley floor, but winds blow up the sidewall CBL at speeds of up to $3-\mathrm{m} \mathrm{sec}^{-1}$.

Five different temperature structure layers have been observed during the inversion destruction period. Above the valley floor CBL and the sidewall CBL just mentioned is the stable core of the potential temperature inversion. A neutral stability layer above the stable core appears to be part of a large scale convective boundary layer that forms over the Western Slope of the Rocky Mountains. Above this layer is the free atmosphere. 

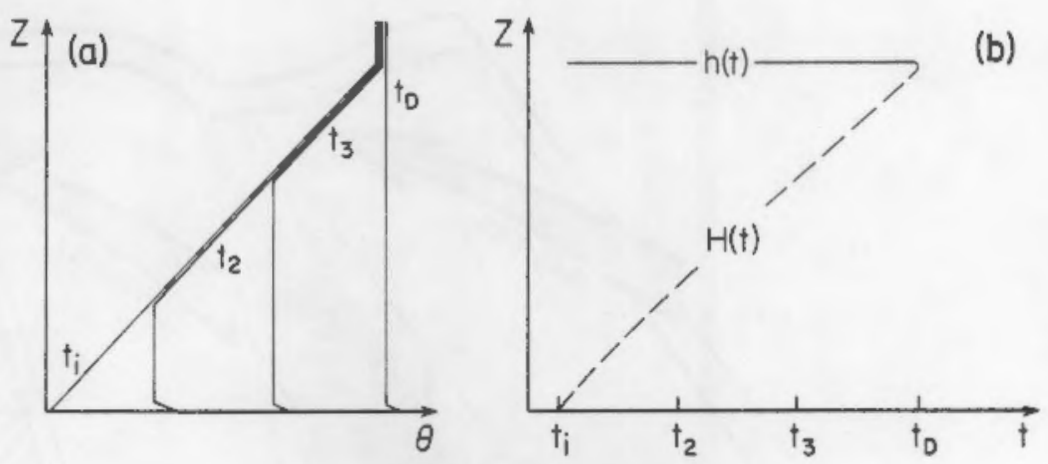

Pattern 1. Growth of CBL.
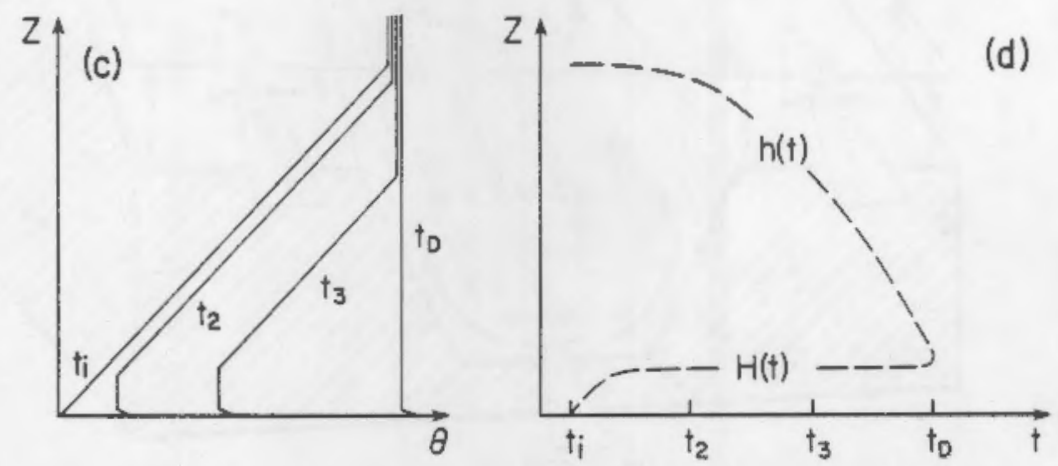

Pattern 2. Descent of inversion top and arrested growth of CBL.
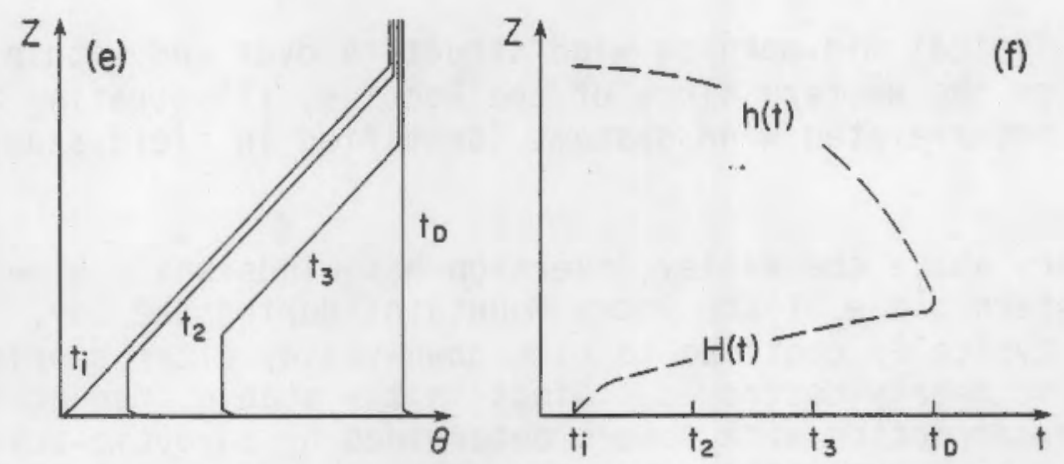

Pattern 3. Descent of inversion top and continuous growth of CBL.

Figure 1. Three patterns of temperature structure evolution during the inversion breakup period. Potential temperature profiles are on the left, and time-height analyses of CBL height $(H)$ and inversion top height $(h)$ are on the right.

Each of the five temperature structure layers, identified primarily by their potential temperature structure, can also be identified by the winds that prevail within them (see Figures 2, 3 and 4). During inversion destruction, the CBLs over the valley floor and sidewalls contain winds which blow up the floor of the valley and up the slopes. The CBL, or 


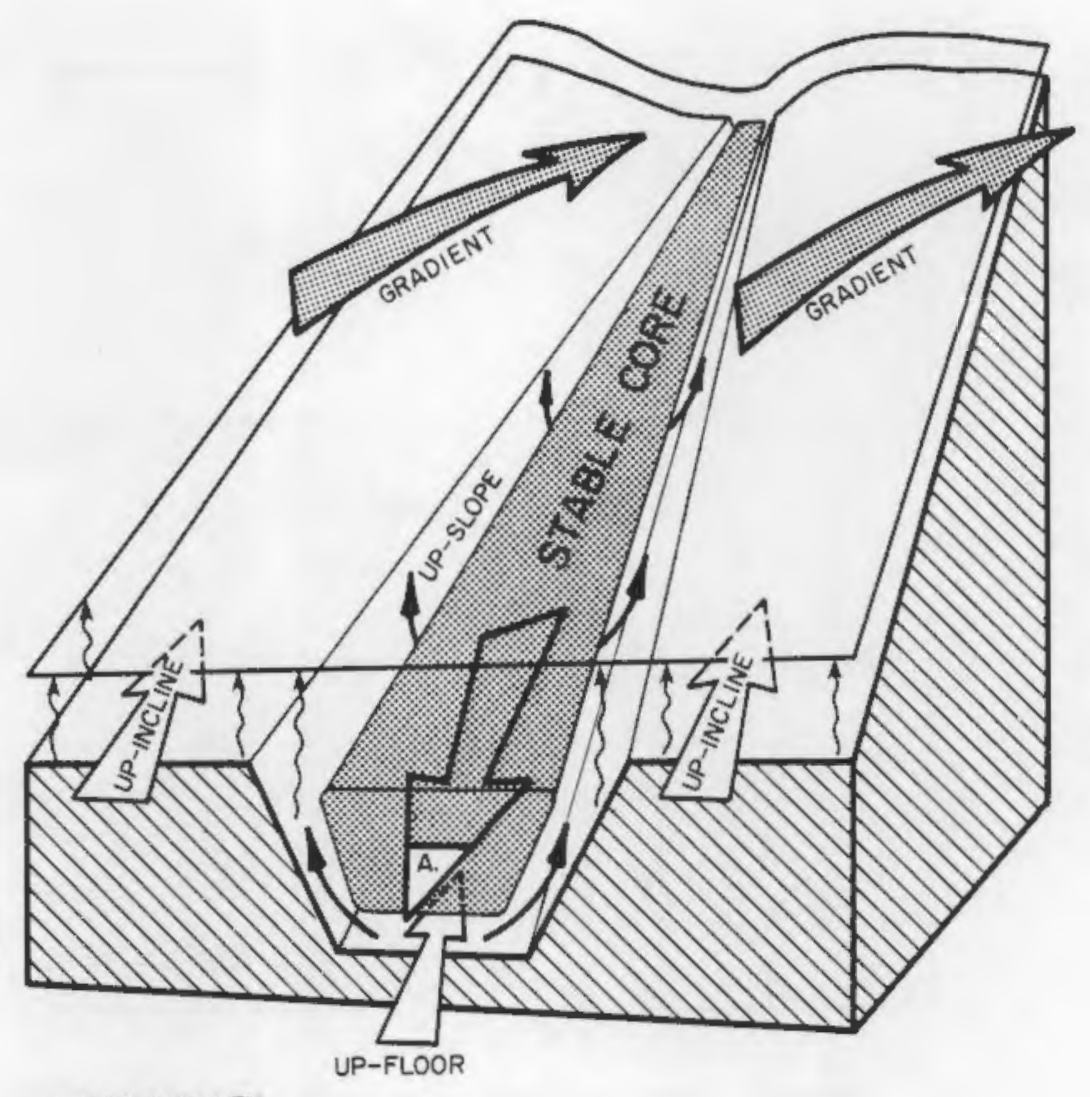

A. DOWN-VALLEY

Figure 2. Typical mid-morning wind structure over and within a deep valley on the western slope of the Rockies, illustrating the five interrelated wind systems identified in field studies.

neutral layer, above the valley inversion has winds which blow up the inclined Western Slope of the Rocky Mountains during the day. Winds in the stable core typically continue to blow down-valley after sunrise until the stable core is nearly destroyed. Winds in the stable free atmosphere may blow from any direction with speeds determined by snyoptic-scale pressure gradients. Despite variability in the strength and timing of reversal of the winds, the temperature structure evolved uniformly from day to day in individual valleys.

On the basis of the wind and temperature observations sumnarized above, an hypothesis (Figure 5) has been developed to explain the temperature structure evolution. Since energy is required to change the temperature structure, and the changes begin at sunrise, it is reasonable to hypothesize that solar radiation is the driving force. A fraction of the solar radiation, received on the valley floor and sidewalls, is converted to the sensible heat flux that provides energy to the valley atmosphere. Sensible heat flux from a surface, as over flat terrain, causes a convective boundary 


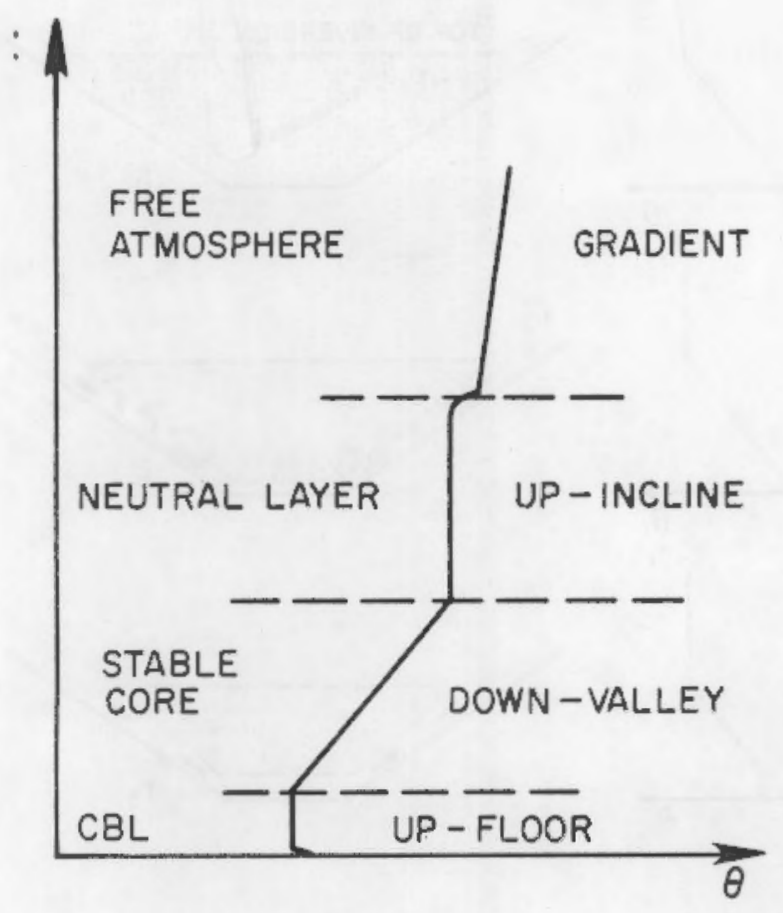

Figure 3. Relationship between temperature structure layers and wind systems. The temperature profile is a typical mid-morning sounding from the floor of a deep valley.

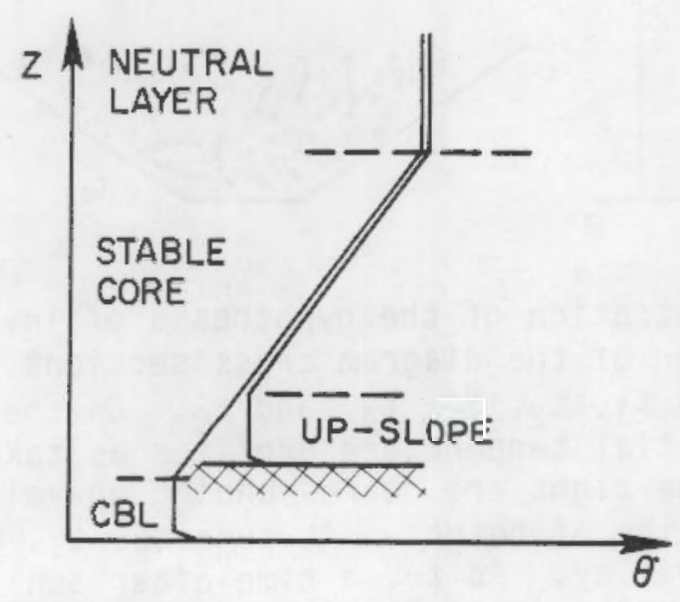

Figure 4. Dual soundings from a valley floor and a valley sidewall illustrating the upslope flow found within the CBL over the sidewall. 

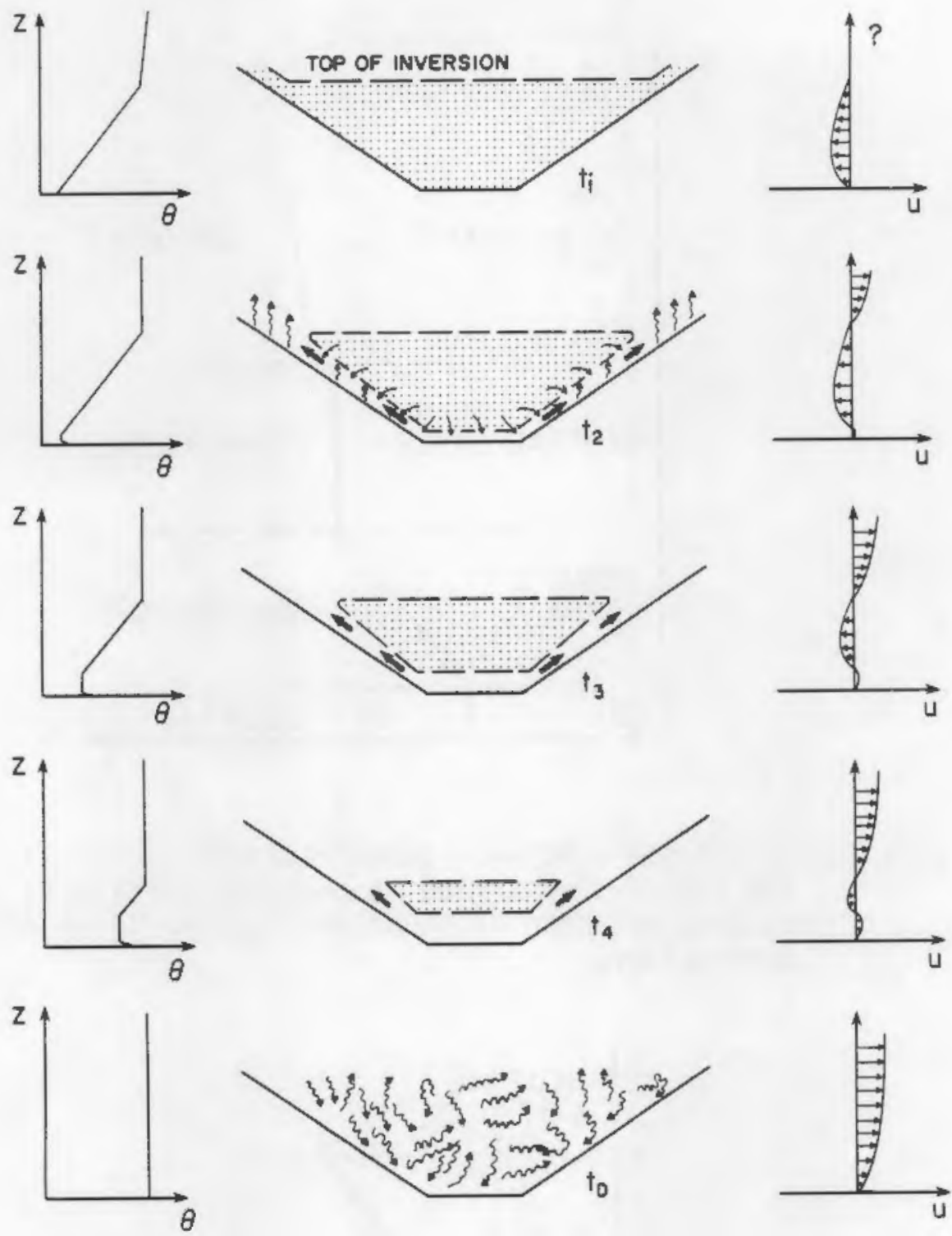

Figure 5. Illustration of the hypothesis of inversion destruction. In the center of the diagram cross sections of a valley are shown at times $t_{1}, t_{2}, t_{3}, t_{4}$, and $t_{p}$. On the left are corresponding potential temperature profiles as taken from the valley center. On the right are corresponding up-valley wind components as a function of height. At sunrise, $t_{j}$, an inversion is present in the valley. At $t_{2}$, a time after sunlight has illuminated the valley floor and slopes, a growing CBL is present over the valley surfaces. Mass and heat are entrained into the CBLS from the stable core above and carried up the sidewalls in the upslope flows. This results in a sinking of the stable core and growth of the CBLs ( $t_{3}$ and $t_{4}$ ) until the inversion is broken $\left(t_{D}\right)$ and a turbulent well-mixed neutral atmosphere prevails through the valley depth. Down-valley winds continue to blow in the stable core during the inversion breakup period. Winds in the CBL below, and in the region above the stable core often blow up-valley during this same period. 
layer to develop over the surface. Mass and heat are entrained into the CBL from the stable core above. Mass entrained into the valley floor and sidewall CBLS, however, is carried from the valley in the upslope flows that develop in the convective boundary layers over the sidewalls. This removal of mass from the base and sides of the stable core causes the elevated inversion to sink deeper into the valley and to warm adiabatically due to subsidence, and decreases the rate of growth of the CBLS. Following this hypothesis, the rate of warming depends directly on the rate of energy input into the valley atmosphere. This energy may be used to deepen the CBLs or to move mass up the sidewalls, allowing the stable core to sink. From this hypothesis a thermodynamic model of temperature inversion destruction has been developed [3]. This model forms the basis for parameterizations of inversion breakup in the VALMET model.

The valley inversion destruction mechanism has important implications for the dispersion of valley air pollution. These implications can be investigated by assuming that the nocturnal inversion at sunrise contains pollutants emitted from a continuous elevated source within the valley. During the night such pollutants would be carried down the valley in the along-valley wind system, undergoing both vertical and horizontal dispersion. The horizontal dispersion in these flows is known to be much greater than the rate of over flat terrain [20]. After sunrise a convective boundary layer forms over the valley floor and sidewalls (Figure 6a). The subsequent disposition of pollutants in the stable core will be affected by two competing processes--the sinking of the stable core and the growth of the CBL. The air pollution implications of the two processes can be considered by studying a valley cross-section down-valley from the source at a later time. The three inversion breakup patterns discussed above have the following air pollution implications [8]:

1. Pattern 1 - Growth of convective boundary layer (Figure 6b): Pure growth of a CBL will result in fumigation [2] of pollutants at the valley floor as the CBL grows upward into the polluted stable core. This process is favored when the slope flows are ineffective in removing mass from a valley, and thus will occur in very wide or shallow valleys.

2. Pattern 2 - sinking of stable core (Figure $6 \mathrm{c}$ ): Failure of the CBL to grow once it has formed over the valley floor and sidewalls results in inversion destruction by sinking of the stable core. Thus, the pollutants sink into the top of a shallow mixed layer, producing high concentrations at the ground. The pollutant plume, once entrained into the CBL, is advected up the sidewalls and dispersed into the neutral layer aloft. This process is favored for narrow to wide valleys when sensible heat flux is weak.

3. Pattern 3 - Combination (Figure 6d): A combination of CBL growth and stable core descent results in the sinking of pollutants into the top of a growing mixed layer. Pollution concentrations should be intermediate between the previous two cases. This pattern is the most common one in Colorado mountain valleys. 

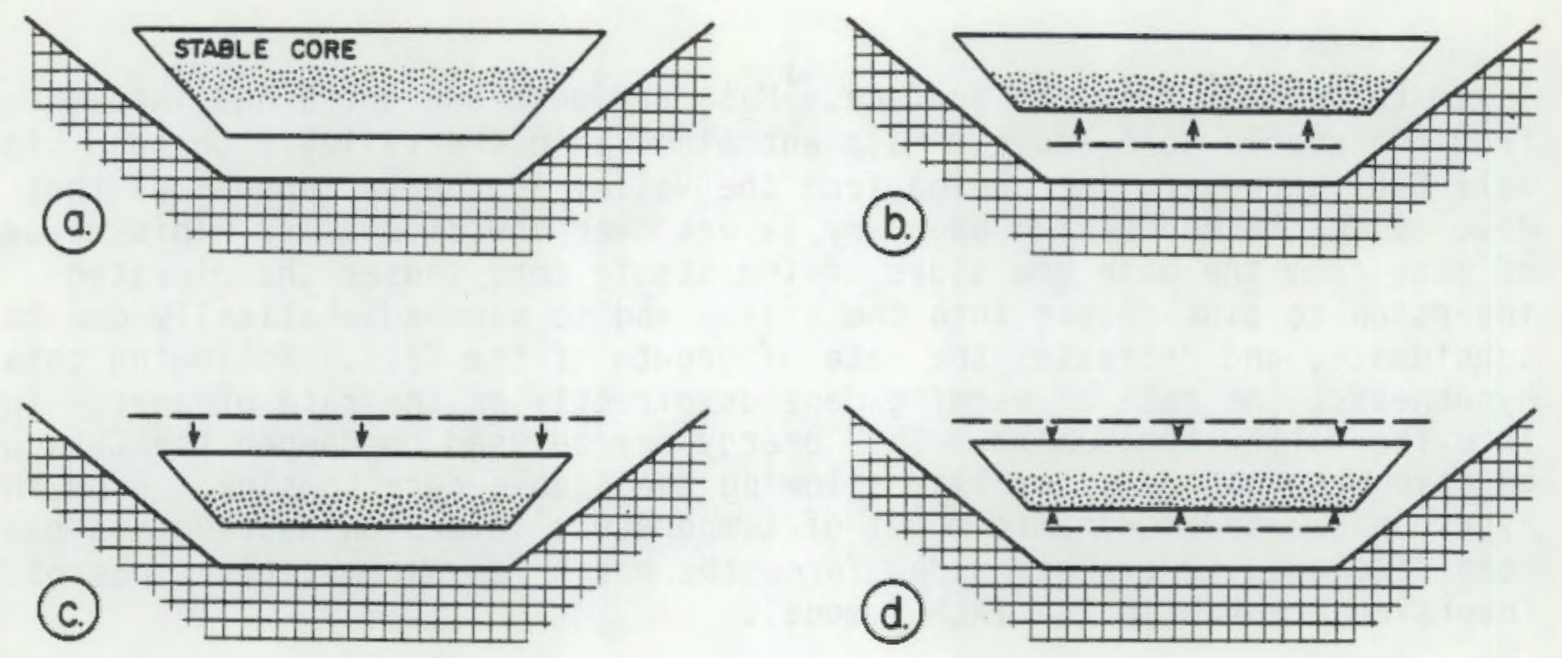

Figure 6. Air pollution implications of $\mathrm{CBL}$ growth and inversion top descent.

Another process, that of cross-valley advection of the pollutant plume due to differential heating of the valley sidewalls, may be important in determining the cross-valley position of maximum pollutant concentration. Unfortunately, relatively little observational evidence is presently available on cross-valley advection or the effects of cross valley advection on pollutant dispersion.

Observations in snow-free valleys of Colorado show that inversions are typically destroyed within 3-1/2 to $5 \mathrm{hr}$ after sunrise, regardless of season. Thus, high pollutant concentrations at the ground may be expected following sunrise in polluted Colorado valleys. But inversions are typically broken every day and, once the inversion is destroyed, good mixing will prevail in an up-valley flow regime that is coupled to flows above the valley.

Moist surface conditions or high albedo due to snow cover may change the surface energy budget components so that sensible heat flux is reduced. In these conditions inversion destruction will be delayed or an inversion may persist all day. In Colorado's snow-covered Yampa Valley on February 23, 1978, the CBL failed to grow deeper than $35-\mathrm{m}$ and the observations were characterized by a slow descent of the stable core. The inversion failed to break during this day, although the top of the stable core descended to within $150-m$ of the ground.

To summarize, the primary factors affecting a valley pollutant plume after sunrise are:

- continued transport of the pollutant plume down the valley in the stable core

- sinking motions in the stable core as inversion destruction progresses after sunrise, bringing the plume closer to the valley floor 
n fumigation of the plume into convective boundary layers growing over the valley floor and sidewalls

- transport and diffusion of pollution in upslope flows that develop over the sidewalls.

These processes continue from sunrise until the valley temperature inversion is destroyed and the valley atmosphere becomes coupled with the overlying circulations. The amount of time required for temperature inversion destruction in Colorado Mountain Valleys is typically $3-1 / 2$ to $5 \mathrm{hr}$, but it depends on many factors including the depth and strength of the initial temperature inversion, the incoming solar energy, the sensible heat flux, the pattern of inversion destruction followed, etc. 


\section{SECTION 3}

\section{TECHNICAL DISCUSSION}

In this section we present a technical discussion of the VALMET valley air pollution model. We begin with a short discussion of the coordinate system and the means used in the model to incorporate topography. Discussions of the mathematical equations used in both the nighttime and daytime portions of the model then follow along with a statement of any assumptions used in the model development. Unless otherwise noted, numerical values of the parameters in the equations are assumed to be in the MKS (meterkilogram-second) system of units, except for pollutant concentrations expressed in micrograms per cubic meter.

\section{CODRDINATE SYSTEM}

VALMET is a two-dimensional air pollution transport and diffusion model in which pollutant concentrations are determined on a valley cross section located an arbitrary distance downvalley from a pollutant source. The distance $x$ is measured following the axis of the valley down the centerline of the valley floor (Figure 7). The local coordinate system utilized on the valley cross section is shown in Figure 8 . The $x$-coordinate system specifies the distance of the cross section downvalley from the pollutant source, as measured on the valley floor centerline following any turns in the valley. The $y$-coordinate system has its origin at the valley floor centerline, is orthogonal to the $x$-axis, and increases to the right when viewed from the mouth of the valley. The $z$-coordinate system is a vertical coordinate system with origin at the valley floor centerline.

\section{TOPOGRAPHIC CROSS SECTION}

For a particular valley cross section, the model assumes that the valley topography can be simply represented by a horizontal valley floor of width, $w$, and two inclined sidewalls of inclination angle $\alpha_{1}$ and $\alpha_{2}$, as shown in Figure 9, below.

To simulate a real valley, the modeler must approximate the topography of any cross section of interest using a topographic map, from which $w, a_{1}$ and $\alpha_{2}$ are estimated. Given the simplified valley cross section and the local coordinate system, one may calculate several secondary topographic parameters that will be used in the model. For example, using definitions shown in Figure 10, the area of the cross section of a valley containing a temperature inversion of depth $h$ is 


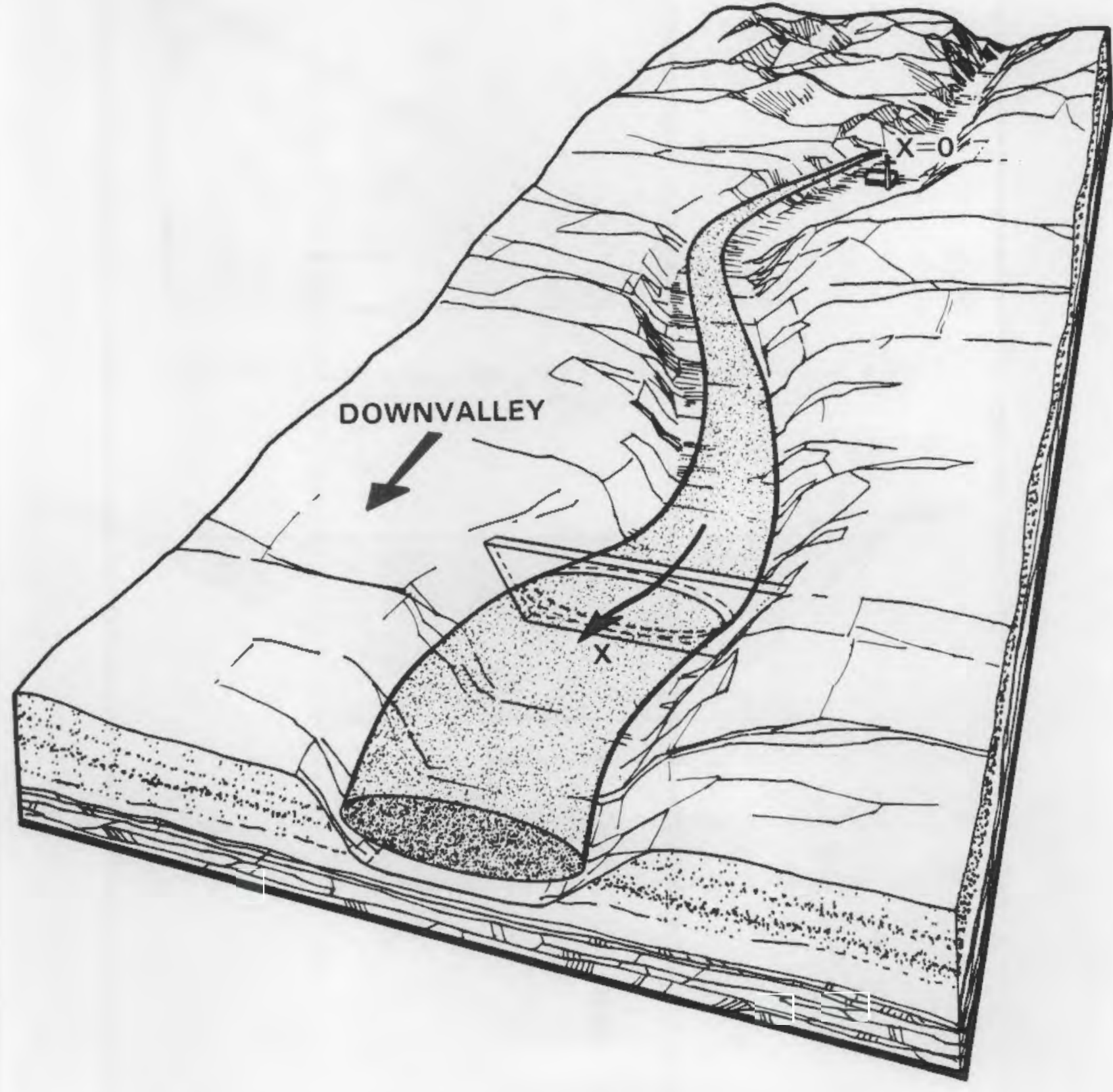

Figure 7. Illustration of the nocturnal down-valley transport and dispersion of a pollutant plume. The terrain following coordinate system, with cross valley section an arbitrary down-valley distance $x$, is illustrated. 


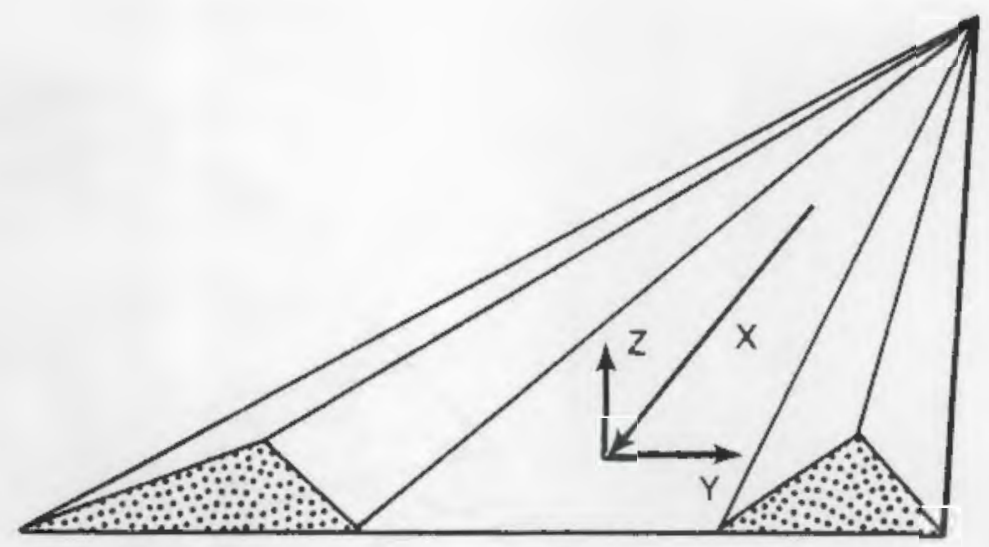

Figure 8. Illustration of the local coordinate system on a cross valley section.

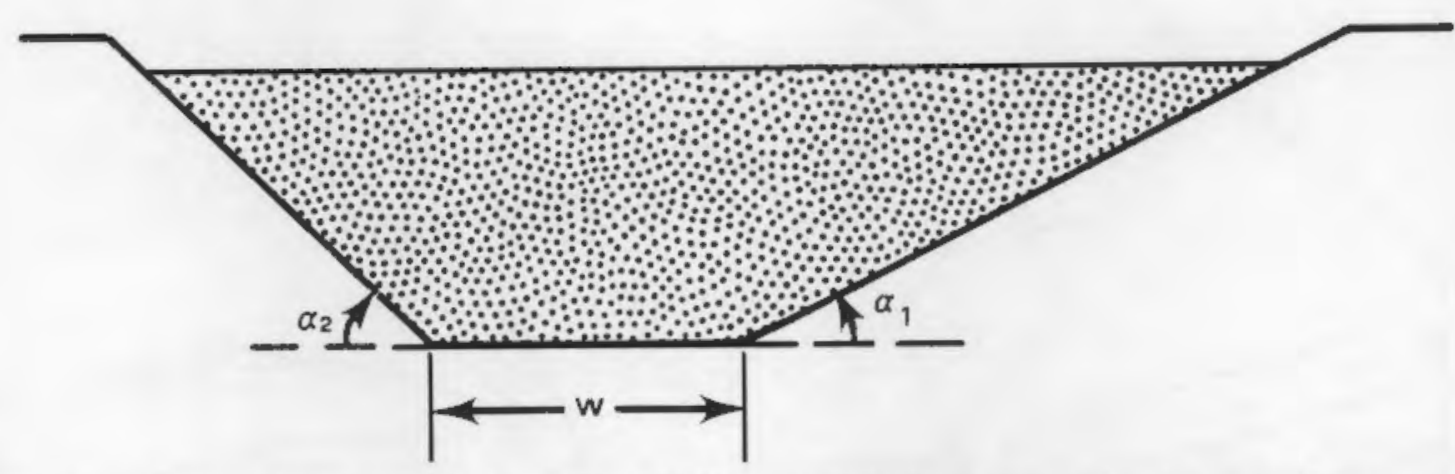

Figure 9. Parameters used in the VALMET model to approximate a valley topographic cross section. The three parameters include the valley width and the two sidewall inclination angles.

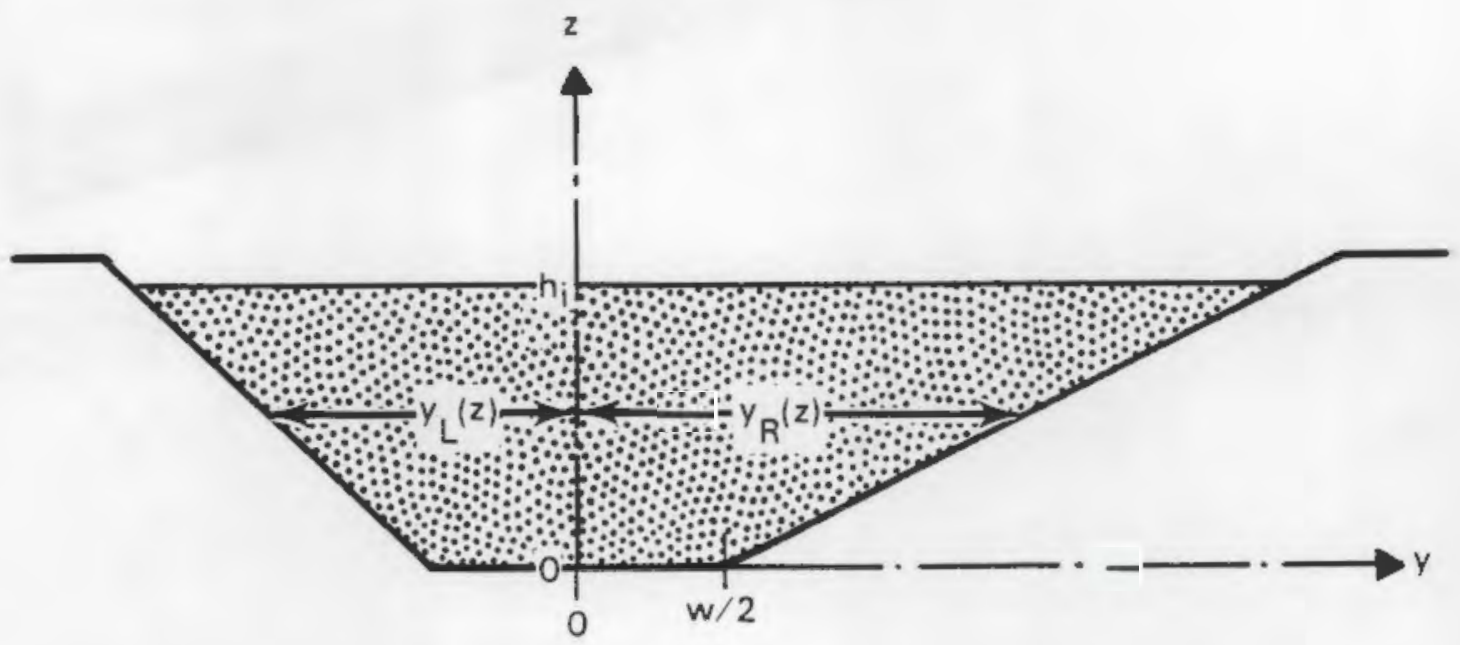

Figure 10. Illustration of the definitions of secondary topographic variables used in the model. 


$$
A=h w+\frac{h^{2}}{2}\left(\cot \alpha_{1}+\cot \alpha_{2}\right)
$$

The $y$-distance to the left and right sidewalls from the vertical coordinate axis is

$$
y_{L}(z)=-\left(\frac{w}{2}+z \cot \alpha_{2}\right)
$$

and

$$
y_{R}(z)=\frac{w}{2}+z \cot a_{1}
$$

The topographic cross section may be considered to have a thickness of unity. In this case the area $A_{T}$ of the top of the inversion $(z=h)$ is

$$
A_{T}=y_{R}(h)-y_{L}(h)=w+h\left(\cot \alpha_{1}+\cot \alpha_{2}\right) \text {. }
$$

NOCTURNAL MODEL

Pollutant Source

The model begins with an elevated pollutant source on the valley floor at the topographic cross section where $x=0$. The pollutant source may be located anywhere on the valley floor. The $y$-position of the source is specified relative to the coordinate origin. For example, the $y$-coordinate of a pollutant source on the valley floor $200 \mathrm{~m}$ off the valley floor centerline would be specified as $y_{0}=+200 \mathrm{~m}$ if the source were in the positive $y$ direction from the centerline, or as $y_{0}=-200 \mathrm{~m}$ if in the negative direction. The present version of the model cannot handle sources on the valley sidewalls. The source is assumed to emit a continuous elevated pollutant plume into a nocturnal valley temperature inversion of depth $h=h_{j}$. This pollutant plume is approximated in the model by a modified Gaussian plume algorithm. The potential temperature gradient within the inversion is $\gamma=\partial \theta / \partial z$, and the downvalley wind speed at plume carrying height is $u_{s}$. Wind speed is assumed not to vary with height. The model, being run for worst case dispersion under nocturnal temperature inversion conditions, would be run for Pasquill-Gifford stability categories D, E or F. In later sections, further details of the Gaussian plume formulation will be given along with details concerning dispersion coefficents. 
Plume Rise

Plume rise is treated in the model according to formulas described by Briggs [21-23] and used in the CRSTER model [24]. The following description of these formulas follows from a description by Drewes and Hales [25].

The "2/3 law" of plume rise is used for all stability categories up to a certain downwind distance $x_{f}$ to calculate the plume rise using the equation

$$
\Delta h=\frac{1.6 \mathrm{~F}^{1 / 3} x^{2 / 3}}{u_{s}}
$$

where $F$ is the plume's buoyancy flux, $x$ is the downwind distance, and $u_{s}$ is the wind speed at the stack. The parameter $F$ is calculated as

$$
F=g V_{e} R^{2}\left(\frac{T_{S}-T}{T_{S}}\right)
$$

where $g$ is the acceleration due to gravity $\left(9.8 \mathrm{~ms}^{-2}\right), V_{e}$ is the exit velocity of gases emitted from the stack, $R$ is the stack radius, and $T_{s}$ and $T$ are the exit and ambient temperatures, respectively. The ultimate rise $\Delta h_{f}$ and the downwind distance $x_{f}$ beyond which it applies are given as follows:

- For unstable or neutral atmospheric conditions, the downwind distance of plume rise is $x_{f}=3.5 x^{*}$, where

$$
x^{*}=\left\{\begin{array}{l}
14 F^{5 / 8} \text { when } F<55 \mathrm{~m}^{4} \mathrm{sec}^{-3} \\
34 F^{2 / 5} \text { when } F>55 \mathrm{~m}^{4} \mathrm{sec}^{-3}
\end{array}\right.
$$

The final plume rise under these conditions is

$$
\Delta h_{f}=\frac{1.6 F^{1 / 3}\left(3.5 x^{*}\right)^{2 / 3}}{u_{s}}
$$


- For stable atmospheric conditions, the downwind distance of final plume rise is $x_{f}=\pi u_{s} s^{-1 / 2}$, where

$$
s=\frac{g}{T} \frac{\partial \theta}{\partial z}
$$

and $y=\partial \theta / \partial z$ is the vertical gradient of potential temperature.

The final plume rise is

$$
\Delta h_{f}= \begin{cases}2.4\left(\frac{F}{u_{s} s}\right)^{1 / 3} & \text { for windy conditions } \\ 5 F^{1 / 4} s^{-3 / 8} & \text { for near calm conditions }\end{cases}
$$

The smaller of these values is used.

The sum of the plume rise as determined above plus the stack height yields the "effective" release height used in the Gaussian dispersion calculations.

Gaussian Plume Model

Steady-state nocturnal pollutant concentrations within a valley cross section are determined by means of a Gaussian plume model which is modified to account for channeling and reflections off the sidewalls within the valley, dilution due to clean air volume flux convergence within the valley, and diffusion of pollutants out the top of the valley inversion. terms :

We begin with the basic Gaussian plume equations having no reflection

$$
x_{G}\left(x, y, z ; \xi ; y_{0}\right)=\frac{10^{9} Q}{2 \pi \sigma_{y} \sigma_{z} u_{s}} G_{1}(y) G_{2}(z)
$$

where

$$
G_{1}(y)=\exp \left[-\frac{1}{2}\left(\frac{y-y}{\sigma_{y}}\right)^{2}\right]
$$




$$
G_{2}(z)=\exp \left[-\frac{1}{2}\left(\frac{z-\xi}{\sigma_{z}}\right)^{2}\right]
$$

and where $x_{G}=\left(x, y, z ; \xi ; y_{0}\right)$ is the pollutant concentration at a receptor located at point $P(x, y, z)$ due to a plume with centerline height $\xi$ and offset distance from the valley floor centerline $y_{0}$. The factor $10^{9}$ is the conversion factor from kilograms to micrograms. $\sigma_{y}$ and $\sigma_{z}$ are the dispersion coefficients, $Q$ is the source strength and $u_{s}$ is the transporting downvalley wind speed at the stack. The pollutant stack is constrained to be on the valley floor, so that

$$
\left|y_{0}\right|<\frac{w}{2}
$$

The normalized or standardized pollutant concentration at a receptor, as adjusted to standard temperature and pressure is given by

$$
x_{N}\left(x, y, z ; \xi ; y_{0}\right)=x_{G} \frac{P_{0}}{p} \frac{T}{T_{0}}
$$

where

$$
\begin{aligned}
& P_{0}=1013 \mathrm{mb}, \\
& T_{0}=293.16^{\circ} \mathrm{K}, \\
& P_{0}=\text { ambient pressure (mb), } \\
& \text { and } \quad T=\text { ambient temperature }\left({ }^{\circ} \mathrm{K}\right) . \\
& \text { Dispersion Coefficients }
\end{aligned}
$$

Nocturnal dispersion coefficients $\sigma_{y}$ and $\sigma_{z}$ for the Gaussian plume equations are determined from the empirically derived Pasquill-Gifford curves $[26,27]$, as developed from atmospheric tracer experiments conducted over homogeneous terrain. The empirical Pasquill-Gifford curves relate the values of $\sigma_{y}$ and $\sigma_{z}$ to down wind distance and stability category. A numerical approximation to the curves has been provided by McMullen [28] and is given as:

$$
\sigma=\exp \left[I+J(\ln x)+K(\ln x)^{2}\right]
$$


where

$$
\begin{aligned}
\sigma= & \text { standard deviation of the concentration in the horizontal }\left(\sigma_{y}\right) \\
& \text { or vertical }\left(\sigma_{z}\right) \text { in meters, } \\
\mathrm{X}= & \text { downwind distance }(\mathrm{km}), \text { and } \\
I, \mathrm{~J}, \mathrm{~K}= & \text { empirical constants for a given stability condition for } \sigma_{y} \text { and } \\
& \sigma_{\mathrm{Z}} \cdot
\end{aligned}
$$

Tables 1 and 2 provide McMulien's [28] values of the constants I, J, and $K$ for determination of oy and $\sigma_{z}$, respectively. Table 3 is provided to determine the proper stability category from meteorological observations.

The above method of determining $\sigma_{y}$ and $\sigma_{z}$ is appropriate for homogeneous terrain. Previous work [20,29-31] shows that dispersion is enhanced in valleys over that experienced over homogeneous terrain where the original empirical Pasquill-Gifford dispersion coefficients were determined. This enhancement is particularly marked for stable conditions [20]. Enhanced dispersion in valleys is due to a number of physical mechanisms that have, to date, been inadequately studied or characterized. In the VALMET model we have taken the approach, which we do not consider entirely satisfactory, of calculating valley dispersion coefficients from the original empirical Pasquill-Gifford curves [26] by simply adjusting the stability categories. From existing data it appears that the enhancement of the horizontal dispersion can be approximated by dropping the stability two categories (e.g., F becomes $\mathrm{D})$. The vertical enhancement of dispersion is approximated by dropping the stability one category (e.g., F becomes $E)$. The use of these simple adjustments to the stability categories should be considered a stopgap measure. Further work will be required to evaluate its appropriateness and seek more appropriate means of handling nocturnal dispersion in deep valley terrain.

Channeling

Calculations with the Gaussian plume model are made assuming the Gaussian plume follows the valley axis, despite meanders in the valley's course. The model user must therefore use a topographic map to determine the downvalley distance of a given cross section.

Plume Dilution

An important factor affecting plume concentrations is the dilution of the plume during its travel down a valley due to tributary flows that bring clean air into the plume. This process could be extremely important in decreasing plume concentrations, especially when the volume of diluent air is large relative to the plume volume, as when a pollutant's source is within a small tributary to a larger valley. Other processes occur in valleys that can affect plume dilution, including converging downslope drainage flows and entrainment of clean air into a valley from above. Any process capable of producing volume flux convergence between two vertical valley cross sections is capable of diluting a plume. At present, the physical 
TABLE 1. VALUES OF THE CONSTANTS I, J, AND $K$, FOR $\sigma_{y}$ AS A FUNCTION OF DOWNWIND DISTANCE, FOR SIX STABILITY CONDITIONS [28]

\begin{tabular}{cccc}
\hline \hline $\begin{array}{l}\text { Stability } \\
\text { Condition* }\end{array}$ & I & J & K \\
\hline A & 5.357 & 0.8828 & -0.0076 \\
B & 5.058 & 0.9024 & -0.0096 \\
C & 4.651 & 0.9181 & -0.0076 \\
D & 4.230 & 0.9222 & -0.0087 \\
E & 3.922 & 0.9222 & -0.0064 \\
F & 3.533 & 0.9181 & -0.0070 \\
& & & \\
\hline
\end{tabular}

*As defined in Table 3.

TABLE 2. VALUES OF THE CONSTANTS I, J, AND $K$, FOR $\sigma_{z}$ AS A FUNCTION OF DOWNWIND DISTANCE, FOR SIX STABILITY CONDITIONS [28]

\begin{tabular}{cccc}
\hline $\begin{array}{l}\text { Stability } \\
\text { Condition* }\end{array}$ & I & J & K \\
\hline A & 6.035 & 2.1097 & 0.2007 \\
B & 4.694 & 1.0629 & 0.0136 \\
C & 4.110 & 0.9201 & -0.0020 \\
D & 3.414 & 0.7371 & -0.0316 \\
E & 3.057 & 0.6794 & -0.0450 \\
F & 2.621 & 0.6564 & -0.0540 \\
\hline
\end{tabular}

*As defined in Table 3 .

understanding of these processes is insufficient to incorporate them explicitly into an air pollution model. The extent to which volume flux divergence is a feature of a particular valley's meteorology can be determined, however, by wind observations.

The approach used in the present version of the model is to modify the Gaussian plume equation in a simple way that makes an initial correction for the dilution of a pollutant plume during its downvalley travel. The correction is applied only when data are available to show that a plume would 
TABLE 3. RELATIONSHIP BETWEEN WEATHER CONDITIONS AND STABILITY CATEGORIES [26]

\begin{tabular}{|c|c|c|c|c|c|c|}
\hline \multirow[b]{2}{*}{$\begin{array}{l}\text { Surface Wind } \\
\text { Speed (at } 10 \mathrm{~m}) \text {, } \\
\mathrm{m} \mathrm{sec}^{-1}\end{array}$} & \multicolumn{3}{|c|}{ Day } & \multicolumn{3}{|c|}{ Night } \\
\hline & $\frac{\text { Incoming }}{\text { Strong }}$ & $\frac{\text { g Solar Ra }}{\text { Moderate }}$ & $\frac{\text { Radiation }}{\text { Slight }}$ & $\begin{array}{r}\text { Thinly } \\
\text { or } \\
\text { Low }\end{array}$ & $\begin{array}{l}\text { Overcast } \\
>4 / 8 \\
\text { Cloud }\end{array}$ & $\begin{array}{l}<3 / 8 \\
\text { Cloud }\end{array}$ \\
\hline$<2$ & A & $A-B$ & B & & & \\
\hline $2-3$ & $A-B$ & B & C & & E & $F$ \\
\hline $3-5$ & B & $B-C$ & C & & D & $E$ \\
\hline $5-6$ & C & $C-D$ & 0 & & D & D \\
\hline 6 & C & D & D & & D & D \\
\hline
\end{tabular}

The neutral class, $D$, should be assumed for overcast conditions during day or night.

actually be diluted in the valley being modeled. The correction is applied to the plume transporting wind speed at the pollution source cross section to obtain a modified or virtual wind speed $u_{v}$. The virtual wind speed is a function of the ratio of the volume fluxes across the source and receptor cross sections, such that

$$
u_{v}=\left[\frac{u_{c} A_{c}}{u_{s} A_{s}}\right] u_{s}
$$

where $u_{c}$ is the measured plume-transporting wind speed at the receptor cross section and $A_{C}$ and $A_{S}$ are the cross sectional areas at the receptor and source cross sections, respectively. The value of $u_{v}$ calculated using this equation is simply substituted for $u_{s}$ in the denominator of the Gaussian plume equation to calculate pollutant concentrations at the receptor cross section. To avoid physically unrealistic results (i.e., plume concentrations increasing with transport distance) $u_{v}$ must always be equal to or greater than $u_{s}$. This is accomplished by specifying

$$
\frac{{ }^{u} c^{A} c}{u_{s}{ }^{A} s}>1
$$


Using this plume dilution approach, pollutant concentrations at the receptor cross section are calculated using the equation

$$
x_{v}=\frac{u_{s}}{u_{v}} x_{N} .
$$

The plume dilution method described above is an initial approach that will need improvement as the physics of the dilution process is more fully understood. The advantages of the method are that it should produce more realistic concentrations than when plume dilution is not considered, and the method can be supported by simple measurements. The above method suffers from several drawbacks, however. First, the separate effects of individual physical processes that can lead to dilution are not clearly separated using the current method. Second, the dilution method does not consider the effects on plume dilution of the enhanced lateral and vertical mixing where tributary flows merge into a main valley or of the drift of a plume centerline towards one sidewall caused by incoming tributary flows. Third, the method does not consider stratification effects that may arise in merging flows of different temperature. Finally, dilution air is assumed in the model to be clean with respect to the pollutant species. The dilution method seems appropriate, however, as an initial means of handling plume dilution until a better understanding is obtained for the individual dilution (and dispersion) processes. The wind observations necessary to use the dilution method could be obtained from a doppler acoustic sounder or special pibal and/or tethersonde campaigns. An industrial permit applicant, for example, might be required to provide data to show that the plume would be diluted due to volume flux divergence, before the dilution module is accepted as an applicable modeling technique for use in the permit application.

\section{Reflections}

Dispersion of pollutants during the plume's nocturnal transport down the valley will result in a spreading of the plume in both the vertical and horizontal, resulting in the plume's eventual contact with the valley surfaces (valley floor and sidewalls). Additional spreading of the plume, using the basic Gaussian equations, would give the physically unrealistic result of appreciable concentrations occurring "beyond" the valley sidewalls or "below" the valley floor. Concentrations calculated for receptors within the valley cross section would be too low and the total pollutant mass of the plume would not be conserved within the valley. Several methods have been proposed to remedy this situation $[26,32]$. The valley may, for example, be treated as a channel having vertical sidewalls. Then, single or multiple reflections of the plume from the sidewalls can be simulated by the method of "image plumes", in exact analogy to the way that reflections off an elevated inversion surface are now handled in many Gaussian models [26]. Other similar means of handling such plume reflections have been 
tried by the authors giving consideration to the inclined sidewalls of real valleys, but all such methods thus far investigated have suffered from drawbacks of one type or another. The most satisfactory solution came from a consideration of pollutant mass conservation within the plume, to be discussed in the following paragraphs.

The Gaussian plume equations are a solution to the classical diffusion equation obtained by means of a number of restrictive assumptions (steadystate motion, $\partial u / \partial z=0$, etc.) and application of certain boundary conditions. Among the boundary conditions is an expression of plume mass conservation, given by

$$
Q=\int_{-\infty}^{\infty} \int_{-\infty}^{\infty} u_{v} x_{v} d y d z \text { for } z>0
$$

This integral constraint, which applies to the basic mathematical form of the Gaussian equation (Equations 11 and 15), has a simple physical meaning. Suppose that a source emits a pollutant at the rate $Q$ of $1 \mathrm{~kg} / \mathrm{s}$ into a horizontal wind of $1 \mathrm{~m} / \mathrm{s}$. This will result in a kilogram of pollutant mass being carried in a meter of transported air. Following the Gaussian plume equation this kilogram of pollutant is simply distributed in the $1 \mathrm{~m}$ slice of air following a bi-normal distribution. The total plume mass within the Im slice, however, does not change. It is $1 \mathrm{kilogram}$ regardless of whether the kilogram is relatively concentrated into a tightly confined plume or widely dispersed about the plume center. Thus, when one integrates the pollutant concentration over the volume of the slice from $y=-\infty$ to $y=+\infty$ and from $z=-\infty$ to $z=+\infty$, and $u_{y}$ is constant, we obtain

$$
\frac{Q}{u_{v}}=\int_{-\infty}^{\infty} \int_{-\infty}^{\infty} x_{v} d y d z=\frac{1 k g}{m} .
$$

In terms of a worst case model of pollutant dispersal in a valley, one must consider ways of preserving or conserving the total pollutant mass so that this relation still holds. This can be done as follows:

Considering that the plume diffuses following the Gaussian distribution, one can determine the plume's shape at a valley cross section. A valley cross section can be superimposed on the theoretical plume cross section (Figure 11) and, through integrations, one can determine the fraction of total plume mass within the cross section within the valley and below the inversion top, as well as the mass that has diffused above the inversion top and beyond the valley sidewalls and valley floor. For example, the fraction of the total mass in the cross section that is within the valley cross section below the inversion top $h_{i}$ is 


$$
f_{1}=\frac{g_{1} u_{v}}{Q}
$$

where

$$
g_{1}=\int_{0}^{h_{i}} \int_{y_{L}}^{y_{R}} x_{v} d y d z
$$

The fraction of plume mass that has diffused out the top of the inversion is

$$
f_{2}=\frac{g_{2} u v}{Q}
$$

where

$$
g_{2}=\int_{h_{i}}^{\infty} \int_{-\infty}^{\infty} x_{v} d y d z
$$

The fraction of plume mass which has diffused "beyond" the valley sidewalls (below the inversion top) and "below" the valley floor is

$$
f_{3}=1-f_{1}-f_{2} \text {. }
$$

In our simple model of plume reflection we must find a means of folding the mass fraction $f_{3}$ back into the valley cross section so that pollutant mass will be conserved within the valley. Although the pollutant mass could be distributed into the valley cross section any number of ways, we choose the simple expedient of mixing it uniformly within the valley unit cross section volume, so that concentrations within the cross section include an offset concentration and are given by

$$
x\left(x, y, z ; \varepsilon ; y_{0}\right)=x_{v}+x_{o f f}
$$




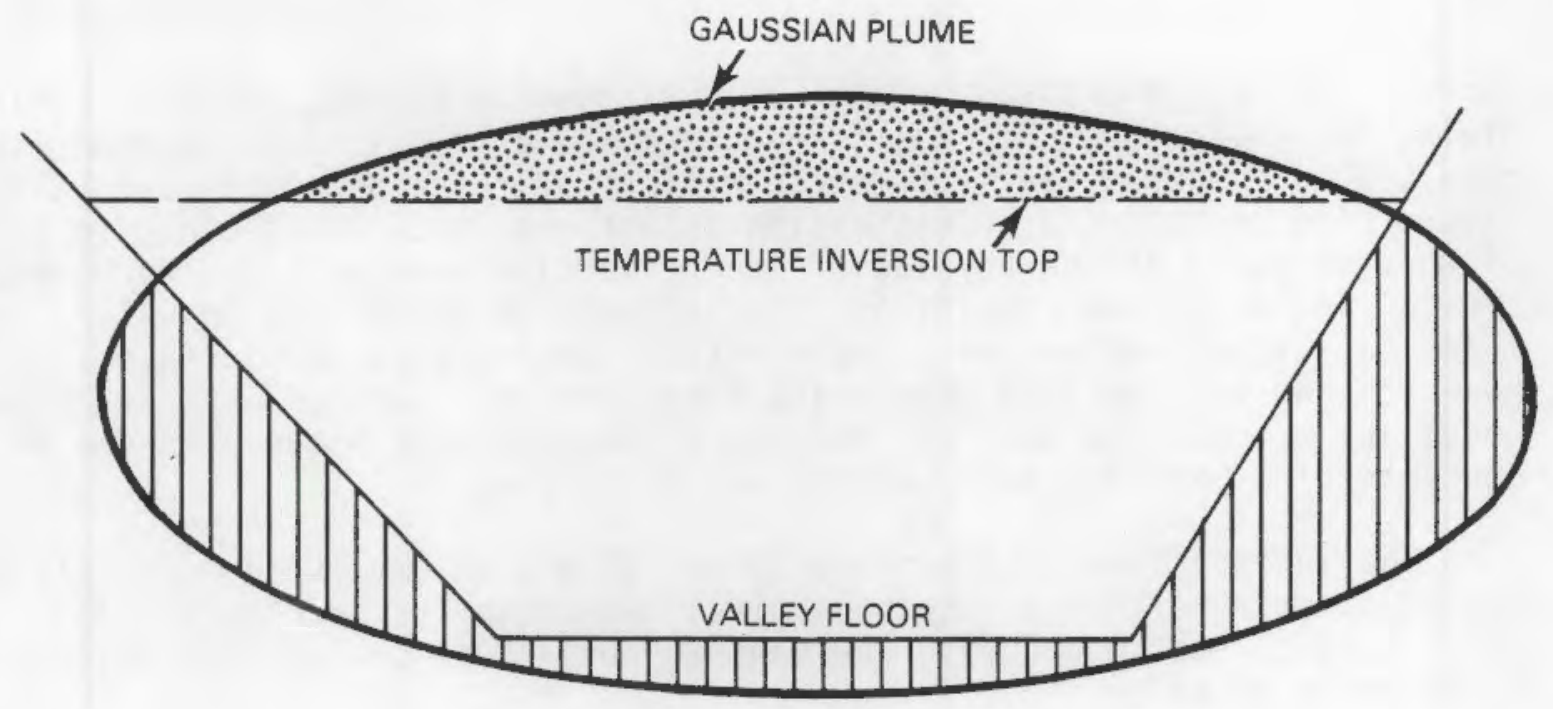

POLLUTION DIFFUSING OUT THE INVERSION TOP

IDID POLLUTION REFLECTED BACK INTO VALLEY CROSS SECTION

Figure 11. Cross section of pollutant plume and valley topography illustrating the integral method of calculation for plume reflection and diffusion out the top of the valley temperature inversion.

where

$$
x_{\text {off }}=\frac{10^{9} \mathrm{p}_{0} T}{\mathrm{p}_{0}} \frac{\mathrm{f}_{3} \mathrm{Q}}{\mathrm{J}_{v} A_{C}}
$$

Equation 26 applies within the spatial domain where

i) $x \geq 0$,

ii) $y_{L}(z) \leq y \leq y_{R}(z)$, and

iii) $0 \leq z \leq h_{i}$

By mixing the lost mass uniformly we are assured that, in the limit of long travel distances $x$, plume concentrations within the valley cross section will approach uniformity.

The above method provides a simplified means of allowing some plume mass to escape upwards out of a valley during its downvalley transport, as well as providing for "reflections" of the plume from sidewalls and the valley floor. An objection to the volumetric mixing of the reflected plume mass 
through the entire cross sectional volume seems necessary, however. This mixing of reflected plume mass through the whole valley cross section will result in an underestimate of concentrations near the sidewalls and valley floor. The amount of underestimation is not easily calculated due to a lack of understanding of the physics of the reflection processes at the boundaries during nighttime conditions. The effects of deposition on valley surfaces may reduce ambient air concentrations near the valley surfaces, however, and will tend to counteract these errors. Further work is deemed necessary to evaluate both the effects of deposition and the presence of concentration underestimates on the valley surfaces.

The integrations in Equations 23 and 25 are accomplished numerically in VALMET using a polynomial equation given by Abramowitz and Stegun [33] attributed to Hastings [34]. The Gaussian or Normal probability density function is given by

$$
Z(x)=\frac{1}{\sqrt{2 \pi}} \exp \left(-\frac{x^{2}}{2}\right)
$$

where variable $x$ is the standard deviation.

The area under the Gaussian function from $-\infty$ to $x$ is given by

$$
P(x)=\frac{1}{\sqrt{2 \pi}} \int_{-\infty}^{x} \exp \left(-\frac{t^{2}}{2}\right) d t=\int_{-\infty}^{x} Z(t) d t .
$$

Using these definitions, we note that $Z(-x)=Z(x)$ and $P(-x)=1-P(x)$.

Following Hastings [34] we may approximate $P(x)$, for $0 \leq x \leq \infty$, by the polynomial equation

$$
P(x)=1-z(x)\left[b_{1} t+b_{2} t^{2}+b_{3} t^{3}+b_{4} t^{4}+b_{5} t^{5}\right]+\varepsilon(x)
$$

where

$$
\begin{aligned}
& t=\frac{1}{1+0.2316419 x}, \\
& |E(x)|<7.5 \times 10^{-8},
\end{aligned}
$$


and

$$
\begin{aligned}
& b_{1}=0.319381530 \\
& b_{2}=-0.356563782 \\
& b_{3}=1.781477937 \\
& b_{4}=-1.821255978 \\
& b_{5}=1.330274429 .
\end{aligned}
$$

The method for the numerical integration is illustrated below for Equation 22.

$$
\begin{aligned}
& f_{1}=\frac{g_{1} u_{v}}{Q}=\frac{u_{v}}{Q} \int_{0}^{h} \int_{L}^{y_{R}(z)} \int_{0}^{1} x_{v} d x d y d z \\
& =10^{9} \frac{p_{0}}{p} \frac{T}{T_{0}} \int_{0}^{h} \int_{y_{L}}^{y_{R}} \int_{0}^{1} \frac{1}{\sqrt{2 \pi} \sigma_{y}} \exp \left[-\frac{1}{2}\left(\frac{y-y_{0}}{\sigma_{y}}\right)^{2}\right] . \\
& \text { - } \sqrt{2 \pi \sigma_{2}} \exp \left[-\frac{1}{2}\left(\frac{z-\xi_{z}}{\sigma_{z}}\right)^{2}\right] d x d y d z \\
& \simeq 10^{9} \frac{P_{0}^{T}}{P T_{0}} \sum_{i=1}^{n}\left\{P\left(\frac{y_{R}\left(z_{i}\right)-y_{0}}{\sigma_{y}}\right)+P\left(\frac{y_{L}\left(z_{i}\right)-y_{0}}{\sigma_{y}}\right)-1\right\} \\
& \left\{\frac{1}{\sqrt{2 \pi} \sigma_{z}} \exp \left[-\frac{1}{2}\left(\frac{z i^{-\xi}}{\sigma_{z}}\right)^{2}\right]\right\} \Delta z
\end{aligned}
$$

where

$n=h / \Delta z$

and $z_{j}=i \Delta z$.

The numerical integration for $f_{2}$ is accomplished in an analogous manner from the equation 


$$
f_{2}=\frac{g_{2} u_{v}}{Q}=\frac{u_{v}}{Q} n_{i} \int_{-\infty}^{\infty} \int_{0}^{\infty} \int_{0}^{1} x_{v} d x d y d z .
$$

The approximation to $f_{2}$ is made in VALMET using \pm 5 standard deviations as the limits of integration for $y$ as this makes the calculations tractable and produces no appreciable error in the results.

Calculation of Steady-State Nighttime Concentrations

Calculation of nighttime pollutant concentrations at receptor point $P(x, y, z)$ can be made in a straightforward way with Equation 27 assuming steady state conditions. The receptor must be located within a valley cross section, so that Equation 27 can be applied for

i) any $x$

ii) $0 \leq z \leq h_{i}$, and

iii) $y_{L}(z) \leq y \leq y_{R}(z)$.

In practice nighttime calculations are performed for a limited number of points on the valley surfaces (floor and sidewalls), choosing points that correspond to locations where daytime pollutant concentrations will be calculated. The fixed daytime grid configuration is shown below in Figure 12. Since the model is run on a half-valley cross setion, the cross section sidewall angle $\alpha$ is chosen to be the average of the observed sidewall angles $\alpha_{1}$ and $\alpha_{2}$. Points for which nighttime pollutant concentrations are calculated are shown on the figure with $x$ 's.

If the grid element numbers are given by $n=1,2, \ldots$ NBOX, locations at points $P(y, z)$ on the valley floor are at

$$
y=\frac{B O X L E N}{2}+(n-1) B O X L E N \text { and } z=0 \text {. }
$$

Calculation points on the valley sidewalls $(n=\mathrm{NBOX}+1, \mathrm{NBOX}+2, \ldots$. NTOTI) are at points $P(y, z)$ where

$$
\begin{aligned}
& y=\frac{w}{2}+z \cot \alpha, \\
& z=\frac{80 X L E N \tan \alpha}{2}+(n-\text { MBOX - 1) BOXLEN } \tan \alpha,
\end{aligned}
$$

and $\alpha=\frac{\alpha_{1}+\alpha_{2}}{2}$. 


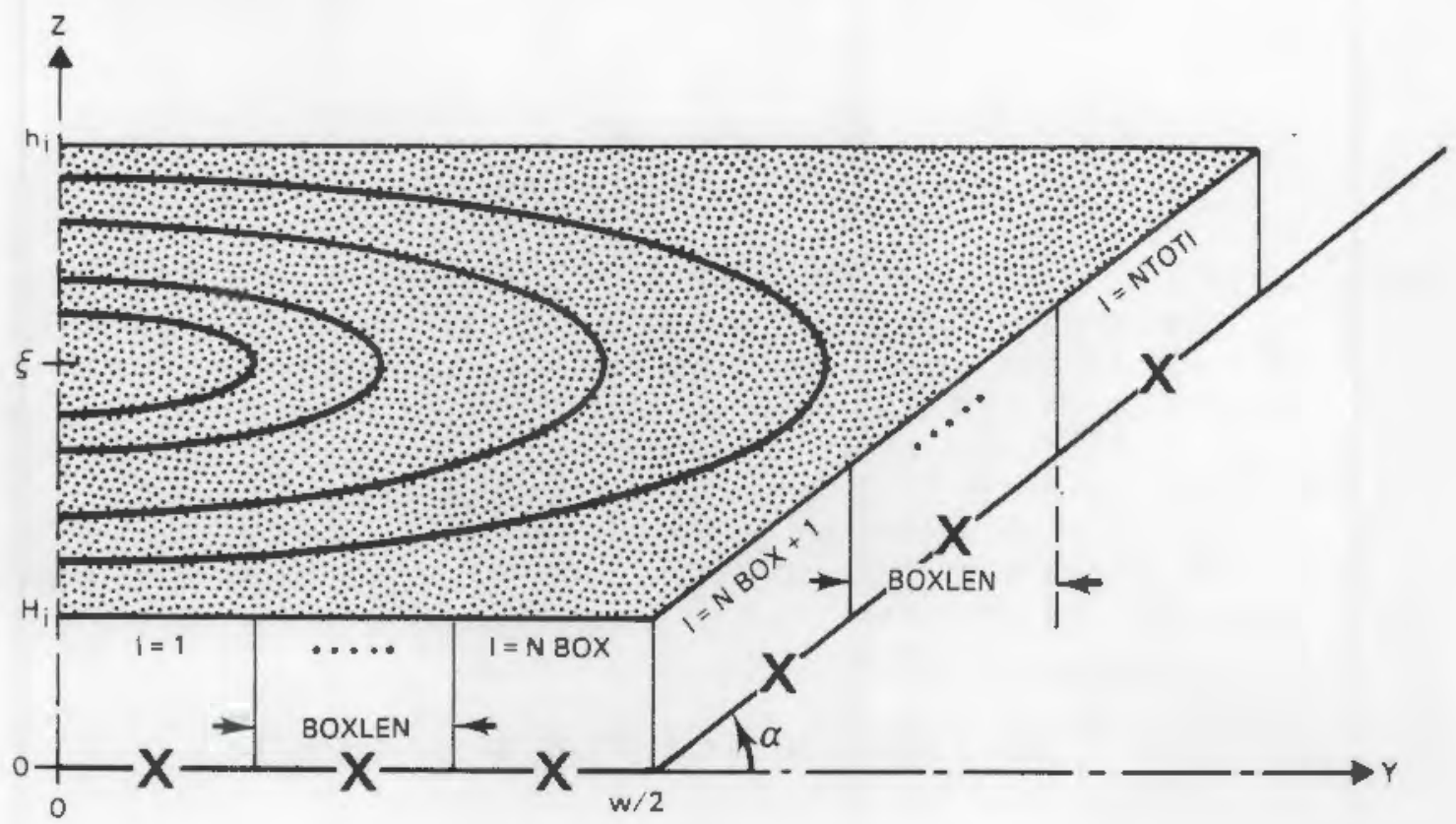

Figure 12. VALMET grid configuration on a valley cross section illustrating the nomenclature used in the model. The cross section is representative of the model configuration at sunrise, when the initial CBL-height $\left(H_{j}\right)$, inversion top-height $\left(h_{j}\right)$ and piume centerline height $(\xi)$ are as shown. The $x^{\prime} s$ on the figure illustrate the locations where nocturnal pollutant concentrations are determined.

\section{DAYTIME MODEL}

The daytime portion of VALMET begins with solar radiation calculations, a parameterization of the surface energy budget, and estimation of the time variation of sensible heat flux which destroys the temperature inversion after sunrise. The valley energy budget model of Whiteman and McKee [3] is invoked to simulate $\mathrm{CBL}$ growth and inversion descent. The nighttime Gaussian plume on a valley cross section is used as the initial condition from which the numerical model proceeds to calculate concentrations in grid elements fixed to the valley floor and sidewalls. The depth of these vertically growing grid elements is identified with the CBL height. Calculations are made of concentrations within the grid elements taking account of fumigation of the Gaussian plume into the elements and upslope advection from grid element to grid element. Pollutants are mixed uniformly within each grid element, roughly simulating atmospheric diffusion processes in the convective (actually, advective) boundary layer.

\section{Extraterrestrial Solar Radiation}

Solar radiation on a plane surface above the earth's atmosphere can be calculated using basic principles of spherical trigonometry. The basic formula for solar flux on a horizontal surface is 


$$
Q_{S h}=s_{0}\left(\frac{d_{d}}{d}\right)^{2} \cos z
$$

where $S_{0}$ is the solar constant $\left(1367 \mathrm{Wm}^{-2}\right)$, defined as the solar flux on a plane surface perpendicular to the sun's rays at the mean earth-sun distance, $\bar{d}$. The factor $\left(\bar{d} / d^{2}\right)$ modifies the solar constant to account for the fact that the earth-sun distance, $d$, varies during the year as the earth travels in an elliptical orbit about the sun. The cosine term accounts for the projection of solar flux onto the horizontal plane. This term is clearly a function of earth-sun geometry, depending on the time of day, day of year, and latitude of the surface. $Z$ is the angle between the normal to the surface and the direction to the sun, known as the zenith angle. From spherical trigonometry $[35,36]$ this is given as

$$
\cos Z=\sin \phi \sin \delta+\cos \phi \cos \delta \cos \ell
$$

where

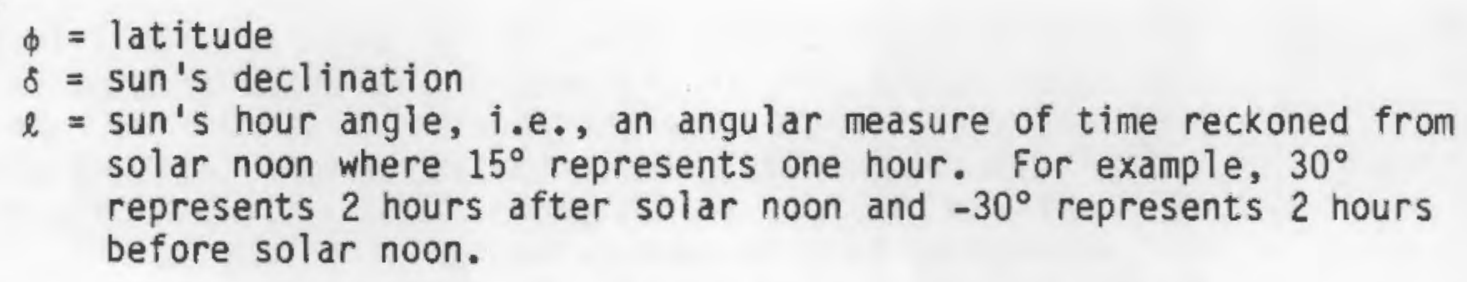

In these equations both the declination and the factor $\left(\bar{d} / d^{2}\right)$ are a function of the day of year ( $D$, from 1 to 365). McCullough [37] gives some approximate analytical formulas that allow the calculation of these terms, utilizing the longitude of the earth $(\lambda)$ in its orbit around the sun as reckoned from the earth-sun radius vector at vernal equinox $\left(D=D_{0}\right)$. The formulas are

$$
\begin{aligned}
& \delta=\sin ^{-1}(\sin \varepsilon \sin \lambda), \\
& \lambda=\omega\left(D-D_{0}\right)+2 e\left(\sin \omega D-\sin \omega D_{0}\right),
\end{aligned}
$$

and

$$
\left(\frac{d}{d}\right)^{2}=(1-e \cos \omega D)^{-2}
$$

where

$$
\begin{aligned}
\varepsilon & =23^{\circ} 26^{\prime}=\text { maximum solar declination, } \\
\omega & =2 \pi / 365, \\
D_{0} & =80=\text { day of vernal equinox, and } \\
\varepsilon & =0.0167 \text { = eccentricity of earth's orbit. }
\end{aligned}
$$


Using these equations, the extraterrestrial solar flux on an arbitrarily oriented plane surface can be calculated as a function of hour angle, $\ell$. Input to the equations must include the latitude and the day of year for which calculations are desired.

The equations are used to calculate the solar flux at any time from the hour angle of sunrise, \&SR, to the hour angle of sunset, \&SS. For a horizontal plane the times of sunrise and sunset are generally specified in terms of half-day length, $R$, calculated from Equation 35 for $\cos Z=0$, or

$$
R=\cos ^{-1}(-\tan \phi \tan \delta) \text {. }
$$

Then

$$
\ell_{S R}=-R \text { and } \quad \ell S S=R \text {. }
$$

Calculations using the above set of equations are made in terms of hour angle and are thus referenced to the time of solar noon at a particular site. To convert the hour angles to local standard time it is necessary to determine the local standard time of solar noon. and to adjust all the times accordingly. This is accomplished by making two corrections to the time of solar noon (12h 00m 00s) in the local solar time coordinate system [38]. Then the standard time of solar noon is given by

$$
\begin{aligned}
t_{N O O N} & =12 \mathrm{~h} 00 \mathrm{~m} 00 \mathrm{~s}+{ }_{\text {time correction }}^{\text {Equation of }}+\begin{array}{l}
\text { Longitude } \\
\text { correction }
\end{array} \\
& =12 \mathrm{~h} 00 \mathrm{~m} 00 \mathrm{~s}+\mathrm{C}_{\mathrm{ET}}+\mathrm{C}_{\mathrm{L}}
\end{aligned}
$$

First, the equation of time correction is applied by adding the appropriate number of minutes and seconds from Table 4. Second, a longitude correction accounting for the difference in geographical longitude between the site and the reference meridian of its time zone is applied. The correction is +4 minutes for each degree of longitude west of the meridian. For example, the reference meridian of the Mountain Time Zone is $105^{\circ} \mathrm{W}$ longitude. For a site at $106^{\circ} \mathrm{W}$ longitude, the correction is $C_{L}=4(106-105)=+4$ minutes.

The above equations can be used to determine extraterrestrial solar flux at any site on a given day for any given time (i.e., hour angle). Calculations using these equations for a latitude of $40^{\circ} \mathrm{N}$ and longitude of $109^{\circ} \mathrm{W}$ show that the solar flux Q 5 h as a function of time on a given day closely follows a sine curve. This simple analytical form proves so accurate at the latitudes and longitudes of interest and is so easy to calculate that it is used in the model instead of the full formulation. The sine approximation is given by

$$
Q_{S h}=A_{1} \sin \frac{\pi}{\tau}\left(t-t_{S R}\right)
$$


TABLE 4. Equation of Time Correction

\begin{tabular}{|c|c|c|c|c|c|c|c|c|c|c|c|c|c|}
\hline$D^{*}$ & \multicolumn{2}{|c|}{$C_{E T^{* \star}}$} & D & \multicolumn{2}{|c|}{$C_{E T}$} & $D$ & \multicolumn{2}{|c|}{$C_{E T}$} & $D$ & \multicolumn{2}{|c|}{$C_{E T}$} & $D$ & $\mathrm{C}_{\mathrm{FT}}$ \\
\hline 1 & $3 m$ & $12 \mathrm{~s}$ & 91 & $4 m$ & $08 \mathrm{~s}$ & 181 & $3 m$ & $21 \mathrm{~s}$ & 271 & $-9 m$ & $06 \mathrm{~s}$ & 361 & Om $47 \mathrm{~s}$ \\
\hline 16 & 9 & 32 & 106 & -0 & 01 & 196 & 5 & 46 & 286 & -13 & 33 & & \\
\hline 31 & 13 & 24 & 121 & -2 & 51 & 211 & 6 & 21 & 301 & -16 & 06 & & \\
\hline 46 & 14 & 16 & 136 & -3 & 44 & 226 & 4 & 44 & 316 & -15 & 53 & & \\
\hline 61 & 12 & 23 & 151 & -2 & 33 & 241 & 1 & 07 & 331 & -12 & 34 & & \\
\hline 76 & 8 & 39 & 166 & 0 & 10 & 256 & -3 & 50 & 346 & -6 & 34 & & \\
\hline
\end{tabular}

$\star D=$ day of year

** $C_{E T}=$ equation of time correction (minutes and seconds).

where

$$
\begin{aligned}
A_{1} & =\text { solar flux at solar noon } \\
\tau & =\text { length of daylight period } \\
\mathrm{t}_{S R} & =\text { time of sunrise, and } \\
t & =\text { time. }
\end{aligned}
$$

One can calculate $A_{1}$ by evaluating Equation 33 with $\ell=0$, such that

$$
A_{1}=S_{0}\left(\frac{\bar{d}^{2}}{d}\right)^{2}(\sin \phi \sin \delta+\cos \phi \cos \delta) .
$$

The length of the daylight period is given by

$$
\tau=2 R=2 \cos ^{-1}(-\tan \phi \tan \delta) .
$$

The time of sunrise is evaluated in local standard time using

$$
t_{S R}=t_{N D O N}+2_{S R}\left(\frac{180}{15 \pi}\right) \text {. }
$$

If the model equations are used far from the latitudes of the central Rocky Mountains, the model user should verify that the sine approximation is a valid representation of solar flux, by comparing its calculations with the full analytical equations. 
Parameterization of Sensible Heat Flux

The sensible heat flux which constitutes the basic driving term of the daytime portion of the model is parameterized from the extraterrestrial solar flux using the formula

$$
F=A_{0}\left[A_{1} \sin \frac{\pi}{\tau}\left(t-t_{S R}\right)\right]=A_{0} Q_{S h}
$$

where $A_{0}$ is a fraction between 0 and 1 . This formula should be recognized as a crude parameterization for sensible heat flux, simply stating that the sensible heat flux is a constant fraction of the time-dependent extraterrestrial solar flux, as illustrated below in Figure 13.

$A_{0}$ depends on a great many factors which are not yet included explicitly in the model. In general, $A_{0}$ should be a time-varying function dependent on the

- transmissivity of the earth's atmosphere,

- cloud cover,

- surface albedo,

- soil moisture,

- surface cover or vegetation,

- longwave radiation budget, and

- other factors.

A future version of VALMET should include some of these factors explicitly, at least the ones which may affect worst case pollutant concentration, using as a basis the extensive work already conducted on these topics by other investigators.

Model Grid

The daytime portion of VALMET uses a numerical technique to simulate time varying pollutant concentrations in grid elements that are fixed to the valley floor and sidewalls. Calculations are made for individual time steps during the temperature inversion breakup period beginning at sunrise and using the nocturnal steady state concentrations within the valley cross section as an initial condition.

The geometry of the valley cross section, illustrating the numerical grid, is shown in Figure 14. Calculations in the model are performed on a half-valley cross section.

Grid elements are arranged from the valley center across the valley floor and up the sidewall, with grid element height representing the height of the CBL, assumed not to vary from grid element to grid element. At sunrise the model is initiated with a $25 \mathrm{~m} \mathrm{CBL}$ height, and an inversion top height that is obtained from observations in the modeled valley. These initial heights 


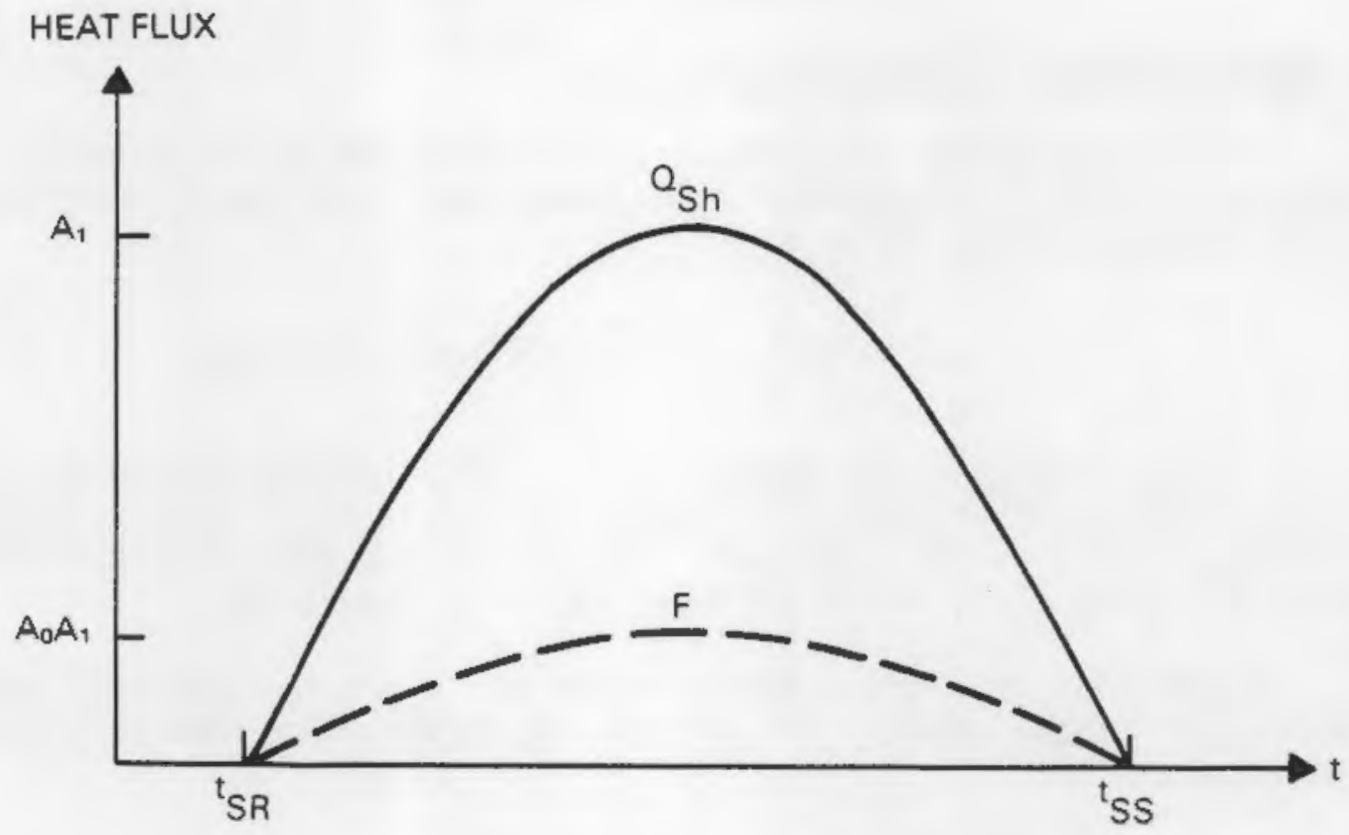

Figure 13. Extraterrestrial solar heat flux as a function of time, showing solar model nomenclature. The figure illustrates how the sensible heat flux $F$ is parameterized as a fraction $A_{0}$ of the extraterrestrial solar heat flux on a horizontal surface above the site. The times of sunrise and sunset are shown. The daylength $\tau$ is defined in the model as the time difference between sunrise and sunset.

change after sunrise as sensible heat flux drives the destruction of the valley inversion. Specifically the height of the CBL, $H(t)$, increases and the height of the inversion top, $h(t)$, decreases. The simulation is accomplished by treating the Gaussian plume within the cross section as being "frozen" within the inversion. After sunrise, concentrations within individual grid elements change as the grid elements grow upwards into the frozen plume, as the inversion sinks causing pollutants to sink into the tops of the grid elements, and as upslope flow develops within the CBL. These upslope flows develop as air parcels are heated by sensible heat flux over the sidewalls and rise up the slope. The speed of the slope flows is calculated under a continuity of mass constraint within the cross section below the (sinking) inversion top. That is, sinking of the top of the inversion with time implies that mass is removed from the cross section below the inversion top level. In the model, the assumption is made that the upslope flows carry the mass required to allow the inversion to sink at the rate predicted from Whiteman and McKee's [3] bulk thermodynamic model. This model is driven by sensible heat flux considering the thermodynamic energy budget of the valley cross section. 


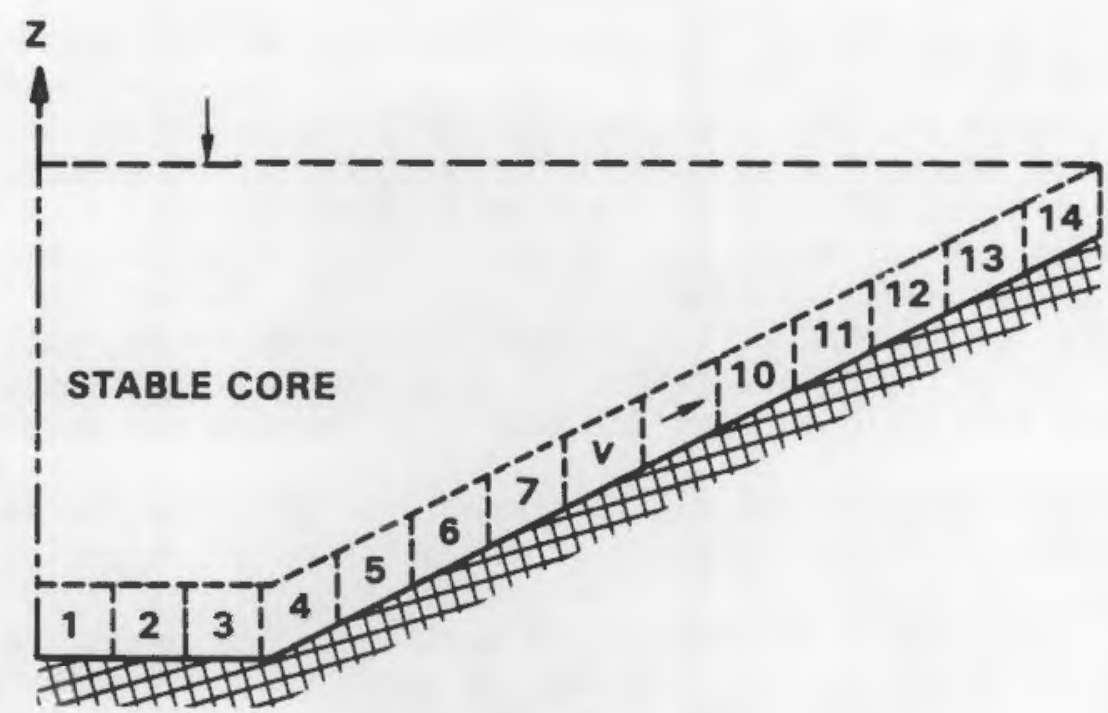

Figure 14. Cross section of the valley floor and sidewalls illustrating the grid elements whose height corresponds to the CBL heights. The rate of sinking of the top of the inversion (arrow) is related to the upslope transport of mass (other arrow) by the equation of mass continuity.

One of the assumptions in the model is that the top of the valley inversion at sunrise extends horizontally across the valley cross section. This assumption is supported by data from an observational program conducted in Colorado mountain valleys [9]. In that study several experiments were conducted by dual tethersondes located on a cross valley section. These observations showed that the inversion top was nearly horizontal. This is not unexpected, since hydrostatic forces should produce settling of cold air masses in topographic depressions or valleys and would result in horizontal isentropes in the absence of major cross valley inflows. This effect would be more pronounced for strong inversions where the hydrostatic forces would be stronger. Gravity waves are known to propagate frequently on the upper boundary of such inversion layers and are frequently noted in acoustic sounder records (personal communication, William Neff; 1983). These waves are generally of small amplitude and should not greatly affect the validity of the assumption of horizontal homgeneity.

Thermodynamic Equations for CBL Ascent and Inversion Descent

For details of Whiteman and McKee's thermodynamic model of temperature inversion breakup in mountain valleys the reader is referred to the original article (Appendix C). Here a brief explanation is given.

One can view a valley temperature inversion as a pool of cold air trapped within a valley. This pool has an energy deficit relative to the air above the valley, and the temperature inversion can be destroyed only by warming the pool to the same potential temperature as the air above the valley. The 
amount of energy required to warm the pool can be calculated from the First Law of Thermodynamics knowing the depth of the pool, the vertical temperature gradient within the pool (assumed constant) and the cross valley dimensions of the pool, by means of a volumetric integration through the valley cross section. This energy deficit is overcome by sensible heat flux, which can be estimated as a fraction of the downward solar radiation coming across the area of the top of the valley temperature inversion. Conversion from solar energy to sensible heat occurs at the ground. Downwards solar heat flux across the inversion top will be intercepted on a valley surface below the inversion top and will be available as sensible heat flux to warm the inversion airmass.

The topography of the valley strongly affects the course of the inversion destruction by determining which of the patterns of inversion destruction will be followed and by controlling the overall rate of heating of the valley atmosphere. This control on the rate of heating can be explained by Figure 15. Consider, for example, a valley that is completely filled by a temperature inversion. Solar energy coming downwards across the top of the valley inversion will be converted to sensible heat flux at valley surfaces and will be used to heat the inversion volume. The ratio of the area at the inversion top through which this radiation comes to the inversion volume governs the rate of warming of the valley atmosphere and, consequently, the time required to destroy the inversion. Given an equally strong and deep inversion over the plains, the valley inversion will be destroyed more rapidly since the same energy input goes to heat a smaller volume of air in the mountain valley. The thermodynamic model includes this important factor, which arises from the volumetric integration in the derivation of the model equations.

Whiteman and McKee's model is a "bulk" thermodynamic model in that it does not differentiate between sensible heat flux over different valley surfaces, dealing only with a bulk heat flux. The heat flux which drives the valley inversion destruction is partitioned or distributed in a fundamentally different way from that for an inversion over homogeneous terrain. There the sensible heat flux destroys the inversion by driving an upward growth from the ground of a convective boundary layer, which warms the inversion air mass from below until the temperature deficit is overcome and the inversion is destroyed. In contrast, in a valley the upward heat flux over valley surfaces develops a convective boundary layer but also, due to sensible heat flux convergence over the slopes, causes warmed air parcels to flow up the slopes in an upslope flow that develops within the convective boundary layer. These upslope flows remove mass from the base of the temperature inversion in the shallow slope flows, and through mass continuity, results in a general subsiding motion over the valley center. The atmospheric energy budget approach used by Whiteman and Mckee is capable of partitioning energy between these two different processes to produce inversion destruction solely by CBL growth, solely by inversion descent (assuming a non-growing CBL is present initially in a simulation), or by a combination of the two processes. The partitioning is controlled by a single parameter, $k$, defined as the fraction of sensible heat flux going to CBL growth. The remaining fraction, $1-k$, is assumed to be responsible for mass transport up the $\mathrm{CBL}$ which results in inversion 

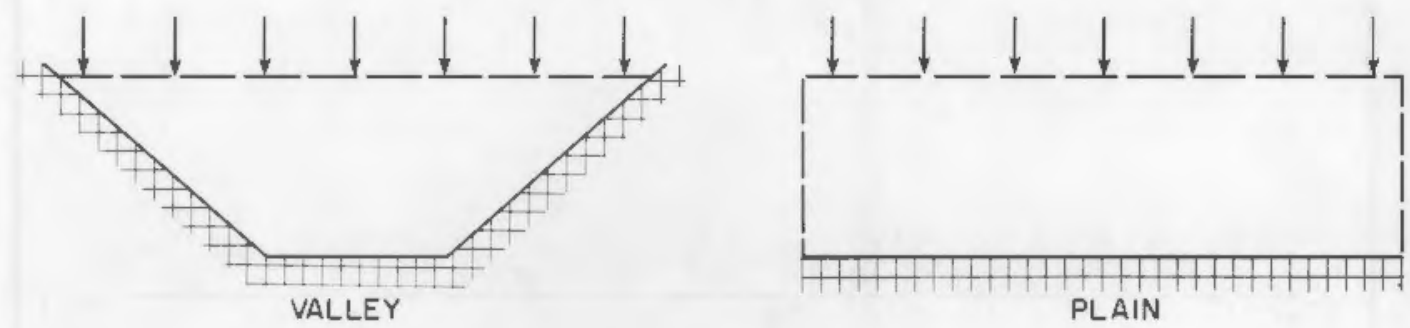

Figure 15. Illustration of the effect of topography in controlling the heating rates of the air within a valley temperature inversion versus the air within an inversion over the plains. The same incoming energy heats a smaller volume of air in the valley case.

descent. The proper partitioning of energy (i.e., the most appropriate value of $k$ ) in a particular valley can be determined by fitting the thermodynamic model to observations in a particular valley. This was done for a Colorado valley by Whiteman and Mckee [9], although they cautioned that the value of $k$ will depend on other factors besides valley geometry, including the magnitude of sensible heat flux.

Further research on the functional value of $k$ is suggested as a high priority in this modeling approach, although the model is functional using the curve fitting approach to determining $k$.

The thermodynamic model is composed of two coupled equations. The first equation is a prediction equation for CBL height where, in accordance with the bulk nature of the model, the CBL depth $H$ is assumed not to differ over the valley floor and sidewalls. The first equation is

$$
H_{j+1}=H_{j}+\Delta H_{j}
$$

where

$$
\Delta H_{j}=\frac{\theta}{T} \frac{k}{\rho C_{p}} \frac{w+H_{j} C}{w+\frac{H_{j} C}{2}} \frac{A_{0} A_{1}}{\gamma H_{j}}\left[\sin \frac{\pi}{\tau}\left(t-t_{j}\right)\right] \Delta t .
$$

Note that a non-zero initial CBL height is necessary to make this prognostic numerical equation tractable. In the model, this requirement is met by using an initial CBL height at sunrise of $25 \mathrm{~m}$. The second equation, describing the inversion top height $h$ is 


$$
h_{j+1}=h_{j}+\Delta h_{j}
$$

where

$$
\begin{aligned}
& \Delta h_{j}=-\frac{\theta}{T} \frac{1}{\rho C_{p}} \frac{\left[w+h_{j} C-k\left(w+H_{j} C\right)\right] A_{0} A_{1} \sin \frac{\pi}{\tau}\left(t-t_{j}\right)-\rho c \frac{T}{\theta} \frac{\beta}{2}\left(h_{j}-h_{j}\right)\left(w+\frac{h_{j}+h_{j}}{2} c\right)}{h_{j} \gamma\left(w+\frac{j}{2} c\right)-\frac{\beta}{2}\left(t-t_{j}\right)\left(w+h_{j} C\right)} \Delta t, \\
& \frac{\theta}{T}=\left(\frac{1000}{p}\right) \cdot 286 \text {, } \\
& p \text { = atmospheric pressure, } \\
& c_{p}=\text { specific heat of air at constant pressure, } \\
& C=\cot \alpha_{1}+\cot \alpha_{2} \text {, } \\
& H_{0} \equiv H_{j} \neq 0 \text {, } \\
& h_{0}=h_{j} \text {, } \\
& t=(j+1) \Delta t+t_{j} \text {, and } \\
& j=0,1,2,3, \ldots, n \text {. }
\end{aligned}
$$

The terms in the numerator and denominator of Equation 47 involving the warming coefficient for the air above the inversion, $B\left({ }^{\circ} \mathrm{Ks}^{-1}\right)$ allow the model to incorporate the retarding effect on temperature inversion breakup caused by warm air advection above the valley temperature inversion. Extra energy is required to destroy the valley temperature inversion if this warming occurs during the temperature inversion breakup period since the inversion cannot be broken until the entire valley atmosphere is warmed to the temperature of the air above the valley.

The numerical simulation using these coupled equations proceeds with discrete time steps and is completed when the inversion is destroyed at the first time step $n$ at which the CBL height becomes greater than the inversion top height, such that

$$
H_{n} \geq h_{n}
$$

In the limit of an infinitely wide valley (i.e., a plain) and $k=1$ (i.e., all sensible heat flux going into CBL growth) the equations reduce to a single equation describing CBL growth over homogeneous terrain. In the limit as $k$ goes to 0 , the equations describe inversion destruction where the CBL fails to 
grow after attaining an initial height, and inversion destruction occurs due to sinking of the inversion and adiabatic warming of the valley atmosphere. Whiteman and Mckee [3] have shown that this approximates inversion destruction in snow covered valleys. Values of $k$ between 0 and 1 allow the coupled equations to describe intermediate methods of inversion breakup in which the sensible heat flux is partitioned between CBL growth and inversion sinking. A typical inversion destruction in the fall in the Eagle Valley of Colorado was simulated well using a value of $k=0.14$. The appropriate value of $k$ for other valleys would be selected based on careful analysis of valley atmospheric data, as discussed further in Section 4.

Sinking of the inversion layer will result in a sinking of the frozen plume within the inversion. The pollution mass can be calculated by considering the vertical Gaussian pollution profile above each of the grid elements. As shown by Equations 44 and 45 for $k \neq 0$ the CBL depth (and hence grid element height) increases with each time step. This CBL growth entrains pollutant mass from the inversion's stable core into the top of each grid element. These two processes, sinking of the frozen plume into the top of each grid element and growth of the grid element upwards into the frozen plume, combine to determine the amount of pollutant mass introduced into each grid element during each time step.

As illustrated in Figure 16 for a grid element on the valley floor, these two processes result in a volume of air of depth $\Delta H_{j}+\Delta h_{j}$ and length $y_{1}-y_{2}$ being entrained into the growing grid element during time step $j$. The average pollutant concentration in this air volume can be calculated from the Gaussian plume equation (Equation 27) by averaging the pollutant concentrations at the centerpoints of the four sides of this volumetric element (Figure 17). A zcoordinate transformation is useful in these calculations so that one may think of the coordinate origin on the valley floor rising into the fixed plume, rather than the frozen plume sinking towards the valley floor.

\section{Advection in the Slope Flows}

Conservation of total air mass on the two-dimensional valley cross section of interest implies that there must be a relationship between the sinking of the inversion top and removal of mass from below the inversion top due to upslope transport of mass in the convective boundary layer over the slope. Thus, at the level of the inversion top, a slow subsidence of the broad stable core must be balanced by stronger upward motions through this level due to flow up the narrower sidewalls CBLS.

The continuity equation for air of constant density on the two dimensional cross section may be written as

$$
\frac{\partial v}{\partial y}=-\frac{\partial w}{\partial z}
$$




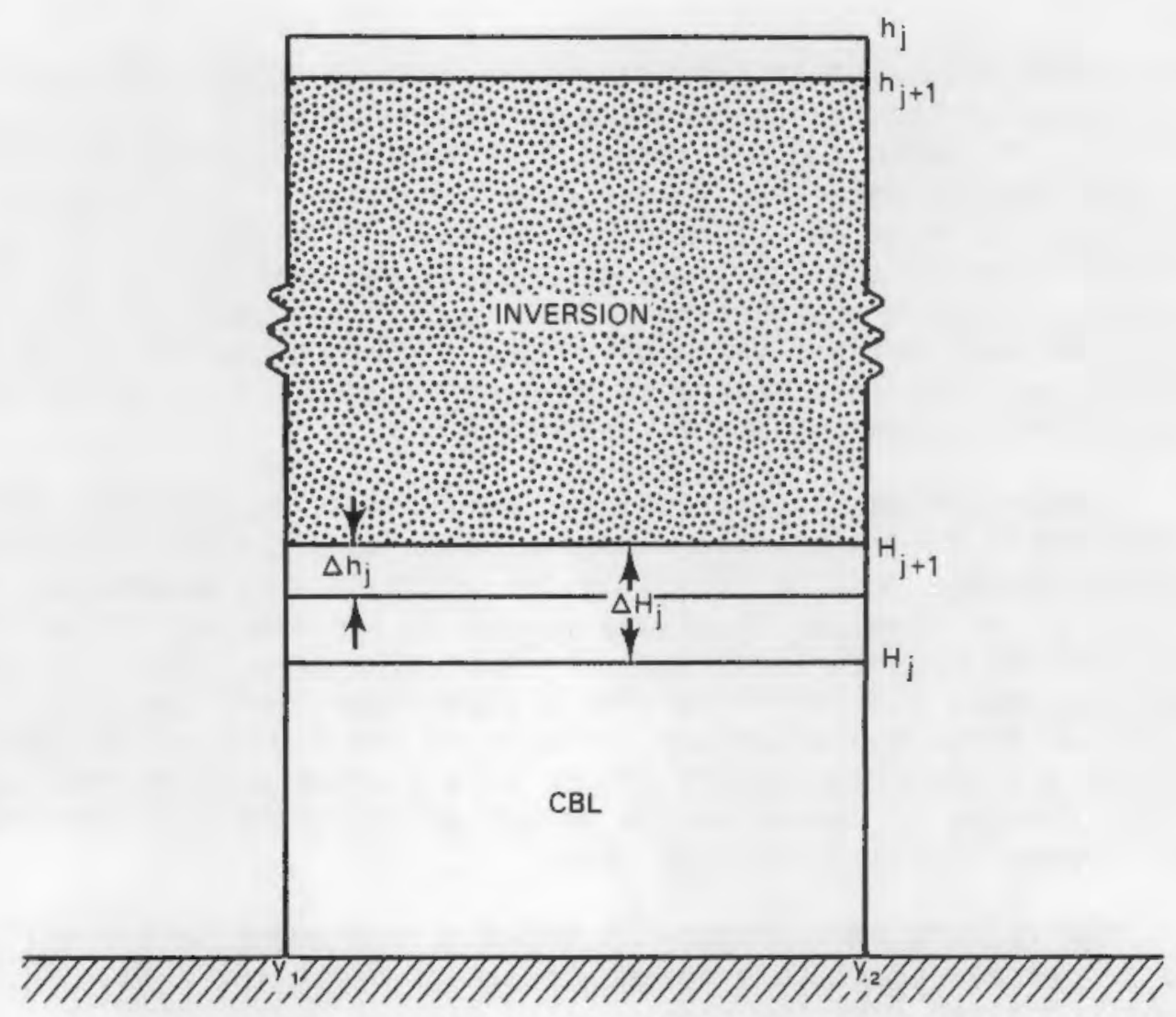

Figure 16. Diagram snowing the changes in CBL and inversion depth at a given time step above a valley floor grid element. The amount of air volume incorporated into the growing CBL at each time step is seen to be represented by $\left(y_{2}-y_{1}\right) \cdot\left(\Delta h_{j}+\Delta H_{j}\right)$ cubic meters.

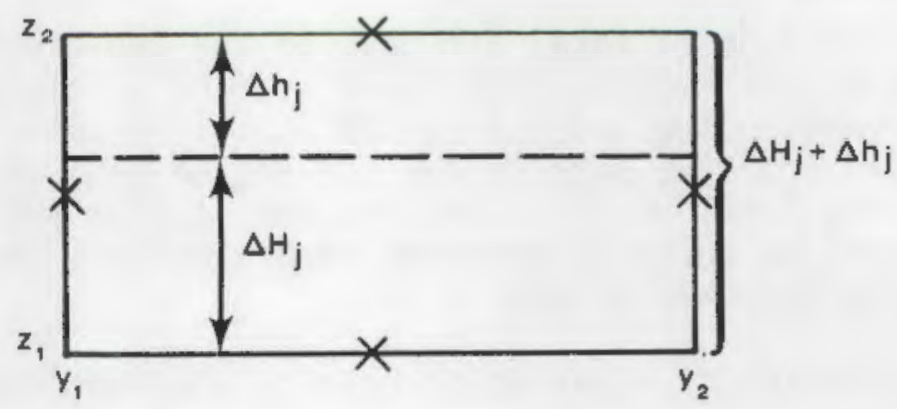

Figure 17. Representation of the volumetric element of mass incorporated into the growing CBL above a valley floor grid element at each model time step. The $x$ 's in the figure represent the positions where pollutant calculations are performed at each time step to estimate the average pollutant concentration carried within the volumetric element during the time step. 
This equation may be used to calculate wind velocities at the boundaries or septa of the grid elements in the slope flow layer. For the first grid element on the valley floor, we assume that the wind velocity on the left septum at the valley center is zero (i.e., there is no mass transferred across the valley center within the $C B L$ ). At a given time step a certain amount of mass sinks into the grid element of length $L$ and depth $D$. Integrating,

$$
\int_{0}^{D} \int_{0}^{L} \frac{\partial v}{\partial y} d y d z=-\int_{0}^{D} \int_{0}^{L} \frac{\partial w}{\partial z} d y d z
$$

or

$$
\overline{V_{L}-V_{0}}=\frac{L}{D} \bar{w}_{L}
$$

Thus, an inversion sinking at the rate of $.01 \mathrm{~m} / \mathrm{s}$ into the top of a $100 \mathrm{~m}$ long grid element of depth $50 \mathrm{~m}$ will produce a wind speed increase from the left septum of the grid element to the right septum of the grid element of

$$
\overline{V_{L}-V_{0}}=\left(\frac{100}{50}\right) .01=.02 \mathrm{~m} / \mathrm{s}
$$

The velocity, $v$, normal to a given septum of any grid element can thus be determined by summing the velocity changes calculated across each grid element beginning at the valley center and ending at the septum of interest.

\section{Pollution Concentration Calculation Method}

Pollution concentration calculations are made for each time step for each grid element following the general outlines of a numerical method described by Whiteman and McKee [11]. Following this method, calculations at each time step are performed sequentially for all of the grid elements, beginning with the grid element at the valley center and progressing up the valley sidewall. Calculations within each grid element (Figure 18) are made under a pollutant mass conservation assumption. The pollutant mass sinking into the top of each growing grid element is calculated using the method described above. Similarly, the advection of pollutant mass into and out of each grid element is accomplished using the velocity calculations at grid element septa as determined using a total air mass conservation constraint as described above. The concentration $C_{n, t}$ of pollutant in grid element $n$ at the end of the $t$-th time step of length $\Delta t$ is given by a simple pollutant mass balance: 


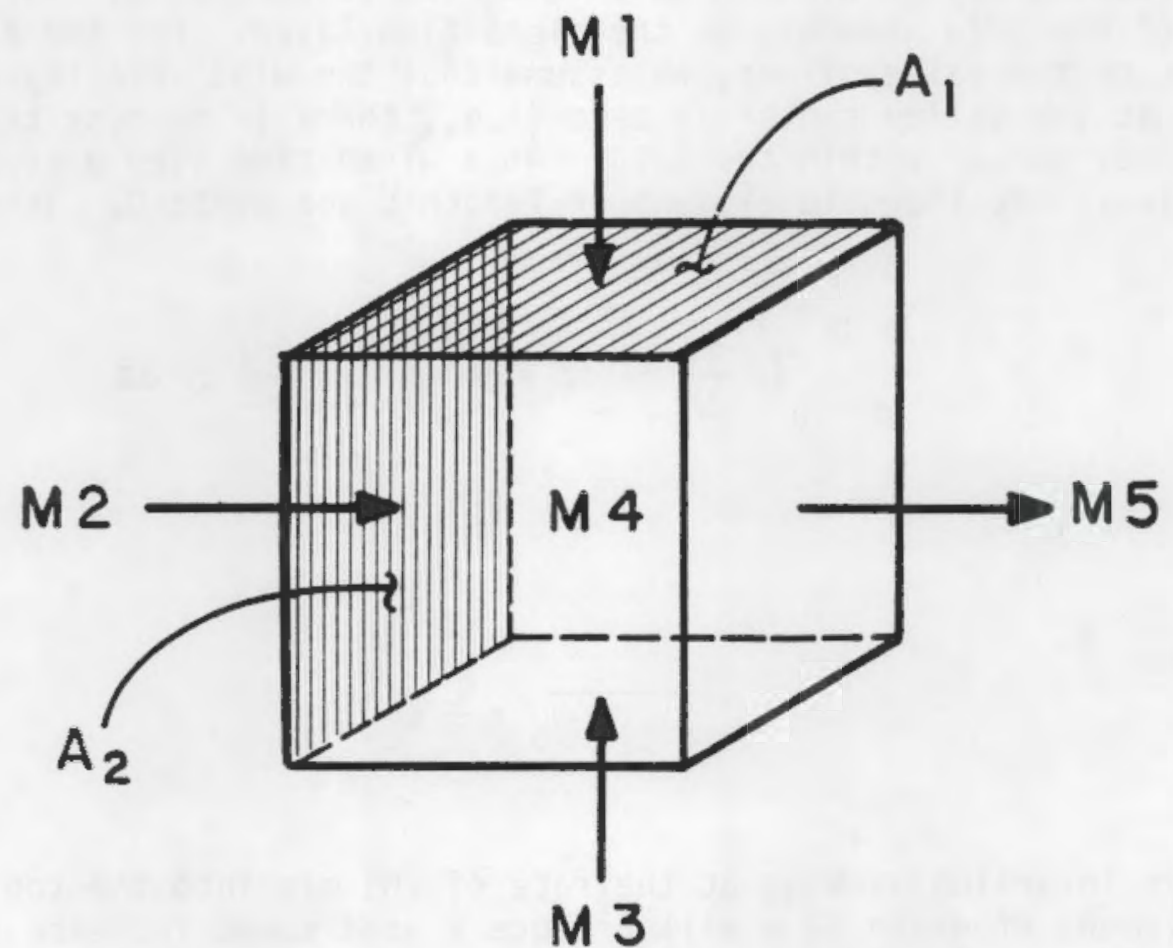

Figure 18. Schematic diagram of an individual model grid element illustrating the pollutant mass balance.

$$
\begin{gathered}
c_{n, t}=\frac{M_{\text {initial }}+M_{\text {in }}-M_{\text {out }}}{V_{n}} \\
\simeq \frac{M 1_{n, t}+M 2_{n, t}+M 3_{n, t}+M 4_{n, t}-M 5_{n, t}}{V_{n}}
\end{gathered}
$$

where

$V_{n}$ is the volume of the nth grid element

$\mathrm{Ml}_{\mathrm{n}}$ is the mass of pollutant coming into the growing grid element $\mathrm{n}$ during time step $\Delta t$

$M 2_{n}$ is the mass of pollutant advected into box $n$ from the adjacent upstream grid element $(n-1)$ during time step $\Delta t$

$M 3_{n}$ is the net mass of pollutant introduced into grid element $n$ during time step $\Delta t$ from pollutant sources and sinks within the grid element 
$M 4 n$ is the initial mass of pollutant in grid element $n$ at the beginning of time step $\Delta t$

$M 5_{n}$ is the mass of pollutant advected out of grid element $n$ into the adjacent downstream grid element $(n+1)$ at the end of time step $\Delta t$ after complete mixing of masses MI through M4 has taken place within the grid element.

The separate terms are calculated as follows:

$$
M 1_{n, t}=\bar{x}_{n} A_{1}\left(\Delta h_{j}+\Delta H_{j}\right)
$$

where $x_{n}$ is the average pollutant concentration within the volume element $\left(\Delta h_{j}+\Delta H_{j}\right)$ that is incorporated into the grid element $n$ at time step $t$ (or, following our previous nomenclature, $j$ ). $A_{1}$, the area of the grid element top (Figure 18), should not be confused with the $A_{1}$ used previously in Equation 40.

$$
M 2_{n, t}=C_{n-1, t} A_{2} v_{1} \Delta t
$$

where

$A_{2}=$ area of box septum

$v_{1}=$ wind velocity component into grid element normal to box septum.

$$
M 3_{n, t}=(Q-S) A_{1} \Delta t
$$

where

$$
\begin{aligned}
& Q=\text { pollutant emission rate }\left[M L^{-2} T^{-1}\right] \\
& S=\text { pollutant removal rate }\left[M L^{-2} T^{-1}\right] \\
& \qquad M 4 n, t=C_{n, t-1} V_{n} \\
& M 5_{n, t}=\left[\frac{M 1_{n, t}+M 2_{n, t}+M 3_{n, t}+M 4_{n, t}}{V_{n}}\right] A_{2} v_{2} \Delta t
\end{aligned}
$$


where

$v_{2}=$ wind velocity component out of box normal to box septum.

Exponential Decay of Concentration

Calculation of concentrations in individual grid elements follows the procedure outlined. A modification of this procedure is necessary, however, for individual grid elements on the sidewalls when the top of the inversion as the depth of the CBL, suddenly increases when this occurs. Concentrations would then be expected to decrease rapidly. This is handled in the model by simply allowing the last concentration calculated in the grid element to decay exponentially with time after the inversion top descends below the grid element. In view of the lack of observational evidence, the time constant of the exponential decay is shown arbitrarily so that the concentration decreases by $2 \%$ at each time step, such that

$$
c_{n, t}=.98 C_{n, t-1}
$$

As with any numerical model, one must be cognizant of the possibility of numerical instabilities affecting model results. The criteria for maintaining stability $[39,40]$ constrains the model user to maintain a certain relationship between the model time step and the grid element length, depending on the upslope wind speed encountered in the simulation. This relationship is

$$
v_{\max } \Delta t<y_{2}-y_{1}
$$

Thus, the maximum upslope wind speed simulated in the model, when multiplied by the time step length must be less than the grid element length in order to maintain computational stability. In the VALMET model, the user may choose $\left(y_{2}-y_{1}\right)$ but has no control over $\Delta t$ and $v_{\text {max }}$. Calculations are made automatically within VALMET to ensure computational stability. Since the maximum upslope wind velocities should never exceed $10 \mathrm{~m} / \mathrm{s}$, we may ensure computational stability by setting

$$
\Delta t=\frac{y_{2}-y_{1}}{10}
$$

Thus, for example, a time step of $10 \mathrm{~s}$ is sufficiently small to ensure computational stability in a model simulation with $100 \mathrm{~m}$ grid elements.

Following the numerical method outlined above, concentration may be calculated for every time step for every gid element. Rather than storing each of these concentrations, which would take a great deal of computer memory, 5-minute-average concentrations are stored. This greatly reduces 
computer storage requirements. The five-minute-average concentrations constitute one of the main outputs of the model.

Maximum 1- and 3-Hour Average Concentrations

Another ouptut of the model os the maximum 1- and 3-hour-average concentrations and their times of occurrence in each of the grid elements. These calculations are made from the basic 5-minute-average concentration array for each grid element by m eans of a moving average method. Initial tests have been conducted to confirm that the maximum 1- and 3-hour-average concentrtions calculated from the 5-minute-average array do not differ significantly from concentrations calculated from a 10-second-average concentration array. 


\section{SECTION 4 \\ OVERVIEW OF MODULAR VALMET MODEL}

The initial valley air quality model called VALMET has been designed and constructed based on hypotheses presented in Section 2 that arose from an observational study of Colorado valley meteorology. The model uses the technical approach and equations outlined in Section 3.

The VALMET model can be used to simulate the transport and diffusion of pollutants released from an elevated source in a well-defined mountain valley during the nighttime and morning transition periods. The model operates on a valley cross section an arbitrary distance downvalley from an air pollution source and has been constructed to include parameterizations of the major physical processes that act to disperse pollution during these time periods.

Before a modeler attempts to use VALMET to simulate dispersion in a particular valley he should critically review Sections 1 through 3 of this report. Since the modeling approach is phenomenological, and individual physical processes affecting pollutant dispersion are parameterized, the modeler should be wary of applying the model to a meteorological or topographical situation where model assumptions are invalidated or physical processes parameterized in the model are clearly not occurring. The modeler should carefully review existing meteorological data for the valley of interest to see whether the model applies.

Even if the model's assumptions seem valid, the present state of the art in such modeling results in the use of rather arbitrarily specified parameters within the model. Further work is necessary to refine our estimates of the values of these parameters $\left(e_{.} . g_{\bullet}, k, \sigma_{y}\right.$, and $\left.\sigma_{z}\right)$. This work would benefit from comparisons of model results with actual diffusion trials in real valleys. No comparisons of model results with diffusion trials have yet been made, although these comparisons are now being planned. In view of our rather tentative understanding of valley meteorology the model has been constructed in a modular fashion. This modularization of the code is a major design feature of the model and should allow the code to be modified easily as we learn more about the meteorology of valleys and find better parameterizations for individual physical processes. The modules have been designed, where possible, so that the analytical or numerical calculations in the modules can be replaced by observational data, when available, with minimal modifications in the computer code structure. For example, if acoustic sounder data are 
available to measure CBL height and inversion top height, these data can replace the analytical scheme for predicting these heights.

The modular structure of the model is 111 ustrated in Figure 19, where the modules are named and the functions of the modules are indicated. In this section we give the model user an overview of the VALMET model, explaining its structure and its input requirements. A full technical description of the modules, including variable name definitions and module inputs and outputs is given in Section 5 for the interested computer programmer. In Section 6 the model outputs are illustrated for two sample simulations. The full VALMET code is given in Appendix $A$.

\section{FEATURES OF THE COMPUTER CODE}

The VALMET model is coded following a FDRTRAN77 standard [41] and should be useable without modification on any computer system having an up-to-date FORTRAN compiler. The model is documented internally through the liberal use of comment statements. These comments explain the purpose of sections of code or individual FORTRAN statements, or serve as variable name definition tables.

Several special features or protocols are included in the code. The dimensions of arrays in the code are generally set using PARAMETER statements. Thus, if the user finds that the array sizes are too small for the length of the simulation or too large to fit in a smaller computer he may easity change the dimensions by modifying PARAMETER statements in the main program and in selected subroutines. COMMON blocks are fully utilized in the code to reduce the memory requirements of the operating progam. Most of the parameters passed to the subroutines are generally passed through the subroutine argument lists. Arrays, however, are usually passed through COMMON blocks.

The model was developed on a VAX/VMS $11 / 780$ computer. After compilation, a single model run generally takes 1 minute of central processor time on the VAX, loads in 95,000 bytes (25K words) of core, and costs approximately $\$ 1.00$. Costs of optional plotting will vary from installation to installation.

MODEL INPUTS

The VALMET program runs in an interactive mode in which the user controls program execution from a remote interactive terminal. The user enters model inputs by following directions given to the user on the terminal screen.

As with any model, model performance will be a function of the suitability of the input data entered by the user. Where worst case values of the input parameters are estimated on the basis of little data the user shouid consider the model results to be a screening analysis only. On the other hand, an industrial installation having a great deal of pollutant concentration and meteorological data could use the model as a site specific model by making specific modifications to the model to include observed plume dilution, dispersion coefficients, etc. This would require considerable field experimentation and data analysis. 


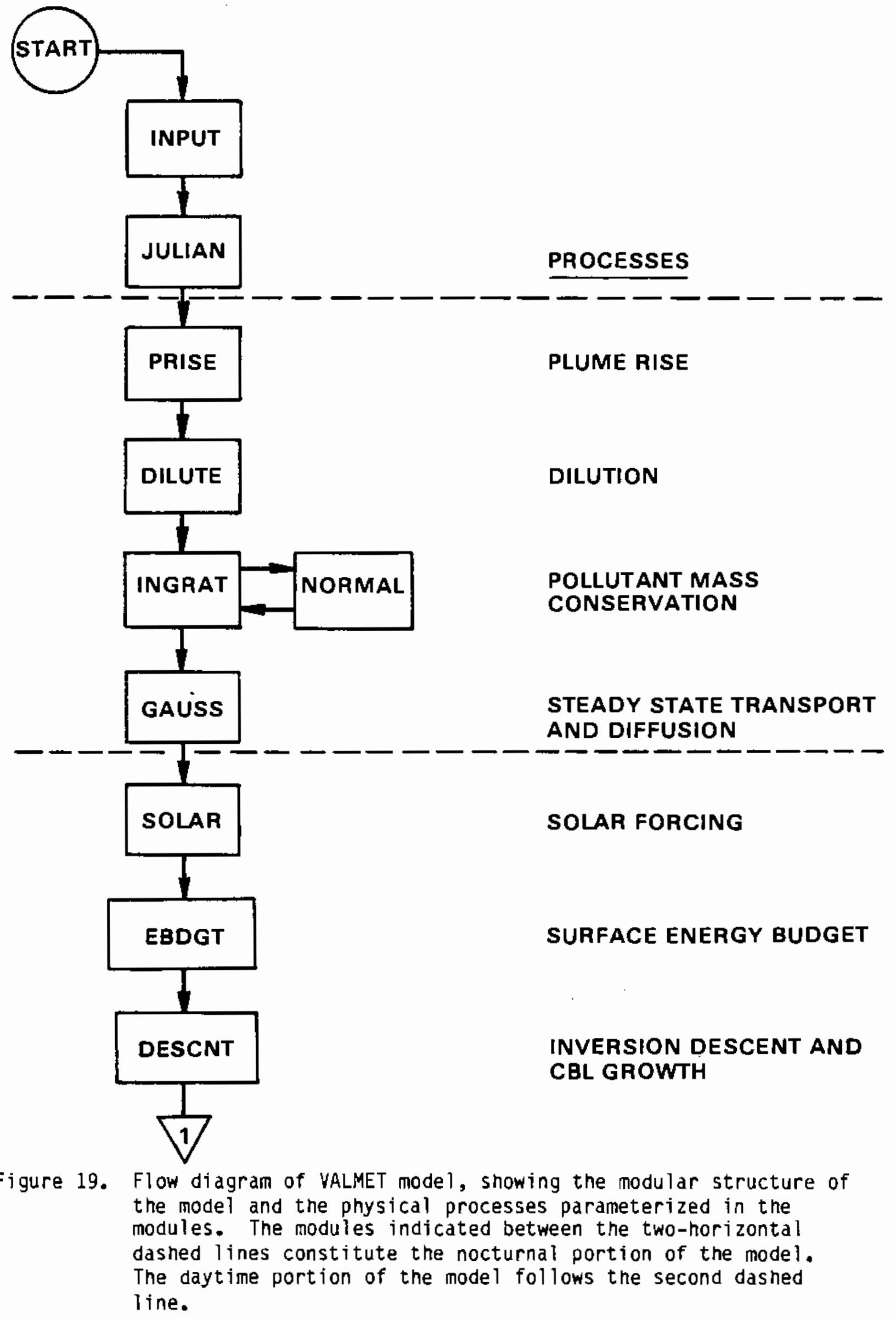




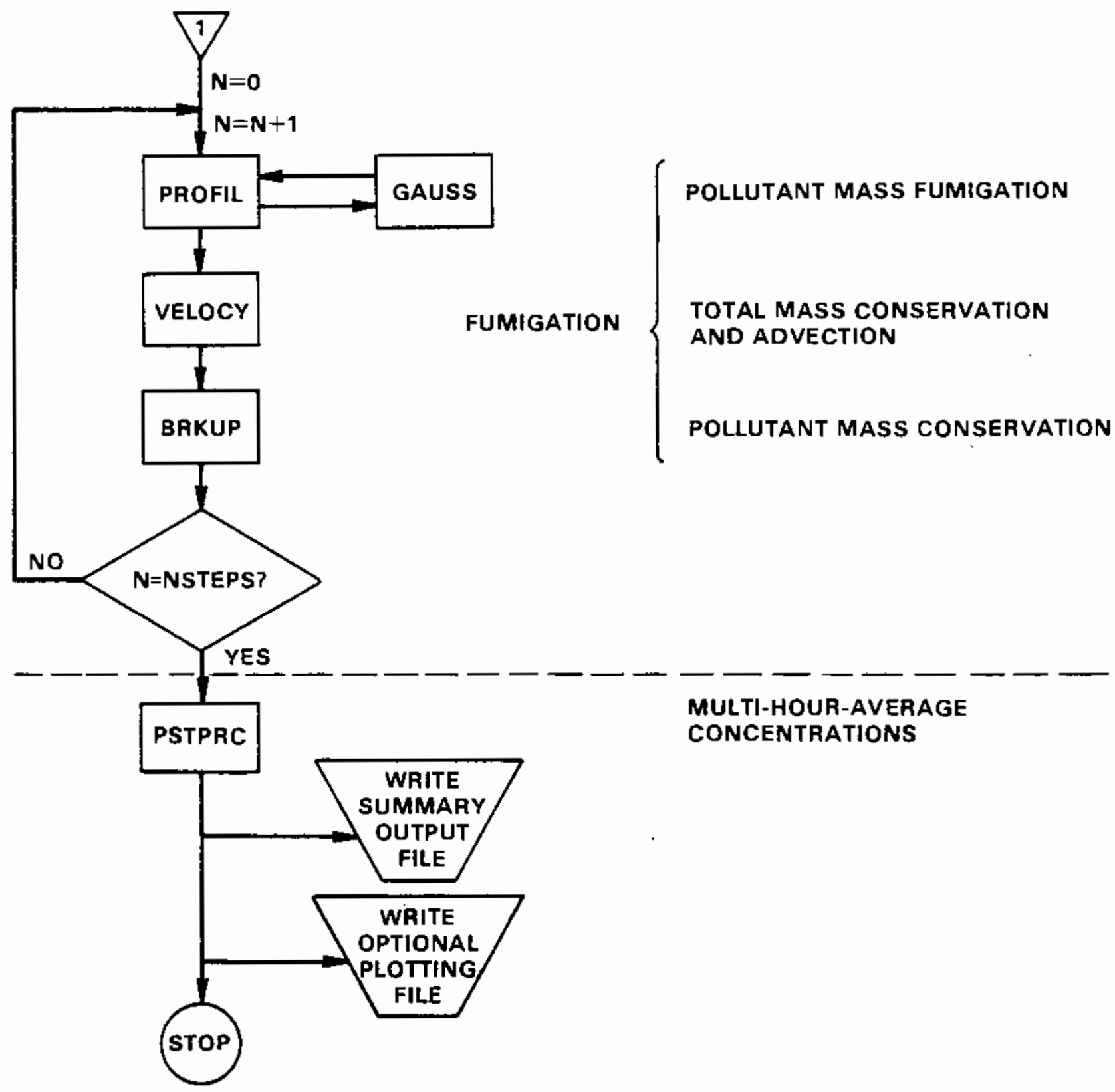

Figure 19. (contd) 
When the user runs VALMET from an interactive terminal, a data tabie appears on the user's screen. This table gives sample input values for a model run. The user may follow directions given on the screen to change any of the input values to simulate air pollution dispersion in any valley of interest, or he may simply specify that the sample (or default) sinulation be run.

The input table (Figure 20) is arranged according to categories of input data. Table input values for the sample simulation are generally specified in the MKS system of units, although pressures are given in millibars and parameters involving potential temperatures are given in degrees Kelvin in conformance with general meteorological practice.

Table 5 below gives a full listing of the appropriate units of all input parameters used in VALMET as well as the default values of these parameters. VALMET is programmed so that the user can change input vaiues as many times as necessary until the input table is properly completed. Once the input table is satisfactory to the user, he instructs VALMET to proceed with the model run.

\section{SPECIFICATION OF THE MODEL INPUTS BY THE USER}

In this section of the report we will instruct the model user how to determine the input parameters that are required by the model. The parameters are entered into the model by the user as he follows instructions given on the interactive terminal screen. The input parameters are discussed in groups, as follows:

\section{Val ley Characteristics}

The characteristics of the valiey topographic cross section must be obtained from topographic maps. The user should plot the terrain cross section at the down valley distance of interest. From this cross section the user should estimate the valley floor width (estimates to the nearest $100 \mathrm{~m}$ should be sufficient) and the two sidewall inclination angles. The user must use his judgment when making these estimates, depending on the representativeness of the topographic cross section plotted. Since the model will deal with the valley sidewalls only to the initial depth of the temperature inversion, the user should ignore the sidewalls that extend above this height when estimating representative sidewall angles.

Date

The user must specify the date of the simulation by giving the month, day and year. The date is necessary in the solar model to calculate day length, time of sunrise, etc. The year is necessary to account for the minor effect of leap years on the simulation. 
THE PROGRAM INITIALIZATION PARAMETERS ARE SET TO THE FOLLOWING VALUES:

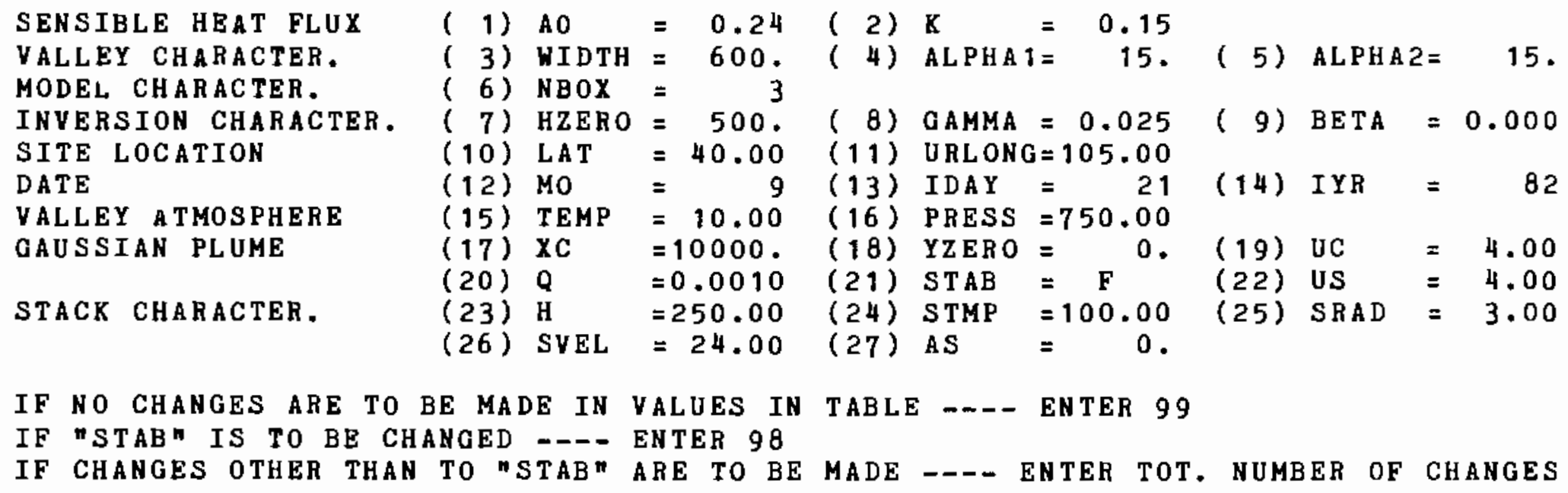

Figure 20. Illustration of the VALMET model input table as it appears on the user's interactive screen. 
TABLE 5. Default Values of VALMET Input Parameters

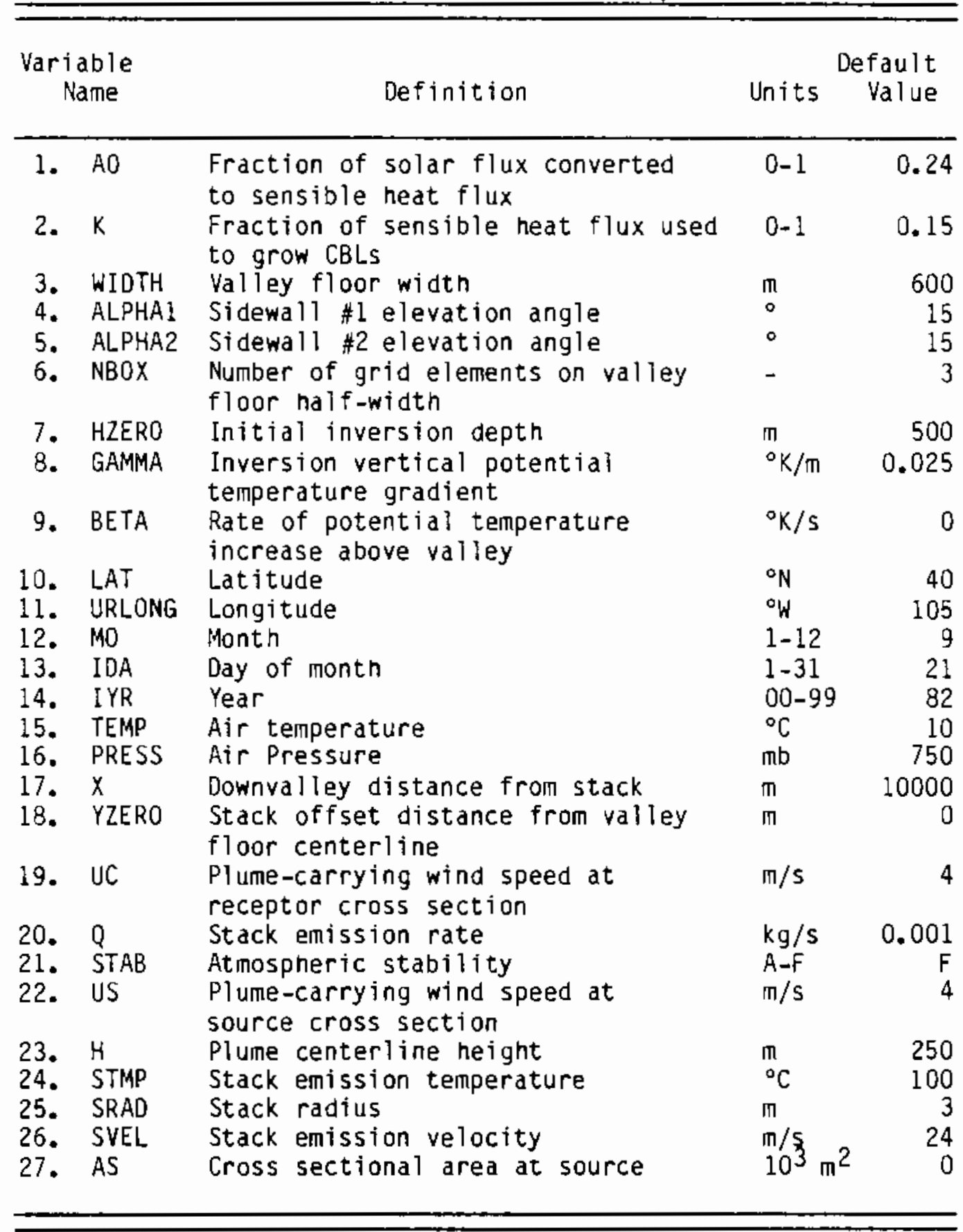


Site Location

Both latitude and longitude of the site must be specified by the user in order to support solar radiation calculations within the model. The longitude value is necessary to account for corrections to the time of sunrise.

Model Characteristics

The user must specify the number of grid elements on the valley floor half width in order to define the model's numerical grid. There are several considerations that the user should keep in mind when specifying this number. The implications of the specification can be considered by referring to Figure 12.

The number of grid elements on the valley floor half width (NBOX) is used in the model to figure the length of the grid elements. The length is given by

\section{$B O X L E N=W /(N B O X \star 2)$}

where $w$ is the valley floor width. Once BOXLEN is calculated, the model then calculates how many grid elements of this length (NTOTI) will be necessary in order to reach the top of the inversion when the grid elements are arrayed end to end. NTOTI must not exceed 30, as currently dimensioned in the model. On the other hand, NTOTI should not be too small, since this parameter affects the spatial resolution of concentrations calculated within the model. As a rule of thumb, NBOX may be chosen to produce grid elements of 100 or $200 \mathrm{~m}$ length.

Valley Atmosphere

The mean temperature and pressure within the valley temperature inversion at sunrise should be estimated using the aititude of the site and knowledge of seasonal changes in atmospheric temperature. Observational data would be useful in estimating both of these parameters, but the accuracy of these estimates is not critical to the model results. The values are used to correct the model concentration values to standard pressure and temperature and to calculate the atmospheric density for use in the inversion breakup or energy budget calculations.

Stack Characteristics

The stack characteristics should be obtained from engineering calculations for the specific air pollution source. The required parameters include physical stack height, effluent temperature, stack inside radius, and exit velocity. The final parameter that must be specified by the user is the area of the valley cross section at the stack. This area, bounded by the valley floor, the two sidewalls and the temperature inversion top at sunrise, is used in the plume dilution module to calculate clean air volume flux across the cross section at the poliutant source. The area should be calculated from Equation 1, but is input in thousands of square meters (i.e., the results of 
the calculation with Equation 1 should be divided by 1000 before being input into the model). The model user will need to know the inversion depth at sunrise in order to calculate the area. If the user does not wish to engage the plume dilution module or does not have the wind speed observations on the cross valley section where pollution calculations are to be made, he should specify the cross sectional area at the stack to be zero. The wind speed specification at the downwind cross section is then deactivated (i.e., is not used in the model) and the plume is advected down the valley with the wind speed specified at the pollutant source with no plume dilution during transport.

\section{Inversion Characteristics}

The user must specify inversion depth and inversion potential temperature gradient at sunrise, as well as the rate of potential temperature increase at the inversion top during the period of inversion breakup. The user should specify these parameters on the basis of observations of temperature inversion development within the valley of interest. These observations are critical to the model results and should be based on vertical soundings taken from the valley floor, if avajlable. The modeler should be cautioned against using observations taken from surface-based instruments, unless these have been shown to be clearly related to vertical profiles over the valley center. A qualified analyst may be able to determine the inversion depth from acoustic sounder records. The modeler must use his judgment in specifying a single number for the potential temperature gradient at sunrise. Actual soundings are often complicated, especially in the lower levels. The potential temperature gradient obtained by subtracting the surface value from the value at the inversion top and dividing by the inversion depth may not be a representative number for the inversion as a whole when a shallow and very strong inversion layer is present near the ground. The temperature gradient is used in the model primarily to calculate the energy deficit within the valley represented by the presence of the temperature inversion. The total energy deficit is obtained under an assumption of cross valley homogeneity by weighting the temperature deficits at various levels by the cross sectional area of the valley. Since the valley is much wider at its top than near the valley floor, errors made in estimating temperature deficits (i.e., determining a representative potential temperature gradient) at the upper levels are more critical to model results than at the lower levels. A better estimate of the valley energy deficit will be obtained by ignoring shallow, but very strong, temperature inversion layers present on the valley floor if this means that the potential temperature gradient estimate is more accurate for upper levels.

In lieu of observations one may use the observations of Whiteman [9] to obtain first estimates of inversion depths, strengths, and inversion top warming rates in Colorado valleys.

When the model is used to estimate worst case air pollution concentrations, one should naturally attempt to arrive at worst case estimates of inversion chracteristics parameters. 
Gaussian Plume Parameters

The model user must specify Gaussian plume parameters including the distance to the cross section of interest, the stack distance of fset from the valley floor centeriine, the plume-carrying wind speed, the source emission rate, and the atmospheric stability.

The downvalley distance is determined from a topographic map by measuring the distance from the source to the cross valley section along the valley floor centerline following any curves or turns in the valley's course.

The stack distance offset is determined as the shortest distance from the valley floor centerline to the pollutant source on the valley floor. The sign of the distance follows from the orientation of the valley coordinate system, as discussed in Section 3.

The wind speeds used in VALMET are critical parameters that must be carefully specified from available data. Downvalley wind speeds in Colorado valleys have been shown to vary significantly from valley to valley [9], so that wind speeds in one valley are not necessarily indicative of wind speeds in another valley. In short, observations are necessary for the valley being modeled. Furthermore, the wind speeds vary on a cross valley section due to vertical and horizontal position within the cross section [42]. On a vertical profile through the nocturnal temperature inversion, the peak winds are often located about midway through the inversion depth with lower wind speeds near the ground and at the inversion top. Near-surface wind speeds, therefore, are not generally indicative of wind speeds at a typical plume carrying level. Near-surface wind direction observations, in fact, may be 180 degrees in error shortly after sunrise when wind continues to flow downvalley in the elevated stable core while the winds reverse to up valley in the CBL which develops over the valley floor. Near-surface wind observations should, therefore, not be used to drive the VALMET model.

Two wind speeds are required inputs for the VALMET model. Both are required in order to allow for plume dilution due to clean air inflow between the source and the cross section where air pollution calculations are made. The user must specify the average nocturnal wind speed at plume carrying leve? at both the source and the receptor characteristic of the nocturnal downvalley flow. They may be obtained from a doppler acoustic sounder or from successive tethersonde or pilot balloon ascents.

The source emission rate may be obtained from engineering calculations for the stack of interest. "Worst case" pollutant calculations should be made on the basis of worst case emission rates. The model can not handle emission rates that vary in time, so a realistic time average emission rate is most appropriate for driving the model.

The model uses Pasquili-Gifford diffusion coefficients $[26,27,43]$ to characterize diffusion in the nighttime, high stability, elevated stable core of the valley temperature inversion. The stability class in this stable region should be $D, E$, or $F$ following the original definitions of atmosopheric 
stability given in Table 3. The user-input stability class is autonatically modified internaliy within VALMET to account for enhanced diffusion in complex terrain.

Sensible Heat Flux

The final two input parameters in the VALMET model are the two sensible heat flux parameters. The parameters, which are both fractions between 0 and 1 , are based on the valley surface energy budget. Little research has yet been done on valley energy budgets and, since the energy budget is known to strongly influence the local diurnal meteorology of valleys, the initiation of such research should be considered an important priority in future studies.

The first sensible heat flux parameter is $A_{0}$, the fraction of extraterrestrial solar heat flux converted to sensible heat flux within the valley. The conversion, of course, occurs at the valley surfaces (valley floor and sidewalls), but the bulk thermodynamic model used as the basis of VALMET cannot distinguish between energy budgets over the different surfaces. The fraction required in the model, then, is the fraction of the (extraterrestrial) solar heat flux coming downward across the upper surface of the temperature inversion which is converted to sensible heat flux within the valley. This fraction is assumed to be constant during the temperature inversion breakup period. Ao depends on the transmissivity of the earth's atmosphere to the solar beam, the albedo of the valley surfaces and vegetative cover, and the presence of clouds, as well as the partitioning of the solar beam upon striking the valley surfaces. The long wave radiative balance also plays a role at these surfaces which affects sensible heat flux. Whiteman [9] has analyzed the individual terms in the surface energy budget to determine that the maximum value of $A_{0}$ is unlikely to be greater than 0.6. A valley having a low reflectivity would approach this value under clear skies only if the valley had no soil moisture. Whiteman and McKee [3] were able to simulate temperature inversion breakup well in a dry Colorado valley in October using an $A_{0}$ value of 0.45 . Maximum values of heat flux observed in the Kansas 1968 experiments [44], if assumed to be representative of solar noon values, correspond to $A_{0}$ values of about 0.25 . The vaiue of $A_{0}$ may be smaller in winter when snow cover is present in a valley and the albedo is large. The overall albedo in winter may depend strongly on the presence of forest cover within the valley or the relative proportions of other lower albedo surfaces. Whiteman and Mckee [3] were able to simulate inversion breakup in Colorado's snow covered Yampa Valley using $A_{0}=0.9$.

The modeler may estimate a value of $A_{0}$ from the discussion in the paragraph above or, if sufficient meteorological data are available for the valley in question, he may base his estimate on one of two alternate quantitative methods. The first method is described below. Then the second, and more comprehensive method, which also provides a means for estimating the second sensible heat flux parameter, $k$, is described. The first method of determining $A_{0}$ involves the solution of Whiteman and McKee's [3] Equation 21, Equation 28 , or a combination of the two for $A_{0}$ knowing, for a particular day, 
a) the sunrise temperature inversion potentiai temperature gradient,

b) the inversion depth at sunrise,

c) the valley floor width and sidewali inclination angles,

d) the solar parameters on the day of interest, and

e) the observed time of temperature inversion breakup.

By using such meteorological information for a variety of days in different seasons, the modeler may determine a climatology of $A_{0}$ values that would be useful in air pollution modeling. For the convenience of the reader, a reprint of the whiteman and Mckee article is included in this report as Appendix C.

The value of the second sensible heat flux parameter, $k$, is the fraction $(0-1)$ of the sensible heat flux used to cause CBL growth. The remaining fraction (1-k) represents the fraction of sensibie heat flux used to transport mass up the valley sidewalls causing the inversion top to sink. The value of $k$ is 1 for flat terrain since temperature inversions are destroyed there entirely by CBL growth, but approaches zero in snow covered valleys where CBL growth is arrested after reaching a certain height [g]. Whiteman and Mckee [3] were able to simulate inversion breakup in a dry Colorado valley using $k=$ 0.14. Inversion breakup in the snow covered Yampa Valley was simulated well using $k=1.0$.

The search for a mathematical relationship between $k$ and parameters that are more easily measured is a high priority for future work. The value of $k$ is expected to depend strongly on valley width and, perhaps, on sensible heat flux itself. Given the present lack of an appropriate mathematical relationship, the best approach for determining $k$ is to simply determine the value of $k$ which best fits observations of inversion breakup in the particular valley being modeled. The means by which this can be accomplished was described by Whiteman and Mckee [3]. They described how the value of $A_{0}$ determines the temperature inversion breakup time, while the value of $k$ determines the height. at which the CBL and inversion top meet to cause inversion breakup, and have presented plots showing the effect of varying $k$ and $A_{0}$ on temperature inversion breakup. Both the time and height can be observed using an acoustic sounder or multiple serial tethersonde ascents in the valley of interest. observed time variations of CBL depth and inversion top height can be fit using a trial and error procedure using Whiteman and McKee's [3] Equations 29 and 30. The reader should refer, again, to Appendix $C$. These equations are programmed in VALMET module "OESCNT" where they may be solved using a numerical method. The modeler who wishes to use the procedure should convert a copy of subroutine DESCNT to a main program where the subroutine arguments are explicitly specified. The number of time steps to inversion destruction, and the CBL and inversion top heights as a function of time would be required outputs of such a program. The effect of changing $A_{0}$ and $k$ could then be easily investigated and fit to actual observations. A time step of 600 seconds would be sufficient for the computations desired. The numerical method requires a CBL height and inversion depth at sunrise as mathematica! initial conditions. The valley meteorologial data necessary to use this approach to determine $k$ and $A_{0}$ include: 
a) inversion depth at sunrise,

b) inversion potential temperature gradient at sunrise,

c) valley floor width and sidewall angles,

d) soiar model parameters $A_{1}$ and $\tau$,

e) the time of inversion destruction, and

f) the height at which the rising CBL and descending inversion top meet at the time of temperature inversion destruction.

Solar parameters can be determined from model equations provided earlier in this report. Topographic parameters can be determined from a topographic map. The potential temperature gradient at sunrise requires a vertical temperature sounding. The other required parameters can also be obtained from such soundings, if they are made frequently through the valley depth during the temperature inversion breakup period. They may also be determined from monostatic acoustic sounder records by a qualified analyst.

\section{ERROR MESSAGES}

The VALMET model has several built-in checking and correction routines which will produce error messages when the model input parameters have been improperly specified by the user, or when the user attempts to use the model in a way unintended by the model developers. These messages are written on the screen of the user's interactive terminal and generally result in a complete termination of the program's execution. This termination occurs after the user has specified all input data, and execution of the program begins. The error messages and their explanations are given below.

1. the plume, after plume Rise, is nOt Within the Stable CORE

This error message is written if the plume, after plume rise, is lower than the initial CBL height (now specified in the model as $25 \mathrm{~m}$ ) or greater than the initial inversion top height. The model should not be applied to a case where the plume is not emitted into the stable core.

2. TOO MANY GRID ELEMENTS FOR THE OIMENSIONS YOU HAVE SPECIFIED

The total number of grid elements in the model at sunrise is greater than the DIMENSION statement allows (i.e, 30). Respecify NBOX to be less than your previous specification.

3. YOU HAVE SPECIFIED A WRONG STABILITY CLASS - F WILL BE USED INSTEAD

The user has specified a stability class outside the range from A to $F$. The model has reset the stability class to $F$ and is continuing execution. 
4. STACK MUST BE ON THE VALLEY FLOOR-RESPECIFY YZERO

The user has specified a stack offset distance that is greater in absolute value than half the valley floor width. The stack is therefore not on the valley floor. The model cannot handle this situation. Please respecify YZERO.

5. STABILITY MUST BE D, E, OR F

The stability within the nocturnal valley temperature inversion should be specified as $D, E$, or $F$. Please respecify.

\section{CROSS SECTION WINDSPEED HAS BEEN RESET TO $1 \mathrm{~m} / \mathrm{S}$}

The user has specified a transport wind speed at the receptor cross section that is less than $1 \mathrm{~m} / \mathrm{s}$. The drainage wind speed in a valley is unlikely to be less than $1 \mathrm{~m} / \mathrm{s}$ and the Gaussian plume equation cannot handle very low wind speeds well. The model has, therefore, reset the wind speed to $1 \mathrm{~m} / \mathrm{s}$ and is continuing execution.

\section{DOWNVALLEY WIND SPEED AT STACK HAS BEEN SET TO $1 \mathrm{M} / \mathrm{S}$}

The user has specified a transport wind speed at the pollutant source cross section that is less than $1 \mathrm{~m} / \mathrm{s}$. The model has reset the wind speed to $1 \mathrm{~m} / \mathrm{s}$ and is continuing execution.

8. MONTH INDEX IS OUT OF RANGE

The month must be specified by the user as a number from 1 to 12. Please respecify the month.

9. DAY INDEX IS OUT OF RANGE

The day of the month must be specified as a number from 1 to 31 . Please respecify the day of the month.

10. YEAR IS INCORRECTLY SPECIFIED

The year must be specified as a two digit number from 00 to 99 . Please respecify the year. 
SECTIUN 5

TECHNICAL DESCRIPTION OF INDIVIOUAL MOOULES

\section{VALMET-Main Program}

VALMET is the main program that controls the moduies or subroutines which, taken together, form the valley air quality model. The function of the main program is to provide the basic structure of the air quality model and to call the specific modules as required. In addition, several computing housekeeping functions are performed in the main program including the establishment of PARAMETER statements and COMMON Blocks, and the opening and closing of output files. Model outputs are written from the main program, as well.

Inputs

Inputs to the main program come through Subroutine INPUT, a subroutine that is run interactively by the user and which features a default input table. Oata coming into the main program from subroutines usually come through arguments listed in the subroutine call statement. Large arrays of data, however, are frequently transferred from the main program to the subroutines (and vice versa) through COMMON blocks.

Outputs

The results of a model run are written to two output disk files. The first output file, named VALMET.OUT, is a formatted file which contains the resuits of the model run. After the model is run, the contents of this file may be printed to obtain a summary record of the model run, including model input parameters and outputs. A second file, named VALMET.PLT, is also automatically generated with every computer run. This formatted file contains time series of pollutant concentrations, temperature inversion depths and convective boundary layer depths, as well as many of the basic parameters used in the model run. The file is created for the model user who wishes to develop his own plotting programs to plot the results of a model run. An example program that the authors used to generate the plots used in this report is shown in Appendix B. Since every user's computer installation will have different plotting software and hardware, this approach of creating a basic data file but not including a specific plotting program in the air pollution model seemed the most appropriate way to proceed. Interested users can develop their own specific plotting software using our example. 
Conventions

The following indexing conventions are used in VALMET where it has proven convenient:

I=grid element index $\quad N$ or $M N=t i m e$ step index

Variable Name Definitions

\begin{tabular}{|c|c|c|}
\hline $\begin{array}{l}\text { Input / } \\
\text { Output }\end{array}$ & $\begin{array}{l}\text { VAR IABLE } \\
\text { NAME }\end{array}$ & DEF INITION \\
\hline I & A0 & $\begin{array}{l}\text { Fraction of extraterrestrial solar flux converted to } \\
\text { sensible heat flux }(0-1)\end{array}$ \\
\hline I & Al & Solar flux on horizontal surface at solar noon $\left(\mathrm{wm}^{-2}\right)$ \\
\hline- & A2 & Same as A0 \\
\hline- & $A C$ & Valley cross sectional area below inversion top \\
\hline I & ALPHAl & $\begin{array}{l}\text { at cross sectional distance } \times C\left(\mathrm{~m}^{2}\right) \\
\text { Sidewall } \# 1 \text { elevation angle (rad) }\end{array}$ \\
\hline I & ALPHA2 & Sidewall \#2 elevation angle (rad) \\
\hline I & & $\begin{array}{l}\text { Valley cross sectional area below inyersion top } \\
\text { at pollution source cross section }\left(\mathrm{m}^{2}\right)\end{array}$ \\
\hline I & BETA & $\begin{array}{l}\text { Rate of increase of potential temperature at } \\
\text { inversion top }\left({ }^{\circ} \mathrm{K} / \mathrm{s}\right)\end{array}$ \\
\hline- & BOXLEN & Length of grid elements (m) \\
\hline- & CCHI & $\begin{array}{l}\text { Noctucnal pollutant concentration in a grid element } \\
\left(\mu \mathrm{g} / \mathrm{m}^{3}\right)\end{array}$ \\
\hline- & CHIOFF & $\begin{array}{l}\text { Concentration offset value due to reflection off } \\
\text { valley floor and sidewalls }\left(\mu \mathrm{g} / \mathrm{m}^{3}\right)\end{array}$ \\
\hline- & CLCONC & Centerline concentration $\left(\mathrm{\mu g} / \mathrm{m}^{3}\right)$ \\
\hline- & DELTAT & Time step size (s) \\
\hline- & DF & Inverse of dilution factor \\
\hline I & GAMMA & Vertical potential temperature gradient $\left({ }^{\circ} \mathrm{K} / \mathrm{m}\right)$ \\
\hline I & & Plume centerline height (m) \\
\hline- & HCBL I & Initial CBL height (m) \\
\hline I & HZERO & Initial depth of inversion (m) \\
\hline- & I & Grid element index \\
\hline- & I1 & Intermediate variable \\
\hline- & IAVG & Averaging period (s) \\
\hline I & IDA & Day of month $(1-31)$ \\
\hline- & IF IX & $\begin{array}{l}\text { Number of grid eiements on sidewall at model } \\
\text { initiation }\end{array}$ \\
\hline- & IF IX2 & $\begin{array}{l}\text { Number of grid eiements on sidewall at given time } \\
\text { step }\end{array}$ \\
\hline $\bar{I}$ & $\begin{array}{l}\text { IND } \\
\text { ISTAB }\end{array}$ & $\begin{array}{l}\text { Loop index } \\
\text { Stability index }(1-6)\end{array}$ \\
\hline- & ISTABY & Stability index for determination of $\sigma_{y}(1-6)$ \\
\hline - & ISTABZ & Stability index for determination of $\sigma_{z}(1-6)$ \\
\hline- & & Intermediate value used in calculating time \\
\hline & & Time unit=LST \\
\hline
\end{tabular}




\begin{tabular}{|c|c|c|}
\hline I & IYR & Year $(00-99)$ \\
\hline - & JULDAY & Julian date $(1-366)$ \\
\hline & $\mathrm{K}$ & $\begin{array}{l}\text { Fraction of sensible neat flux used to grow CBL } \\
(0-1)\end{array}$ \\
\hline & LAT & Latitude $\left({ }^{\circ} \mathrm{N}\right)$ \\
\hline & MN & $\mathrm{N}-1$ \\
\hline & MO & Month $(1-12)$ \\
\hline & N & Time step counter \\
\hline & NAS & Number of averaging intervals in NINDX \\
\hline & NB & $\begin{array}{l}\text { Parameter giving the maximum number of model grid } \\
\text { elements, for use in dimensioning arrays }\end{array}$ \\
\hline & NB1 & $\mathrm{NB}+1$ \\
\hline 1 & NBOX & $\begin{array}{l}\text { Number of grid elements on the valley floor } \\
\text { half-width }\end{array}$ \\
\hline & ND & Loop index \\
\hline & NINDX & $\begin{array}{l}\text { Number of time steps in simulation, including } \\
\text { exponential decay after breakup }\end{array}$ \\
\hline & NS & $\begin{array}{l}\text { Parameter giving the maximum number of model time } \\
\text { steps, for use in dimensioning arrays }\end{array}$ \\
\hline - & NSTEPS & $\begin{array}{l}\text { Number of time steps required to destroy initial } \\
\text { temperature inversion }\end{array}$ \\
\hline - & NTOT & $\begin{array}{l}\text { Total number of grid elements left in the model at } \\
\text { a given time step }\end{array}$ \\
\hline - & NTOT I & $\begin{array}{l}\text { Total number of grid elements in the model at } \\
\text { initiation }\end{array}$ \\
\hline - & NTSA & Number of time steps in averaging interval \\
\hline & NTSR & Time of sunrise (LST) \\
\hline - & $P$ & $\begin{array}{l}\text { Number of grid elements on the valley floor } \\
\text { half-width }\end{array}$ \\
\hline I & PRESS & $\begin{array}{l}\text { Atmospheric pressure at center of temperature } \\
\text { inversion (mb) }\end{array}$ \\
\hline I & Q & Stack emission raţe $(\mathrm{kg} / \mathrm{s})$ \\
\hline$\rightarrow$ & RHO & Air density $\left(\mathrm{kg} / \mathrm{m}^{3}\right)$ \\
\hline- & SIGMAY & Sigma y (m) \\
\hline & SIGMAZ & Sigma $z$ (m) \\
\hline I & SRAD & Stack radius $(m)$ \\
\hline I & STMP & Stack temperature $\left({ }^{\circ} \mathrm{K}\right)$ \\
\hline - & SUM1 & $\begin{array}{l}\text { Fraction of plume mass within valley cross section } \\
(0-1)\end{array}$ \\
\hline - & SUM2 & $\begin{array}{l}\text { Fraction of glume mass above valley cross section } \\
(0-1)\end{array}$ \\
\hline I & SVEL & Stack exit velocity $(\mathrm{m} / \mathrm{s})$ \\
\hline & T1 & Intermediate variable used to calculate time \\
\hline & T2 & Intermediate variable used to calculate time \\
\hline & T3 & Intermediate variable used to calculate time \\
\hline & T4 & Intermediate variable used to calculate time \\
\hline & TAU & Length of daylight period (s) \\
\hline I & & Air temperature $\left({ }^{\circ} \mathrm{K}\right)$ \\
\hline & TMAXC1 & $\begin{array}{l}\text { Ending time of the } 1-h \text { average concentration max } \\
(h \text { LST) }\end{array}$ \\
\hline
\end{tabular}




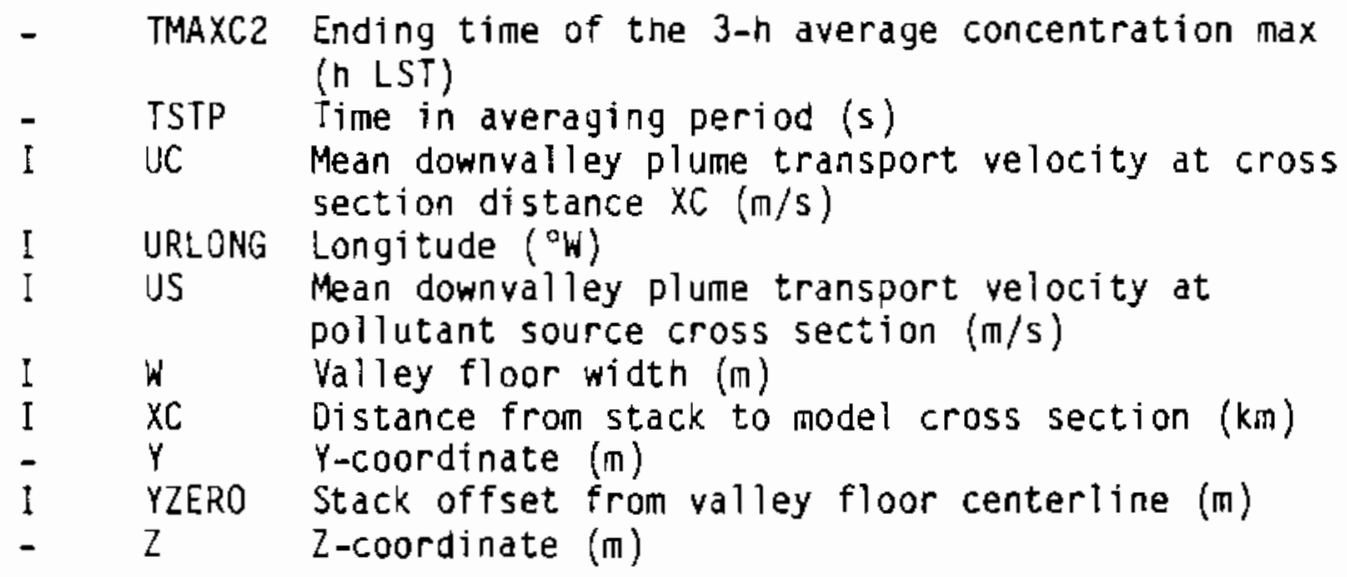

Array Name Definitions

\begin{tabular}{|c|c|c|}
\hline $\begin{array}{l}\text { INPUT / } \\
\text { OUTPUT }\end{array}$ & $\begin{array}{l}\text { ARRAY } \\
\text { NAME }\end{array}$ & DEF INITION \\
\hline- & $A \cup G(N B, 2)$ & $\begin{array}{l}\text { Maximum } 1-h \text { and } 3-h \text { average concentration array } \\
\left(\mu \mathrm{g} / \mathrm{m}^{3}\right)\end{array}$ \\
\hline- & $\mathrm{CCH}(2, \mathrm{NB})$ & $\begin{array}{l}\text { Short term storage location for concentrations } \\
\text { at two adjacent time steps }\left(\mathrm{\mu g} / \mathrm{m}^{3}\right)\end{array}$ \\
\hline - & $\mathrm{CHI}(\mathrm{NB})$ & $\begin{array}{l}\text { Nocturnal steady state concentration array } \\
\left(\mu \mathrm{g} / \mathrm{m}^{3}\right)\end{array}$ \\
\hline - & CHIBAR (NB) & $\begin{array}{l}\text { Average pollutant concentration injected into } \\
\text { the top of grid elements at each time step } \\
\left(\mu \mathrm{g} / \mathrm{m}^{3}\right)\end{array}$ \\
\hline 0 & $\operatorname{CONC}(N S, N B)$ & Poljution concentration array $\left(\mathrm{kg} / \mathrm{m}^{3}\right)$ \\
\hline- & $\mathrm{HC}(\mathrm{NS})$ & Height of CBL top (m) \\
\hline- & HITEL (NB) & $\begin{array}{l}\text { Height of lower side of grid element on sidewall } \\
\text { (m) }\end{array}$ \\
\hline - & HITEU & $\begin{array}{l}\text { Height of upper side of grid element on sidewail } \\
\text { (m) }\end{array}$ \\
\hline - & $\mathrm{HT}(\mathrm{NS})$ & Height of inversion top (m) \\
\hline- & $\operatorname{NDXTIM}(N B, 2)$ & Index number of TMAXCl and TMAXC2 \\
\hline - & NTS (2) & Number of time steps in $1-h$ and $3-h$ \\
\hline - & SUM(NB) & $\begin{array}{l}\text { Summing array to accumulate pollutant } \\
\text { concentrations during averaging interval }\end{array}$ \\
\hline- & TIME (NS) & $\begin{array}{l}\text { Midpoint time array for averaging intervals } \\
\text { (h MST) }\end{array}$ \\
\hline- & $V(N B 1)$ & Slope flow velocity array (m/s) \\
\hline
\end{tabular}

Subroutines Called

BRKUP

DESCNT

DILUTE

EBDGT 
GAUSS

INGRAT

INPUT

JULIAN

PROFIL

PSTPRC

SOLAR

VELOCY

Common Blocks

BLK1

BLK2 Not used in main program

BLK3 Not used in main program

$B L \times 4$

BLX5

BLK6 
INPUT-Input Module

Purpose

The VALMET program runs in an interactive mode in which the user controls program execution from a remote interactive terminal. The user enters mode : inputs from the remote terminal by following directions given to the user on the terminal screen by subroutine INPUT. Once the input values are specified by the user he can direct the program to begin the air pollution simulation. The functions of the INPUT module are to obtain the proper input data from the model user, to convert the input data to the proper units for processing in later modules of VALMET, to check the input data for errors, and to notify the user of any errors.

Inputs

Inputs to this module come entirely through user input from an interactive terminal, uniess default values of the input parameters are selected by the user.

Outputs

Outputs from the module go to the main program through the subroutine argument list.

Variable Name Definitions

INPUT/ VARIABLE

OUTPUT NAME

DEF INITIONS

$\begin{array}{lll}\text { I } & \text { AO } & \begin{array}{l}\text { Fraction of solar flux converted to sensible neat } \\ \text { flux }(0-1)\end{array} \\ \text { I } & \text { ALPHA1 } & \text { Sidewall \#I elevation angle }\left({ }^{\circ}\right) \\ \text { I } & \text { ALPHA2 } & \text { Sidewall \#2 elevation angle }\left({ }^{\circ}\right) \\ \text { I } & \text { AS } & \text { Cross sectional area at source }\left(\mathrm{m}^{2}\right) \\ \text { I } & \text { BETA } & \text { Rate of potential temperature increase above valley } \\ & & \text { (ox/s) } \\ 0 & \text { DELTAT } & \text { Time step (s) } \\ \text { I } & \text { GAMMA } & \text { Inversion vertical potential temperature gradient } \\ & & \left({ }^{\circ} \text { ) }\right. \\ \text { I } & \text { H } & \text { Plume centerline neight (m) } \\ \text { I } & \text { HZERO } & \text { Initial inversion depth (m) } \\ \text { I } & \text { IDA } & \text { Day of month (1-31) } \\ 0 & \text { ISTAB } & \text { Atmospheric stability (1-6) } \\ \text { I } & \text { IYR } & \text { Year (00-99) } \\ - & \text { J } & \text { Index } \\ - & \text { J6 } & \text { Index } \\ - & \text { J12 } & \text { Index } \\ - & \text { J13 } & \text { Index } \\ - & \text { J14 } & \text { Index }\end{array}$




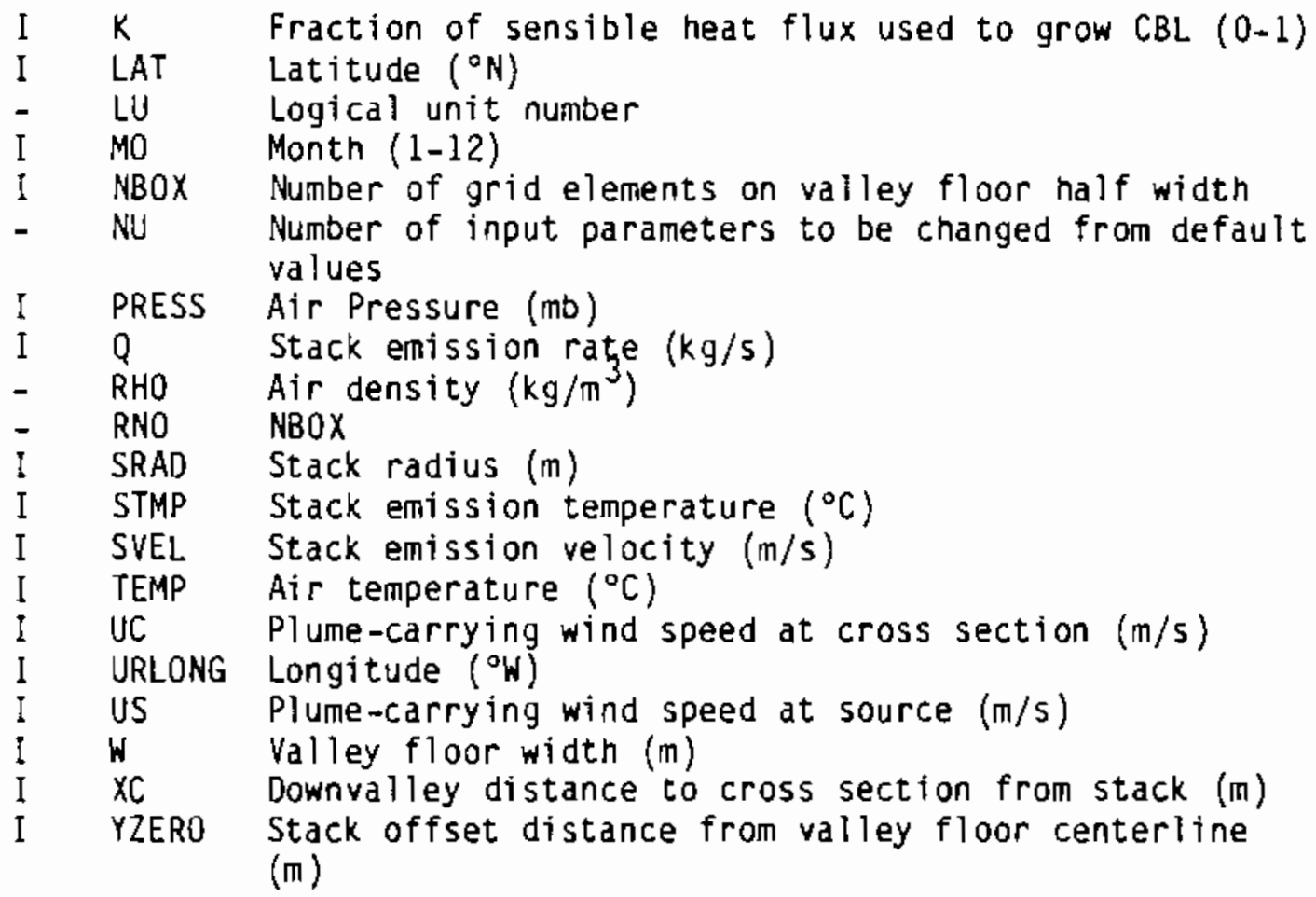

Array Name Definitions

INPUT /

OUTPUT ARRAY NAME DEF INITIONS

\begin{tabular}{|c|c|c|}
\hline & $\begin{array}{l}\operatorname{ASTAB}(6) \\
\operatorname{CAT}(10) \\
\operatorname{ID}(27)\end{array}$ & $\begin{array}{l}\text { Atmospheric stability array } \\
\text { Input parameter category array } \\
\text { Array of identification numbers for input } \\
\text { Darameters }\end{array}$ \\
\hline & $\operatorname{NAM}(27)$ & Input parameter name array \\
\hline & $U(3)$ & Wind speed array (m/s) \\
\hline & VAL $(27)$ & Default input value array \\
\hline & VAL & New values of input parameters \\
\hline
\end{tabular}

Subroutine Called

None

Common Blocks

None 
JULIAN-Juli an Day Module

Purpose

JULIAN caiculates the Julian date, given the month, day and year of the air pollution simulation.

Inputs

The month, day and year are input to the subroutine from the main program through the subroutine argument list.

Outputs

The Julian date is sent to the main program through the subroutine argument list.

Variable Name Definitions

INPUT/ VARIABLE

OUTPUT NAME DEF INITION

$\begin{array}{lll}\vec{I} & \text { A } & \text { Leap year indicator } \\ \text { I } & \text { IDA } & \text { Day of month }(1-31) \\ \text { I } & \text { IYR } & \text { Year }(00-99)(1-366) \\ 0 & \text { JULDAY } & \text { Julian date }(1-366) \\ \text { I } & \text { MO } & \text { Month }(1-12)\end{array}$

Array Name Definitions

INPUT/

OUTPUT ARRAY NAME DEFINITION

- NDAY(12) Cumulative days of year, by month

Subroutines Called

None

Common Blocks

None 
PRISE-Plume Rise Module

Purpose

PRISE calculates plume rise using the Briggs plume rise algorithms documented in the CRSTER User's Manual, taking account of both plume momentum and buoyancy effects.

Inputs

The inputs to PRISE come through the subroutine argument list and include stack characteristics (radius, exit velocity, exit temperature), ambient atmosoheric characteristics (air temperature, wind speed, stability class, potential temperature gradient) and downvalley distance to the cross section of interest.

Outputs

The output of PRISE is the plume centerline rise above the physical stack height. This value is passed to the main program through the subroutine argument list.

FORTRAN Library Subroutines

Name Function

$\operatorname{AMINI}(x 1, x 2, \ldots . x n) \quad$ Determine the minimum value of a list of real numbers

Variable Name Definitions

INPUT/ VARIABLE

OUTPUT NAME

DEFINITION

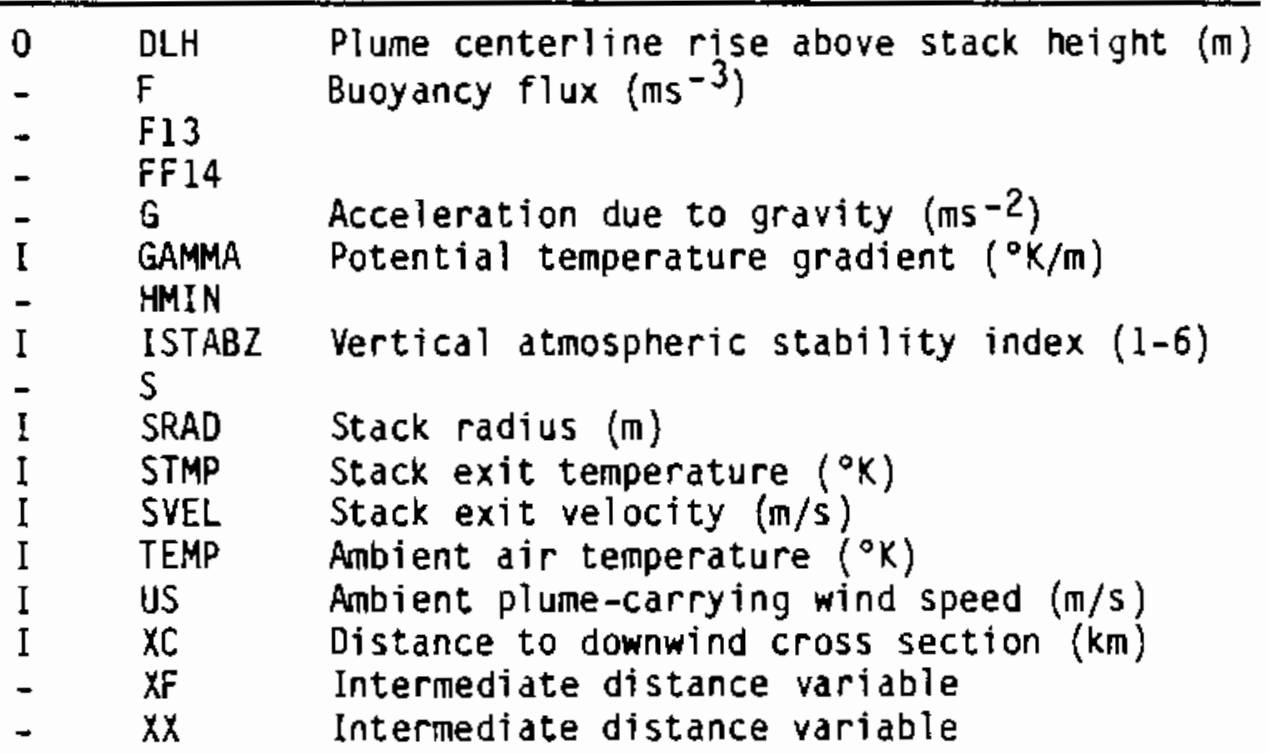


Array Name Definitions

None

Subroutines Called

None

Common Blocks

None

Special Note

The VALMET code, as listed in Appendix A, has the calling statements to Subroutine PRISE (1ines 58-65) deactivated or "commented out" in the main program. This was done while making various tests of the code where the user wished to specify an "effective stack height", rather than specifying a physical stack height and the parameters necessary to calculate plume rise. The appropriate statements may be reactivated by the user who wishes to engage the plume rise algorithms. 


\section{DILUTE-Plume Dilution Module}

Purpose

DILUTE calculates the dilution factor necessary to account for clean air dilution of the nocturnal pollutant plume during its transport down the valley due to clean air inflow from valley tributaries, slope flows, or entrainment at the top of the down valley flow layer.

Inputs

The inputs to DILUTE come from the main program through the subroutine argument list. They include the cross sectional areas and wind speeds at the pollutant source and the receptor cross sections.

Outputs

The output from DILUTE is the dilution factor calculated from the ratio of volume fluxes at the two cross sections. It is passed to the main program through the subroutine argument list.

Variabie Name Definitions

INPUT/ VARIABLE

OUTPUT NAME DEFINITION

I AC Area of valley cross section at distance $x\left(m^{2}\right)$

I AS Area of valley cross section at pollutant source $\left(\mathrm{m}^{2}\right)$

0 DF Inverse of dilution factor

I UC Wind speed at cross section at distance $x(\mathrm{~m} / \mathrm{s})$

I US Wind speed at pollutant source cross section $(\mathrm{m} / \mathrm{s})$

Array Name Definitions

None

Subroutines Called

None

Common Blocks

None 
INGRAT-Valley Plume Reflection Module

Purpose

The purpose of Subroutine INGRAT is to calculate Gaussian diffusion coefficients and to accomplish cross wind integrations of plume mass on a valley cross section in order to determine the amount of plume mass within the valley cross section and the amount of plume mass which has escaped out the top of the valley inversion. These mass calculations are necessary to simulate valley piume channeling so that nocturnal plume reflection off the valley floor and sidewalis can be handled in the main program.

Inputs

Inputs to Subroutine INGRAT come into the subroutine through the subroutine argument list. Outputs include the fraction of plume mass within the valley inversion, the fraction which has diffused out the top of the inversion, and the two dispersion coefficients, sigma $y$ and sigma $z$.

Variable Name Definitions

\begin{tabular}{|c|c|c|}
\hline $\begin{array}{l}\text { INPUT/ } \\
\text { DUTPUT }\end{array}$ & $\begin{array}{l}\text { VAR IABLE } \\
\text { NAME }\end{array}$ & DEF INITION \\
\hline I & ALPHAl & Sidewall \#1 elevation angle (rad) \\
\hline I & ALPHA2 & Sidewall \#2 elevation angle (rad) \\
\hline- & $\mathrm{F}$ & Analytical formula for Gaussian distribution \\
\hline 1 & $\mathrm{H}$ & Plume centerline height $(m)$ \\
\hline I & HZERO & Initial inversion height (m) \\
\hline- & I & Height increment counter \\
\hline I & ISTABY & Horizontal atmospheric stability index $(1-6)$ \\
\hline I & ISTABZ & Vertical atmospheric stability index $(1-6)$ \\
\hline- & NP & Number of height increments to inversion top \\
\hline - & $\mathrm{P}$ & Number of height increments to inversion top \\
\hline - & PHIY & Area under Gaussian curve from yl to y 2 \\
\hline - & PHIY1 & Area under Gaussian curve from minus infinity to yl \\
\hline - & PHIY 2 & Area under Gaussian curve from minus infinity to y2 \\
\hline - & $\mathrm{PI}$ & Trigonometric constant \\
\hline - & $\mathrm{R}$ & Height increment counter \\
\hline 0 & SIGMAY & Standard deviation of plume concentration in y-direction (m) \\
\hline 0 & SIGMAZ & Standard deviation of plume concentration in z-direction (m) \\
\hline 0 & SUM1 & Fraction of pollution within valley inversion $(0-1)$ \\
\hline 0 & SUM2 & Fraction of pollution diffusing out inversion top $(0-1)$ \\
\hline I & $W$ & Width of valley floor (m) \\
\hline $\mathrm{I}$ & $x C$ & Downvalley distance from stack to cross section $(\mathrm{km})$ \\
\hline 1 & $\hat{Y} 1$ & $Y$-coordinate of sidewall $\# 1$ at height $z$ (m) \\
\hline- & 12 & Y-coordinate of sidewali $\$ 2$ at height $2(\mathrm{~m})$ \\
\hline 1 & YZERO & off-centerline displacement of stack (m) \\
\hline- & & Vertical coordinate (m) \\
\hline - & ZINC & Height increment for integration (m) \\
\hline
\end{tabular}


Array Name Definitions

$\begin{array}{lll}\text { INPUT/ } & & \text { DEFINITION } \\ \text { OUTPUT } & \text { ARRAY NAME } & \text { DCMullen's coefficients for P-G } \sigma_{y} \\ - & \text { SIGGY(18) } & \text { McMullen's coefficients for P-G } \sigma_{z}\end{array}$

Subroutines Called

NORMAL

Common Blocks

None 
NORMAL-Normal or Gaussian Curve Integration Module

Purpose

Subroutine NORMAL is used to calculate the area under a Gaussian or Normal distribution curve from minus infinity to $x$ standard deviations. The polynomial approximation technique used in this subroutine comes from Abramowitz and Stegun [33, p. 932] following a formulation attributed to Hastings [34].

Inputs

The sole input is the standard deviation $X$ where $X$ is between 0 and positive infinity. This input comes into the subroutine through the subroutine argument list.

Outputs

The sole output is the area under the Gaussian curve, PHI. This output is carried back to the calling program (Subroutine INGRAT) through the argument list.

Variable Name Definitions

\begin{tabular}{cll}
$\begin{array}{lll}\text { INPUT } \\
\text { OUTPUT }\end{array}$ & $\begin{array}{l}\text { VARIABLE } \\
\text { NAME }\end{array}$ & \multicolumn{1}{c}{ DEF INITION } \\
\hline 0 & PHI & Area under curve $(0-1)$ \\
- & PI & Trigonometric constant \\
- & SIGH & Intermediate variable \\
- & $I$ & Intermediate variable \\
$I$ & $X$ & Standard deviation
\end{tabular}

Array Name Definitions

INPUT/ VARIABLE

OUTPUT NAME DEFINITION

- C(6) Coefficients of polynomial

Subroutines Called

None

Common Blocks

None 
GAUSS-Gaussian Plume Module

Purpose

This subroutine uses a Gaussian plume algorithm to calculate pollutant concentration at an arbitrary receptor location $P(x, y, z)$. The present version uses Pasquill-Gifford dispersion coefficients, sigma $y$ and sigma $z$, calculated using McMulien's [28] method. The atmospheric stability used in the calculations is adjusted to account for enhanced dispersion observed in complex terrain situations by a number of other investigators [20,29-31]. The resulting concentration calculations are adjusted for standard pressure and temperature.

Inputs

The subroutine requires information on the coordinates of the receptor and source, the plume centerline height, source strength, wind velocity, dispersion coefficients, atmospheric temperature, and atmospheric pressure. The inputs come into the subroutine through the subroutine argument list.

Outputs

The subroutine output is the pollutant concentration at the receptor in micrograms per cubic meter. The output is sent to the calling program (MAIN or PROFIL) through the subroutine argument list.

Variable Name Definitions

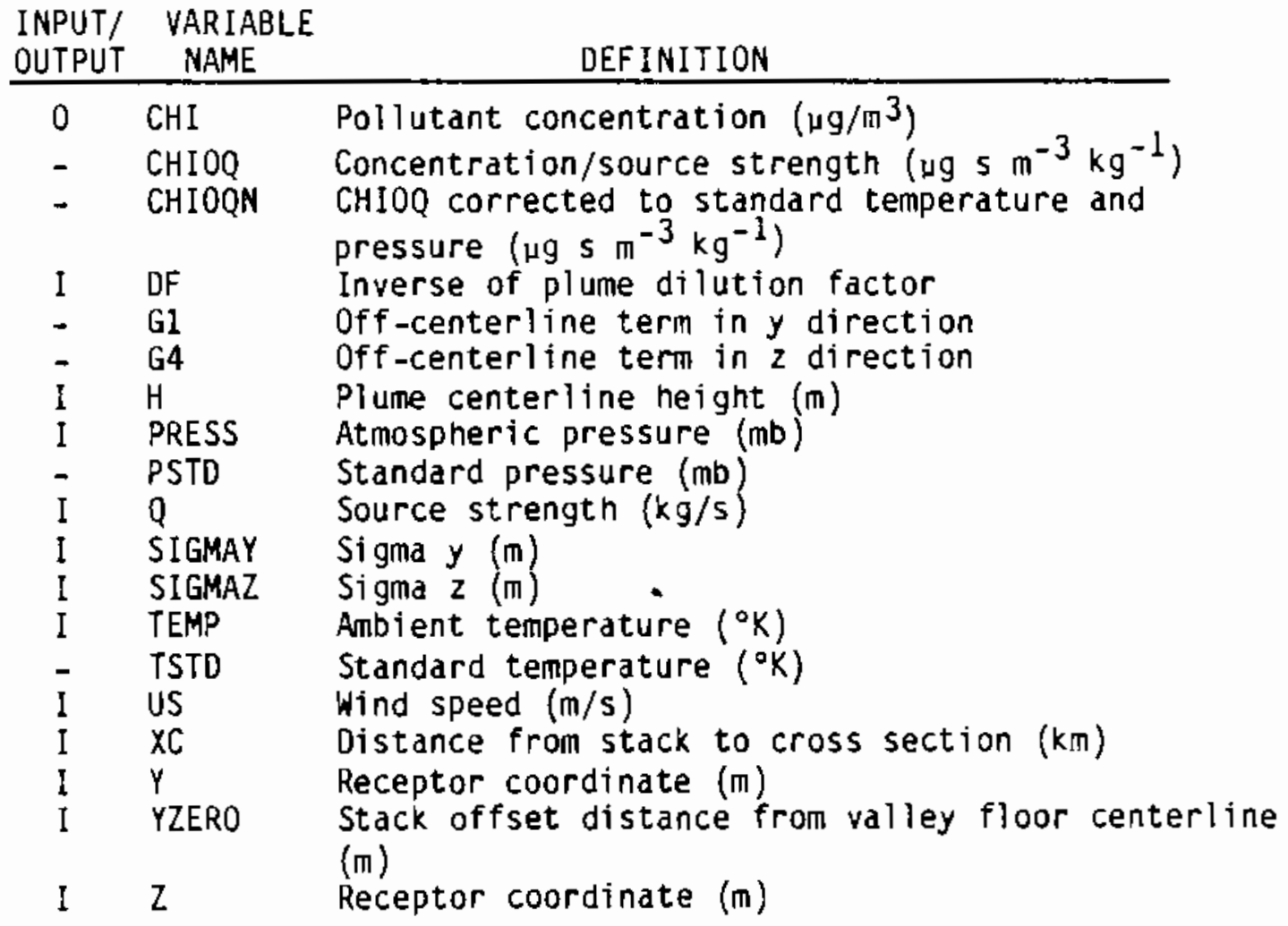


Array Name Definitions

None

Subroutines Called

None

Common Blocks

None 
$\underline{\text { Purpose }}$

The purpose of Subroutine SOLAR is to calculate the time of sunrise, length of day, and extraterrestrial solar flux on a horizontal surface at solar noon given the day of year and the latitude and longitude of the site. The outputs of SOLAR are necessary to drive the daytime portion of VALMET.

Inputs

Necessary subroutine inputs include the latitude and longitude of the site and the Julian date of the simulation. These three inputs come into 50LAR through the subroutine argument list.

Outputs

Outputs from Subroutine SOLAR include the local standard time of sunrise, the length of the daytime period, and the extraterrestrial solar flux on a horizontal surface at solar noon.

Variable Name Definitions

\begin{tabular}{|c|c|c|}
\hline $\begin{array}{l}\text { INPUT/ } \\
\text { OUTPUT }\end{array}$ & $\begin{array}{l}\text { VARIABLE } \\
\text { NAME }\end{array}$ & DEF INITION \\
\hline 0 & Al & 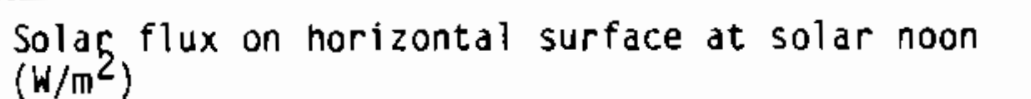 \\
\hline- & CONV & Conversion factor-degrees to radians (rad/deg) \\
\hline- & $\cos Z$ & Cosine of zenith angle \\
\hline - & 0 & Julian date $(1-366)$ \\
\hline- & $\mathrm{D} 2$ & Date interpolation variable for equation of time \\
\hline- & DECLIN & Declination (rad) \\
\hline - & DECMAX & Maximum declination (rad) \\
\hline- & DZERO & Julian date of vernal equinox \\
\hline- & ECCENT & Eccentricity of earth's orbit \\
\hline- & ID & Date interpolation variable for equation of time \\
\hline - & IT & Time unit conversion variable \\
\hline I & JULDAY & Julian date $(1-365)$ \\
\hline I & LAT & Lat itude $\left({ }^{\circ} \mathrm{N}\right)$ \\
\hline- & LONCOR & Longitude correction (h) \\
\hline- & LONG & Longitude of earth in its orbit around sun (rad) \\
\hline 0 & NTSR & Time of sunrise (hnmm) \\
\hline- & OMD & $\begin{array}{l}\text { Earth's position in orbit around sun on date of } \\
\text { interest (rad) }\end{array}$ \\
\hline- & OMDZRO & $\begin{array}{l}\text { Earth's position in orbit around sun at date of } \\
\text { vernal equinox (rad) }\end{array}$ \\
\hline- & OMEGA & Revolution rate of earth (rad/day) \\
\hline- & ONEHR & Conversion factor $(\mathrm{rad} / \mathrm{h})$ \\
\hline - & PI & Trigonometric constant \\
\hline
\end{tabular}


- RDVCSQ Earth-sun distance factor

- SC Solar constant $\left(W / m^{2}\right)$

- SR Hour angle of sunrise (rad)

- STDLON Longitude of standard meridian of time zone ( ${ }^{\circ} \mathrm{W}$ )

- T1 Time unit conversion variable

- T2 Time unit conversion variable

0 TAU Length of daylight period (n)

- TIMCOR Correction due to equation of time (n)

- TMNOON Local standard time of solar noon ( $h$ )

I URLONG Longitude of site ( $\left.{ }^{\circ} \mathrm{W}\right)$

Array Name Definitions

INPUT/

OUTPUT ARRAY NAME

DEF INITION

- EQNTIM(25) Equation of time correction at 15 day intervals (n)

Subroutines Called

None

Common Blocks

None 
Purpose

The purpose of EBDGT is to determine the fraction of extraterrestrial solar heat flux that is converted to sensible heat flux in the valley of interest. It is this sensible heat flux that drives the post-sunrise inversion breakup that leads to air pollution fumigations on the valley floor and sidewalls. The fraction depends on factors associated with the surface energy budget, including surface albedo, soil moisture, surface cover, cloud cover, atmospheric transmissivity, and longwave radiative transfer within the valley. The present version of the subroutine is not fully developed and does not yet explicitly include these factors. The present skeletal version of the subroutine merely specifies a fraction that the user has previously input using guidance given in earlier sections of this report. Further development of this subroutine is a suggested priority for future work.

Inputs

The fraction of extraterrestrial solar flux converted to sensible heat flux in the valley is the sole input to the present version of EBDGT, and is input to the subroutine through the subroutine argument list.

Dutputs

The present version of EBDGT simply outputs to the main program the userspecified input value. The output is transferred to the main program through the subroutine argument list.

Variable Name Definitions

INPUT/ VARIABLE

OUTPUT NAME DEF_____LITIONS

I AO Fraction of extraterrestrial solar flux converted

0 A2 Same as A0 $(0-1)$

Array Name Definitions

None

Subroutines Called

None

Common Blocks

None 
DESCNT-Inversion Descent and CBL Growth Module

Purpose

DESCNT uses Whiteman and McKee's [3] bulk thermodynamic model of temperature inversion breakup to calculate post-sunrise changes in valley inversion and CBL depths. The method considers that the valley temperature inversion represents an energy deficit relative to the warmer air above the inversion. The energy deficit is destroyed after sunrise by solar energy input into the valley as it is converted to sensible heat flux at valley surfaces. The energy is used in two ways - it is used to grow CBLs over valley surfaces and to cause air to flow upslope in the valley sidewall CBLs. Air flowing up the sidewalls in the CBLs causes corresponding descending motions over the valley center, resulting in a descending inversion top after sunrise. The module uses a numerical method for the calculations, and incorporates the effects of warming above the valley in retarding the inversion breakup.

Inputs

The inputs to DESCNT include solar flux parameters, valley characteristics parameters, model time step, initial CBL and inversion top heights, an above valley warming rate parameter, inversion potential temperature gradient, and mean valley air temperature and pressure. These inputs are passed to the subroutine through the subroutine argument list.

Outputs

The main outputs of DESCNT are CBL neights and inversion top heights as a function of time (actually, time step). These outputs are passed back to the main program in arrays located in common block BLK1. The number of time steps required to destroy the valley inversion is also an output of the subroutine, passed to the main program through the subroutine argument list.

Variable Name Definitions

\begin{tabular}{|c|c|c|}
\hline $\begin{array}{l}\text { I NPUT/ } \\
\text { OUTPUT }\end{array}$ & $\begin{array}{l}\text { VARIAB } \\
\text { NAME }\end{array}$ & DEF INITIONS \\
\hline I & AO & Fraction of $A 1$ converted to sensible heat flux $(0-1)$ \\
\hline I & $\mathrm{Al}$ & Solar flux on horizontal surface at solar noon ( $\mathrm{wm}^{-2}$ ) \\
\hline 1 & ALPHA1 & Sidewall \#1 elevation angle (rad) \\
\hline I & ALPHA2 & Sidewall \#2 elevation angle (rad) \\
\hline I & BETA & Rate of temperature change at inversion top $\left({ }^{\circ} \mathrm{K} / \mathrm{s}\right)$ \\
\hline- & & Intermediate factor \\
\hline- & $\mathrm{CP}$ & Specific heat at constant pressure $\left(\mathrm{J} \mathrm{kg}^{-}\right.$ \\
\hline I & DELTAT & Time step (s) \\
\hline - & $\mathrm{DHC}$ & Change in CBL height (m) \\
\hline - & DHDT & Change of CBL height with time $(\mathrm{m} / \mathrm{s})$ \\
\hline- & DHT & Change in inversion top height (m) \\
\hline
\end{tabular}




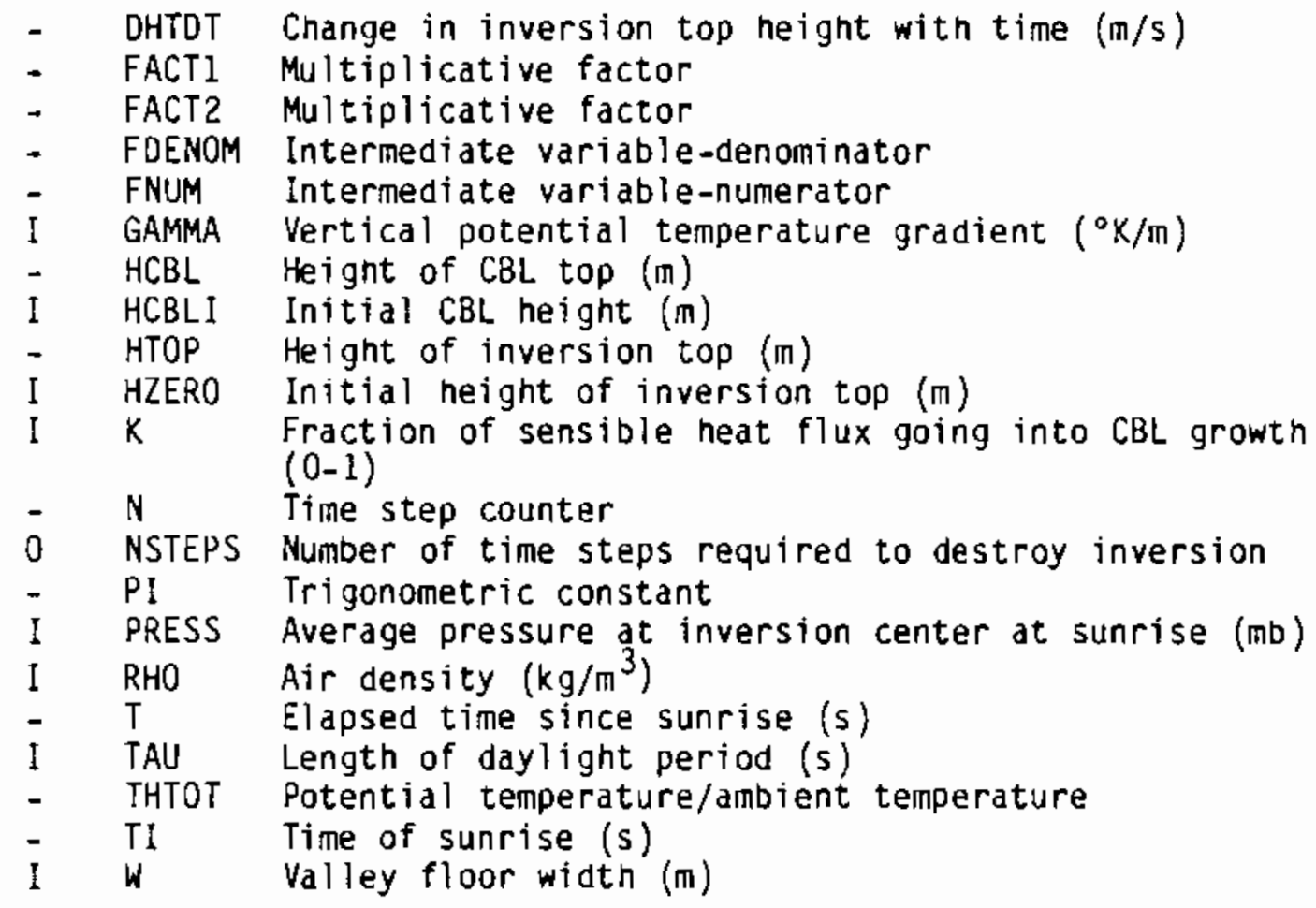

Array Name Definitions

\begin{tabular}{|c|c|c|}
\hline $\begin{array}{l}\text { INPUT/ } \\
\text { OUTPUT }\end{array}$ & ARRAY NAME & DEF INITIONS \\
\hline $\begin{array}{l}0 \\
0\end{array}$ & $\begin{array}{l}H C(N S) \\
H T(N S)\end{array}$ & $\begin{array}{l}\text { Array of CBL heights (m) } \\
\text { Array of inversion top heights (m) }\end{array}$ \\
\hline \multicolumn{3}{|c|}{ Subroutines Called } \\
\hline \multicolumn{3}{|c|}{ None } \\
\hline Common & Blocks & \\
\hline
\end{tabular}


PROFIL-Concentration Profite Module

Purpose

The purpose of Subroutine PROFIL is to calculate the pollutant concentration injected into the top of each of the model grid elements at each time step.

Inputs

Subroutine PROFIL requires a number of inputs, dealing primarily with the valley characteristics, grid element locations and specifications, and Gaussian plume characteristics. Subroutine PROFIL is called for each model time step and does calculations for each of the grid elements. All inputs come into the subroutine through the subroutine argument list.

Outputs

For each model time step, Subroutine PROFIL calculates the pollutant concentration injected into the top of each of the growing grid elements. To maintain accuracy in the calculations, the concentration for each grid element is calculated as the average of four concentration determinations made at the various sides of the quadrilateral Gaussian plume element which sinks into the grid element.

Variable Name Definitions

INPUT/ VARIABLE

OUTPUT NAME

DEF INITIONS

\begin{tabular}{|c|c|c|}
\hline & & \\
\hline & ALPHA & Average of ALPHAl and ALPHA2 \\
\hline [ & ALPHA1 & Sidewall 1 elevation angle (rad) \\
\hline 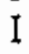 & ALPHA2 & Sidewall \$2 elevation angle (rad) \\
\hline & BOXLEN & Grid element length $(m)$ \\
\hline ? & $\mathrm{CHIOFF}$ & $\begin{array}{l}\text { Offset air pollution concentration due to reflections } \\
\left(\mu \mathrm{g} / \mathrm{m}^{3}\right)\end{array}$ \\
\hline & CHIYI & Concentration at $P(X, Y,, Z) \quad\left(\mu \mathrm{g} / \mathrm{m}_{2}^{3}\right)$ \\
\hline & CHIY2 & Concentration at $P(X, Y 2, Z)$ \\
\hline & $\mathrm{CHIZ1}$ & Concentration at $P(X, Y, Z 1)$ \\
\hline & CHIZ2 & Concentration at $P(X, Y, Z 2) \quad\left(\mu \mathrm{g} / \mathrm{m}^{3}\right)$ \\
\hline I & DF & Inverse of plume dilution factor \\
\hline I & $\mathrm{H}$ & Plume centerline height (m) \\
\hline & $\mathrm{HCL}$ & CBL height at lower time step (m) \\
\hline & $\mathrm{HCU}$ & CBL height at upper time step (m) \\
\hline I & HTL & Inversion top height at lower time step (m) \\
\hline & HTU & Inversion top height at upper time step (m) \\
\hline I & HZERO & Inversion depth at sunrise (m) \\
\hline & I & Grid element index \\
\hline I & NBOX & Number of grid elements on valley floor half-width \\
\hline & NTOT & Number of model gid elements at a given time step \\
\hline
\end{tabular}




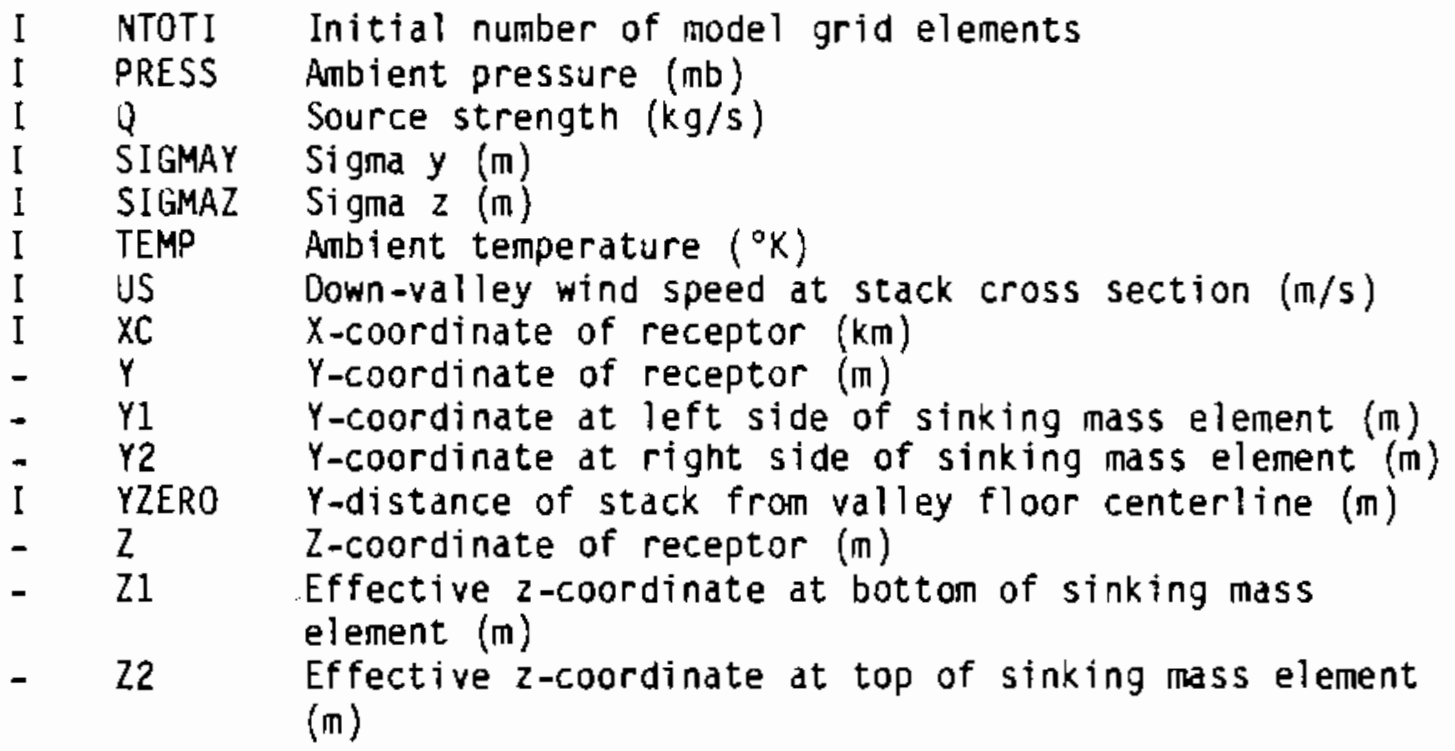

Array Name Definitions

INPUT/

OUTPUT ARRAY NAME DEF INITIONS

0 CHIBAR(NB) Average concentration injected into top of each grid element $\left(\mu \mathrm{g} / \mathrm{m}^{3}\right)$

Subroutines Called

GAUSS

Common Blocks

BLK2 
VELOCY-Upslope Flow Velocity Module

Purpose

Subroutine VELOCY uses the mass continuity equation for air to calculate the slope flow velocity profile, under the assumption that the convective boundary layer depth does not vary as a function of distance up the slope. An implicit assumption is that all mass lost from the valley inversion cross section as the inversion top sinks is transported from the valley in the upslope flows which develop in the convective boundary layers over the slopes. The upslope velocities are calculated at the boundaries between grid elements.

Inputs

The inputs to this subroutine come through the subroutine argument list and through the common block labeled BLKL. BLKI provides the inversion top and CBL heights for every time step. Inputs from the argument list include the time step index number, the time step length, and information about the size and location of the grid elements.

Output

The output of VELOCY is an array of upslope wind velocities calculated at the NTOTI+1 boundaries between the NTOT grid elements. The subroutine is called from the main program at each model time step, and the calculated velocities are passed back to the main program through the common block labeled BLK3.

Variable Name Definitions

\begin{tabular}{|c|c|c|}
\hline $\begin{array}{l}\text { INPUT/ } \\
\text { OUTPUT }\end{array}$ & $\begin{array}{l}\text { VAR I ABLE } \\
\text { NAME }\end{array}$ & DEFINITIONS \\
\hline I & BOXLEN & Length of grid elements (m) \\
\hline- & $\mathrm{CIH}$ & Inversion top displacement during time step (m) \\
\hline I & DELTAT & Time step (s) \\
\hline- & I & Grid element index \\
\hline I & MN & $\mathrm{N}-1$ \\
\hline I & $\mathbf{N}$ & Time step index \\
\hline I & NBOX & Number of grid elements on valley floor half-width \\
\hline 1 & NTOT & $\begin{array}{l}\text { Total number of grid elements in simulation at a } \\
\text { given time step }\end{array}$ \\
\hline I & NTOTI & $\begin{array}{l}\text { Number of grid elements in simulation at beginning } \\
\text { of simulation }\end{array}$ \\
\hline
\end{tabular}


Array Name Definitions

\begin{tabular}{lll} 
INPUT/ & & \multicolumn{1}{c}{ DEFINITIONS } \\
OUTPUT & ARRAY NAME & \multicolumn{1}{c}{ CBL height array (m) } \\
\hline I & HC(NS) & Inversion top heignt array $(m)$ \\
I & HT(NS) & Inver \\
0 & $V(N B I)$ & Upslope wind velocity array $(\mathrm{m} / \mathrm{s})$
\end{tabular}

Subroutines Called

None

Common Blocks

BLKI

BLK3 
BRKUP-Pollutant Mass Budget Module

Purpose

The purpose of Subroutine BRKUP is to calculate pollutant concentrations in each of the grid elements using a pollutant mass balance. The calculations are made for each model time step, taking account of pollution sinking into the top of each grid element, CBL growth, upslope advection of pollution, mixing within each grid element and carryover of pollution in each grid element from the previous time step. A currently unused feature of the pollution mass budget in each grid element is the provision for sources and sinks of pollution within the element. A special feature of BRKUP is the exponential decay of air pollution concentrations in grid elements that are dropped from the simulation as the top of the inversion sinks below the grid element.

Inputs

Inputs to the subroutine coning through the subroutine argument list include time step index, number of grid elements on the valley floor haif. width, total number of grid elements at model initiation, the grid element length, and model time step length. Other inputs are available through labeled common blocks $B L K 1, B L K 2$, and $B L K 3$. BLK1 provides information on CBL and inversion depths for each time step. BLX2 provides information generated in Subroutine PROFIL on the amount of air pollution mass sinking into the top of each grid element at the given time step. BLK3 provides the upslope wind velocities used to advect pollutant mass up the valley sidewalls at the given time step. These velocities were generated in Subroutine VELOCY.

Outputs

BRKUP calculates air pollution concentrations in the model grid elements for each time step. These calculations constitute the main output of the VALMET model, and are output to the main program through the subroutine argument list. The main program performs further calculations on these concentrations to determine 5-minute-average concentrations which are stored in the main program for further processing into maximum one- and three-hour-averages.

Variable Name Definitions

\begin{tabular}{|c|c|c|}
\hline $\begin{array}{l}\text { INPUT/ } \\
\text { OUTPUT }\end{array}$ & $\begin{array}{l}\text { VARIABLE } \\
\text { NAME }\end{array}$ & DEF INITIONS \\
\hline- & A & $\begin{array}{l}\text { Pollutant mass within the grid element at previous } \\
\text { time step }(\mu \mathrm{g})\end{array}$ \\
\hline - & B & $\begin{array}{l}\text { Pollutant mass coming from adjacent downhill grid } \\
\text { element }(\mu \mathrm{g})\end{array}$ \\
\hline I & BOXLEN & Grid element length $(m)$ \\
\hline- & & $\begin{array}{l}\text { Pollutant mass sinking through growing top of } \mathrm{CBL} \\
(\mu \mathrm{g})\end{array}$ \\
\hline$\rightarrow$ & 0 & $\begin{array}{l}\text { Pollutant mass transported into adjacent uphill grid } \\
\text { element }(\mu g)\end{array}$ \\
\hline
\end{tabular}


- DELTAH Entrainment at top of grid element (m)

I DELTAT Time step (s)

- I Grid el ement index

I MN Index of previous time step

I $N \quad$ Current time step index

I NBOX Number of grid elements on valley half-width

I NTOTI Total number of grid elements at model initiation

- 5 Exponential decay time constant $\left(5^{-1}\right)$

Array Name Definitions

INPUT/

OUTPUT ARRAY NAME DEFINITIONS

$0 \quad \mathrm{CCH}(2, \mathrm{NB})$ Grid element concentration array $\left(\mu \mathrm{g} / \mathrm{m}^{3}\right)$

- CHIBAR(NB) Average pollutant concentration injected into

- $\quad H C(N S)$

- $\quad H T(N S)$

- $\quad V(N B 1)$ top of grid element $\left(\mu \mathrm{g} / \mathrm{m}^{3}\right)$

CBL height array (m)

Inversion top height array (m)

Upslope velocity array (m/s)

Subroutines Called

None

Common Blocks

BLK1

BLK2

BLK3 
PSTPRC-Post Processor Module

Purpose

This subroutine is a post-processor. It processes the time series of calculated 5 -minute-average concentrations for each grid element to obtain maximum short term (1- and 3-hour) average concentrations which can be compared to regulatory standards. The maximum 1- and 3-hour average concentrations are determined by means of a moving average of the 5-minute-average concentration time series, determining maximum values for each of the grid elements. A time index value is saved for each of the maximum values so that the time of occurrence of the maximum can be calculated in the main program. The subroutine is written so that the averaging intervals can be easily changed, if necessary.

\section{Procedure}

The moving average is calculated by stepping backwards through the 5 -minute-average concentration array using a $1-h$ and $3-h$ averaging "window", beginning at the last 5 -minute average calculated for each grid element. As they travel backwards through the 5 -minute concentration array the 1 - and 3-h averaging intervals will eventually pass the time of sunrise. The nocturnal steady state concentrations are added into the average at that point.

Inputs

The inputs to PSTPRC include the series of 5 -minute average concentrations for each of the grid elements, the steady state nocturnal concentrations in each grid element, the averaging interval (300 s), total number of grid elements and index number of the last 5 minute concentration values. The time series of 5-minute averaged values is input through common block BLK2. The nocturnal concentrations are input through common block BLK. The other parameters are input through the subroutine argument list.

Outputs

The outputs of Subroutine PSTPRC are passed to the main program through common block BLK6. They include the maximum 1 - and $3-$ h average concentrations for each grid element, the time index numbers for each of these concentrations, and the number of 5 minute time steps in the regulatory averaging intervals ( 1 - and $3-h)$.

Variable Name Definitions

\begin{tabular}{|c|c|c|}
\hline $\begin{array}{l}\text { INPUT/ } \\
\text { OUTPUT }\end{array}$ & $\begin{array}{l}\text { VARIABLE } \\
\text { NAME }\end{array}$ & DEF INITIONS \\
\hline$\overline{-}$ & $\frac{I}{K}$ & $\begin{array}{l}\text { Index for grid elements } \\
\text { Index for averaging intervals } \\
=1 \text { for one hour averages } \\
=2 \text { for three hour averages }\end{array}$ \\
\hline
\end{tabular}




$\begin{array}{lll}- & \text { N } & \text { Index for } 5 \text {-minute-average time series } \\ \text { I } & \text { NAS } & \text { Number of elements in } 5 \text { minute series } \\ - & \text { NSTART } & \text { NAS+1 } \\ - & \text { NTIMES } & \text { Time index intermediate variable } \\ \text { I } & \text { NTOTI } & \text { Total number of grid elements in model at sunrise } \\ - & \text { ONEHR } & \text { Number of seconds in one hour (s) } \\ - & \text { Q1 } & \text { Intermediate summation variable } \\ - & \text { SUM } & \text { Summation variable for concentrations } \\ - & \text { THREE } & \text { Number of seconds in three hours (s) } \\ - & \text { TS } & \text { Number of 5-minute-averages in averaging interval } \\ \text { I } & \text { TSTP } & \text { Averaging interval of basic model concentration } \\ & & \text { array } 5 \text { min= } 300 s\end{array}$

Array Name Definitions

\begin{tabular}{|c|c|c|}
\hline $\begin{array}{l}\text { INPUT } / \\
\text { OUTPUT }\end{array}$ & ARRAY NAME & DEF IN I T IONS \\
\hline 0 & $\mathrm{AVG}(\mathrm{NB}, 2)$ & $\begin{array}{l}\text { Maximum } 1-\text { and 3-hour-averages for each grid } \\
\text { element }\left(\mu \mathrm{g} / \mathrm{m}^{3}\right)\end{array}$ \\
\hline I & $\mathrm{CHI}(\mathrm{NB})$ & $\begin{array}{l}\text { Noctugnal concentrations in grid elements } \\
\left(\mu \mathrm{g} / \mathrm{m}^{3}\right)\end{array}$ \\
\hline I & $\operatorname{CONC}(N A, N B)$ & Array of 5-minute-average concentrations \\
\hline 0 & $\operatorname{NDXTIM}(N B, 2)$ & Array of time index values for maximum 1 - and \\
\hline 0 & NTS $(2)$ & Number of 5 -min intervals in 1 and 3 nours \\
\hline- & $\operatorname{SUMM}(\mathrm{NB}, 2)$ & $\begin{array}{l}\text { Summing variable for } 5 \text { minute average } \\
\text { concentration }\end{array}$ \\
\hline
\end{tabular}

Subroutines Called

None

Common Blocks

BLK4

BLK5

BLK6 


\section{SECTION 6}

SAMPLE MODEL RUNS

In this section we present sample model runs to illustrate model performance and model outputs. In the first model run we present the model results for a run using default input parameters. The first time model user may compare his results with the results from this run to see that the model is operating properly at his installation. In the second sample run we make calculations for a downwind distance of $30 \mathrm{~km}$ rather than the default $10 \mathrm{~km}$, but maintain all other default values for model inputs.

Simulation Number 1

The first simulation to be illustrated was obtained using default input values obtained from Table 5. A full listing of the summary output file (VALMET.OUT) generated from this simulation is given below in Figure 21 . This output file would be printed by the model user at the completion of the model run and consists of three pages of printer output. Outputs shown in the figure include:

1. a model input table,

2. a listing of numerical simulation parameters,

3. a summary listing of nocturnal model output values,

4. a listing of the output values from the solar model,

5. an output table of maximum 1-hour- and 3-hour-average concentrations in each grid element, and

6. a table of 5 -minute-average $(300 \mathrm{~s})$ concentrations as a function of time for each model grid element.

The user who wishes to get a graphical depiction of model results may manually plot the model results from the output listing. Alternatively, he may develop a plotting program using as input the special file of model output data, VALMET.PLT, that is generated with each model run. Figures 22 and 23 illustrate the types of plots that may be generated using such a plotting program. A listing of the plotting program that generated these figures is given in Appendix $B$. 


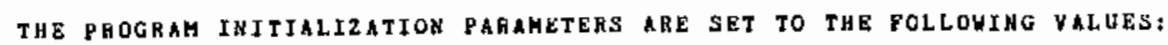

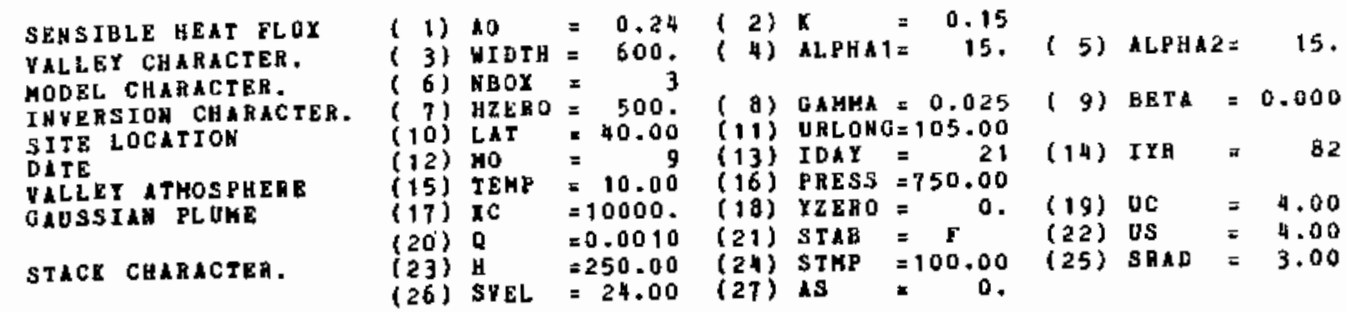

NUHEAICAL SIHULATIOR PARAHETERS:

TIMESTEPS ARE 10.0 SECONDS LONG

GRID ELEHENTS ARE 100.0 METERS LOHO

NUMBER OF TIMESTEPS FHOH SULRISE TO INYERSION DESTRUCTION= 1337

MUHEER OF TIHESTEPS IV SIHULATION (INCLUDES EXPONENTIAL DECAY AFTER INVERSION DESTRUCTION)= 1697 CONCEHTRATIOH AVEAHGIHO IHTERYALE 300 SECONDS

NUHBER OF AYEHAGTHO INTERYALS IN THE STHULATION= 5

PLUHE DIFTUSTON DURING HOCTURHAL TRAVEL:

作

A PLUHE CENTERLIME CONCENTRATTON OF

AT THE TAKVEL DISTANCE OF 0.0 XH 9.

AT THE TRAVE DISTAKCE OF TO. KH

THE REAATA

ARE AT STHULATON CFOSS SECTION IR THOUSANDS OF SQ METERS IS 1234

CLEAN ATH DILUTYON FACTOA IS 1.000

SOLAR HODEL RESULTS:

TIHE OP SUMRISE $=550$ LST

$D=12,10 \mathrm{HRS}$

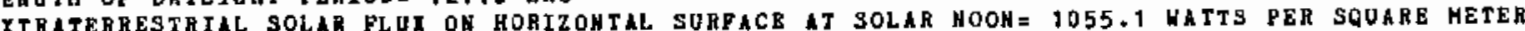

\begin{tabular}{|c|c|c|c|c|c|c|}
\hline $\begin{array}{l}\text { GRIO } \\
\text { ELEHENT } \\
\text { MUABER }\end{array}$ & $\begin{array}{l}\text { HEIGHT } \\
\text { VALLEY } \\
\text { ( })\end{array}$ & $\begin{array}{l}\text { ABOYE } \\
\text { F1OOA } \\
\text { 1) }\end{array}$ & $\begin{array}{l}\text { FARIMUH } \\
\text { I-HOUR } \\
\text { AVERAGE }\end{array}$ & $\begin{array}{c}\text { TIHE OF } \\
\text { OCCURRENCE } \\
\text { (LST) }\end{array}$ & $\begin{array}{l}\text { MAXINOH } \\
\text { J-HOUR } \\
\text { AVERAGE }\end{array}$ & $\begin{array}{c}\text { TIHE OF } \\
\text { OCCURREACE } \\
(1 S T)\end{array}$ \\
\hline 1 & $0 .-$ & 0 . & 0.63 & B.21-9.21 & 0.36 & $6.79-9.79$ \\
\hline 2 & & & 0.69 & $8.21-9.21$ & 0.39 & $6.79-$ \\
\hline 3 & $0 .-$ & 0 . & 0.69 & $8.21-9.21$ & 0.39 & $6.79-$ \\
\hline q & $0 .-$ & & 0.68 & $8.21-9.2 i$ & 0.38 & $6.71-$ \\
\hline 5 & $27 .-$ & 54. & 0.60 & $6.13-9.13$ & 0.36 & $6.62-$ \\
\hline 6 & 54.- & 80. & 0.53 & $8.13-9.13$ & 0.33 & $6.46=$ \\
\hline 7 & $80 .-1$ & 107. & 0.47 & $8.04-9.04$ & 0.31 & $6.29-$ \\
\hline 8 & $107 .-1$ & 134. & $0 . \$ 1$ & $7.96-0.96$ & 0.29 & $6.13-$ \\
\hline 9 & $134 .=1$ & 161. & 0.36 & $7.88-8.68$ & 0.26 & $5.95=$ \\
\hline 10 & $161 .-1$ & 187. & 0.31 & $7.71=8.71$ & 0.24 & $5.79-$ \\
\hline 11 & $187 .-2$ & 214. & 0.26 & $7.54-8.54$ & 0.21 & $5.63=$ \\
\hline 12 & $214 .-2$ & $2 \$ 1$. & 0.22 & $7.38-8.38$ & 0.18 & $5.46-$ \\
\hline 13 & $241 .-2$ & 268, & 0.19 & $7.21-8.21$ & 0.15 & $5.29-8.29$ \\
\hline 14 & $268 .=2$ & 295. & 0.16 & $7.04=8.04$ & 0.12 & $5.21=$ \\
\hline 15 & $295 .-3$ & 321. & 0.14 & $6.88-7.08$ & 0.09 & $5.04=8.04$ \\
\hline 16 & $321 .-3$ & 348. & 0.12 & $6.63=7.63$ & 0.07 & $4.88-7.88$ \\
\hline 17 & $348 .-5$ & .375. & 0.10 & $6.46-7.46$ & 0.05 & $4.63-7.63$ \\
\hline 18 & $\begin{array}{l}375 .-1 \\
402-1\end{array}$ & 402 & 0.07 & $6.29-7.29$ & 0.03 & $4.38-7.38$ \\
\hline $\begin{array}{l}19 \\
20\end{array}$ & $\begin{array}{l}402 .-1 \\
428 .-2\end{array}$ & 428 & $\begin{array}{l}0.04 \\
0.01\end{array}$ & $\begin{array}{l}6.04-7.04 \\
5.54-6.54\end{array}$ & $\begin{array}{l}0.02 \\
0.01\end{array}$ & $3.54-6.54$ \\
\hline
\end{tabular}

Figure 21. Listing of summary output file generated by Sample Simulation 1. 


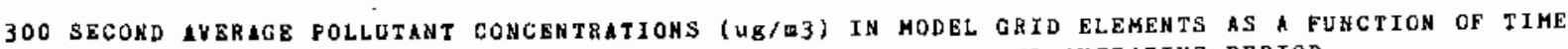
IMDICATED TIHE IS AT THE HIDPOINT OF 300 SBCOND NVERAGING PERIOD

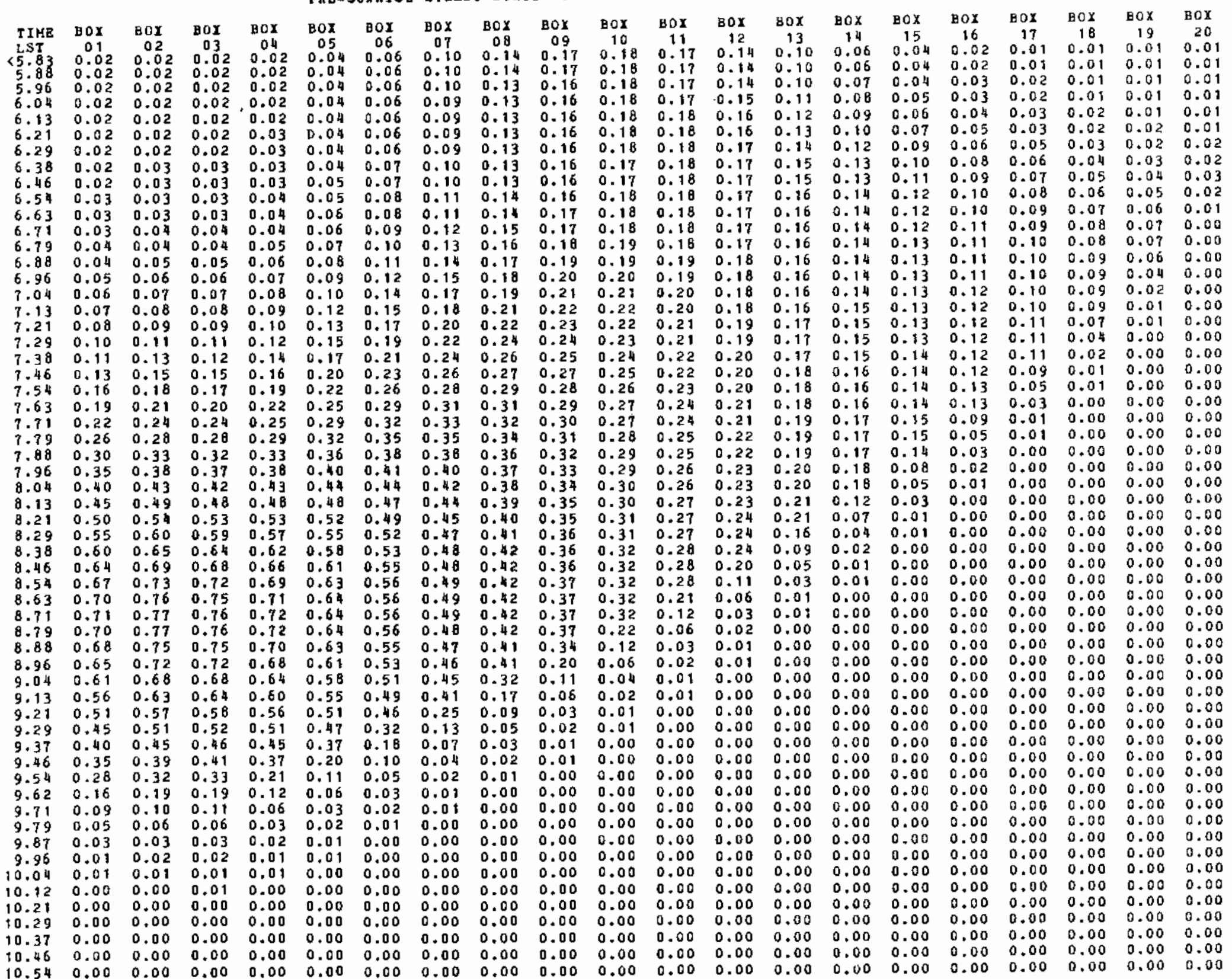

Figure 21. (contd) 

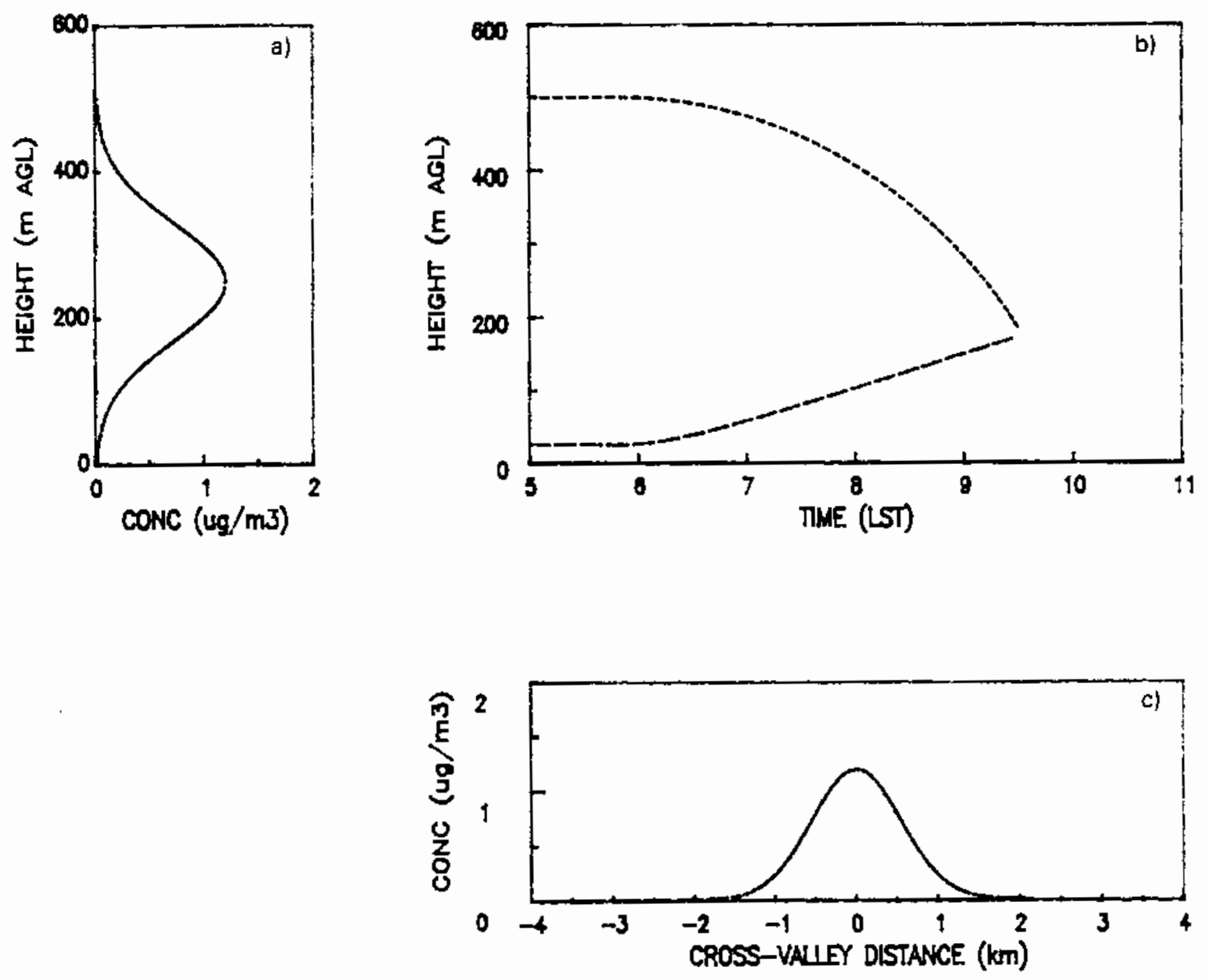

Figure 22. Plots of Sample Simulation 1: (a) nocturnal vertical concentration profile through plume centerline, (b) CBL height (long dashes) and inversion height (short dashes) as a function of time, and (c) nocturnal cross valley concentration profile through plume centerline.

Figure 22 illustrates some of the characteristics of the simulation. It presents plots of the nocturnal vertical air pollution concentration profile at the valley center (Figure 22a), the nocturnal cross-valley concentration profile through the plume centerline (Figure 22c), and plots of CBL neight (long dashes) and inversion top height (short dashes) as a function of time (Figure 22b).

Figure 23 presents plots of the 5 -ninute-average pollution concentrations for selected model grid elements. Twenty grid elements are necessary for the 


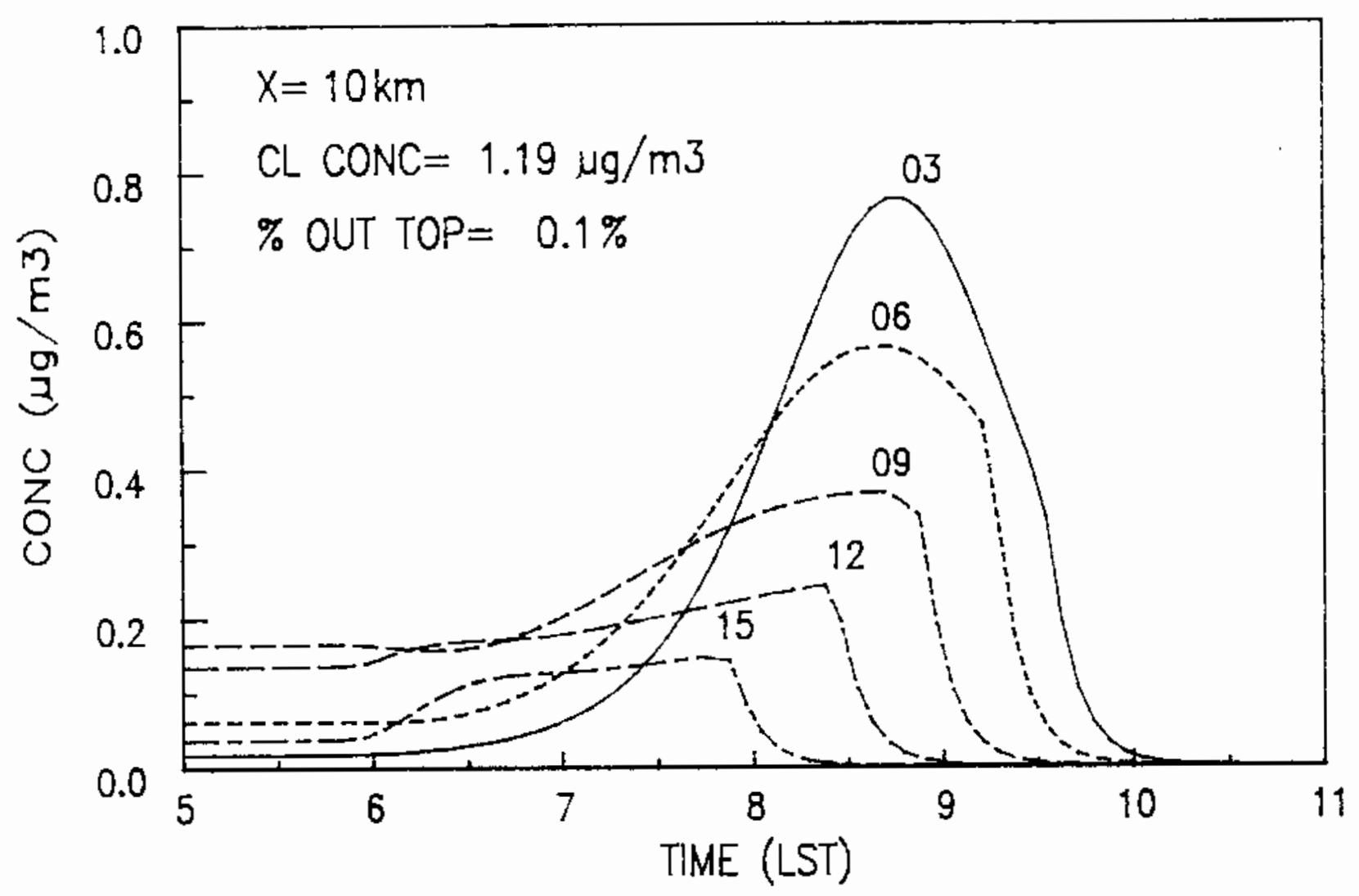

Figure 23. Pollutant conentration versus time for selected grid elements for Sample Simulation 1. The downvalley distance, centerline concentration and fraction of mass diffusing out the top of the valley inversion during the plume's nocturnal transport are indicated on the figure.

default simulation - three on the valley floor and 17 on the valley sidewall. Plots are shown for grid elements $3,6,9,12$, and 15. Sunrise on the date of the simulation was at 0550 am LST. Low steady-state concentrations are seen in the figure before sunrise, with time-varying concentrations arising from fumigations and upslope advection after sunrise. Nocturnal concent. rations on the valley floor and sidewalls are low since the plume, traveling down the valley centerline at $250 \mathrm{~m}$ height, has diffused insufficiently both vertically and horizontaily to produce high concentrations on the valley surfaces. The predominant feature of the concentration curves at the $10 \mathrm{~km}$ travel distance is the post-sunrise fumigation of the pollutant plume on the valley floor and sidewalls. The highest concentrations occur on the valley floor as the high concentrations at plume centerline subside into the growing CBL. The highest concentration shown occurred in grid element number 3 and is 0.76 micrograms per cubic meter. This may be compared to the nocturnal plume 
centerline concentration of 1.19 micrograms per cubic meter. Grid elements on the valley sidewalls are strongly affected by upslope advection. For example, the concentration in grid element 15 increases rapidly just following sunrise as the higher concentrations in downslope grid elements (e.g., see grid element 12) are advected up the sidewall. Another feature of the simulations, apparent in the figure, is the exponential decay of concentrations in individual grid elements as the temperature inversion top subsides below their elevation. This occurs earliest at the highest grid elements. The exponential decay in concentrations simulates the effect of a sudden increase in mixing depth that occurs when the temperature inversion descends below the grid element. The concentration in grid element 3 begins to drop rapidly to zero at the time of temperature inversion destruction (0933 LST).

Simulation Number 2

The results of sample simulation number 2 are shown beiow in Figures 24 and 25 , in the same way that the results of simulation number 1 were 111 lustrated. Input parameters for this simulation, $30-k m$ downvalley from the pollutant source, differ from the previous simulation only in downalley distance.

At the $30 \mathrm{~km}$ cross section, the nocturnal plume had diffused sufficiently during travel that substantial reflections had occurred from the valley surfaces. The vertical and horizontal concentration profiles through the plume centerline (Figure 24) show that the concentrations were more uniform within the valley than at the $10 \mathrm{~km}$ section. At the $30 \mathrm{~km}$ section, $2.7 \%$ of the plume had diffused out the top of the valley inversion, and the plume centerline concentration was 0.37 micrograms per cubic meter. The CBL growth, inversion top descent, and inversion breakup occur exactly as shown in the first simulation. Concentrations (Figure 25) differ during both the pre-sunrise and postsunrise periods, however, due to the different nocturnal concentration profiles within the cross section at the longer travel distance. Nocturnal concentrations are higher at the valley surfaces due to the broader distribution of the plume about its centerline. The highest concentration in sidewall grid element 12 occurs during the night. Since the pollutant is more evenly distributed across the cross section, the effects of fumigations are less pronounced than at the $10 \mathrm{~km}$ cross section. Again, as at the $10 \mathrm{~km}$ cross section, the greatest effect of fumigation is on the valley floor.

The example shown here as simulation number 2 is used merely to illustrate the effect of changing downvalley distance, other parameters remaining constant. Other parameters could have been changed along with the downvalley distance (such as valley width, for example) to simulate the physical characteristics of a real valley more accurately. 

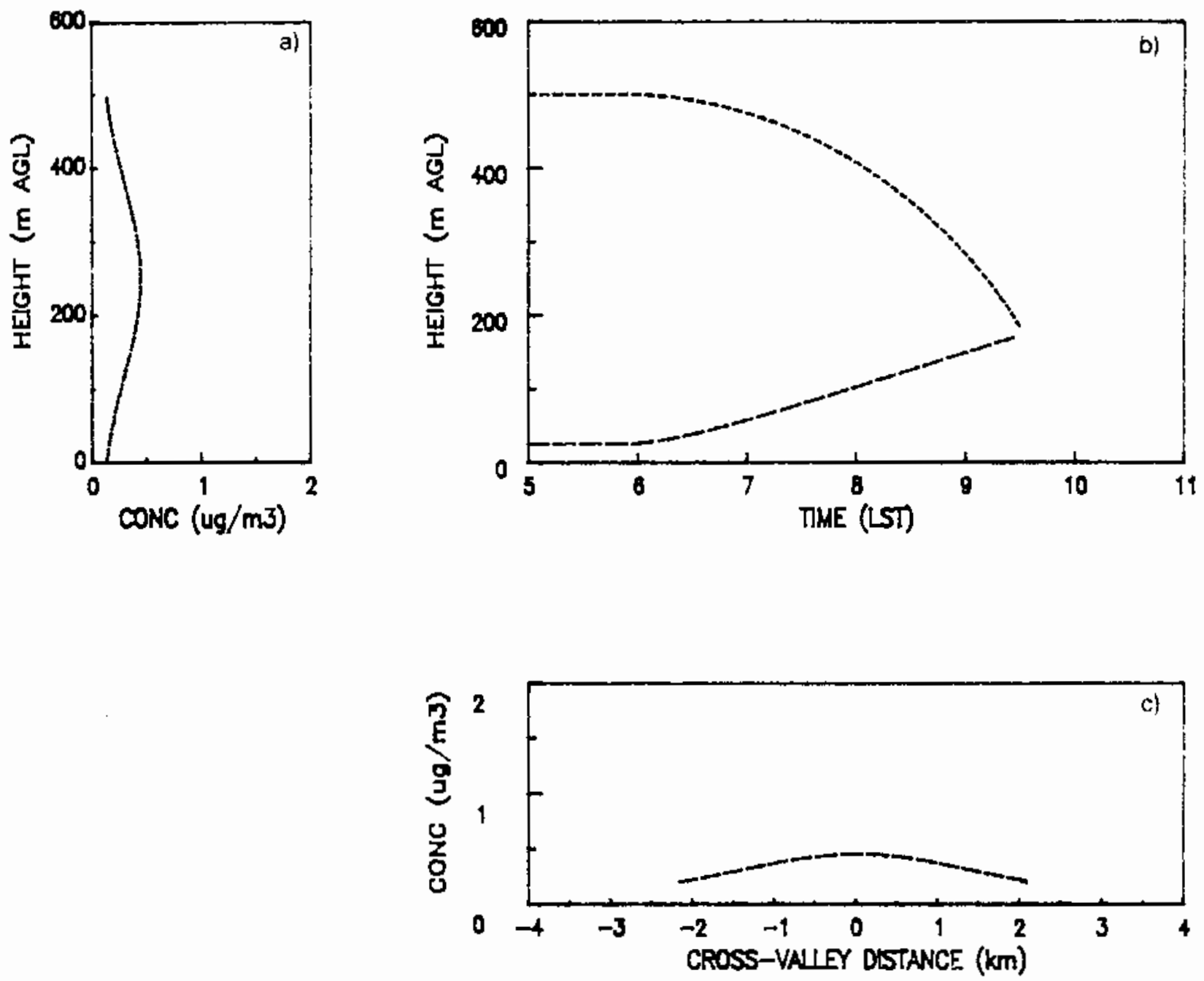

Figure 24. Same as Figure 22, for Sample Simulation 2. 


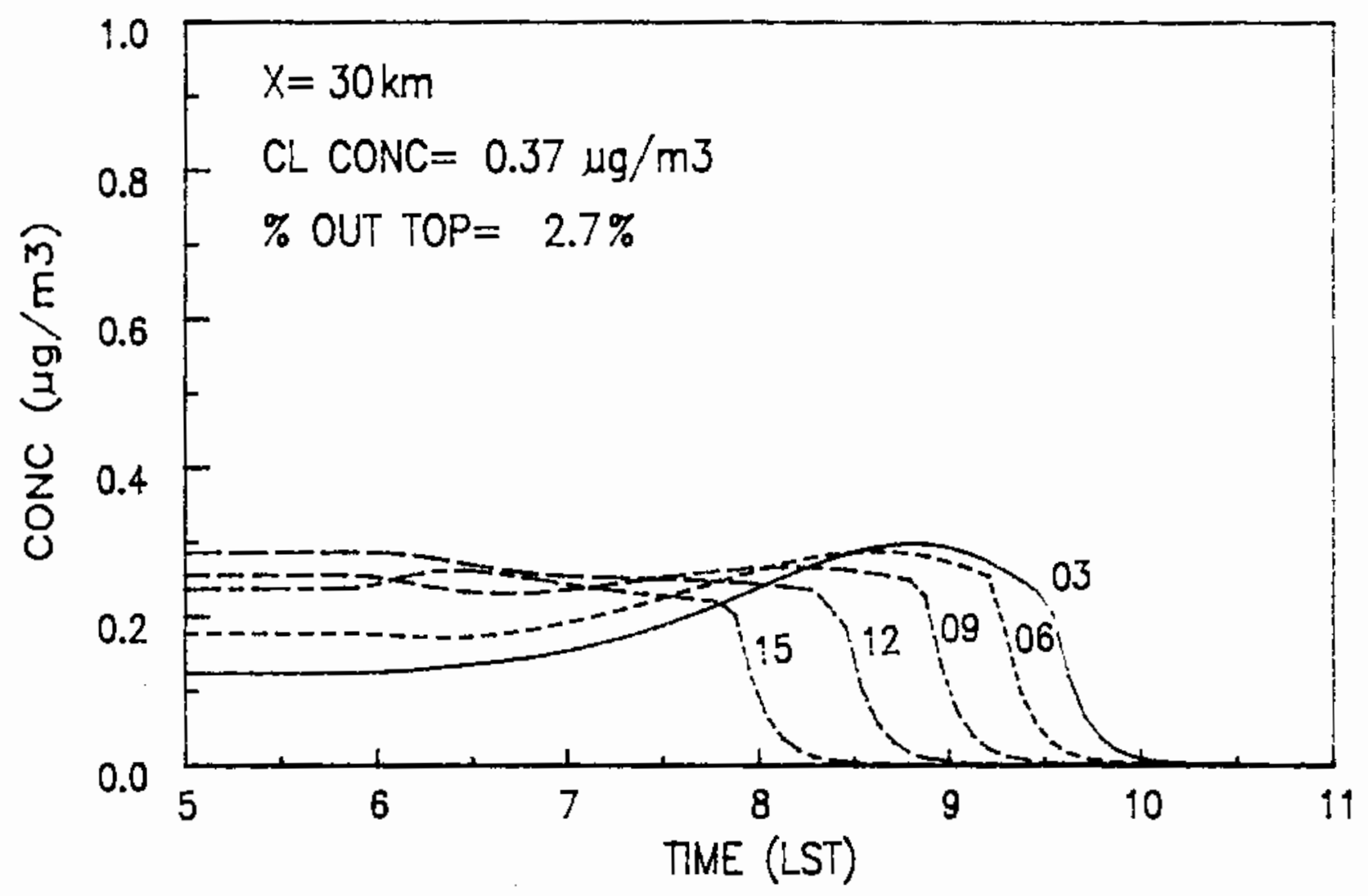

Figure 25. Same as Figure 23, for Sample Simulation 2. 
SECTION 7

FURTHER WORK

VALMET, as described above, is a working model able to simulate many of the observed features of the meteorology of Colorado's deep valleys. The model has been developed in a modular fashion so that the modules can be upgraded as we learn more about valley meteorology. The model, while incorporating what are thought to be the relevant physical processes that lead to air pollution transport and dispersion, has not yet been tested against actual air quality data. Tracer experiment data suitable for testing the model were collected in a joint DOE/EPA experiment in Brush Creek, Colorado during a series of experiments in july and August 1982. This data will be analyzed and the model will undergo preliminary evaluations in FY 1984.

The basic modeling approach in VALMET is to explicitly parameterize a number of physical processes acting to disperse pollutants in the valley atmosphere. Based on the parameterizations now included in the model, a number of suggestions can be made for model improvenent, even before the field evaluations are conducted. Some of these suggestions are presented below. The simpler modifications are listed first.

Deposition

Deposition of pollutants during transport could be incorporated into the model at two points. Deposition during along-valley transport of the plume could be included in modules INGRAT and NORMAL, while deposition occurring in the slope flows could be rather easily incorporated into module BRKUP using a surface sink term in the pollutant mass budget calculations.

Emission Above or Below Stable Core

The present model assumes implicjtly that pollutants are emitted into the stable core, which is then advected downvalley. Concentrations are produced by fumigation of pollutants from this elevated plume as the CBL grows upward into it. Modifications to the model will be required if the emissions fail to enter the stable core. This will happen at the stack location $(x=0)$ once the CBL grows to the effective stack height. Pollutants would then be emitted into the CBL. Similariy, once the inversion top sinks below the effective stack height, the pollutants are dispersed above the valley inversion and do not affect the stable core. 
Calculations of air pollution concentrations down-valley of the stack shouid take account of these possibilities by modifying pollutant calculations when changes in the stable core concentration profiles are advected over the cross section of interest. The advection time depends on the distance $x$ downvalley of the stack and the wind speed in the stable core, such that the advection time is

$$
t_{1}-t_{0}=x / u_{5}
$$

where $t_{0}$ is the time of sunrise and $t_{1}$ is the time when the inversion top descends below the effective stack height or the CBL grows above the effective stack height. When calculations are made far downwind of the stack $(x>>0)$, or downvalley flows are weak ( $u_{s}$ smali) the travel time will be so long that the inversion will be broken before any change in concentration calculations is necessary. It may be necessary, however, to modify the model calculations in short, well-drained valleys. Similarly, the model, when applied to ground Tevei sources, will need modification to account for the post-sunrise emission directly into the CBL.

Energy Budget

The energy budget model needs a great deal of further work. It presently includes a simple bulk parameterization of the fraction of extraterrestrial solar radiation converted to sensible heat flux at the valley surfaces. This fraction, in general, should vary throughout the day and should depend on cloudiness, soil moisture, albedo, ground heat flux, vegetation, atmospheric absorption of the solar beam, etc. It may be worthwhile to adapt existing surface energy budget parameterization schemes for use in the energy budget module. This will, of course, increase the input requirements of the overall model. A different approach is possible. One could look at existing data sets and try to determine the value of this fraction leading to the "worstcase" pollution episodes in different parts of the country. The model could then be used with these fractions to simulate such conditions. Such an empirical approach should also be focused on determining the other free parameter in the model, the fraction $k$ of sensible heat flux causing CBLs to grow. A major effort is required to do a good job on either approach.

Cross Valley Flows

The model could be modified to incorporate cross valley flows in the stable core. Such flows have been postulated by others [45]. They are expected to be strongest in valleys where differential heating occurs on the sidewalls. An example would be a north-south valley where the morning sun would shine on one sidewall while the other was still in the shade. Such organized cross valley flows were not a prominent feature of the colorado observational programs and have not been incorporated in the model. Guidance from more sophisticated primitive equation models [46-49] seems appropriate before cross valley flows can be included in the present model. 
Turbulent Erosion of the Valley Inversion by Overlying Flows

Too little is presently known about postulated turbulent erosion $[15,50]$ of the top of a valley temperature inversion to include it in the present version of the model. It is not clear that it should be incorporated anyway, since the model is more conservative without it. Lenschow et a1. [50] have developed an approach that could be rather easily incorporated into the present model if a means could be found to relate a local Richardson number at the top of the inversion to the rate of turbulent erosion. No way is yet available to do this. Additionally, recent primitive equations modeling indicates that turbulent erosion is not a major factor affecting temperature inversion breakup under conditions of light to moderate winds aloft when inversions are strong (personal communication, T. B. Mckee, 1983). Fluid modeling experiments may be useful here in the future.

\section{Effect of Tributary Flows on the Enhancement of Diffusion}

The present version of the model incorporates a simple means of nandling dilution due to valley tributary flows. The model does not treat the effect of these tributary flows on enhancing diffusion within the main valley. At present there seems to be too little observational data to incorporate this effect or the related thermodynamic effects caused by converging air masses of different temperature or stratification. The DOE ASCOT program may look into these effects in their future Colorado field programs.

Diffusion Coefficients

The diffusion coefficients in the model need improvement. At present we are modifying Pasquill-Gifford [43] flat terrain coefficients on the basis of the Huntington canyon data of start et al. [20] and other data summarized by others [29-31]. We need to look at more data or conduct specific diffusion experiments to determine the most appropriate values of these coefficients.

Time-Varying Wind Speeds in the Stable Core

The model could be modified to handle time-varying wind speeds in the stable core. There is no doubt that the downvalley wind speeds in the stable core decrease after sunrise during the temperature inversion destruction period, since this has been frequently observed [9]. It is not entirely clear what the effect of this decrease will be on calculations, since the wind speed, in addition to modifying plume concentration calculations, will also affect plume rise calculations.

Temperature Inversion Buildup

The present version of the model simulates the nocturnal steady-state period and the inversion breakup or morning transition period. The model could be extended to simulate the temperature inversion formation and growth 
period, when downvalley winds first become established within a valley. A large quantity of data on this period was collected in whiteman's NSFsupported dissertation program in 1977 and 1978. The data have been processed, but not analyzed. A case study [6] indicated some promising research approaches that could lead to an air pollution model for the inversion buildup period.

Differential Heating

One might expect CBLs to grow at different rates over the different sidewalls of a valley, especially when the energy budgets of the sidewalls are substantially different. This might occur frequentiy in north-south oriented valleys where the differential insolation on the sidewalls varies strongly with time (see Figure 26 for an example). The present version of VALMET has as its basis a bulk energy budget model of the valley inversion that does not treat the sidewall energy budgets separately. A major modification to the model would be required to simulate CBLs growing at different rates on the individual sidewalls. This would require an additional free parameter in the model, specifying the fraction of sensible heat used for growing CBLs over one sidewall, as opposed to the other. At present there seem to be no vertical structure data available taken on a single day on two opposite sidewalls. Without this kind of data it is difficult to come up with accurate parameterizations of the differentiai CBL growth. Brehm [51], based on the Innsbruck, Austria Slopewind Experiment of 1978, has presented a conceptual model showing differential CBL growth on opposite sidewalls (Figure 27). His conceptual model also shows subsidence in the stable core. Bader and Mckee [47], nowever, in their two-dimensional simulation of valiey inversion breakup, noted no significant differential boundary layer growth over opposite valley sidewalis even when substantialiy different sensible heat flux functions were used on the different valley sidewails. They explained this as due to the effects of horizontally propagating gravity waves that act to keep isotherms horizontal within the stable core. They also noted the existence of multiple closed cross valley circulations within the stable core early in the postsunrise period that acted to warm the valley temperature inversion differentially with height, destabilizing the valley atmosphere. This process acts in consort with stable core subsidence to warm the valley atmosphere. As snown by the different conclusions reached in these two studies, it seems appropriate to verify differential CBL growth using specially designed field studies. 


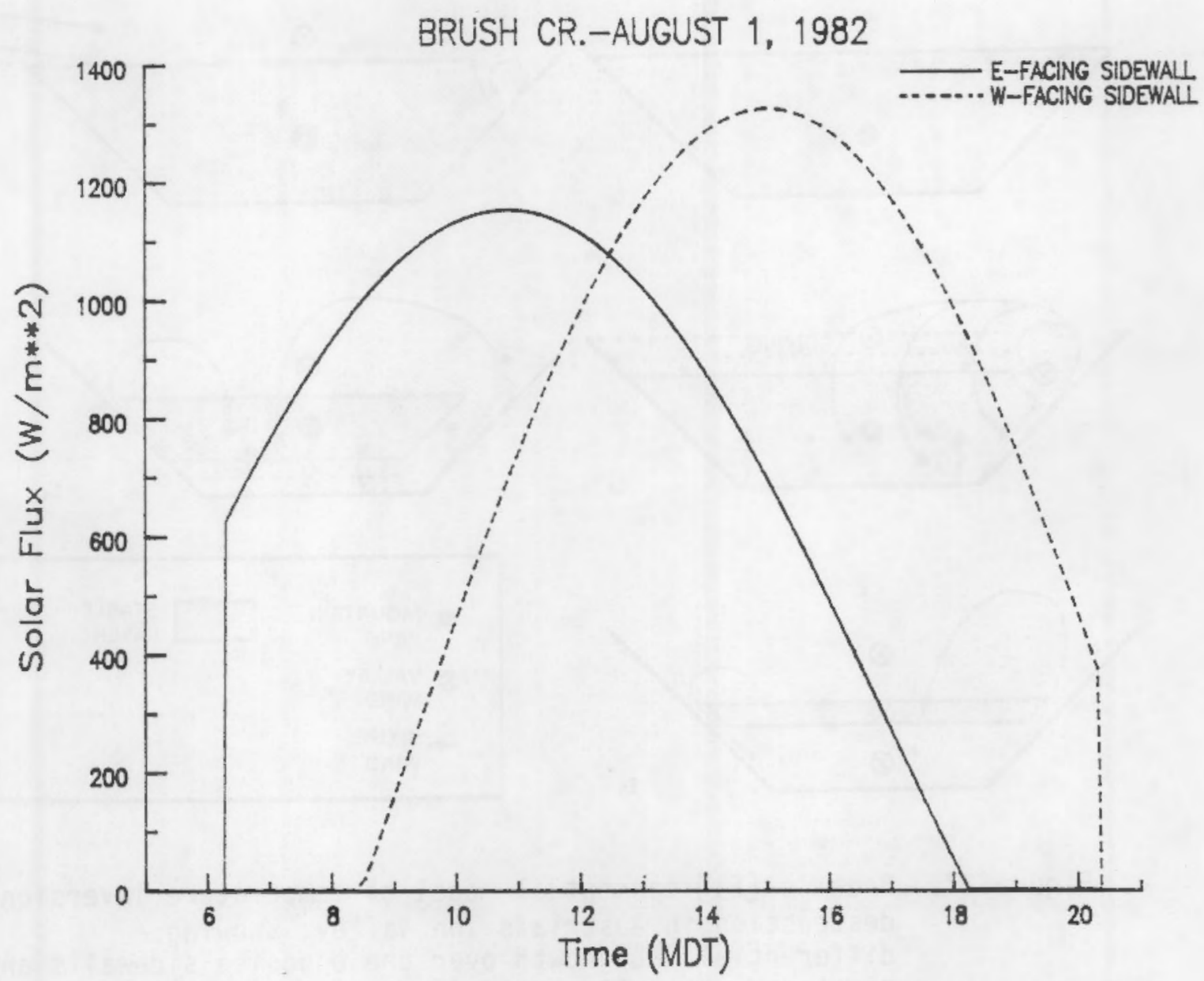

Figure 26. Illustration of differential solar flux on opposing sidewalls for Brush Creek Colorado on August 4, 1982. The Brush Creek Valley drains from NW to SE. The curves represent extraterrestrial solar flux (i.e., they assume no atmosphere) and were determined using a solar radiation model. 

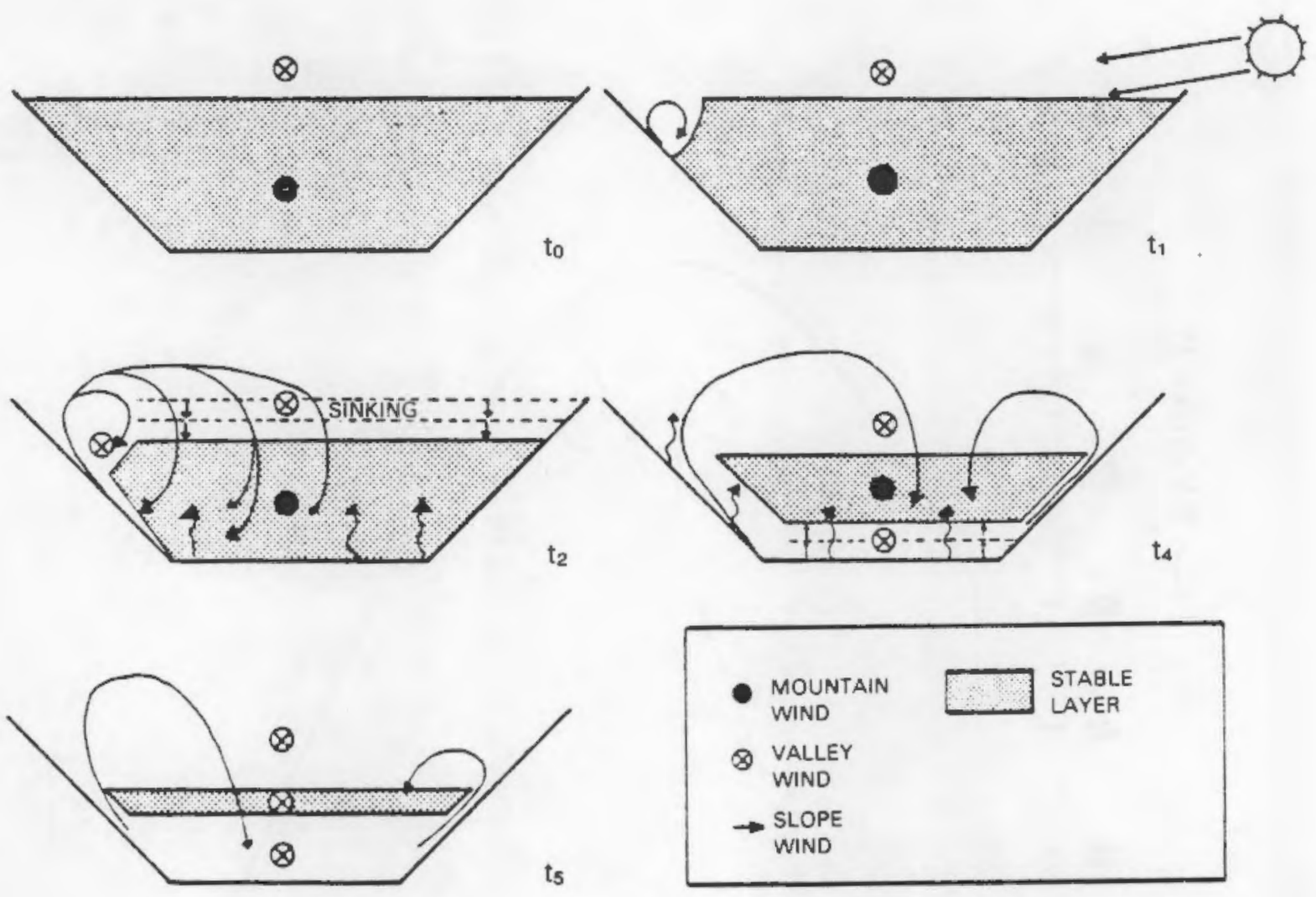

Figure 27. Brehm's [51] conceptual model of temperature inversion destruction in Austria's Inn Valley, showing differential CBL growth over the opposite sidewalls and continued downvalley flow in the elevated stable core. 


\title{
SECTION 8
}

\author{
SUMMARY
}

Following a thorough analysis of meteorological data obtained from deep valleys of western Colorado, a modular air pollution model has been developed to simulate the transport and diffusion of pollutants released from an elevated point source in a well-defined mountain valley during the nighttime and morning transition periods. This initial or preliminary version of the model, named VALMET, operates on a valley cross section an arbitrary distance downvalley from a continuous point source. The model has been constructed to include parameterizations of the major physical processes that act to disperse poliution during these time periods.

The nighttime simulation uses a modified Gaussian plume to calculate concentrations on the valley floor and sidewalls. The Gaussian plume model uses Briggs' piume rise equations and Pasquill-Gifford diffusion coefficients, as modified for complex terrain diffusion enhancement. Dilution of the plume due to tributary flows can be handled in the model, and a new method has been incorporated to insure conservation of plume mass as the plume is transported down the valley axis. The purpose of the nighttime simulation is to provide air pollution concentrations on a cross valley section at sunrise, as an initial condition for the daytime simulation.

The daytime simulation uses numerical techniques and a valley energy budget to predict how concentrations will vary in time as pollutants from the elevated plume are fumigated onto the valley floor and sidewalls during the post-sunrise temperature inversion breakup period. The effects of CBL growth, temperature inversion subsidence, transport and diffusion in upslope flows, warm air advection above the valley, albedo, sensible neat flux, and other physical processes are incorporated in the model. The daytime simulation is driven by solar radiation and a simplified surface energy budget, taking account of valley topography.

Valley meteorological observations are required in order to obtain the necessary input parameters to the model. The required observations can be obtained using standard meteorological instrumentation, and the costs for the observations necessary to perform a simple screening analysis are expected to be within the means of a small industrial applicant wanting a permit for operation in a mountain valley. The VALMET model could form the basis for a more comprehensive site-specific model if further meteorological and tracer 
data were avajlable in a given valley. The model outputs are in a form suitable for regulatory decision making. The model predicts the maximum 1 - and 3-hour average concentrations for locations on the valley floor and sidewalls.

The model shows promise for use as a planning tool and, eventually as a regulatory tool. Further development, testing, and tracer evaluations of the model will be necessary before sufficient confidence can be gained to justify the model's use in a regulatory setting. The priorities for further development and testing have been provided in the body of the report. Testing of the model's sensitivity to input parameters, and an initial evaluation of the model with tracer experiment data are high priority tests that are now being planned. These tests will, no doubt, result in modifications to the initial version of the model.

Contractual requirements have dictated that this report be prepared to document progress on development of the model. The authors are concerned that the ready availability of this document, of itself, will result in attempts by others to utilize the model before it is adequately developed and thoroughly tested. We can only stress that the model's ultimate utility in addressing and providing solutions to potential air pollution problems in mountain valleys will depend on the further evaluation of the model. In order to have confidence in model predictions it is necessary to test the model against actual air pollution data. Several parameters in the model ( $A_{0}, k$, $\sigma_{y}$, and $\sigma_{z}$ ) are, at present, poorly understood for mountain valleys due to a dearth of experimental data and theoretical research. We nope, by pointing out these deficiencies, that attention will be focused on the need for information on both turbulent diffusion and valley energy budget studies. The use of full physics models may help in providing some of the answers necessary to improve the present model. 


\section{REFERENCES}

1. Hewson, E. W., and G. C. Gill. 1944. "Meteorological Investigations in Columbia River Valley Near Trail, B.C.," Bur. Mines Bull., U.S. Department of Interior, 453, 23-228.

2. Bierly, E. W., and E. W. Hewson. 1962. "Some Restrictive Meteorological Conditions to be Considered in the Design of Stacks." J. Applied Meteor., $1,383-390$.

3. Whiteman, C. 0., and T. B. McKee. 1982. "Breakup of Temperature Inversions in Deep Mountain Valleys: Part 11. Thermodynamic Model." J. Applied Meteor., 21, 290-302.

4. U.S. Environmental Protection Agency. 1978. Handbook for Preparing Office of Research and Development Reports, Revised. Report EPA-60079-78-032, December 1978, 0.S. EPA, Cincinnati, Ohio.

5. Peterson, W. B., J. S. Irwin, D. B. Turner and J. A. Catalano. 1982. Handbook for Preparing Users' Guides for air Quality Models. August 1982, U. S. EPA, Research Triangle Park, North Carolina.

6. Whiteman, C. D. 1981. "Temperature Inversion Buildup in Valleys of the Rocky Mountains." Preprints, Second Conference on Mountain Meteorology. Nov. 9-12, 1981, St eamboat Springs, Colorado, pp. 276-272.

7. Whiteman, C. D. and T. B. MCKee. 1977. "Observations of Vertical Atmospheric Structure in a Deep Mountain Valley." Arch. Meteor. Geophys. Bioklimat., Ser. A, 26, 29-50.

8. Whiteman, C. D., and T. B. McKee. 1979. Temperature Inversion Destruction in Mountain Valleys - Implications for Air Pollution Dispersion. Proceedings of the Tenth International Technical Meeting on Air Pollution Modeling and Its Application, NATO/CCMS Pi Tot Study, Oct. 23-26, 1979, Rome, Italy, 217-224.

9. Whiteman, C. D. 1980. Breakup of Temperature Inversions in Colorado Mountain Valleys. Ph.D. Dissertation, Colorado State University, PP. 250. Avajlable from University Microfilms, Ann Arbor, Michigan, or as Atmospheric Science Paper No. 328 from Department of Atmospheric Science, Colorado State University, Fort Collins, Colorado. 
10. Whiteman, C. D. 1982. "Breakup of Temperature Inversions in Deep Mountain Valleys: Part I. Observations." J. Applied Meteorology, 21, $270-289$.

11. Whiteman, C. D., and T. B. McKee. 1978. "Air Pollution Implications of Inversion Descent in Mountain Valleys." Atmospheric Environment, 12, 2151-2158.

12. Whiteman, C. D., and T. B. McKee, 1981. "Valley Wind Systems Under Temperature Inversion Conditions." Proceedings, Symposium on Intermediate Range Atmospheric Transport Processes and Technology Assessment. October 1-3, 1980, Gatingburg, Tennessee, pp. 351-358.

13. Whiteman, C. D., and R. L. Drake. 1981. The Green River Ambient Model Assessment Program September 1981 Progress Report an Local Scale Modeling Activities. PNL-4058. September 1981. Pacific Northwest Laboratory, Richland, Washington, $249 \mathrm{pp}$.

14. Whiteman, C. D., and K. J. AlIwine. 1982. Green River Ambient Model Assessment Program FY-1982 Progress Report. PNL-4520, Dctober 1982. Pacific Northwest Laboratory, Richiand, Washington, 187 pp.

15. Davidson, B., and P. K. Rao. 1958. Preliminary Report on Valley Wind Studies in Vermont, 1957. Final Report AFCRC-RT-58-29, Contract AF 19(604)-1971, College of Engineering, New York University, 54 pp.

16. Beuttner, J. K., and N. Thyer. 1966. Valley Winds in the Mount Rajnier Area. Arch. Meteor. Geophys. Bioklimat., Ser. B., 14(2):125-147.

17. Tyson, P. D., and R. A. Preston-Whyte. 1972. "Observations of Regional Topographically-Induced Wind Systems in Natal." J. Applied Meteor., 11, 643-650.

18. Sterten, A. K. 1963. A Further Investigation of the Mountain and Valley Wind System in South-Eastern Norway. Intern Rapport K-254, Forsvarets Forskningsinstitutt, Norwegian Defence Research Establishment, Kjeller, Norway, $51 \mathrm{pp}$.

19. Urfer-Henneberger, C. 1970. Neuere Beobachtungen uber die Entwicklung des Schonwetterwindsystems in einem V-formigen Alpental (Dischmatal bei Davos). Arch. Meteor. Geophys. Bioklimat., Ser. B, 18, 21-42.

20. Start, G. E., C. R. Dickson and L. L. Wendell. 1975. "Diffusion in a Canyon Within Rough Mountainous Terrain." J. Applied Meteor., 14(3):333346.

21. Briggs, G. A. 1969. Plume Rise. AEC Critical Review Series TID-25075.

22. Briggs, G. A. "Some Recent Analyses of Plume Rise Observations." Paper presented at the 197D International Air Poliution Control Conference, Washington, D.C. 
23. Briggs, G. A. 1972. "Discussion of Cnimney Plumes in Neutral and Stable Surroundings." Atmos. Environ., 16, 507-510.

24. U.S. Environmental Protection Agency. 1977. User's Manual for SingleSource (CRSTER) Model. EPA-450/2-77-013. July 1977. Office of Air Quality PJanning and Standards, Research Triangle Park, North Carolina.

25. Drewes, D. R. and J. M. Hales. 1979. Non-Reactive Pollutant Deposition Modeling for Fossil 1 and 2. Report prepared for Pacific Gas and ETectric Co. under Contract No. 23112-03630 by Battelle, Pacific Northwest Laboratories.

26. Turner, D. 8. 1969. Workbook on Atmospheric Dispersion Estimates. Public Health Service Publications No. 999-AP-26.

27. Slade, D. H. (ed.). 1968. Meteorology and Atomic Energy 1968. U.S. Atomic Energy Commission, Division of Technical Information, Oak Ridge, Tennessee, $445 \mathrm{pp}$.

28. McMullen, R. W. 1975. "The Change of Concentration Standard Deviations with Distance." J. Ajr Poll. Control Assoc., 25(10):1057-1058.

29. Minnott, D. H., D. L. Shearer and Y. Gotaas. 1979. "Measurements of the Vertical Dispersion Rate in Deep-Valiey Terrain." Preprint Volume:

Fourth Symposium on Turbulence, Diffusion and Air Pollution. January 1518, 1979, Reno, Nevada. Published by Anerican Meteorological Society, Boston, Massachusetts.

30. Minnott, D. H., D. L. Shearer and and R. S. Marker. 1977. Development of Vertical Dispersion Coefficients for Deep-Valley Terrain. Report CO0-4026-3 prepared for U.S. ERDA by TRC EnvironmentaT Consultants, Inc.

31. Shearer, D. L., D. H. Minnott and G. R. Hilst. 1977. Development of Vertical Dispersion Coefficients for Rolling Terrain Environments. The Research Corporation of New England (TRC) Report C00-4026-1, January 1977.

32. Gotaas, Y. 1972. A Model of Diffusion in a Valley from a Continuous Point Source." Arch. Meteor. Geophys. Bioklimat., Ser. A, 21, 13-26.

33. Abramowitz, M., and I. A. Stegun. 1965. Handbook of Mathematical Functions with Formulas, Graphs, and Mathematical Tables. Dover Publications, Inc., New York, $1046 \mathrm{pp}$.

34. Hastings, C., Jr. 1955. Approximations for Digital Computers. Princeton University Press, Princeton, New Jersey.

35. Sellers, W. D. 1965. Physical Climatology. The University of Chicago Press. Cnicago, Illinois, $272 \mathrm{pP}$. 
36. Kreith, F., and J. F. Kreider. 1978. Principles of Solar Engineering. Hemisphere Publishing Corp., Washington, D.C., 778 pp.

37. McCullough, E. C. 1968. Total Daily Radiant Energy Available Extraterrestrially as a Harmonic Series in the Day of the Year. Arch. Meteor. Geopnys. Bioklimat.., Ser. B, 16, 129-243.

38. Waugh, A. E. 1973. Sundials: Their Theory and Construction. New York, Dover Publications, Inc., $228 \mathrm{pp}$.

39. Thompson, P. D. 1961. Numerical Weather Analysis and Predictions. The MacMillan Co., $170 \mathrm{pp}$.

40. Haltiner, G. J. 1971. Numerical Weather Prediction. John Wiley and

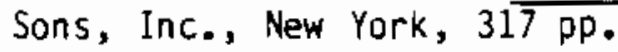

41. Friedman, F. L., and E. B. Koffman. 1981. Problem Solving and Structured Programming in FORTRAN, Second Edition. Addison-Wesley Publishing Co., Reading, Massachusetts.

42. Müller, H., R. Reiter, R. Sladkovic, and K. Munzert. 1982. "Aerologische Untersuchungen des Tagesperiodischen Windsystems im Loisachtal." XVII Internationale Tagung fur Alpine Meteorologie. Berchesgaden, 21-25 September 1982. Annalen der Meteorologie, (Neue Folge), Nr. 19, 186-188.

43. Hanna, S. R., G. A. Briggs and R. P. Hosker, Jr. 1982. Handbook on Atmospheric Oiffusion. DUE/TIC-11223. Technical Information Center, U.S. Department of Energy. $102 \mathrm{pp}$.

44. Sundararajan, A., and S. A. Macklin. 1976. "Comments on the Heat Flux and Friction Velocity in Free Convection Near the Ground." J. Applied Meteor., 33, 715-718.

45. Gleeson, T. A. 1951. "On the Theory of Cross-Valley Winds Arising From Differential Heating of the Slopes." J. Meteor., $\underline{8}(6), 398-405$.

46. Bader, D. C. 1981. Simulation the Daytime Boundary Layer Evolution in Deep Mounta in Valleys. M.S. Thesis, Atmospheric Science Department, Colorado State University, fort Collins, Colorado.

47. Bader, D. and T. B. McKee. 1983. "Dynamical Model Simulation of the Morning Boundary Layer Development in Deep Mountain Valleys." J. Climate and Appl. Meteor. In Press.

48. McNider, R. T. 1981. "Investigation of the Impact of Topographic Circulations on the Transport and Dispersion of Ajr Pollutants." Ph.D. Thesis. Department of Environmental Science, University of Virginia, Charlottesville, Virginia (available from University Microfilm, Ann Arbor, Michigan). 
49. McNider, R. T., and R. A. Pielke. 1981. "Diurnal Boundary-Layer

Development Over Sloping Terrain." J. Atmos. Sci., 38(10), 2198-2212.

50. Lenschow, D. H., and B. B. Stankov, 1979. "The Rapid Morning BoundaryLayer Transition." J. Atmos. Sci., 36, 2108-2124.

51. Brehm, M. 1981. Hangwindexperiment Innsbruck 1978 - Gebirgswindsystem und Inversionsaufiosung. Ph.o. Oissertation, Ludwig-MaximiliansUniversitat, Munich, West Germany. 
APPENDIX A

FORTRAN LISTING OF VALMET 


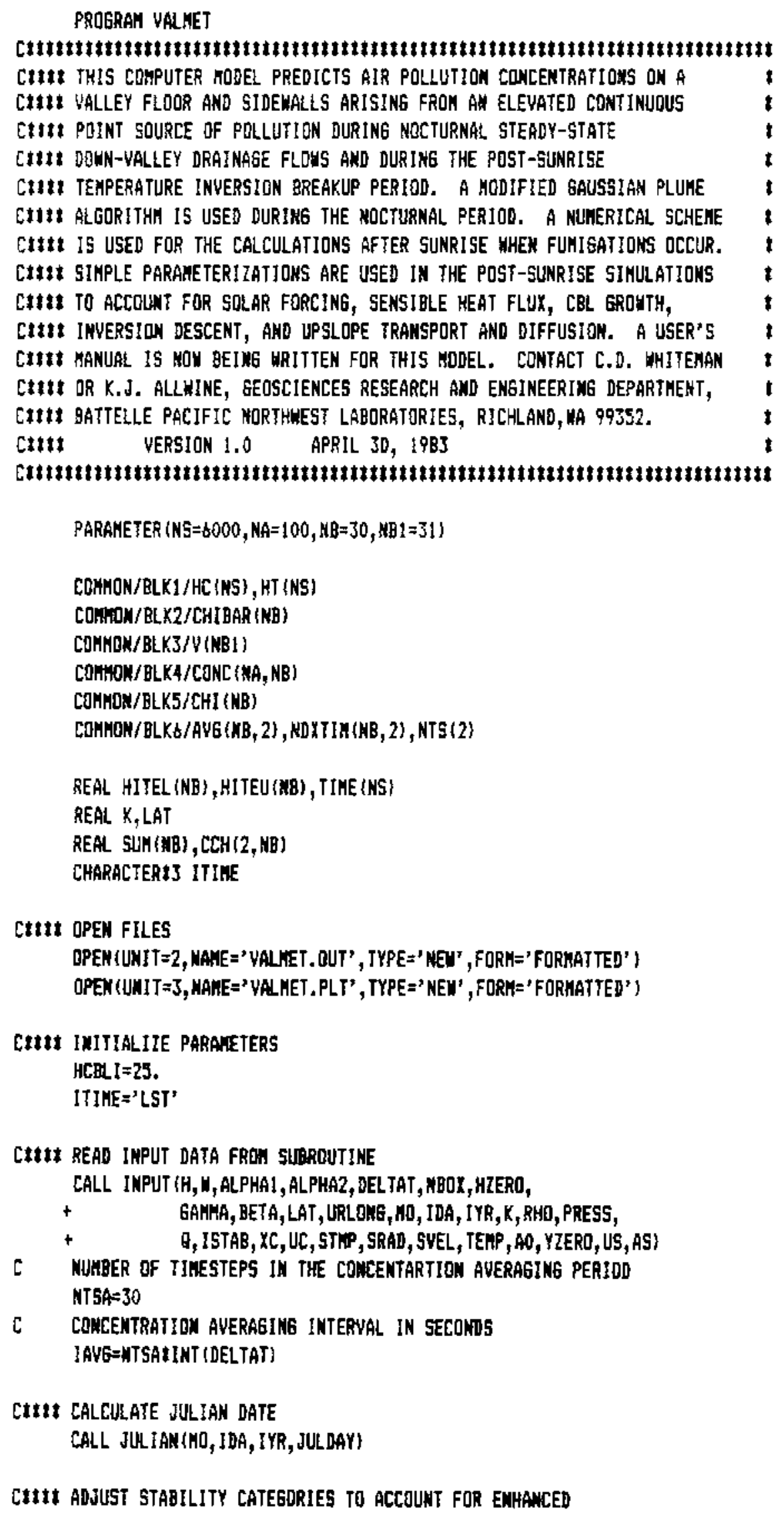




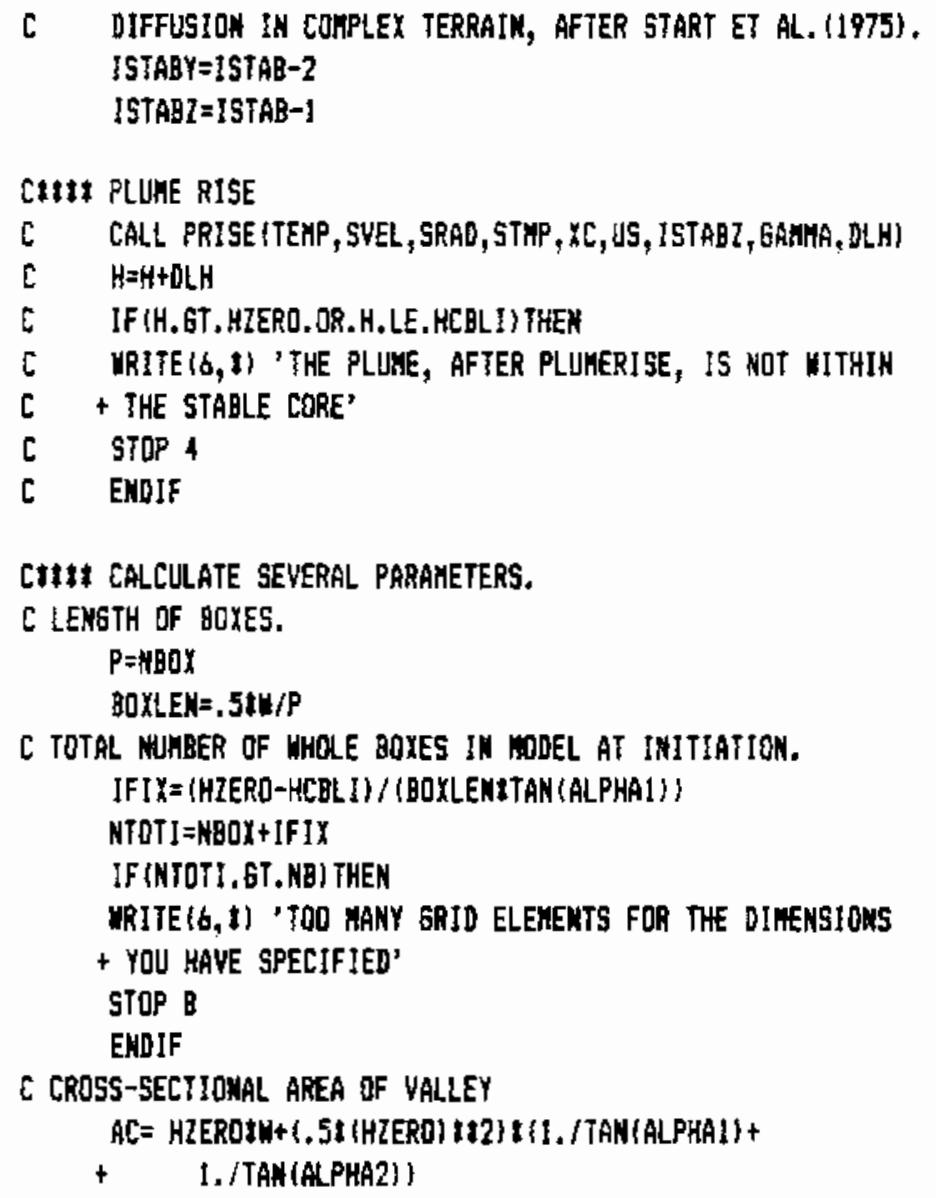

CtIt VOLUMETRIC DILUTIDN DUE TO SLOPE FLOU CONVERGENCE, TRIBUTARY CatIt FLOLS, OR EXTRAIHIEMT,

CALL DILUTE (US, UC, AS, AC, DF)

CItu: DETERHINE DIFFUSION COEFFICIENTS AND CALCLLATE THE FRACTION CIIt: OF POLLUTANT HASS IN THE VALLEY CROSS-SECTION THAT HAS Citit DIFFUSED "BEYOND" THE VALLEY UALLS AMD "BELOY" THE GRDUND. CALL INGRAT IXC, YIERO, ISTAGY, ISTABI, W, ALPHAL, ALPHAZ, $+\quad$ HZERD, H, SLM I, SUM 2, SIGMAY, SIGHAZ?

CIIt! DISTRIBUTE THE LOST MASS FRACTION BACK INTO THE CROSS-

CIII SECTION. USE MELL HIXED ASSUHPTION.

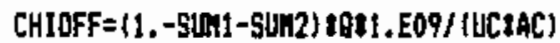

CItIt USE gAUSSIAN PLIME EQUATION TO CALCHLATE THE MAXIHUM cItI CEMTERLINE COACENTRATION WITHIN THE VALLEY CROSG-SECTION CALL GAUSS IXC, O. H, YIERQ, H, Q, US, DF, SIGHAY, SIGMAZ, TEMP, $+$ PAESS, CLCONC)

CLCONC $=$ CLCONC+CHIOFF

CIIIt USING EAUSSIAN PLUHE EQUATION, CALCULATE STEADY-STATE CIIII NOCTURNAL CORCENTRATIDAS AT POIKTS ON THE YALLEY FLOOR AND CIIII SIDEWALLS CORRESPOMDIMS TO THE GRID ELEHEMTS USED FOR THE CIIII AFTER-SUNRISE CALCULATIONS. 


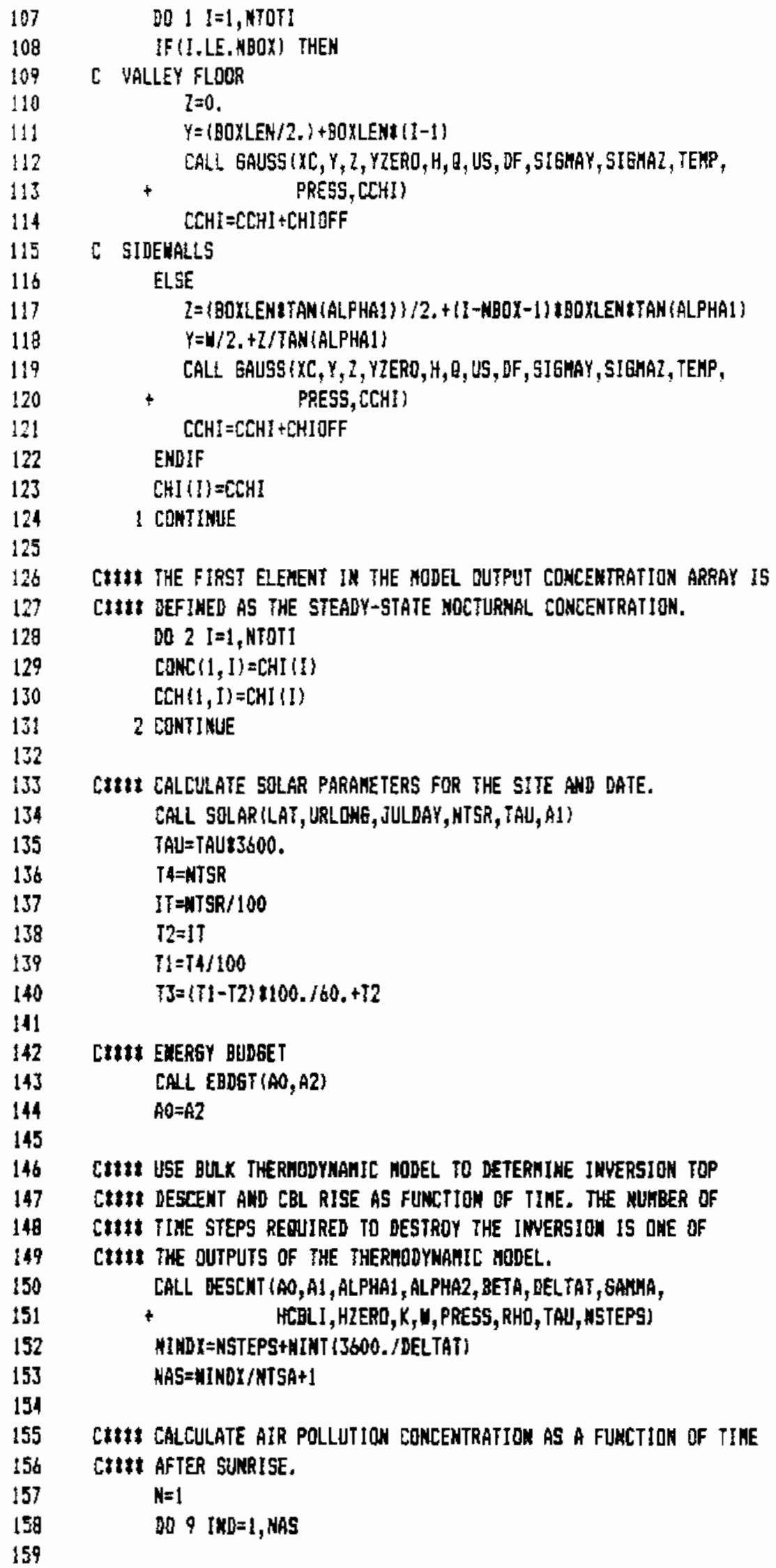




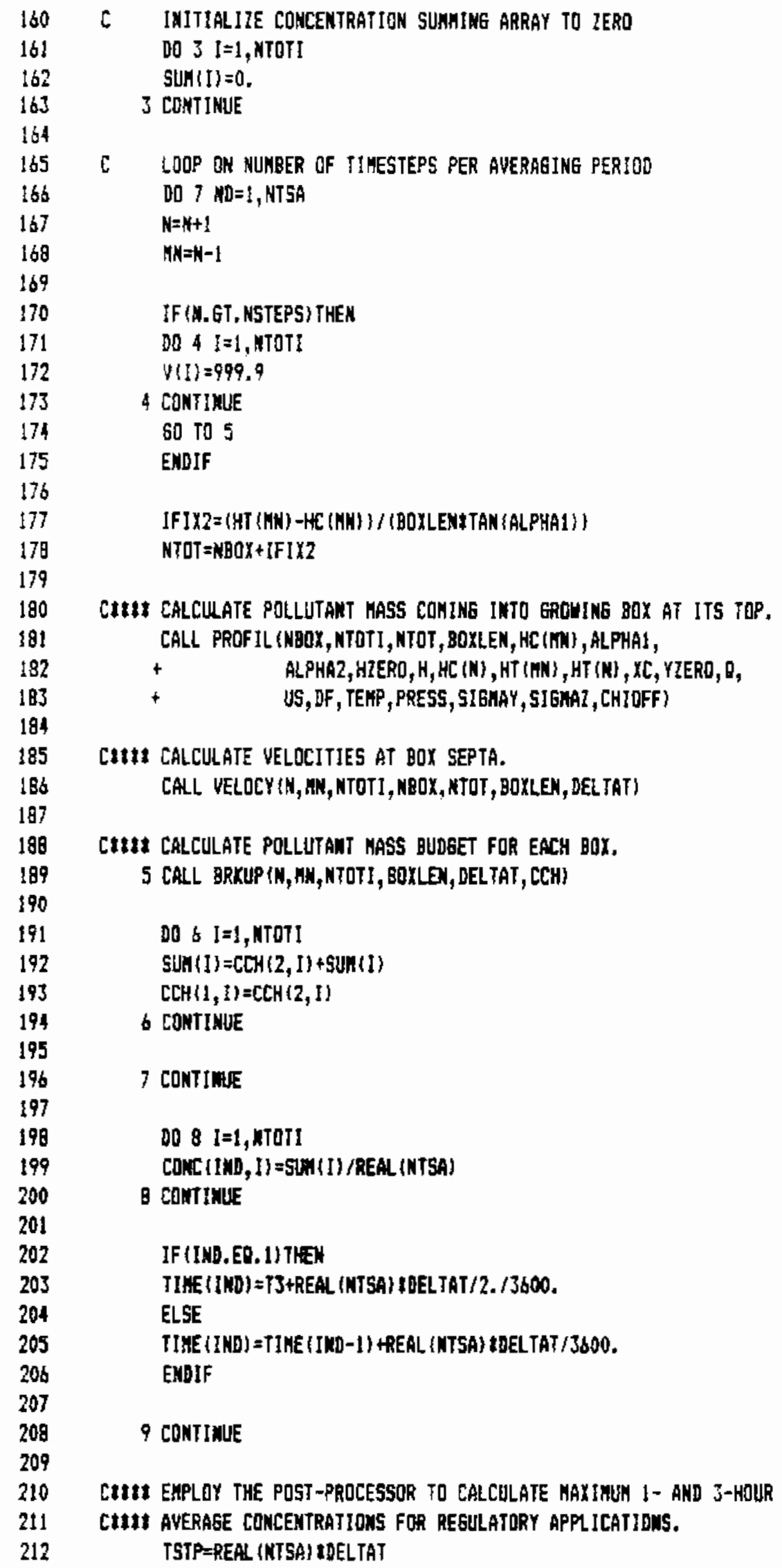




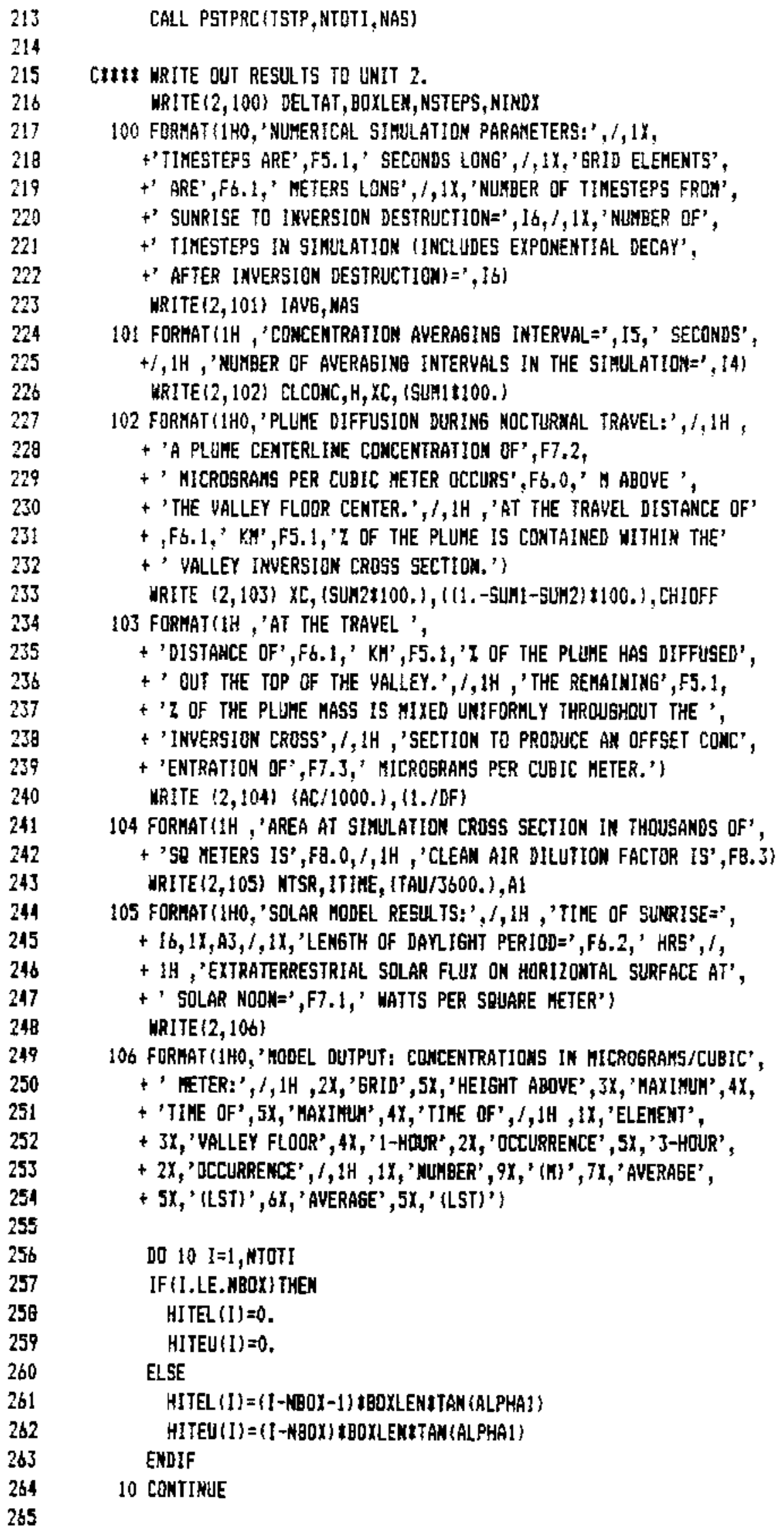




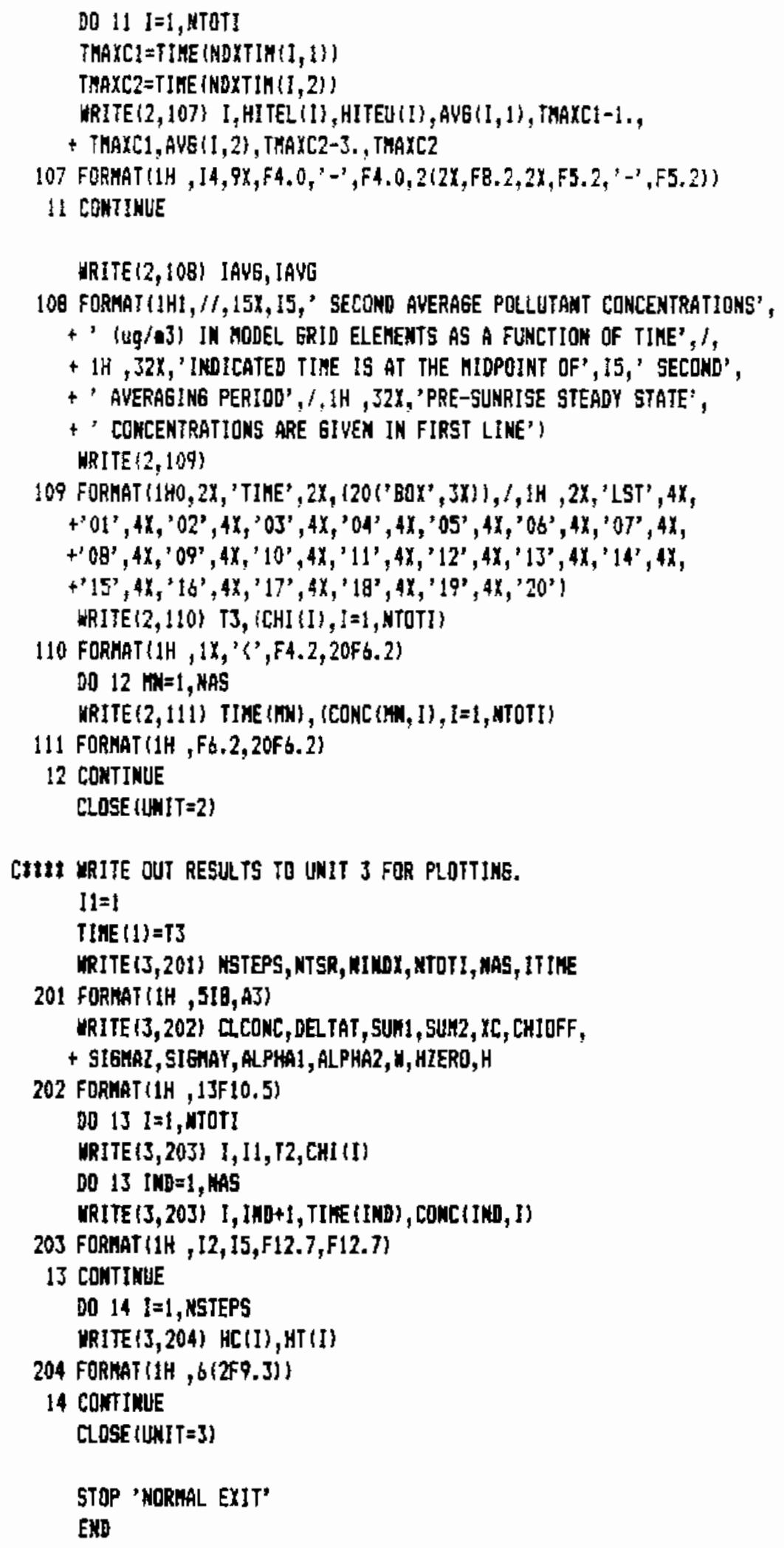




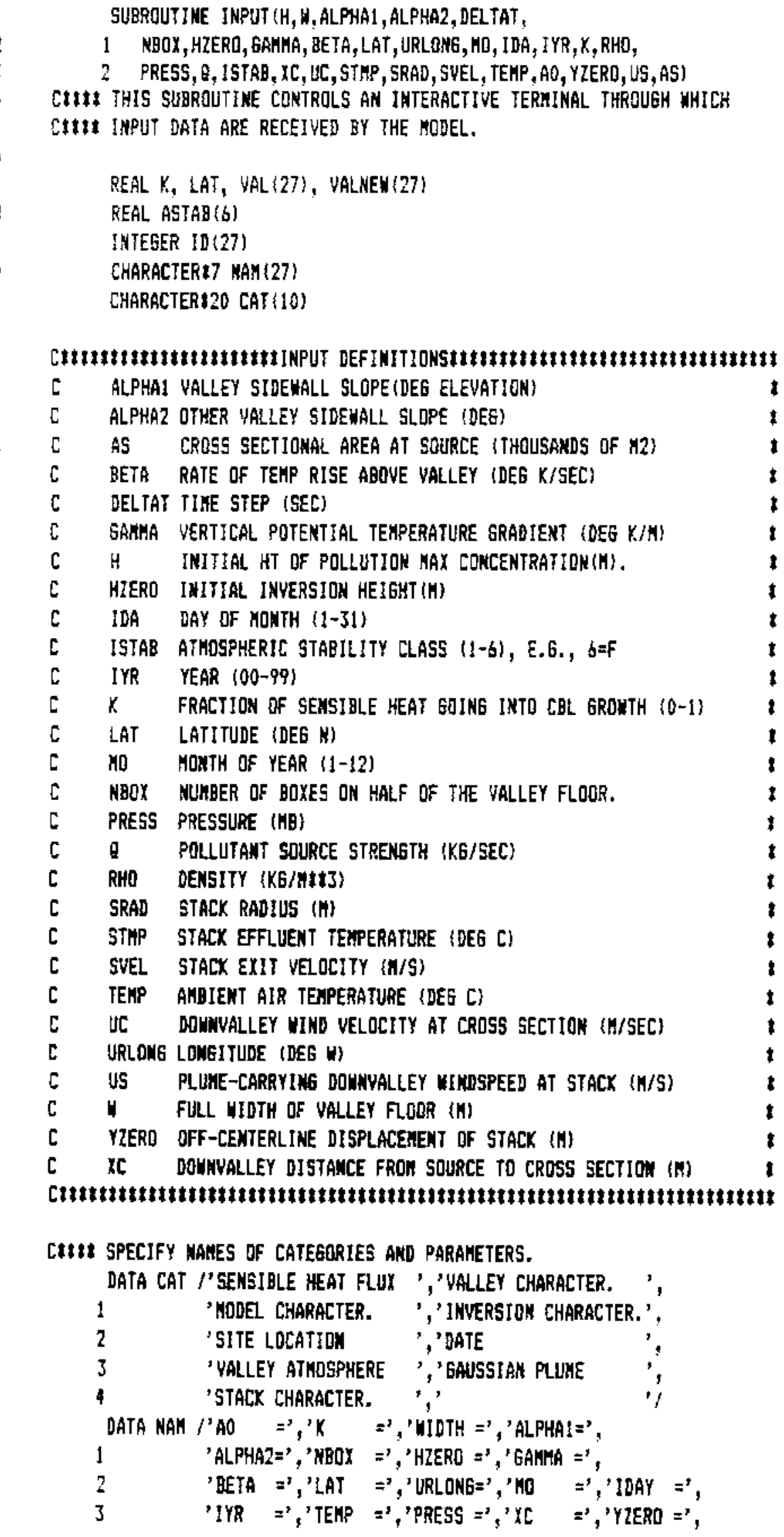




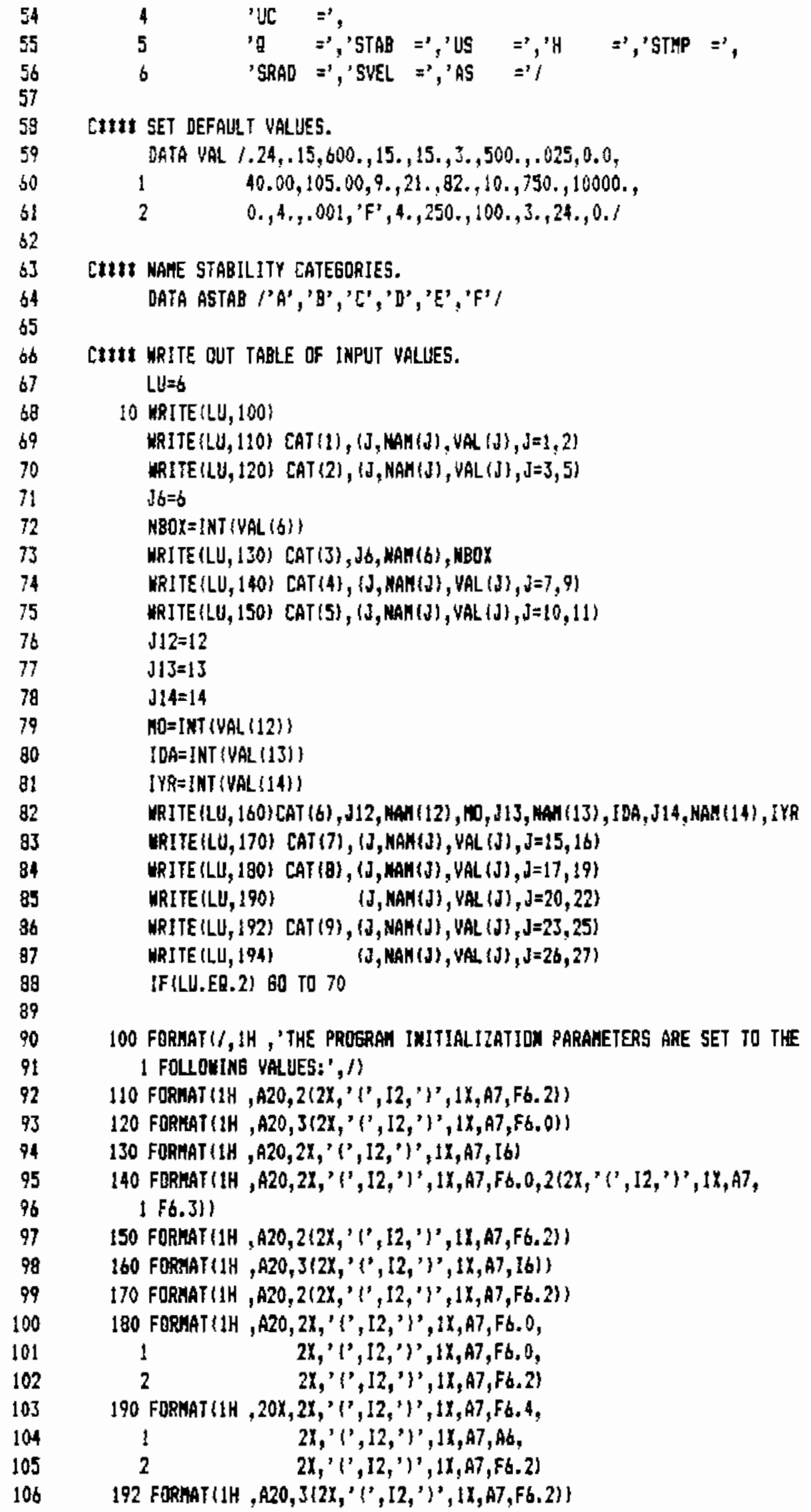




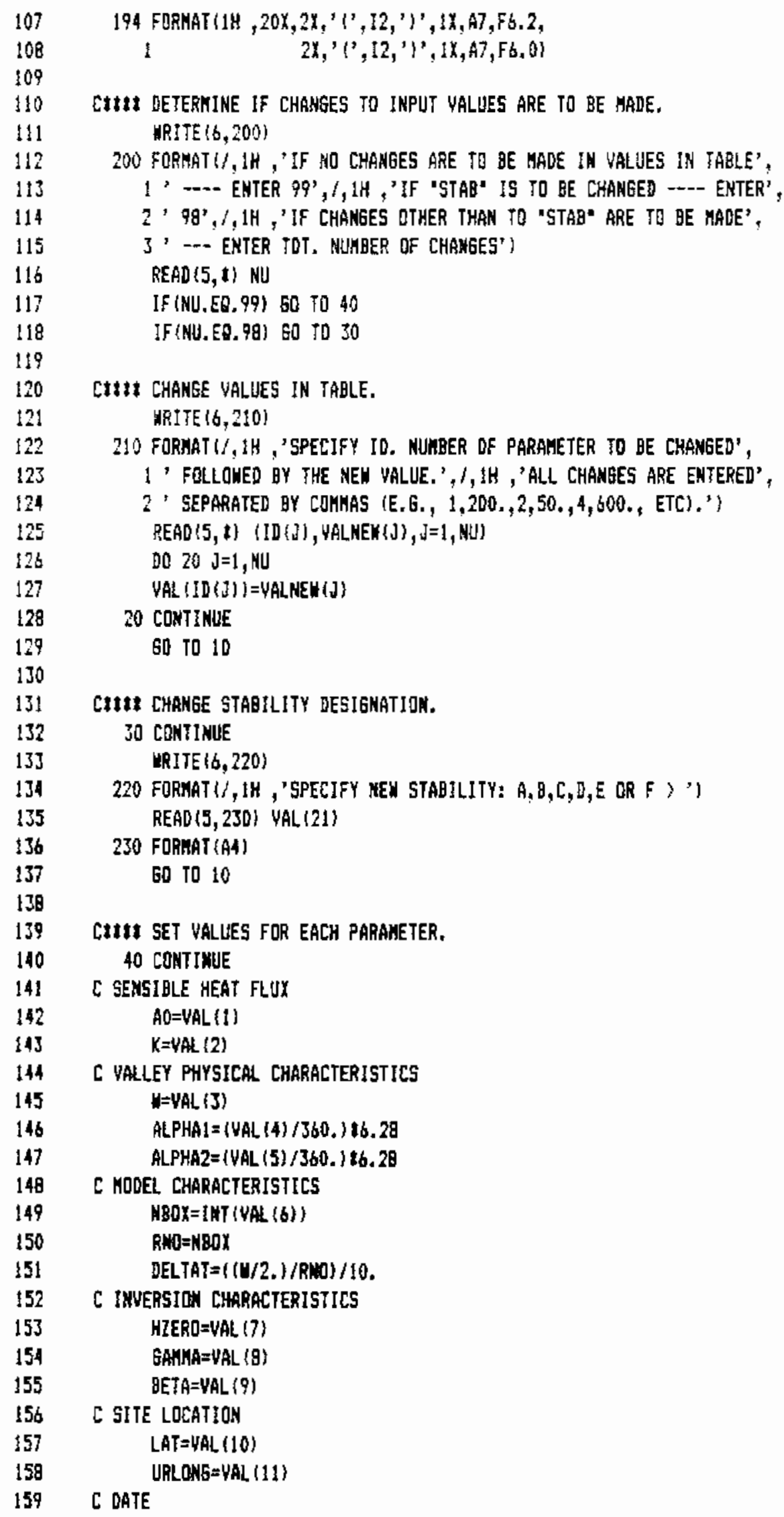

$$
194 \text { FORMAT }\left(1 \mathrm{H}, 20 \mathrm{X}, 2 \mathrm{X},{ }^{\prime}(', 12, ') ', 1 \mathrm{X}, \mathrm{A7}, \mathrm{Fb} .2\right. \text {, }
$$$$
\left.1 \quad 2 X,{ }^{\prime}\left(', 12,{ }^{\prime}\right)^{\prime}, 1 X, A 7, F_{6}, 0\right)
$$

Ett $t$ DETERHINE IF CHAHGES TO INPUT VALUES ARE TO BE MADE, HRITE $(6,200)$

200 FORHAT U, IH, 'IF NO CHANGES ARE TO GE MADE IH VALUES IN TABLE', 1 ' -.- ENTER 99', $/, 14$,'IF 'STAB' IS TO BE CHANGE --- ENTER', 2 ' $99^{\prime}, 1,1 \mathrm{H}$,'IF CHANGES DTHER THAN TO "STAB" ARE TO BE MADE', 3 ' - - ENTER TDT, MUMAER QF CHAH6ES')

READ $\{5, t)$ NU

IF (NU.EQ.99) 50 TO 40

IF (NU.EQ. 98) 60 TO 30

CIII CHANGE VALUES IN TABLE. HRITE $(6,210)$

210 FORMATU/,IH, 'SPECIFY ID. NUMBER DF PARAMETER TO BE CHANGED',

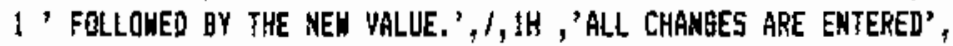
2 ' SEPARATED gY COMHAS (E.G., 1,200.,2,50.,4,600., ETC). ${ }^{3}$ ) READ (5, t) (ID (d), YALAEYY (J), $J=1$, NU)

$0020 \mathrm{~J}=1$, $\mathrm{NU}$ VAL (ID (d) $=$ VALAEH (J)

20 CONTINUE

60 TO 10

Cutt CHANGE STABHLITY DESIGNATIOH.

30 CONTINUE

LRITE $(6,220)$

220 FORNAT (, IH ,'SPECIFY KEN STABILITY: $A, 8,[, B, E$ OR F >') READ (5, 230) YAL (21)

230 FORMAT (A4)

ED TO 10

Cutt SET VALLES FOR EACH PARAMETER.

40 COATIMUE

(C SEMSIBLE HEAT FLUX $A 0=V A L\{1\}$

$K=V A L(2)$

C VALLEY PHYSICAL CHARACTERISTICS $W=$ VAL (J) ALPHA1 $=($ VAL $(4) / 360)$.

ALPHA2 $=$ (VAL (5)/360. $) \div 6.28$

[ MODEL, CHARACTERISTICS HBOX=IHT (VAL (6)) RiNO=NBOX DELTAT $=((U / 2.) / R M) / 10$.

C INUERSIDN CHARACTERISTICS HIERO=VAL (7) GAMMA $=$ VAL (9) DE $T A=V A L(9)$

C SITE LOCATION $\angle A T=W A L(10)$ URLONG=VAL (11)

C DATE 


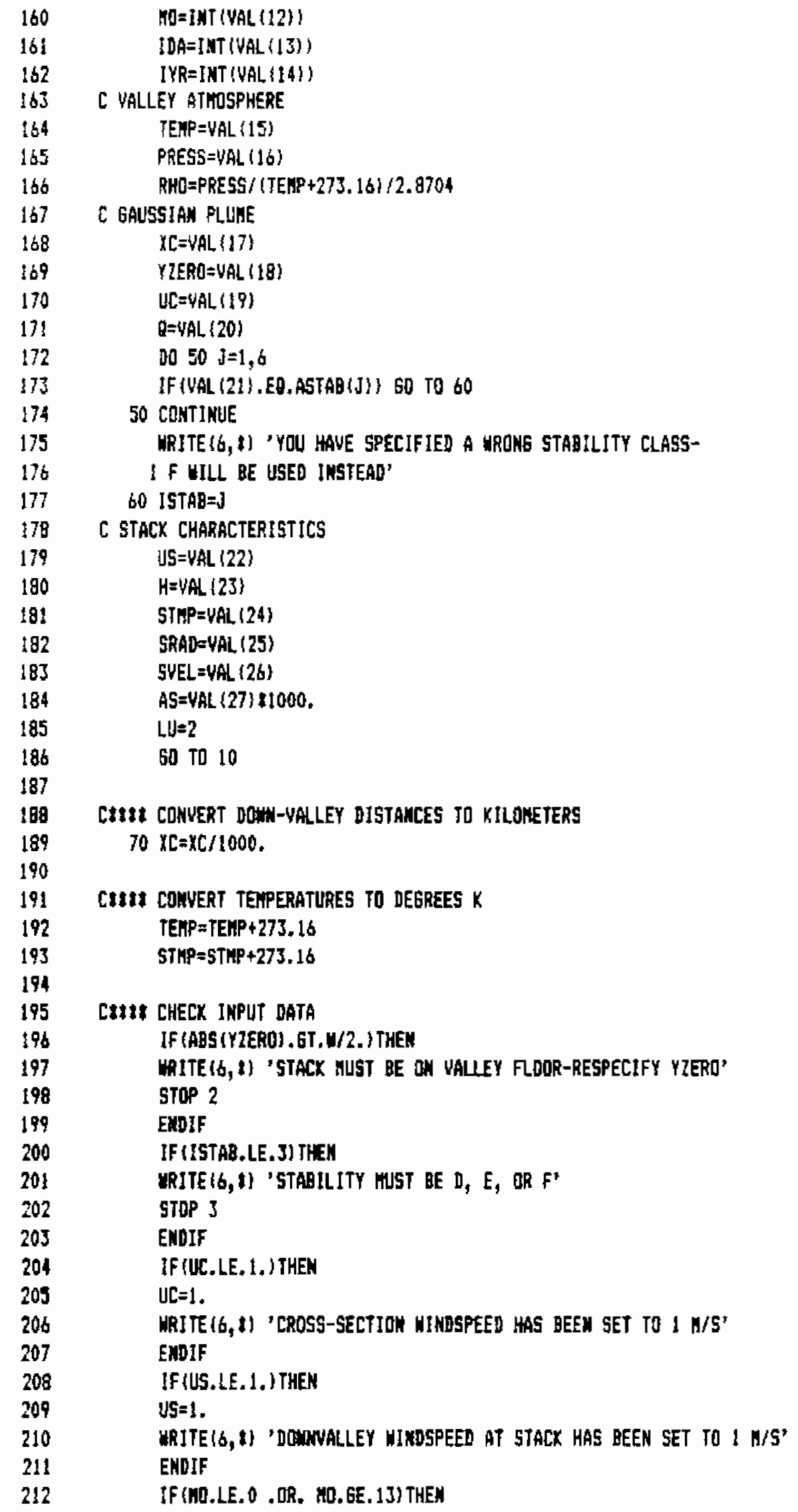




\begin{tabular}{|c|c|}
\hline 213 & MRITE $(b, 2)$ 'MON?H INDEX IS OUT OF RANGE' \\
\hline 214 & stop 5 \\
\hline 215 & ENDIF \\
\hline 216 & IF (IDA.LE.O . DR. IDA.GE.Z2) THEH \\
\hline 217 & HRITE $(b, t)$ 'DAY INDEX IS GUT OF RANGE' \\
\hline 218 & STOP 6 \\
\hline 219 & ENDIF \\
\hline 220 & IFUIYR.ET.99 .OR. IYR.LT.OUTHEN \\
\hline 221 & WRITE $(6,1)$ 'YEAR IS INCQRRECTLY SPECIFIED' \\
\hline 222 & STQP 7 \\
\hline 223 & ENDIF \\
\hline 224 & \\
\hline 225 & RETLRK \\
\hline 226 & END \\
\hline
\end{tabular}




\begin{tabular}{|c|c|c|}
\hline 1 & & SUBROUTINE JULIAR (YO, IDA, IYR, JULDAY) \\
\hline 2 & C & IHIS SUBRDUTINE CALCULATES THE JULIAN DATE GIVEN YHE \\
\hline 3 & c & MONTH, DAY, AND YEAR. \\
\hline 4 & & \\
\hline 5 & & DIMEYSION MDAY(12) \\
\hline b & & \\
\hline 7 & & DATA NDAY/0,31, 59,90,120,151,181,212,243,273,304,334/ \\
\hline a & & \\
\hline 9 & & $J U L D A Y=I D A+H D A Y(M D)$ \\
\hline 10 & c & ADSUST FOR LEAP YEAR \\
\hline $1 !$ & & $A=F L O A T(I Y R) / 4-I Y R / 4$ \\
\hline 12 & & IF (A,EQ, O. .AND. WD.GE.3) JULDAY=JULDAY+1 \\
\hline 13 & & \\
\hline 14 & & RETURN \\
\hline 15 & & END \\
\hline
\end{tabular}




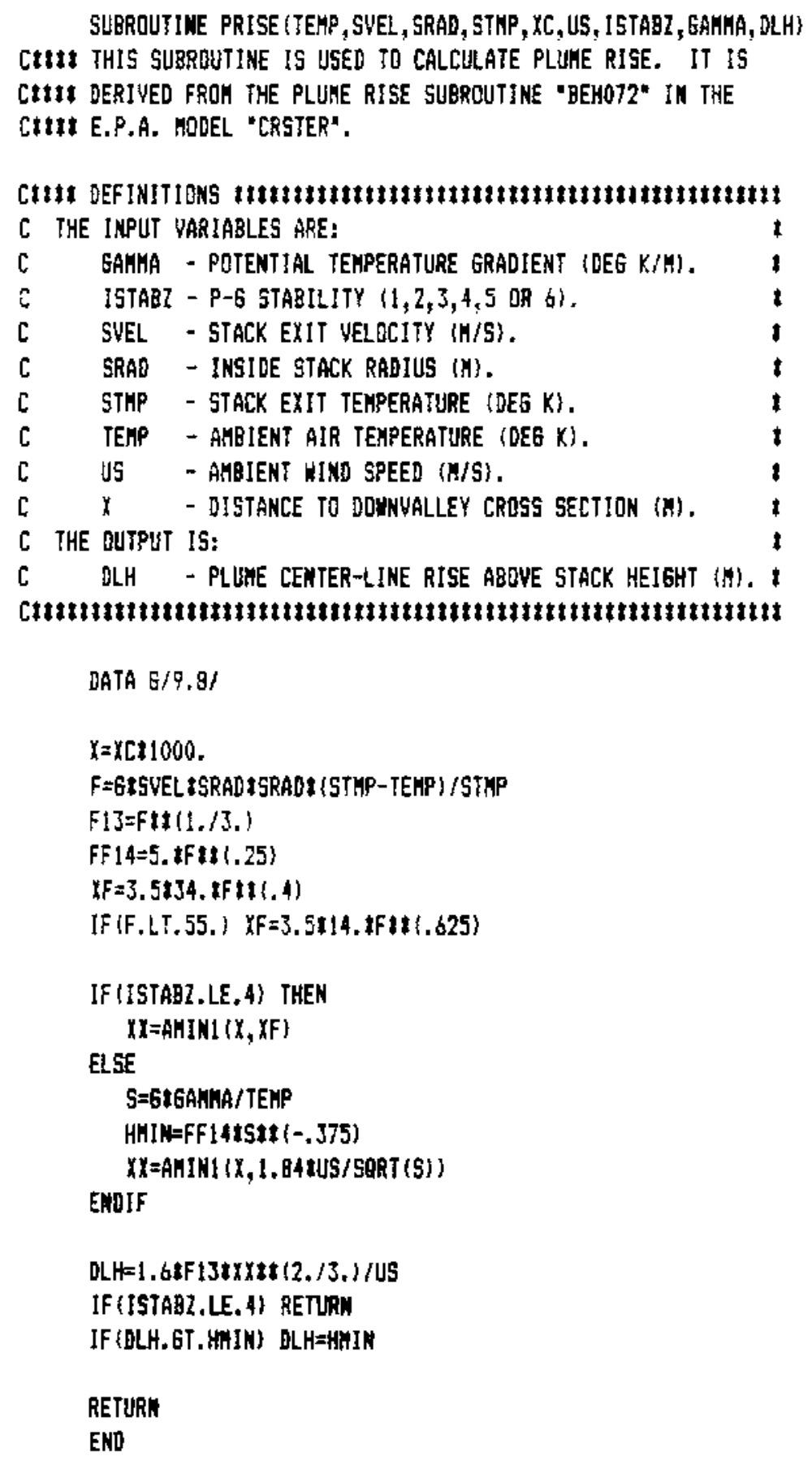




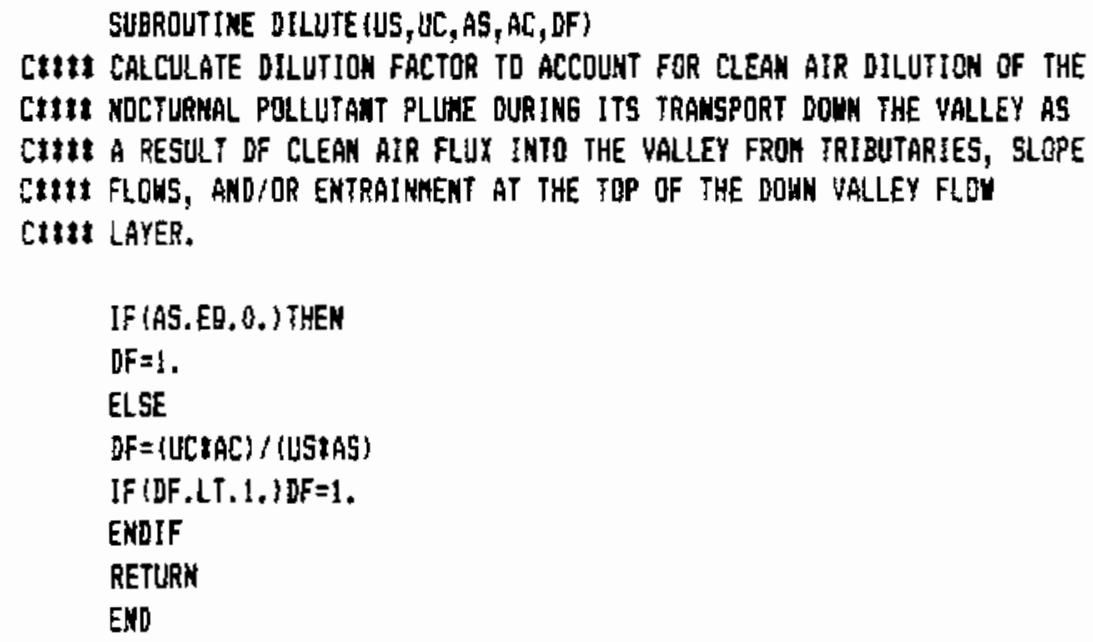




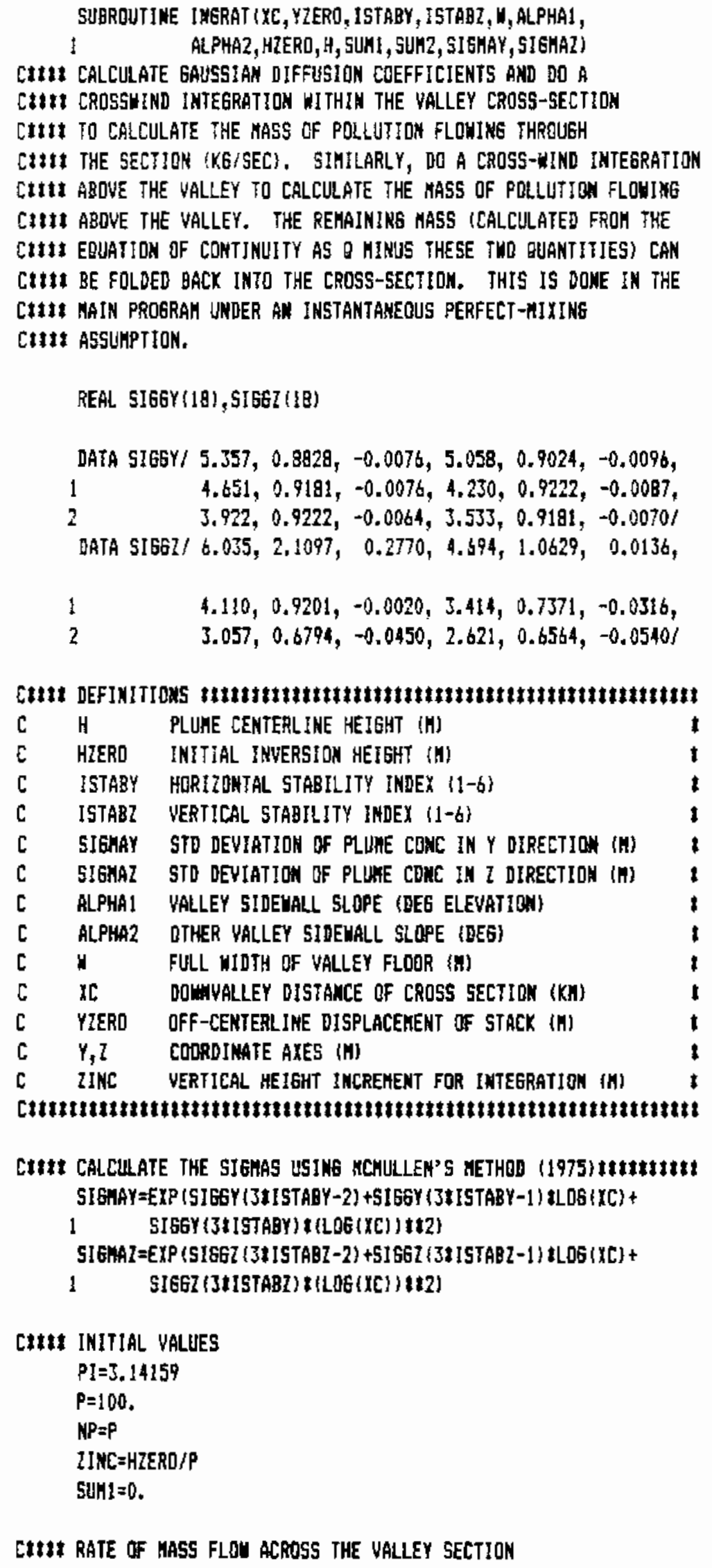

CIt3* RATE OF MASS FLOU ACROSS THE VALLEY SECTION 


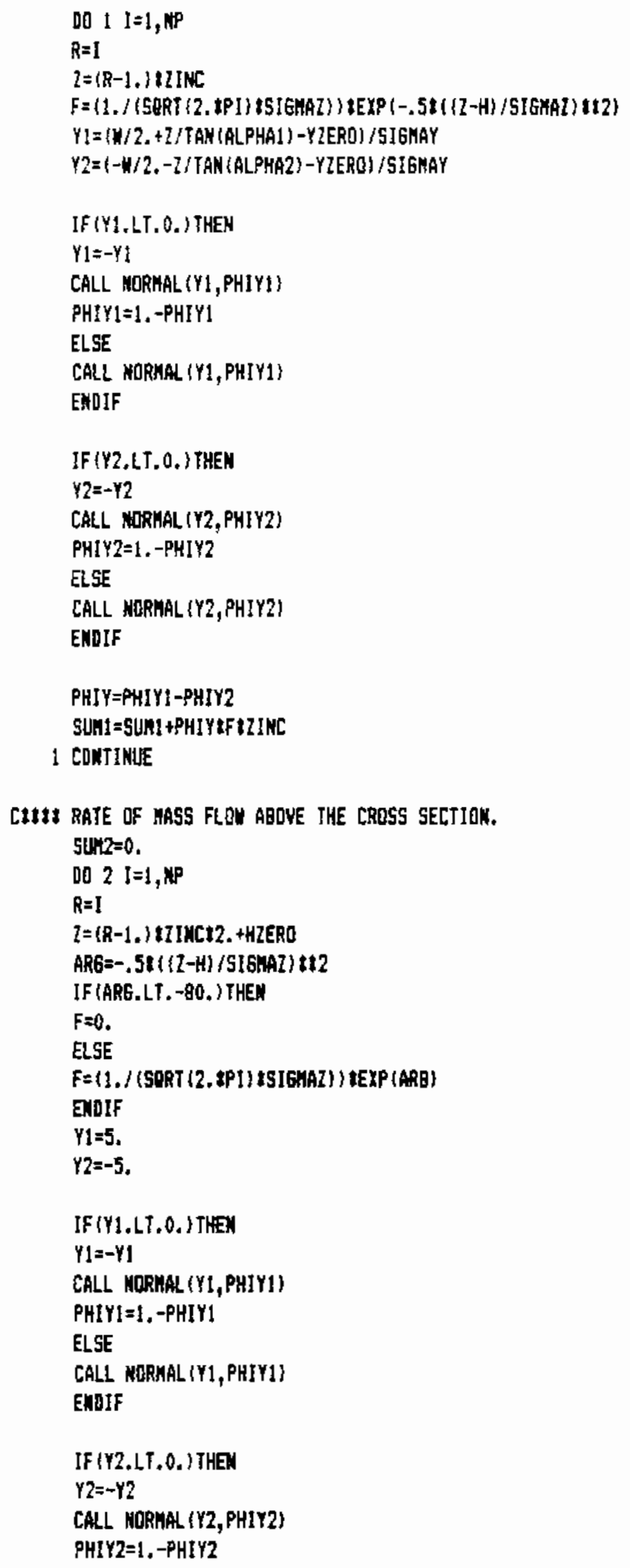




\begin{tabular}{|c|c|}
\hline 107 & ELSE \\
\hline $10 \mathrm{~B}$ & CALL NORNAL (Y2,PHIY2) \\
\hline 109 & ENDIF \\
\hline 110 & \\
\hline 111 & PHIY=PHIY1-PHIY2 \\
\hline 112 & SUMZ $=$ SUM $2+$ PHIYtF $121 M C t 2$. \\
\hline 113 & 2 CONTIMUE \\
\hline 114 & \\
\hline 115 & END \\
\hline
\end{tabular}




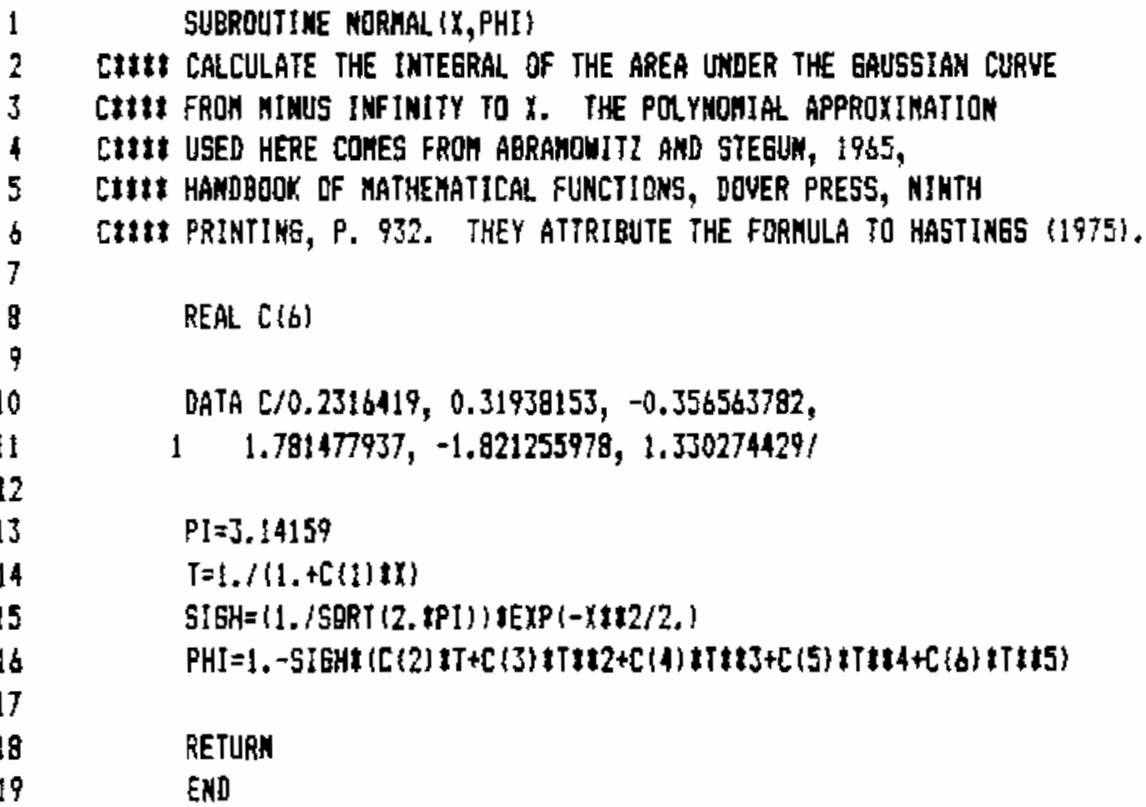




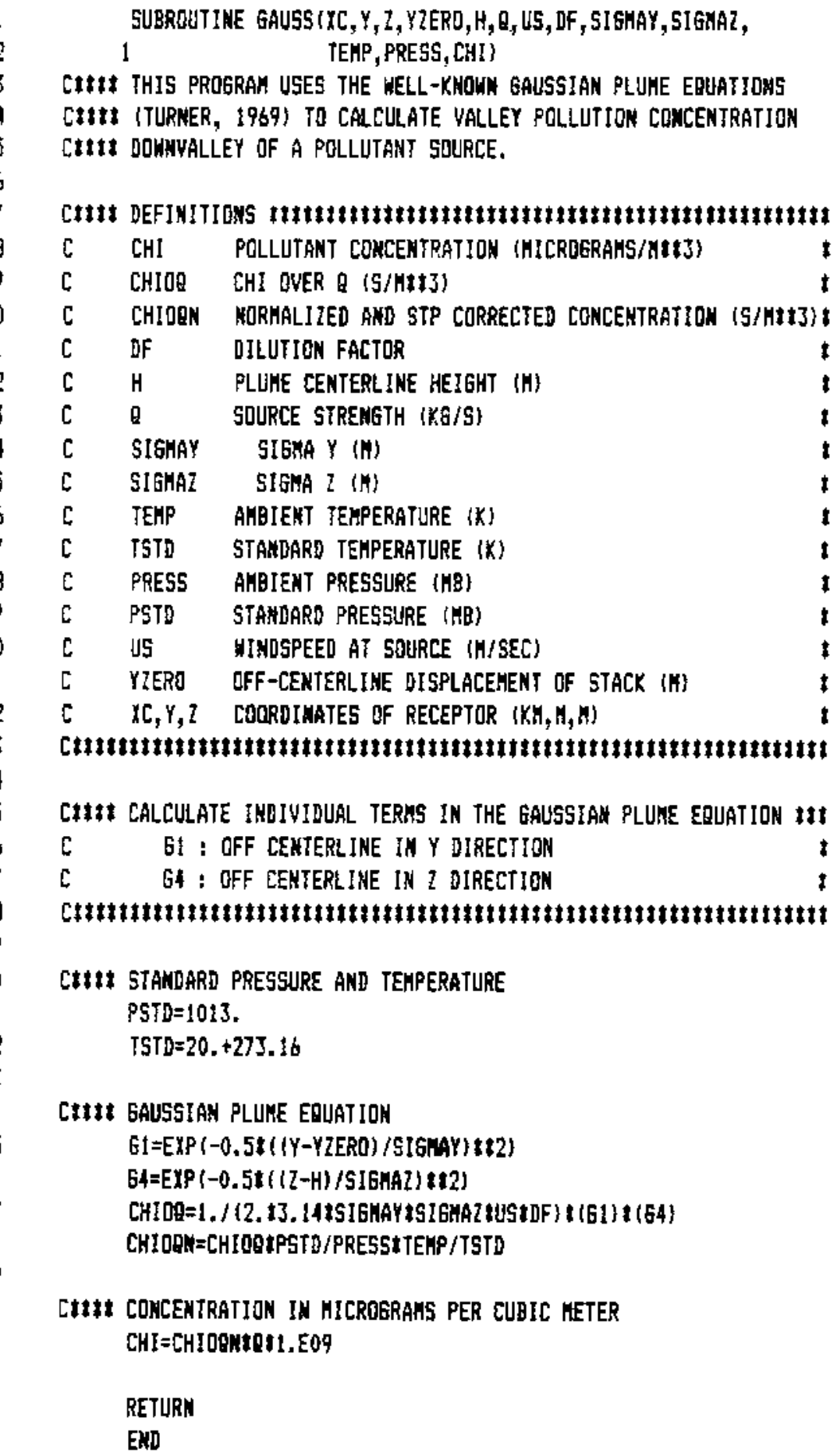




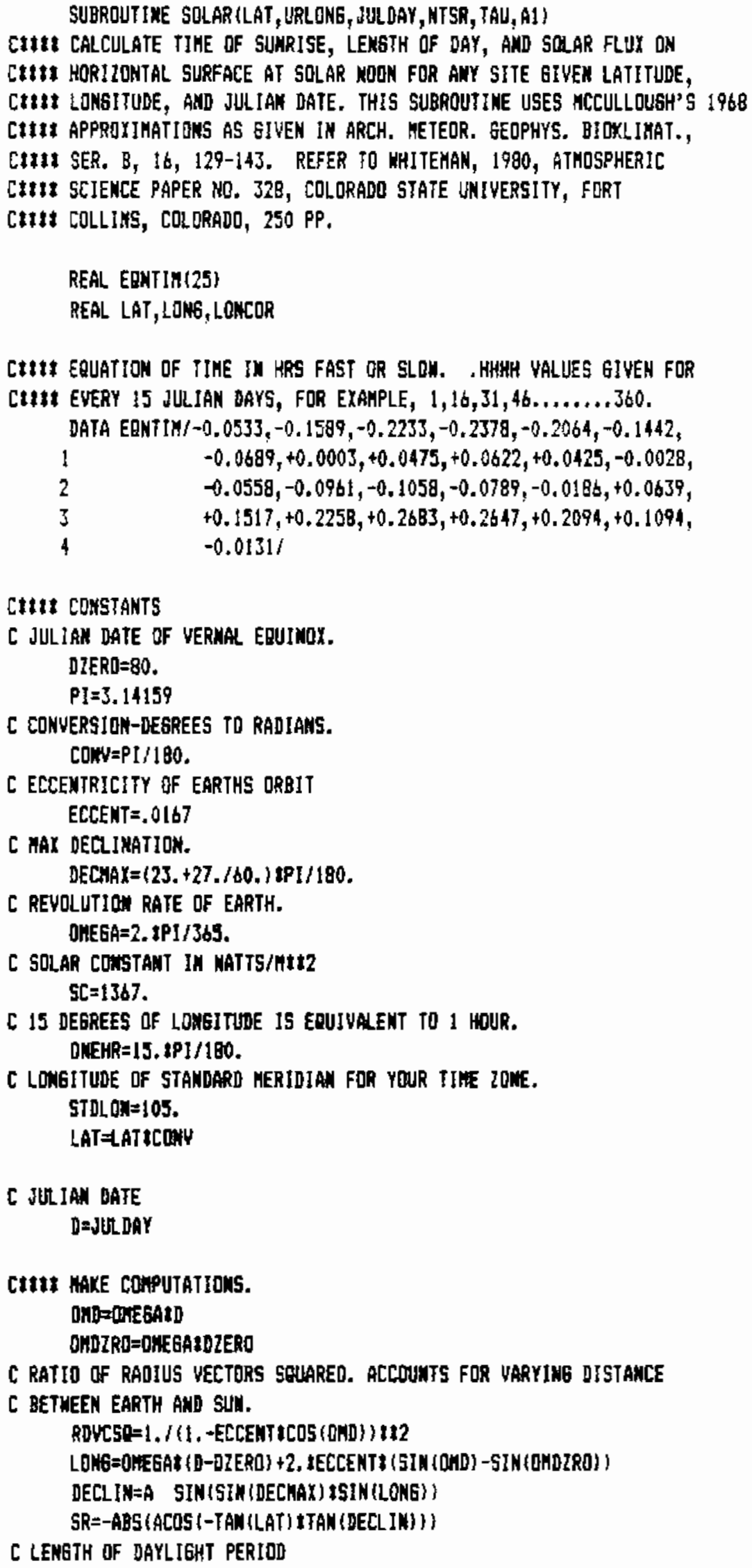




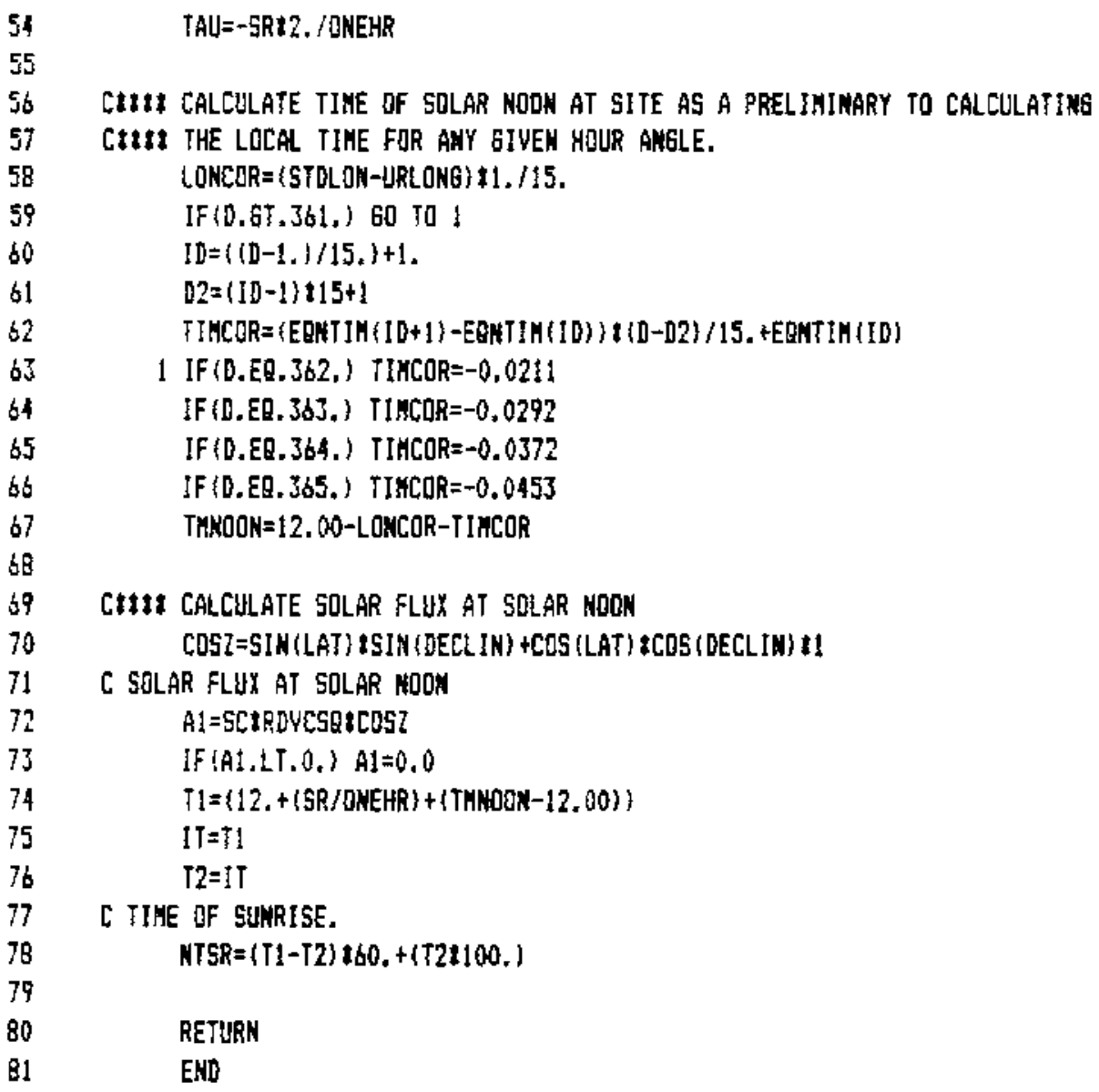

76 


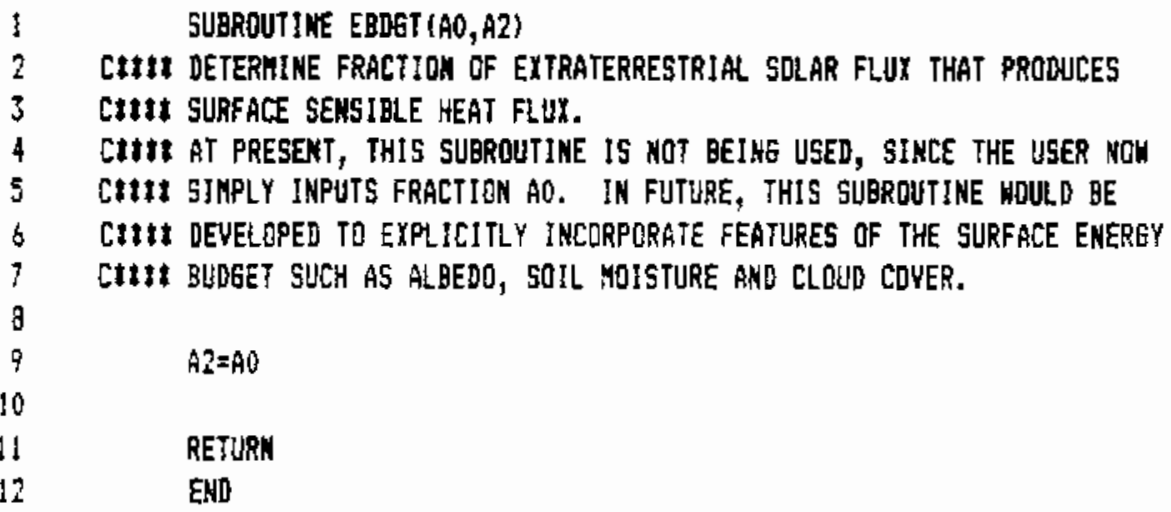




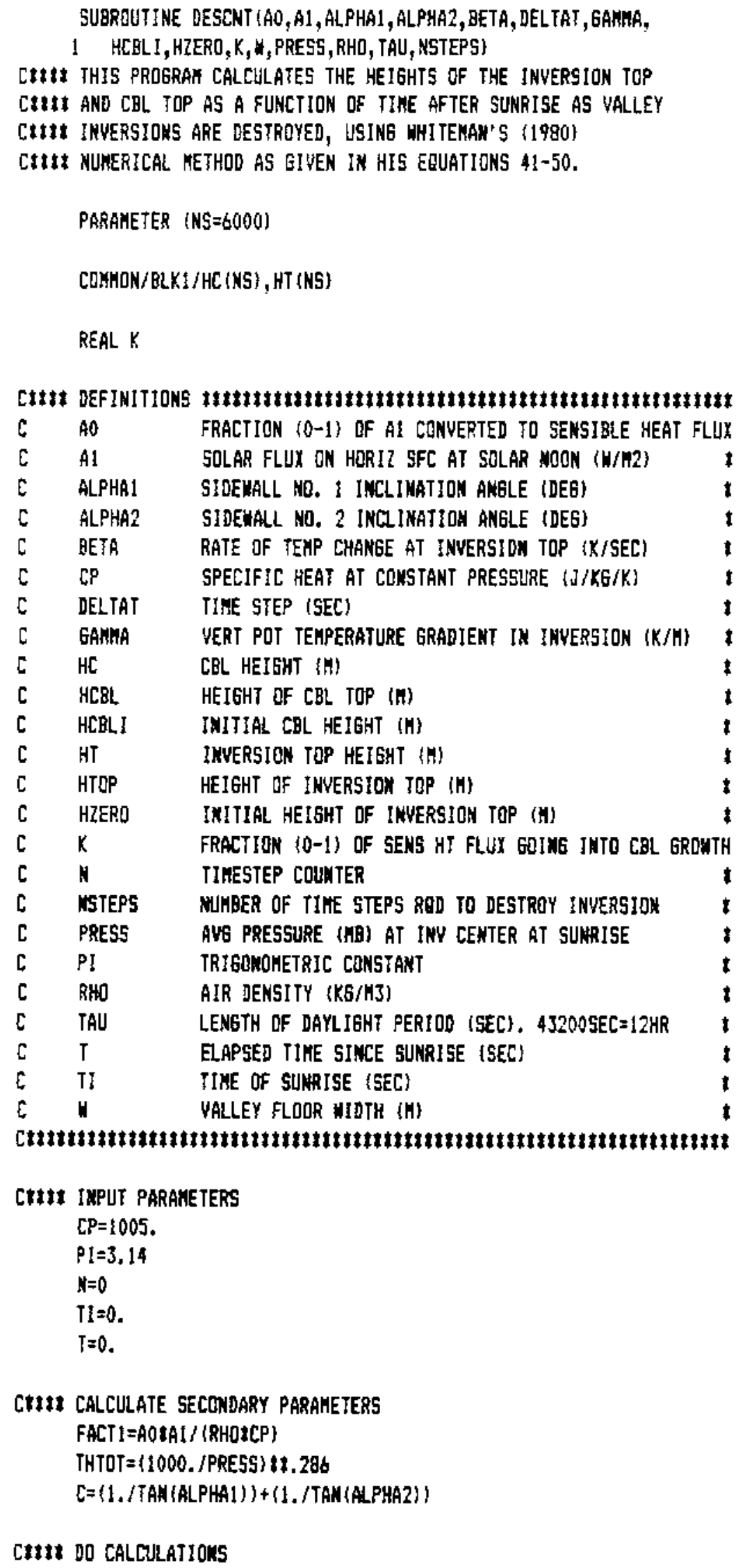




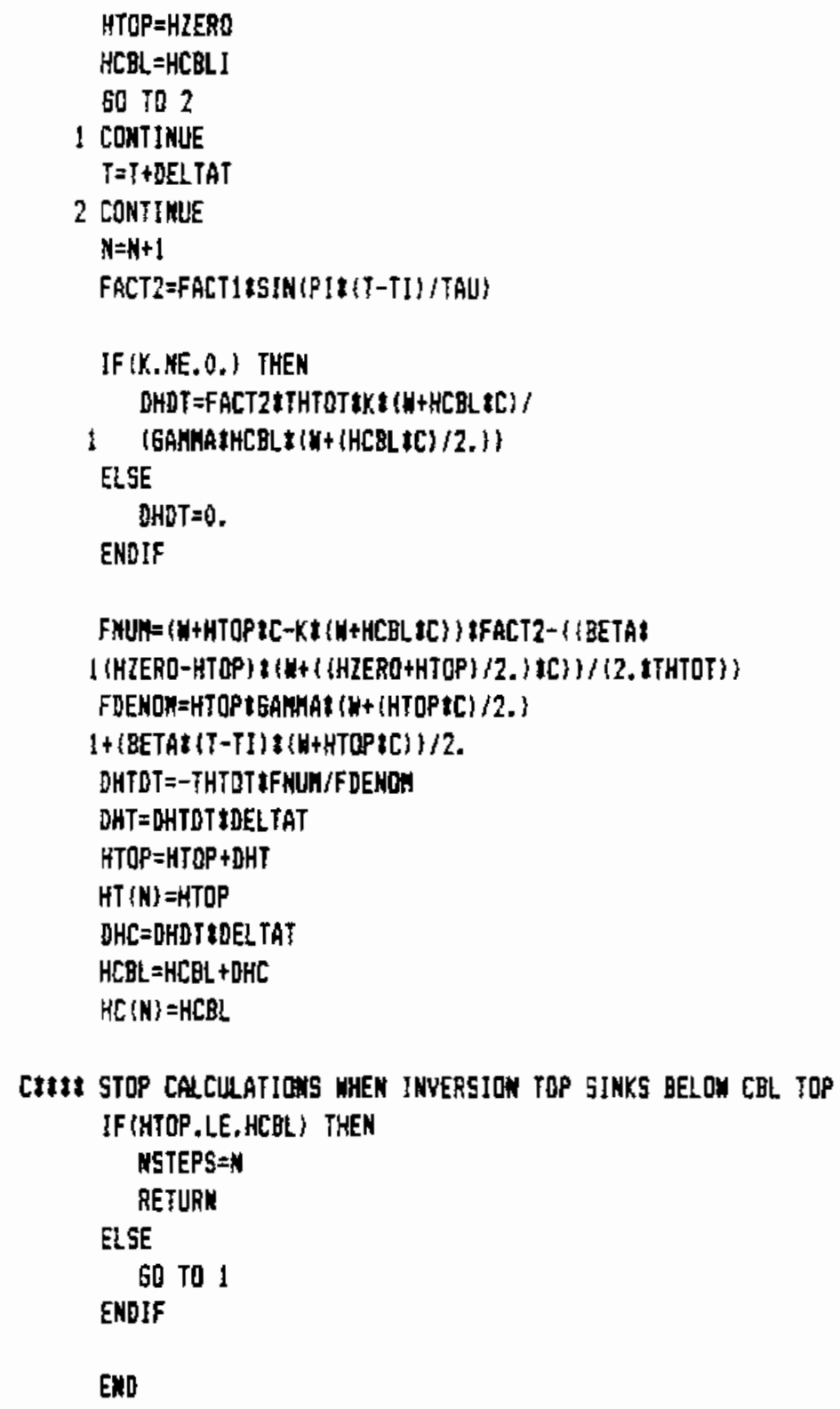




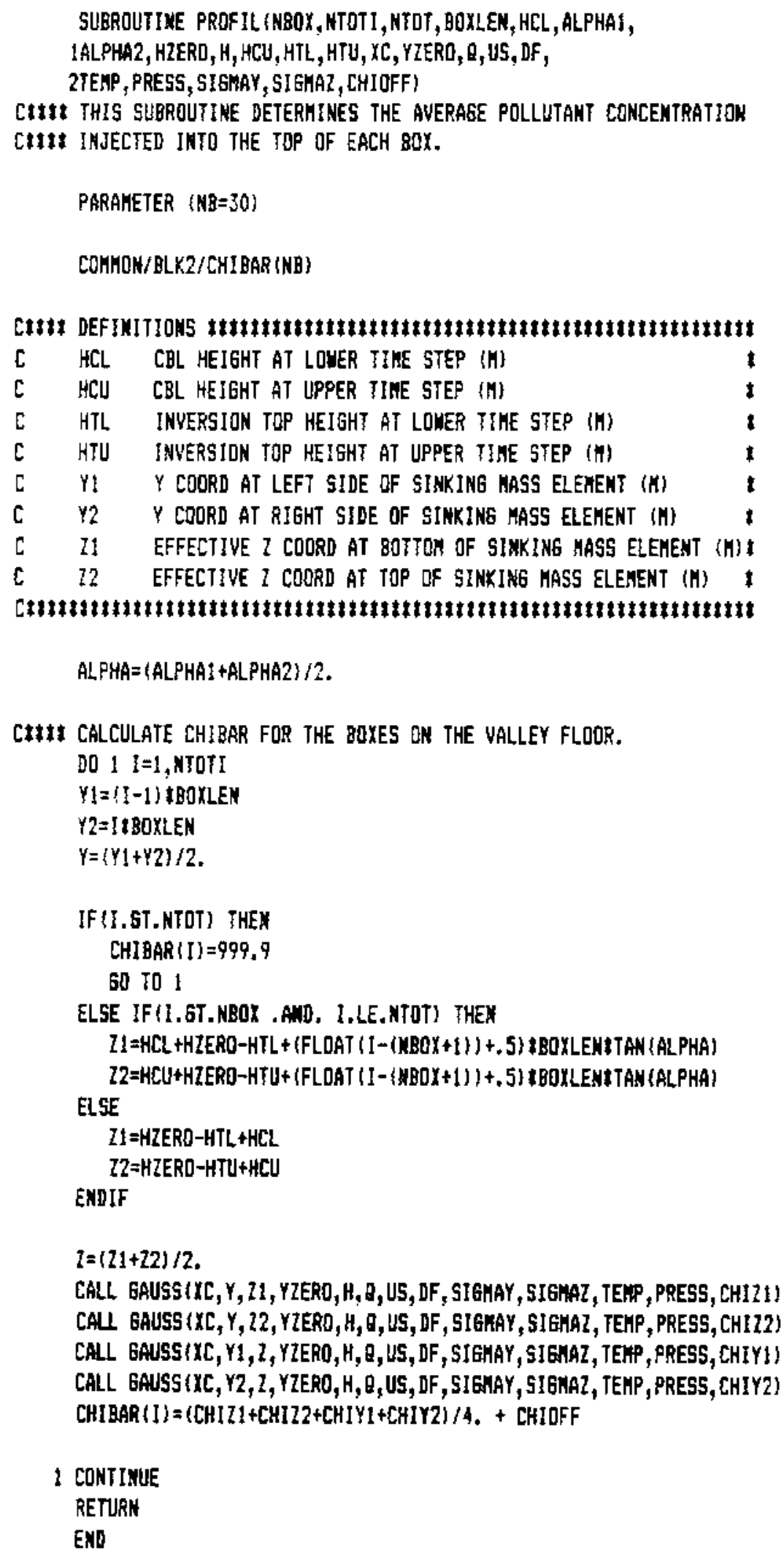




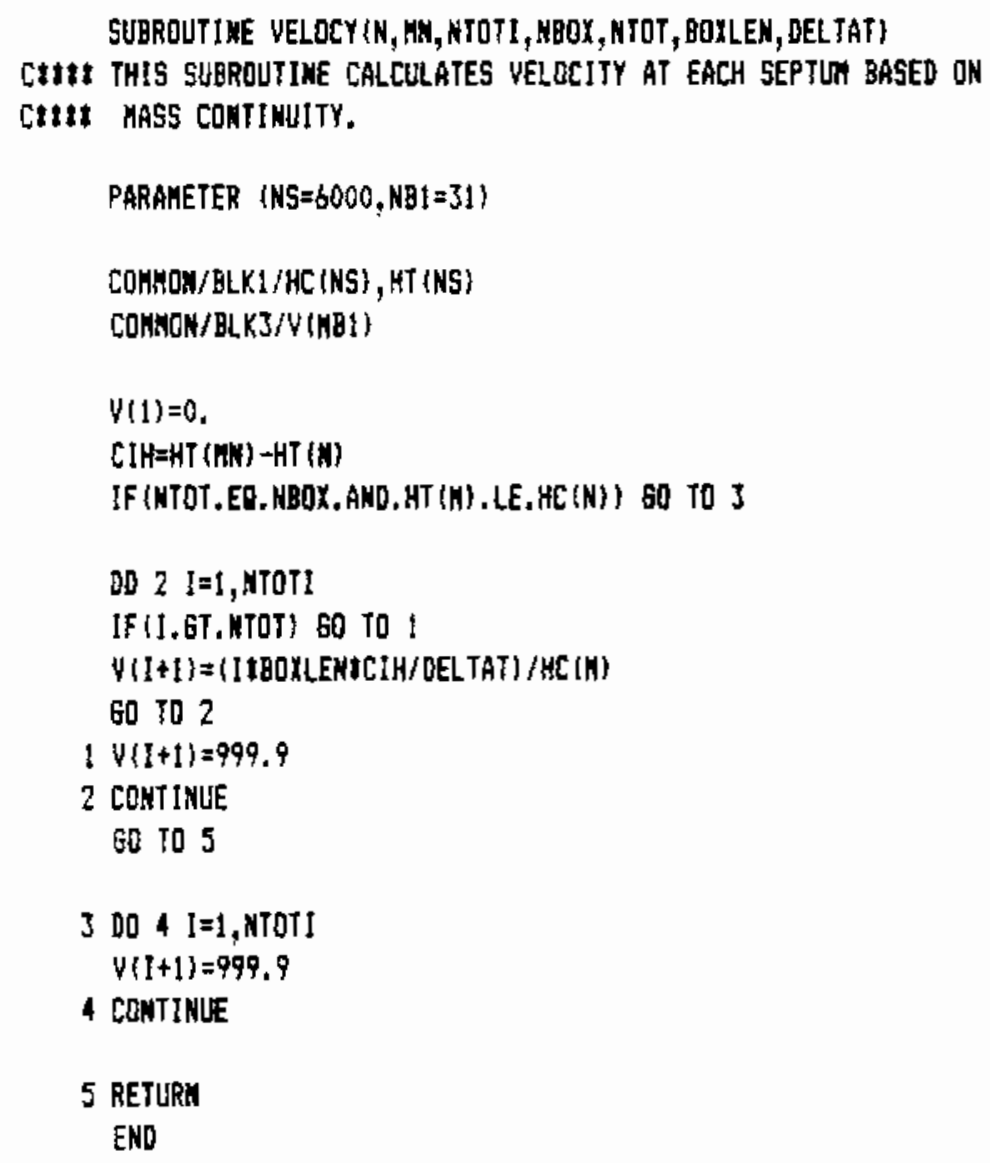




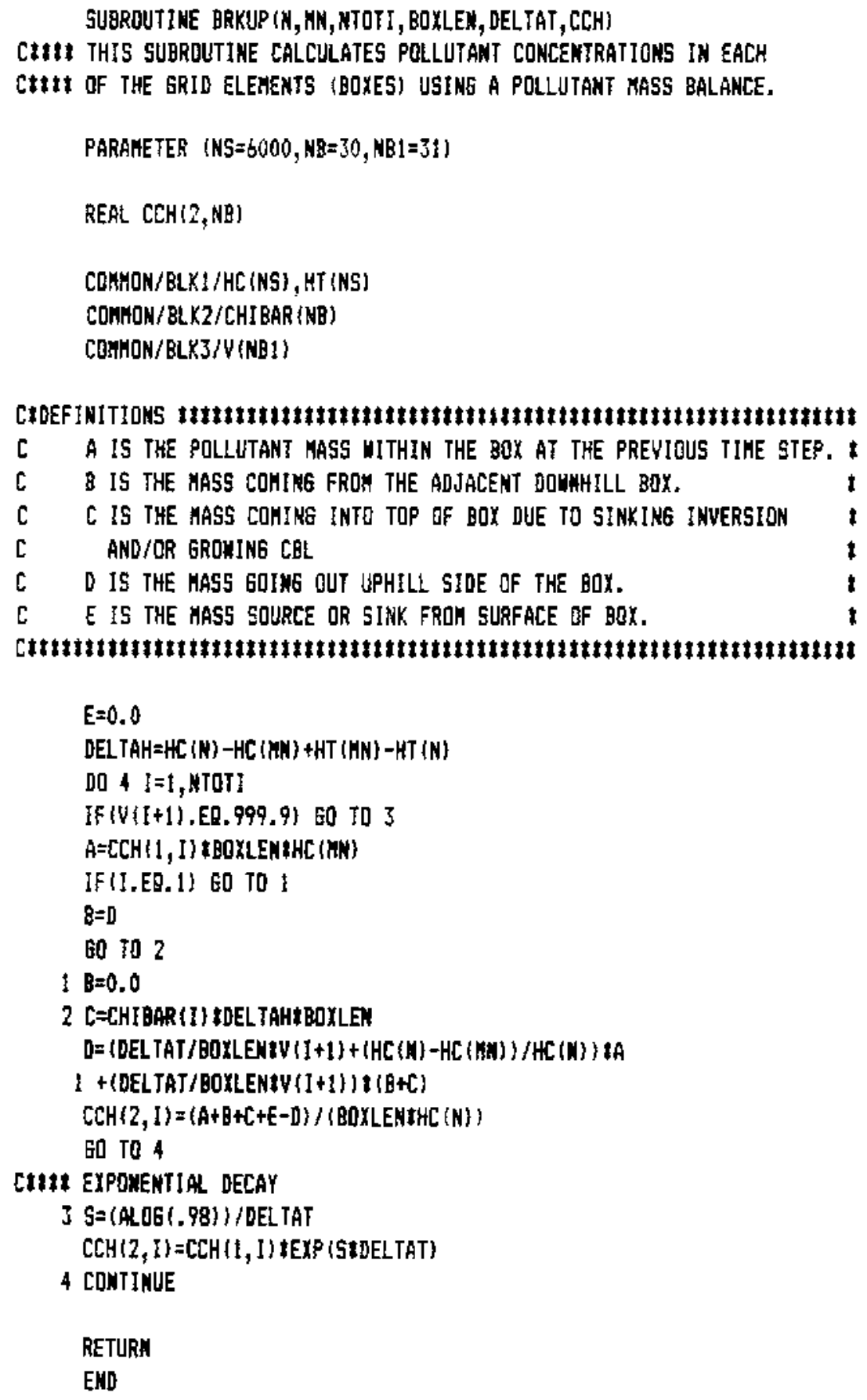




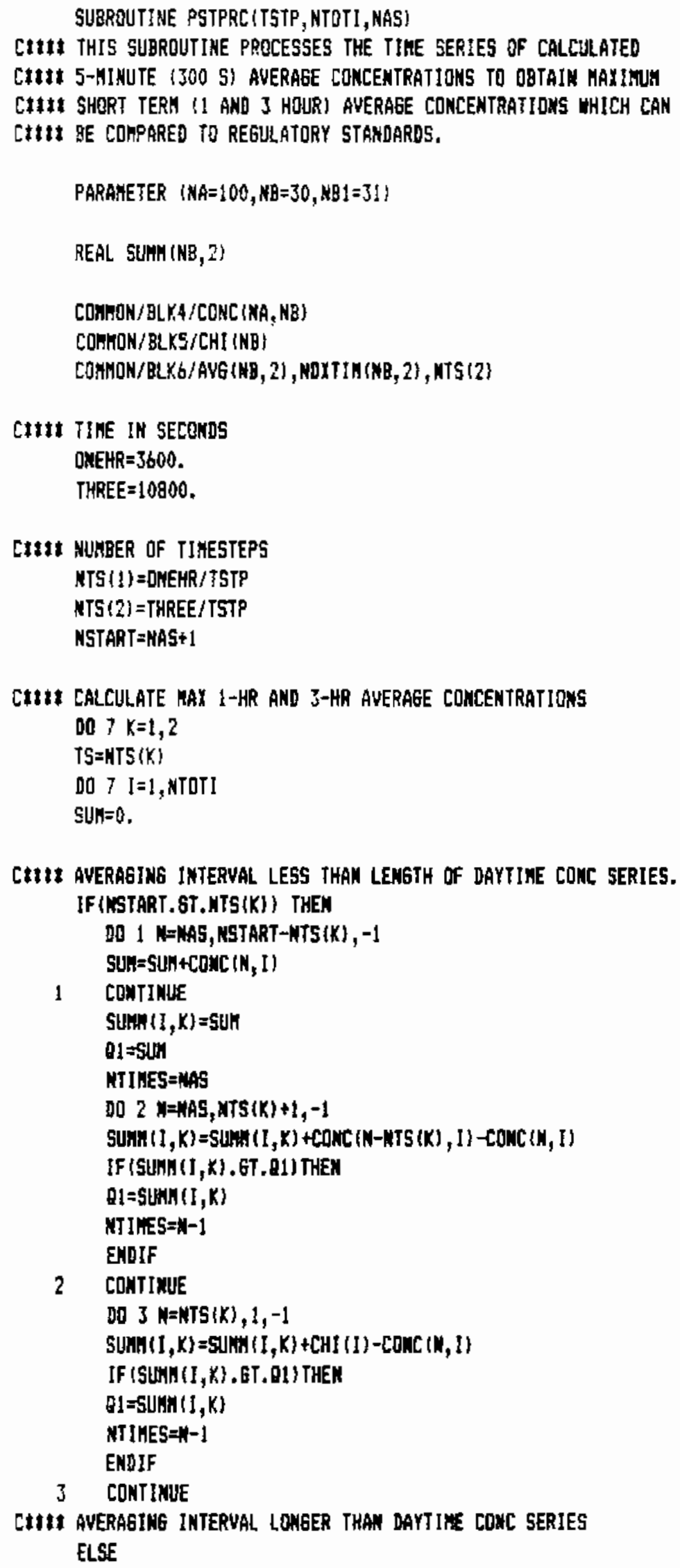




\begin{tabular}{|c|c|c|}
\hline 54 & 4 & DO 5 H=NAS, $1,-1$ \\
\hline 55 & & $S U_{N}=S U H+\operatorname{COKC}(N, 1)$ \\
\hline 56 & 5 & COMTINUE \\
\hline 57 & & SUHA $(I, K)=S U H+C H I(1),(N T S(K)-N A S)$ \\
\hline 58 & & Q1=SUH \\
\hline 59 & & NTIMES $=$ NAS \\
\hline 60 & & DO $6 \mathrm{~N} N=\mathrm{NA5}, 1,-1$ \\
\hline 61 & & SUHA $(I, K)=\operatorname{SUHH}(1, X)+\mathrm{CHI}(\mathrm{I})-\operatorname{CONC}(\mathrm{N}, \mathrm{I})$ \\
\hline 62 & & IF (SUMH $(1, K) .6 T .81\}$ THEN \\
\hline 63 & & $\theta 1=5 \operatorname{LH} H(I, X)$ \\
\hline 54 & & NTIRES $=N-1$ \\
\hline 65 & & ENDIF \\
\hline $6 \hat{6}$ & b & CONTIAUE \\
\hline 67 & \multirow{2}{*}{\multicolumn{2}{|c|}{ ENDIF }} \\
\hline 68 & & \\
\hline 69 & \multicolumn{2}{|c|}{ ROXTIH $(I, X)=N T I M E S$} \\
\hline 70 & \multicolumn{2}{|c|}{ AVS $\{!, K\}=Q I / T 5$} \\
\hline $\begin{array}{l}71 \\
72\end{array}$ & \multicolumn{2}{|c|}{7 CONIIMUE } \\
\hline 73 & \multicolumn{2}{|c|}{ RETURN } \\
\hline 74 & \multicolumn{2}{|c|}{ END } \\
\hline
\end{tabular}


APPENDIX B

FORTRAN LISTING OF VALMET OUTPUT PLOTTING PROGRAM 


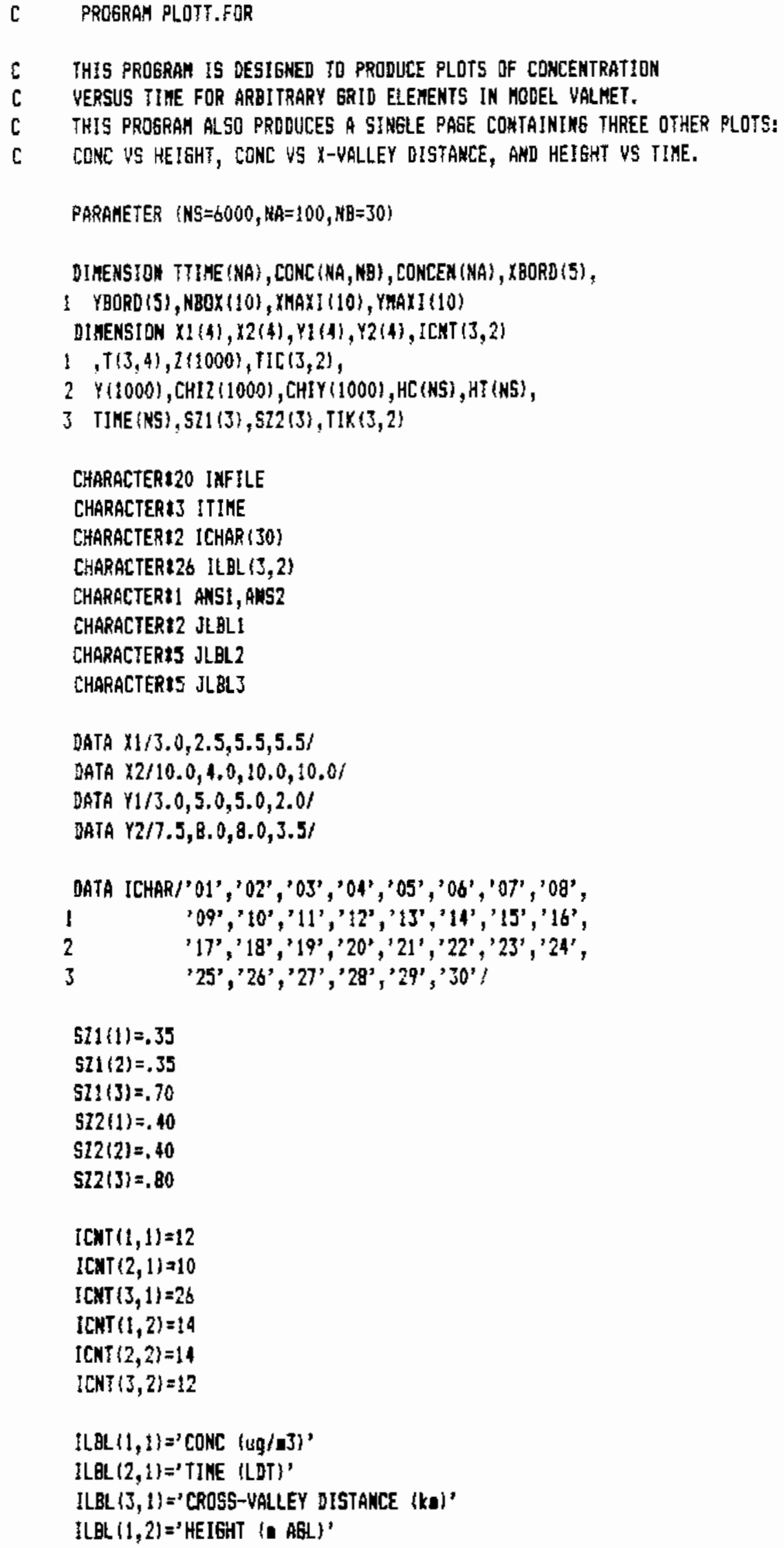




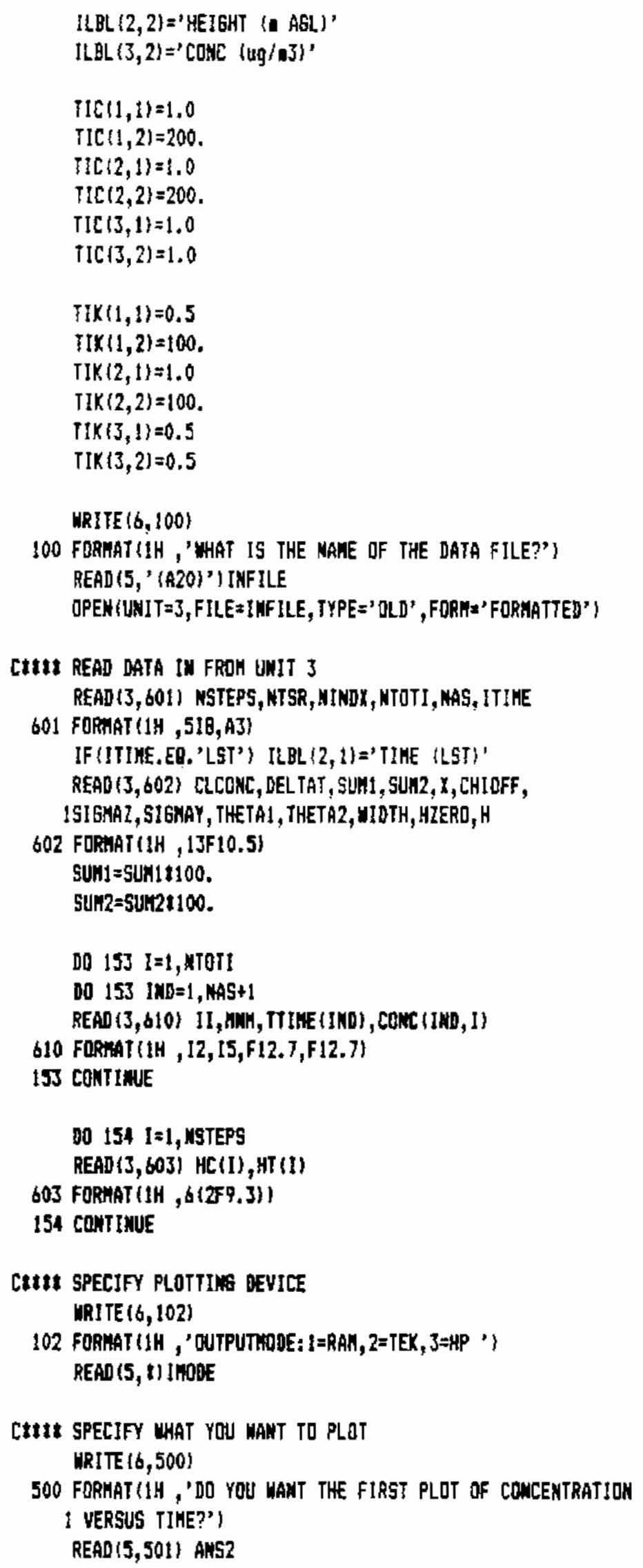




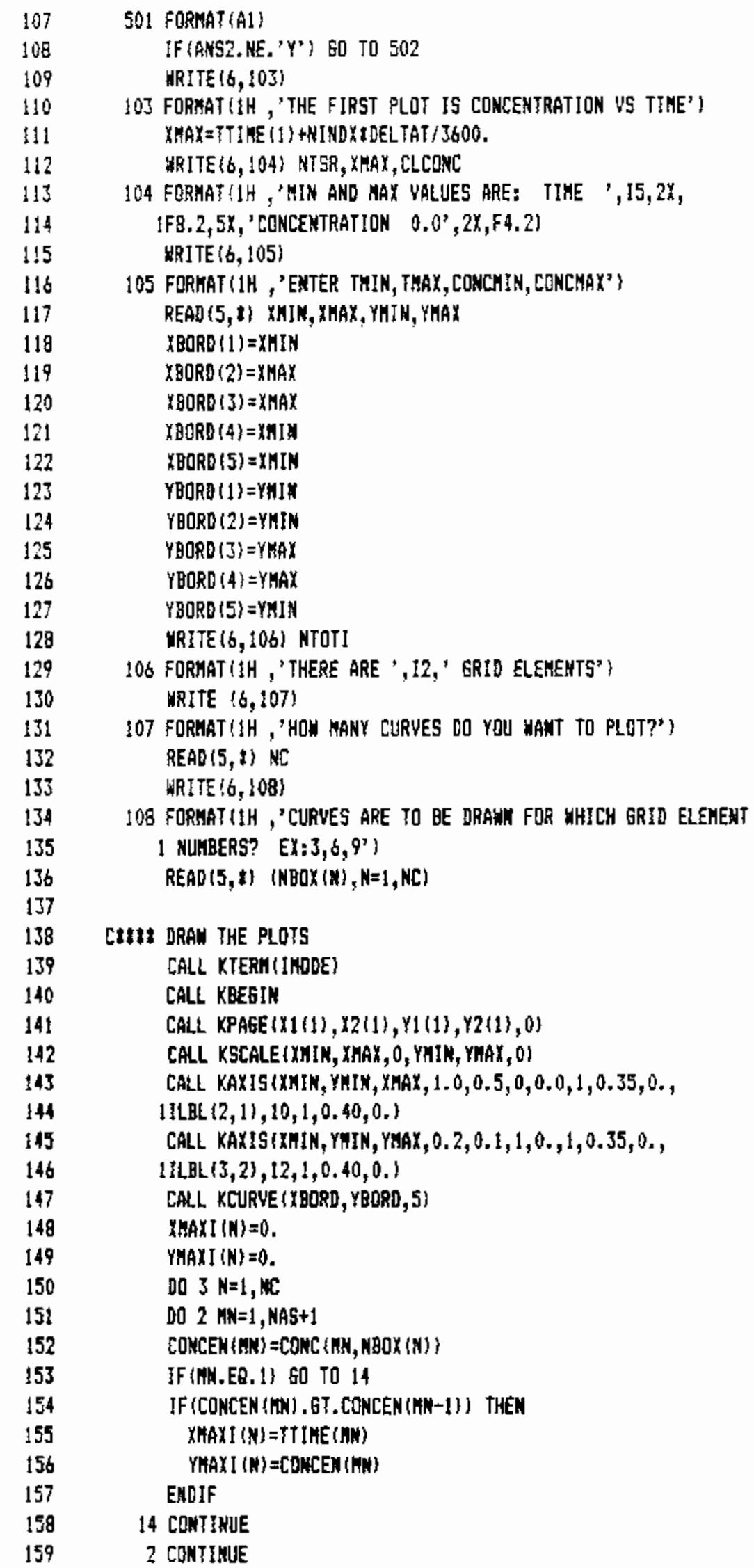




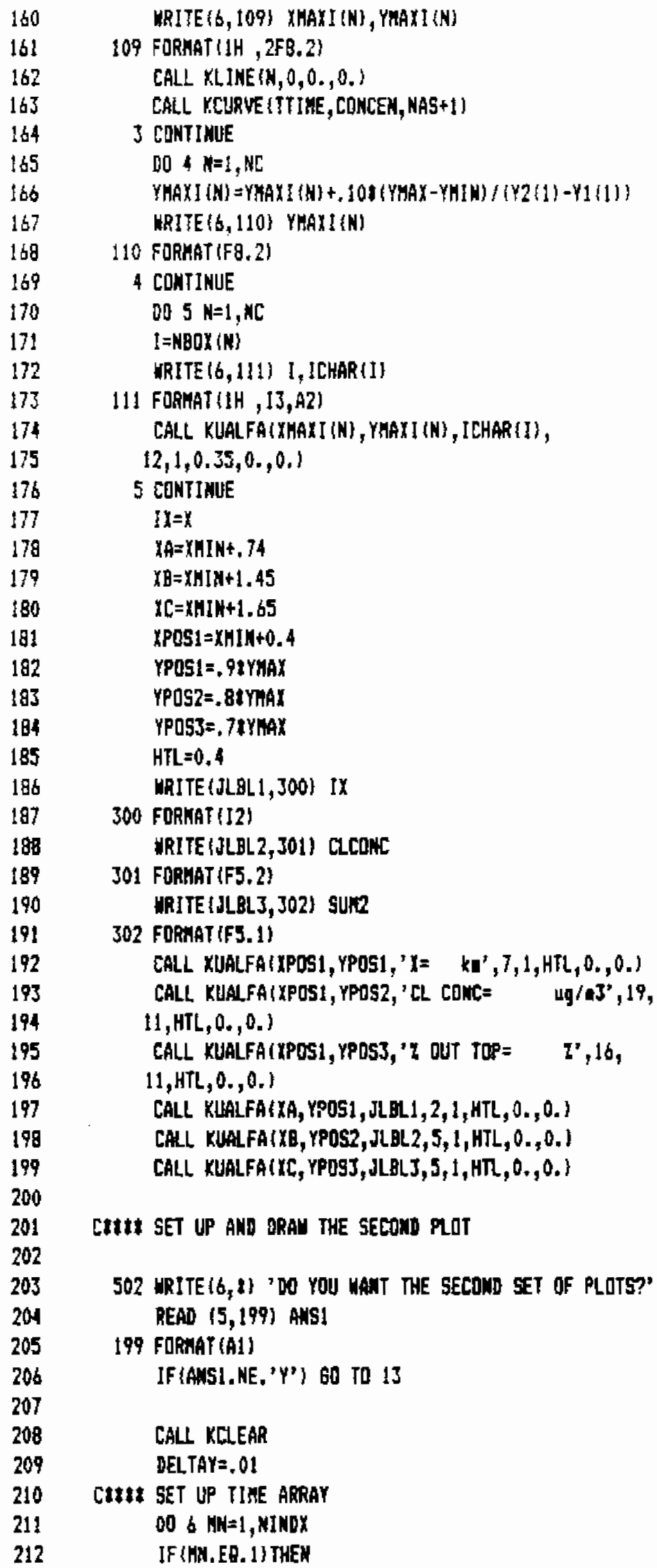




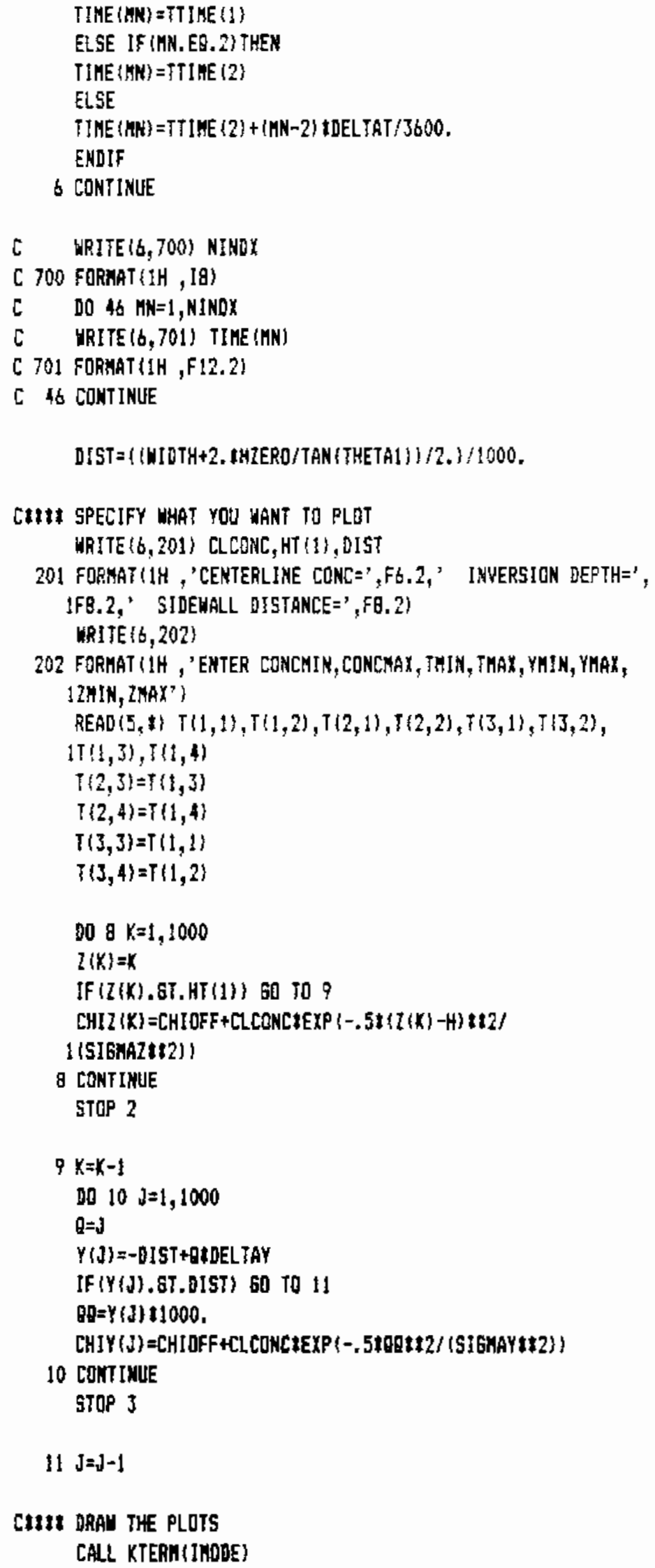




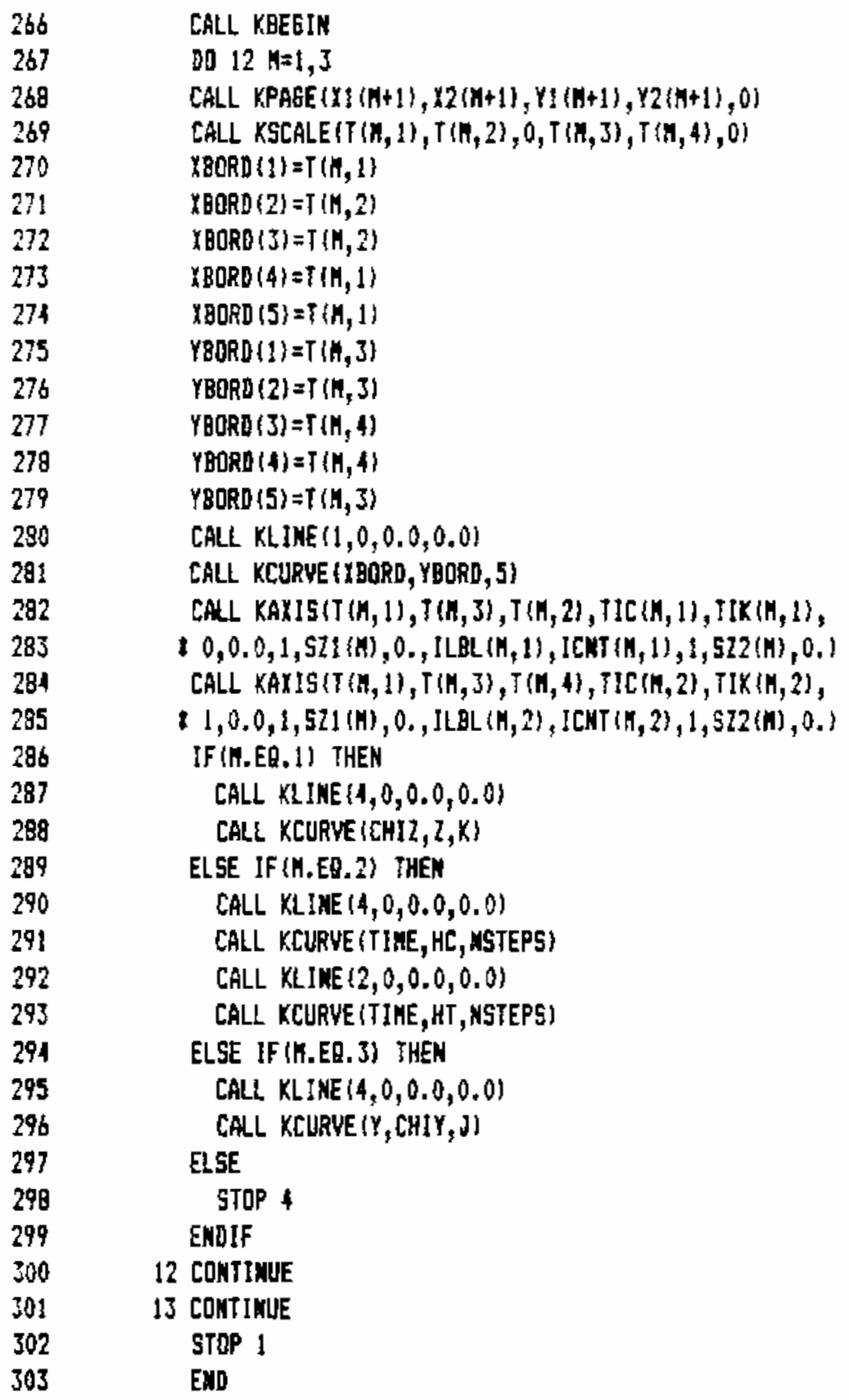




\section{APPENDIX C \\ RESEARCH PAPER ENTITLED "BREAKUP OF TEMPERATURE INVERSIONS IN DEEP MOUNTAIN VALLEYS: \\ PART II. THERMODYNAMIC MDOEL"}


Reprinted from Jouamal of Applied Metgorolooy, Yoi. 21, No. 3, March 1982

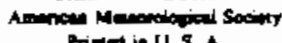

Primed in U. I A

Breakup of Temperature Inversions in Deep Mountain Valleys:

Part II. Thermodynamic Model

C. David Whiteman

ThOMAS B. MCKeE 


\title{
Breakup of Temperature Inversions in Deep Mountain Valleys: Part II. Thermodynamic Model
}

\author{
C. DAVID WhITEMAN \\ Pacific Northmest Laboratory. Richland, WA 99352
}

Thomas B. MCKeE

Department of Atmospheric Science, Colorado State University. Fort Collins 80523

(Manuscript received 31 March 1981, in final form 7 December 1981)

ABSTRACT

\begin{abstract}
A thermodynamic model is developed to simulate the evolution of vertical temperature structure during the breakup of nocturnal temperature inversions in mountain valleys. The primary inputs to the model are the valley floor width, sidewall inclination angles, characteristics of the valley inversion at sunrise, and an estimate of sensible heat flux obtained from soiar radiation calculations. The outputs, obtained by a numerical integration of the model equations, are the time-dependent height of a convective boundary layer that grows upward from the valley foor after sunrise, the height of the inversion top, and vertical potential temperature profiles of the valley atmosphere. The model can simulate the three patterns of temperature structure evolution observed in deep valleys of western Colorado. The well-known inversion breakup over flat terrain is a special case of the model. for which valley floor width becomes infinite. The characteristics of the model equations are investigated for several limiting conditions using the topography of a reference valley and typical invergion and solar radiation characteristics. The model is applied to simulate observations of inversion breakup taken in Colorado's Eagle and Yampa Valleys in different seasons. Simulations are obtained by fitting two constants in the model, relating to the surface energy budget and energy partitioning, to the data. The model accurately simulates the evolution of vertical potential temperature profiles and predicts the time of inversion destruction.
\end{abstract}

\section{Introduction}

In Part I (Whiteman, 1982) observations of vertical temperature structure and wind evolution were summarized for 21 case studies of nocturnal temperature inversion breakup in deep Colorado mountain valleys. Breakup occurred following one of three patterns of vertical temperature structure evolution. A hypothesis was offered to explain the observations in which sensible heat flux was the driving force and one of the three patterns occurred, depending on whether the sensible heat flux was used primarily to cause convective boundary layers (CBLs) to grow over the valley floor and sidewalls (Pattern 1), to remove mass from the inversion in the upsiope flows (Pattern 2), or to accomplish both (Pattern 3). In Part II, a bulk thermodynamic model of temperature inversion destruction is developed based on the hypothesis, using several simplifying assumptions.

\section{Mathematical model of inversion destruction}

a. General equations

Two approaches can be used to develop a mathematical model able to simulate temperature changes in the valley atmosphere. In the first approach detailed mathematical equations can be developed for the individual components of the overall system, including the various boundary layers and stable core. However, the valley atmosphere consists of many interrelated layers, and the coupling of the equations for the different layers to simulate potential temperature changes in the valley atmosphere as a whole would be difficult due to geometrical considerations and lack of detailed information on physical characteristics of the various layers. Consequently, a second approach is taken in which a bulk thermodynamic model is developed for the valley inversion. As more is learned about the individual components of the system, the model can be refined to introduce greater detail into the simulation of the individual components.

The thermodynamic model of valley temperature structure evolution developed here is based on the hypothesis of Part I. Fig. I shows a unit thick cross section of a mountain valley having sidewalls of inclination $\alpha_{1}$ and $\alpha_{2}$ and valiey foor width $l$. At sunrise $\left(t_{i}\right)$ the valley is assumed to have an inversion of depth $h_{l}$ and constant vertical potential temperature gradient $\gamma$. The variable width of the valley at the 

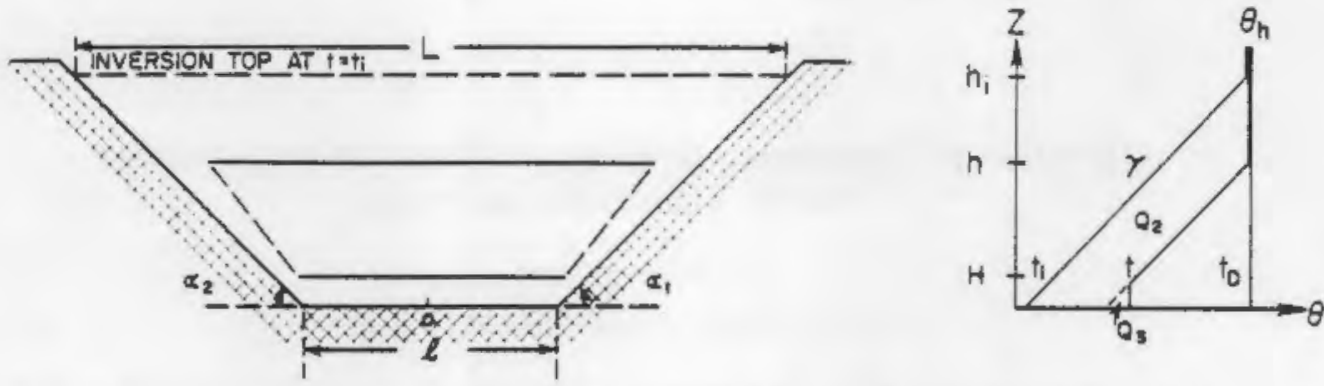

FIG. 1. Valley geometry and potential temperature profiles used to formulate a mathematical model of inversion destruction.

top of the inversion is designated by $L$, and the origin of a $y-z$ coordinate system is placed at the center of the valley floor at point 0 . After sunrise a typical Pattern 3 potential temperature evolution ensues, in which a CBL develops over the valley floor and sidewalls. Removal of mass from the valley in these CBLs allows the stable core to sink so that a sounding taken at an arbitrary later time $t$ will show a lower inversion top height $h(t)$ and a shallow CBL of height $H(t)$ near the ground. A later sounding, taken at a time $t_{D}$ when the inversion has just been destroyed, will show a neutral atmosphere having a potential temperature $\theta=\theta_{h}$.

From the first law of thermodynamics, the increment of energy required to increase the potential temperature of a mass of air $m$ by the potential temperature increment $\Delta \theta$ is

$$
\Delta Q=m c_{p} \frac{T}{\theta} \Delta \theta=\rho V c_{p} \frac{T}{\theta} \Delta \theta,
$$

where $T / \theta=(P / 1000)^{R / c}, \approx 1, \rho$ is the density (assumed constant) and $V$ is volume. Using (1), the energy required to change the valiey potential temperature profile at time $t_{t}$ to the profile at time $t$ can be obtained by an integration over the valley volume below the height of the inversion top. The total energy requirement is composed of two parts: the energy increment $Q_{2}$ that removes mass from the valley and allows the top of the inversion to sink, and the energy increment $Q_{3}$ that causes a CBL to grow. These energies are represented by the areas designated in Fig. I and are given by

$$
\begin{aligned}
Q_{2} & =\rho c_{p} \frac{T}{\theta}\left[\int_{0}^{h_{1}} \int_{\nu_{L}}^{y k} \int_{0}^{1} \Delta \theta_{i} d x d y d z\right. \\
& \left.-\int_{0}^{\omega} \int_{y_{L}}^{y \pi} \int_{0}^{1} \Delta \theta_{1} d x d y d z\right], \\
& =\rho c_{p} \frac{T}{\theta} \gamma\left[\frac{l}{2}\left(h_{i}^{2}-h^{2}\right)+\frac{C}{6}\left(h_{i}^{3}-h^{3}\right)\right],
\end{aligned}
$$

where

$$
\omega_{i}=\gamma\left(h_{i}-z\right)
$$

$$
\begin{aligned}
y_{L} & =-\left(\frac{l}{2}+\frac{z}{\tan \alpha_{2}}\right), \\
y_{R} & =\frac{l}{2}+\frac{z}{\tan \alpha_{1}}, \\
C & =\frac{1}{\tan \alpha_{1}}+\frac{1}{\tan \alpha_{2}}, \\
\Delta \theta_{1} & =\gamma(h-z),
\end{aligned}
$$

and

$$
\begin{aligned}
Q_{3} & =\rho c_{\rho} \frac{T}{\theta} \int_{0}^{H} \int_{\nu_{L}}^{y k} \int_{0}^{1} \Delta \theta_{2} d x d y d z, \\
& =\rho c_{\rho} \frac{T}{\theta} \gamma\left[\frac{l}{2} H^{2}+\frac{C}{6} H^{3}\right],
\end{aligned}
$$

where

$$
\Delta \theta_{2}=\gamma(H-z) .
$$

In order to simplify the integration, it was assumed that the valley temperature structure is horizontally homogeneous across the valley, that mass is removed from the valley in such a way that the potential temperature gradient in the inversion layer does not change with time, and that $\rho$ and $c_{p}$ are constant. By differentiating the individual energies $Q_{2}$ and $Q_{3}$ with respect to time, the rates of change of the height of the top of the inversion and the height of the CBL are obtained, such that

$$
\begin{aligned}
& \frac{d Q_{2}}{d t}=\rho c_{1} \frac{T}{\theta} \gamma\left[-h \frac{d h}{d t}\left(l+\frac{h C}{2}\right)\right], \\
& \frac{d Q_{3}}{d t}=\rho c_{p} \frac{T}{\theta} \gamma\left[H \frac{d H}{d t}\left(l+\frac{H C}{2}\right)\right] .
\end{aligned}
$$

The total rate of energy input into the valley to accomplish these changes is the fraction $A_{0}$ of solar irradiance $F$ coming across the area $L$ of the top of the inversion that is converted to sensible heat. The solar irradiance may be approximated by a sine function having a certain amplitude $A_{1}$ and period $\mathrm{r}$, so that the total rate of energy input becomes

$$
\frac{d Q_{1}}{d t}=A_{0} L F=A_{0}(l+h C) A_{1} \sin \frac{\pi}{\tau}\left(t-t_{i}\right) .
$$


An energy balance for the valley inversion is obtained by equating (14) to the sum of (12) and (13). Alternatively, a fraction of the energy input is available to drive the growth of the CBL while the rest of the incoming energy is used to remove mass from the valley. The fraction of energy input used to drive the $\mathrm{CBL}$ growth is assumed to be of the form

$$
k\left(\frac{l+H C}{l+h C}\right) \text {. }
$$

where $k$ is a number between 0 and 1 . This form is chosen in order to simplify later equations. Equating this fraction of the energy input to (12) and the remainder to (13) and solving for $d H / d t$ and $d h / d t$ results in the final model equations

$$
\begin{aligned}
& \frac{d H}{d t}=\frac{\theta}{T} \frac{k}{\rho c,}\left(\frac{l+H C}{l+k H C}\right) \\
& \times \frac{A_{0} A_{1}}{\gamma H} \sin \left[\frac{\pi}{r}\left(t-t_{i}\right)\right], \\
& \frac{d h}{d t}=-\frac{\theta}{T} \frac{1}{\rho c,}\left[\frac{l+h C-k(l+H C)}{l+1 / h h C}\right] \\
& \times \frac{A_{0} A_{1}}{\gamma h} \sin \left[\frac{\pi}{\tau}\left(t-t_{i}\right)\right] .
\end{aligned}
$$

These equations specify the dependence of the rate of ascent of the CBL and the rate of descent of the inversion top on inversion characteristics, incoming energy and valley topography. An integration of the coupled equations allows the simulation of the timedependent behavior of the heights of the CBL and inversion top. If the potential temperature $\theta_{h}$ at the top of the inversion is known and is independent of time, and $\gamma$ is constant, knowledge of the variation of $h$ and $H$ with time is sufficient to specify how vertical profiles of potential temperature change with time. When $k=0$, the equations provide an approximate simulation of Pattern 2 inversion destruction in which destruction occurs solely due to the removal of mass from a valley in the slope flows, resulting in a descent of the inversion top. When $k$ $=1$, the equations provide a simulation of Pattern 1 inversion destruction, in which destruction occurs mainly due to the growth of a CBL over the valiey floor. When $k=1$ and the valley foor becomes very wide, the simulation approaches that of inversion destruction over the plains. When $k$ is between 0 and 1 , the equations provide a simulation of Pattern 3 inversion destruction in which the inversion is destroyed by the combined effect of a growing CBL and a descending inversion top. A more complete description of the characteristics of the model equations for Pattern 1, 2 and 3 temperature structure evolution follows.

\section{b. Pattern 2 inversion destruction}

The physical hypothesis of Pattern 2 inversion destruction requires a shallow CBL to form over the sidewalls so that additional energy can be used to cause mass to flow up them. Pattern 2 destruction may be approximated by assuming that all the energy available to destroy the inversion goes solely to move mass up the sidewalls, causing the top of the inversion to descend. This can be accomplished by setting $k$ equal to zero in (15) and (16) resulting in the two equations

$$
\begin{gathered}
\frac{d H}{d t}=0, \\
\frac{d h}{d t}=-\frac{\theta}{T}\left(\frac{l+h C}{l+1 / 3 h C}\right) \frac{A_{0} A_{1}}{\rho c_{p} \gamma h} \sin \left[\frac{\pi}{\tau}\left(t-t_{i}\right)\right] .
\end{gathered}
$$

Following these equations, the CBL does not grow as a function of time, and the inversion is destroyed as the top of the inversion sinks. The rate of descent of the top of the inversion increases as the inversion descends. The descent rate is faster when more energy is available and when the potential temperature gradient of the inversion is weaker. The factor in large parentheses in (18) is a topographic factor that varies from 1 to 2 depending on the shape of the valley cross section. This accounts for the reduced volume of air within the mountain valley relative to that over the plains for the same energy flux on a horizontal surface. Since the valley has less volume to be heated by the same incoming energy, it warms more rapidly. By separating variables $h$ and $t$ and integrating from the initial conditions $h=h_{i}$ and $H$ $=0$ at $t=t_{t}$ to $h=h$ and $H=H$ at $t=t$, analytical expressions are obtained which describe how $H$ and $h$ vary with time, i.e.,

$$
\begin{gathered}
H=0 \\
1 / 4\left(h^{2}-h_{i}^{2}\right)+\frac{l}{2 C}\left(h-h_{i}\right)+\frac{l^{2}}{2 C^{2}} \ln \left(\frac{l+h_{t} C}{l+h C}\right) \\
=\frac{\theta}{T} \frac{A_{0} A_{1}}{\rho c_{p} \gamma} \frac{\tau}{\pi}\left\{\cos \left[\frac{\pi}{T}\left(t-t_{t}\right)\right]-1\right\} .
\end{gathered}
$$

Fig. 2 illustrates the shapes of the curves of $h$ vs $t$ for a reference simulation and for two cases where one parameter in the reference simulation is changed. The reference simulation uses representative values of valley parameters observed in western Colorado including $l=1000 \mathrm{~m}, \alpha_{1}=\alpha_{2}=15^{\circ}, h_{i}=500 \mathrm{~m}$, $\gamma=0.025 \mathrm{~K} \mathrm{~m}^{-1}, \tau=12 \mathrm{~h}=43200 \mathrm{~s}, T / \theta=1$ and $\rho=1 \mathrm{~kg} \mathrm{~m}^{-3}$. The reference inversion takes nearly $4^{1 / 2} \mathrm{~h}$ to be destroyed when $A_{0} A_{1} / \rho c_{p}=0.25 \mathrm{~K} \mathrm{~m} \mathrm{~s}^{-1}$. Fig. 2 was obtained by a numerical integration of (18) using a forward finite difference scheme and a time step of $10 \mathrm{~min}$.

An analytical expression for the time required to 


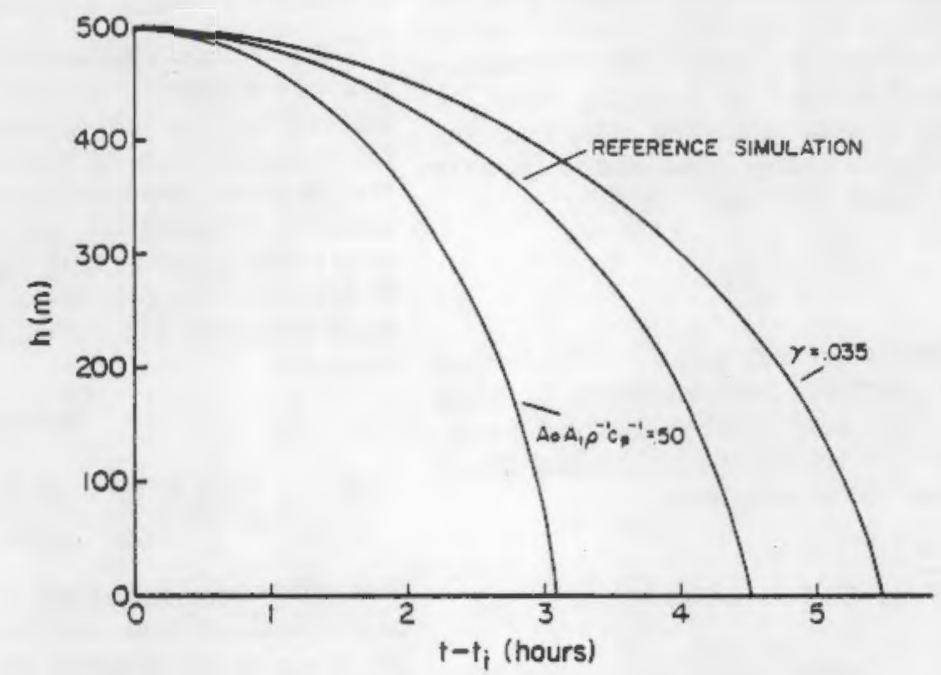

Fig. 2 Descent of inversion top as a function of time for the reference inversion simulation and for two simulations for which the single parameters indicated were changed. Pattern 2 deatruction.

destroy an inversion can be obtained by inregrating (18) from the initial conditions to the final conditions of $h=0$ at $t=t_{D}$. This expression,

$$
\begin{aligned}
t_{D}-t_{i}= & \frac{\tau}{\pi} \cos ^{-1} 1-\frac{T}{\theta} \frac{\rho C_{p} \gamma}{A_{0} A_{1}} \frac{\pi}{\tau} \\
& \left.\times\left[\frac{h_{i}^{2}}{4}+\frac{l h_{i}}{2 C}+\frac{l^{2}}{2 C^{2}} \ln \left(\frac{l}{l+h_{i} C}\right)\right]\right\},
\end{aligned}
$$

enumerates the factors affecting inversion breakup time. The sensitivity of inversion breakup time (measured from sunrise) to the various parameters is il- lustrated in Fig. 3 using the reference simulation above. The reference inversion takes $4.4 \mathrm{~h}$ to break (vertical line in Fig. 3). The effect on the time required to destroy the reference inversion by varying the individual parameters is obtained by following the labeled curves. Thus, varying the initial height of the inversion from 400 to $600 \mathrm{~m}$, other parameters being equal, changes the time required to destroy the inversion from 3.5 to $5.4 \mathrm{~h}$. For the reference inversion, the most sensitive parameters affecting the time required to break an inversion are the available energy and the initial potential temperature gradient

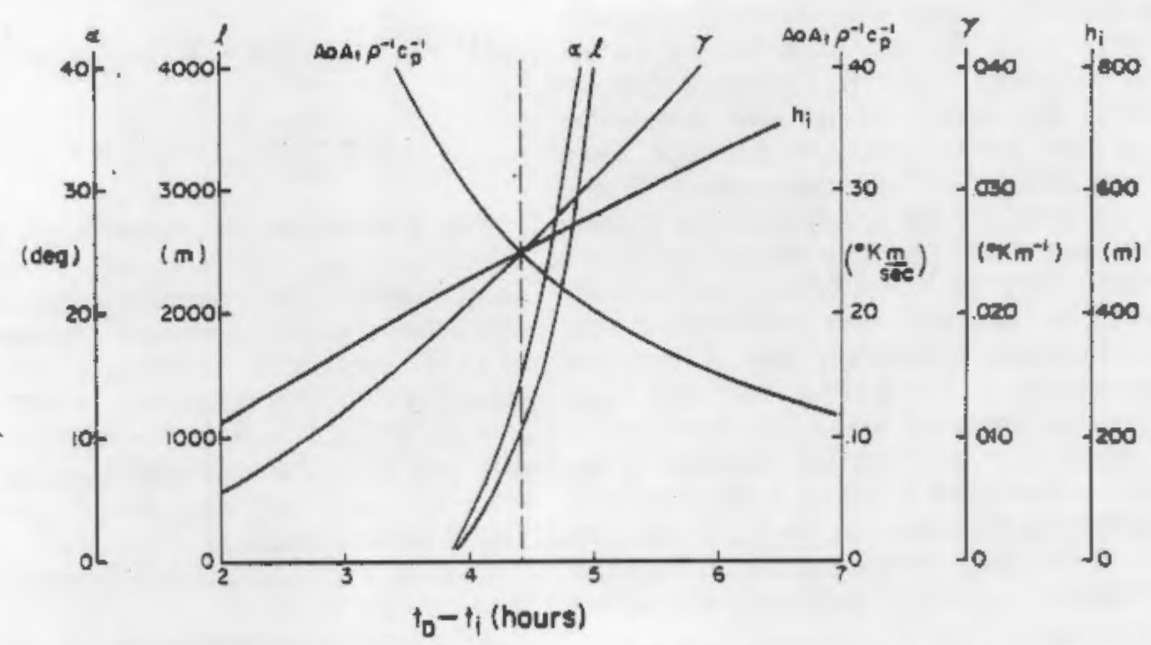

F1c. 3. Sensitivity of inversion destruezion time to various model parameters for Pattern 2 destruction. 


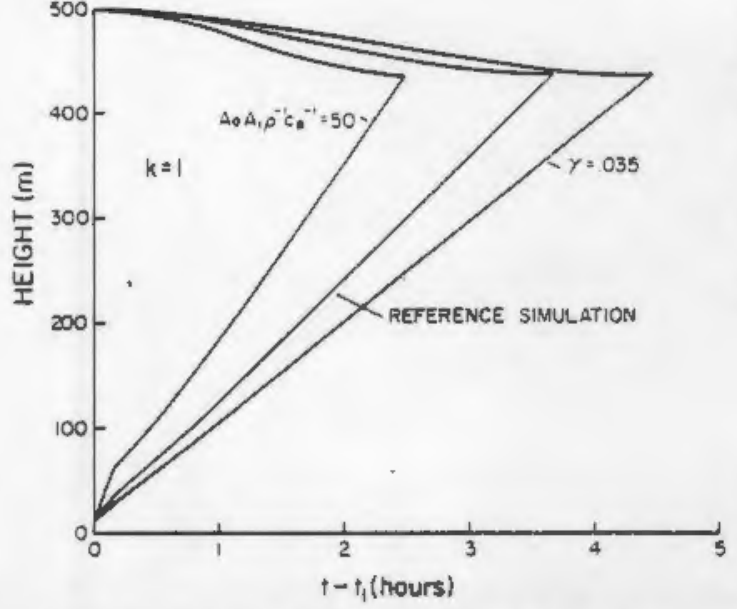

FrG. 4. Ascent of CBL and descent of inversion top as a function of time for Patcern 1 inversion destruction in a valley for the reference simulation and for two simulations in which single parameters were changed to the values indicated.

and inversion height. In the normally dry Colorado valleys the most important factors affecting the available energy are albedo (snow versus no snow) and latent heat flux. The effect of valley shape on the breakup time is relatively smail for normal ranges of $\alpha$ and $l$ encountered in valleys of western Colorado. Nevertheless, it is apparent that the valley width and sidewall angies may affect the mode of inversion destruction since they control, to a certain extent, the divergence of mass in the CBL's and thus determine whether inversion destruction more nearly follows Pattern 1 or Pattern 2. Overall, predictions of the time required to destroy inversions, given typical values of the parameters observed in field experiments, are consistent with the observed range of $3.5-5 \mathrm{~h}$.

\section{c. Pattern I inversion destruction-Valley case}

A useful approximation to Pattern ! inversion destruction can be obtained from the model equations by setting $k=1$ in (15) and (16). The general equations then reduce to the two equations

$$
\begin{aligned}
& \frac{d H}{d t}=\frac{\theta}{T}\left(\frac{l+H C}{l+H_{h H C}}\right) \frac{A_{0} A_{1}}{\rho c_{p} \gamma H} \sin \left[\frac{\pi}{\tau}\left(t-t_{t}\right)\right], \\
& \frac{d h}{d t}=-\frac{\theta}{T}\left[\frac{(h-H) C}{l+1 / 2 h C}\right] \\
& \times \frac{A_{0} A_{1}}{\rho c_{p} \gamma h} \sin \left[\frac{\pi}{\tau}\left(t-t_{i}\right)\right] .
\end{aligned}
$$

Eq. (22) is formulated so that the entire fraction $A_{0}$ of the energy coming across the area $(l+H C)$ of the top of the CBL is ased to cause the CBL to grow. The energy ased to cause the top of the in- version to descend is the fraction $A_{0}$ of the difference between the energy coming across the top of the inversion and the energy coming across the top of the CBL. The time-dependent behavior of the height of the CBL can be obtained by an integration of (22) from the initial condition of $H=0$ at $t=t_{i}$ to the final condition of $H=H$ at $t=t$, such that

$$
\begin{aligned}
\frac{H^{2}}{4}+\frac{l H}{2 C} & +\frac{l^{2}}{2 C^{2}} \ln \left(\frac{l}{l+H C}\right) \\
& =\frac{\theta}{T} \frac{A_{p} A_{1}}{\rho c_{p} \gamma} \frac{\tau}{\pi}\left(1-\cos \left[\frac{\pi}{T}\left(t-t_{1}\right)\right]\right\} .
\end{aligned}
$$

The integration of (22) and (23) can be accomplished numerically to determine how $h$ and $H$ change with time in a Pattern 1 inversion destruction in a mountain valley. This is done for the reference simulation and for two simulations in which a single parameter of the reference simulation is changed. The resulting plots are shown in Fig. 4. The characteristics of the plots include a near-linear growth of the CBL with time, a slow descent of the inversion top, and a more rapid breakup than for Pattern 2 destruction. Pattern 1 destruction takes $3.7 \mathrm{~h}$ versus the $4.4 \mathrm{~h}$ required for Pattern 2 breakup. The same total amount of energy is required to destroy the reference inversion, whether it is destroyed following Pattern 1 or Pattern 2. However, since the energy available to destroy the inversion comes across the area of the top of the inversion, and this area is larger when the inversion top sinks more slowly, the total amount of energy required to destroy the inversion is attained earlier in the day, resulting in an earlier inversion breakup.

\section{d. Pattern I inversion destruction-Flat plains case}

Application of (22) and (23) to a valley that is very wide or approaches a plain $(l \rightarrow \infty)$ results in the equations

$$
\begin{aligned}
& \frac{d H}{d t}=\frac{\theta}{T} \frac{A_{0} A_{1}}{\rho c_{\rho} \gamma H} \sin \left[\frac{\pi}{t}\left(t-t_{i}\right)\right], \\
& \frac{d h}{d t}=0 .
\end{aligned}
$$

Thus, over flat terrain where no topographically induced mass divergence occurs from the CBL, the inversion is destroyed solely by the growth of a CBL. Performing integrations on (25) as described in the previous section resuits in the analytical expression

$$
H(t)=\left\{2 \frac{\theta}{T} \frac{\tau}{\pi} \frac{A_{0} A_{1}}{\rho c_{p} \gamma}\left[1-\cos \frac{\pi}{\tau}\left(t-t_{i}\right)\right]\right\}^{1 / 2},
$$

and an expression for the breakup time,

$$
t_{D}-t_{i}=\frac{\tau}{\pi} \cos ^{-1}\left(1-\frac{T}{\theta} \frac{\rho c_{p} \gamma}{A_{0} A_{1}} \frac{\pi}{\tau} \frac{h_{f}^{2}}{2}\right) .
$$




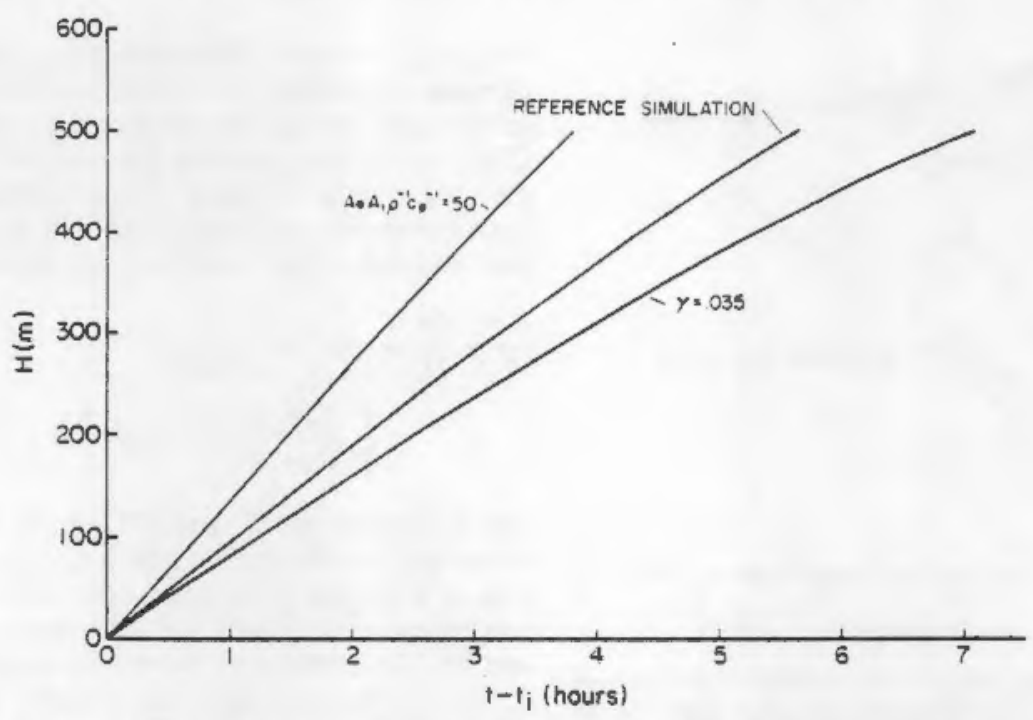

FIG. 5. Grownth of CBL over flat terrain as a function of time for the modified reference inversion $(\alpha=0,1 \rightarrow \infty)$ and for two simulations in which single parameters were changed to the values indieated Pattern 1 destruction.

Eq. (27) is nearly identical to an equation for CBL growth over homogeneous terrain as derived by Leahey and Friend (1971). Following (27), Fig. 5 presents plots of $H$ vs time for the reference simulation and for two cases where one parameter in the reference simulation has been changed. The reference inversion is destroyed in $5.65 \mathrm{~h}$ by a near-linear increase in the depth of the CBL. If the incoming energy is doubled, the inversion takes $3.8 \mathrm{~h}$ to break, and if the potential temperature gradient is increased to $0.035 \mathrm{~K} \mathrm{~m}^{-1}$, the inversion is broken in $\sim 7.1 \mathrm{~h}$. Fig. 6 indicates the sensitivity of the time required to break an inversion on the different parameters of (28). The effect on the breakup time of changing individual parameters in the reference simulation is obtained by following the individual curves.

\section{e. Pattern 3 inversion destruction}

A simulation of Pattern 3 inversion destruction uses the general model [Eqs. (15) and (16)], in which a partitioning of energy is required to allow both $\mathrm{CBL}$ growth and inversion top descent. In order to use the general model equations, the fraction of sen-

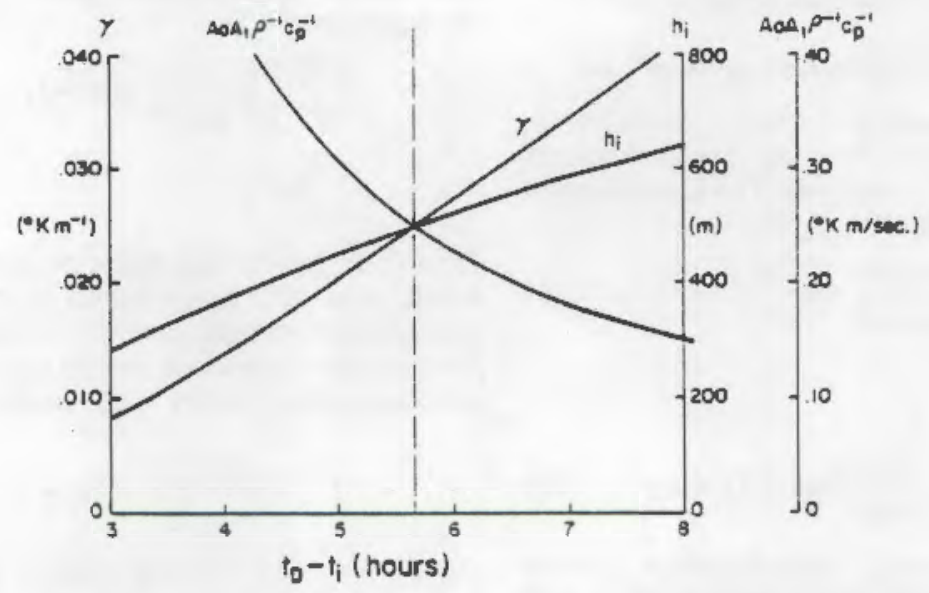

FIG. 6. Sensitivity of inversion destruction time to various model parameters for Pattern 1 inversion destruction over flat terrain. 


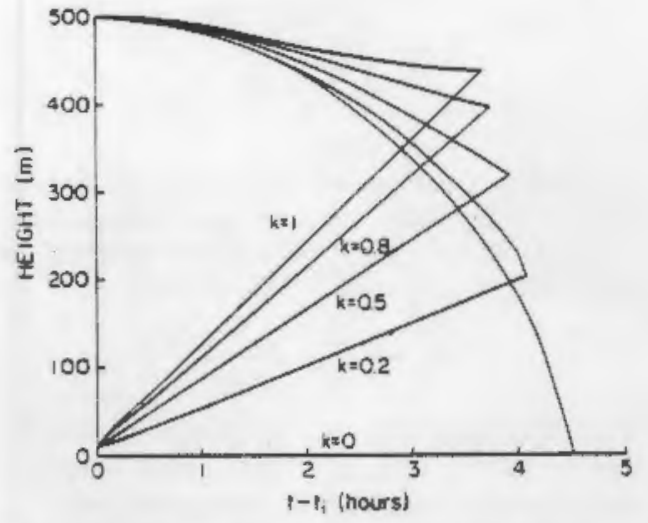

FyG. 7. Aveent of CBL and descent of inversion top as a function of time for Pattern 3 destruction of the reference inversion for different values of $k$.

sible heat flux $K=k[(l+H C) /(l+h c)]$ that drives the growth of the CBL must be determined. It is apparent that the fraction $\boldsymbol{K}$ is a function of time, since the initial energy input must be used primarily to develop the CBL's before appreciable mass can be carried up them. Factor $K$ also depends on the topographic characteristics of the valley, since $K$ must approach 1 as the valley width approaches infinity. It seems probabie that $K$ may aiso be a function of sensible heat flux. Since the functional dependencies of $K$ are not yet known, it is assumed that $k$ is a constant and, by comparing model simulations to actual data, the constant value of $k$ that results in the best fit to data is determined. This approach allows an investigation of the effect of $k$ on the simulation. Further research is necessary to determine the actual functional form of $K$, so that a better understanding of the energy partitioning phenomenon can be obtained, resulting in more accurate simulations.

The equations used to simulate Pattern 3 destruction are thus

$$
\begin{array}{r}
\frac{d H}{d t}=\frac{\theta}{T} \frac{k}{\rho c}\left(\frac{l+H C}{l+1 / 2 H C}\right) \frac{A_{0} A_{1}}{\gamma H} \\
\times \sin \left[\frac{\pi}{\tau}\left(t-t_{i}\right)\right], \\
\frac{d h}{d t}=-\frac{\theta}{T} \frac{1}{\rho c_{p}}\left[\frac{l+h C-k(l+H C)}{l+1 / 2 h C}\right] \frac{A_{0} A_{1}}{\gamma h} \\
\times \sin \left[\frac{\pi}{\tau}\left(t-t_{i}\right)\right],
\end{array}
$$

where

$$
0 \leqslant(k=\text { constant }) \leqslant 1 .
$$

These equations can be integrated numerically to determine how $H$ and $h$ vary with time from a given initial state. Fig. 7 shows several numerical integrations using this method, time steps of $10 \mathrm{~min}$, the reference simulation, and several values of $k$. Replotted on the same n̂gure are some of the limiting cases of the general equations for destruction of the reference inversion discussed earlier. The time required to break the reference inversion decreases from 4.4 to $3.7 \mathrm{~h}$ as the value of $k$ is increased from 0 to 1 . For all values of $k$ the growth of the CBL is nearly linear.

Fig. 8 shows the effect of varying individual parameters in the reference simulation with $k$ fixed. The inversion is destroyed when the ascending CBL and the descending inversion top meet at a height of $H_{D}=h_{D}=205 \mathrm{~m}$. The fact that the fraction $k$ uniquely determines the height at which the ascending $C B L$ meets the descending inversion top at the time of inversion destruction, suggests a means of fitting the model results to actual data that will be used in a later section.

\section{f. Model modification to account for warming of the neutral layer}

Field observations show that the potential temperature $\theta_{h}$ at the top of the inversion usually increases slowly with time. The warming rate varies from valley to valley and from day to day with the average warming rate being about $0.4 \mathrm{~K} \mathrm{~h}^{-1}$. From the physical hypothesis, this warming requires that more energy be spent to move mass up the sidewalls, since the parceis must be warmed to a higher temperature $\theta_{h}(t)=\theta_{h}\left(t_{i}\right)+\left(d \theta_{h} / d t\right) \delta t$ to be removed from the valley. The energy requirement can be cal-

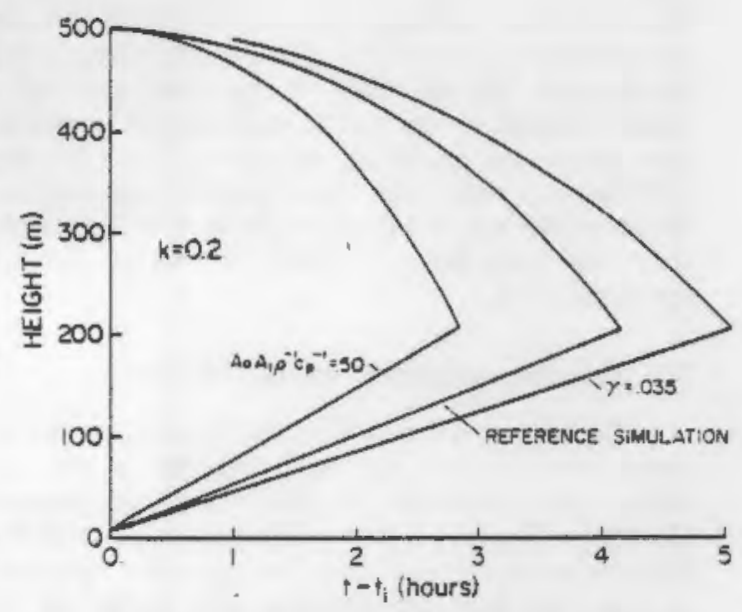

FiG. 8. Ascent of CBL and descent of inversion top for Pattern 3 deatruction $(k=0.2)$ of the reference invertion, and for two simulations in which single parameters were changed to the values indicated. 
culated by considering that the mass of air removed from the valley to allow the top of the inversion to sink from $h_{i}$ to $h$ is given by

$$
\text { mass removed }=\rho V
$$

$$
=\rho\left(h_{i}-h\right)\left[l+1 / 2\left(h_{i}+h\right) C\right],
$$

and that the energy required to move this mass across a potential temperature jump at the top of the inversion, $\theta_{h}(t)-\theta_{h}\left(t_{i}\right)$ can be approximated by

$$
Q_{4}=\rho V c_{p} \frac{T}{\theta} 1 / 2\left[\theta_{k}(t)-\theta_{k}\left(t_{i}\right)\right] .
$$

If the warming in the neutral layer occurs linearly in time, the potential temperature jump is given by $\beta\left(t-t_{i}\right)$ where $\beta=\partial \theta_{h} / \partial t$ is the rate of waming. Then

$$
\begin{aligned}
Q_{4}=\rho c, \frac{T}{\theta} \frac{\beta}{2}\left(h_{t}-h\right)\left(t-t_{t}\right) & \\
& \times\left[l+1 / 2\left(h_{t}+h\right) C\right],
\end{aligned}
$$

$$
\begin{array}{r}
\frac{d Q_{4}}{d t}=\rho c_{p} \frac{T}{\theta} \frac{\beta}{2}\left[\left(h_{i}-h\right)\left[l+1 / 2\left(h_{i}+h\right) C\right]\right. \\
\left.-\left(t-t_{i}\right) \frac{d h}{d t}(l+h C)\right] .
\end{array}
$$

The model equations are modified to account for this extra energy requirement by specifying that the fraction $k\{(l+H C) /(l+h C)\}$ of the inversion energy input $d Q_{1} / d t$ drives the CBL growth, or

$$
k\left(\frac{l+H C}{l+h C}\right) \frac{d Q_{1}}{d t}=\frac{d Q_{2}}{d t},
$$

while the remainder of the energy input drives the descent of the inversion and carries parcels across the potential temperature jump, such that

$$
\left[1-k\left(\frac{l+H C}{l+h C}\right)\right] \frac{d Q_{1}}{d t}=\frac{d Q_{3}}{d t}+\frac{d Q_{4}}{d t} .
$$

Substituting Eqs. (12), (13), (14) and (35), the modified model equations are

$$
\frac{d H}{d t}=\frac{\theta}{\mathrm{T}} \frac{\mathrm{k}}{\rho \mathrm{c}_{p}}\left(\frac{l+H C}{l+1 / 2 H C}\right) \frac{A_{0} A_{1}}{\gamma H} \sin \left[\frac{\pi}{\tau}\left(t-t_{l}\right)\right] \text {, }
$$

These equations can be used to simulate inversion breakup when significant warming occurs in the neutral layer above. Eq. (39) reduces to (30) when $\beta$ is zero. It is important to note that $(38)$ has the same form as before but, since more energy is required to move mass up the sidewalls, the partitioning of energy may be affected. If this actually occurs in nature, then the functional dependency of $K$ is more complicated than previousiy discussed, since it will depend not only on time, energy input and valley width, but also on the rate of warming of the neutral layer above the inversion. As before, Eqs. (38) and (39) may be integrated numerically to simulate valley inversion breakup if $\theta_{h}(t)$ is known. If $\theta_{h}$ does not vary with time, Eqs. (29) and (30) can be used for the simulation.

\section{Comparison of model results with data}

In this section a finite difference form of the model equations (38) and (39) will be applied to simulate actual data collected in the valleys of western Colorado. The input parameters needed to solve the equations are given in Table $l$ along with a summary of how they may be obtained. The output of the model is $h(t)$ and $H(t)$. From these outputs and the assumptions that $\gamma$ is constant for altitudes between $H$ and $h$, that potential temperature is independent of height in the CBL and neutral layer, and that $\theta_{h}\left(t_{i}\right)$ and $\partial \theta_{h} / \partial t$ are known, $\theta(t, z)$ for the CBL. stable core and neutral layer can be determined. Unfortunately, since two of the input parameters to the thermodynamic model ( $k$ and $A_{0}$ ) were not observed in the field programs, the equations cannot be applied directly. Instead, arbitrary values for $k$ and $A_{0}$ are chosen until the best simulation of the data is obtained with the model. It is then determined whether the values of $k$ and $A_{0}$ are reasonable for the situation at hand. Both $k$ and $A_{0}$ are bounded, since they are fractions between 0 and 1 . The value of $k$ specifies the constant fraction of sensible heat flux that is used to cause the CBL to deepen. The model results are presented below for a winter Pattern 2 inversion destruction in the wide Yampa Valley and for a fall Pattern 3 inversion destruction in the Eagie Valley.

\section{a. Pattern 2 simulation-Yampa Valley, 23 Feb- ruary 1978}

The model input parameters required to simulate the Pattern 2 inversion destruction observed in the snow covered Yampa Valley on 23 February 1978 were obtained as follows. First, $\theta T^{-1}=1.07$ and $\rho c_{p}=1040 \mathrm{~J} \mathrm{~m}^{-3} \mathrm{~K}^{-1}$ were calculated using the ap- 
TABLE 1. Model input parameters.

\begin{tabular}{|c|c|c|c|}
\hline Model input & & & Source \\
\hline Constants & $\begin{array}{l}\text { (i) } \\
\text { (ii) }\end{array}$ & $\begin{array}{l}\theta / T \\
\rho C\end{array}$ & from average $P$ and $T$ of valiey atmosphere \\
\hline Valley topography & $\begin{array}{l}\text { (iii) } \\
\text { (iv) }\end{array}$ & $\frac{1}{c}$ & from topographic maps \\
\hline Initial inversion characteristics & $\begin{array}{l}(v) \\
\text { (vi) }\end{array}$ & $\begin{array}{l}\gamma \\
h_{f}\end{array}$ & from sunrise sounding \\
\hline Solar irradiance. & $\begin{array}{l}\text { (vii) } \\
\text { (viii) } \\
\text { (ix) }\end{array}$ & $\begin{array}{l}A_{1} \\
i_{t}\end{array}$ & $\begin{array}{l}\text { from extraterresurial solar irradiance model } \\
\text { or fieid notes for } t_{i}\end{array}$ \\
\hline External conditions (neutral layer warming) & $(x)$ & $\beta$ & $\begin{array}{l}\text { from sequential soundings laken during } \\
\text { observation of inversion breakup or from } \\
\text { climatic dala }\end{array}$ \\
\hline Energy partition & (xi) & $k$ & comparisons of theory and dala \\
\hline Surface energy bajance & (xii) & $A_{0}$ & measurements, if availabie \\
\hline Numerical & $\begin{array}{l}\text { (xiii) } \\
\text { (xiv) }\end{array}$ & $\begin{array}{l}H_{1} \sim 0 \\
N\end{array}$ & arbitrary \\
\hline
\end{tabular}

proximate mean pressure $(780 \mathrm{mb})$ of the early morning inversion and an average temperature of the valiey atmosphere $\left(-10^{\circ} \mathrm{C}\right)$ from the defining equation for potential temperature and from the equation of state, respectively. Second, the valley topographic parameters $\left(l=2580 \mathrm{~m}, \alpha_{1}=9^{\circ}, \alpha_{2}=16^{\circ}, C\right.$ $=9.80$ ) were obtained from topographic maps. Third, the initial inversion parameters $\left(h_{i}=530 \mathrm{~m}\right.$, $\gamma=0.0345 \mathrm{~K} \mathrm{~m}^{-i}$ ) were estimated from a straight line fit to the top of the 0714 MST sounding on this date. The hyperbolic lower region of the sounding could not be adequately fit with a straight line, so it is ignored in the analysis. Fourth, a sinusoidal fit to the extraterrestrial solar flux curve obtained from a standard solar irradiance model (e.g., Sellers,
1965) provides solar irradiance parameters $\left(A_{1}\right.$ $=878 \mathrm{~W} \mathrm{~m}^{-2}, t_{\mathrm{t}}=0655 \mathrm{MST}, \tau=10.9 \mathrm{~h}$ ). The output of the solar irradiance model for the horizontal surface of interest is presented in Fig. 9. For reference, the solar fluxes on extraterrestrial surfaces with the same aspect and inclination angles as the valley sidewalls are indicated on the figure. The input required to run the solar irradiance model includes the date and the latitude and longitude of the Yampa Valley site. The remaining parameters necessary to run the inversion destruction model are fractions $k$ and $A_{0}$ and the neutral layer warming rate $\beta$. To simulate a Pattern 2 destruction, $k$ must be zero. The neutral layer warmed only $1.1 \mathrm{~K}$ during the inversion destruction, for a warming rate $\beta$ of $2.8 \times 10^{-5} \mathrm{~K}$

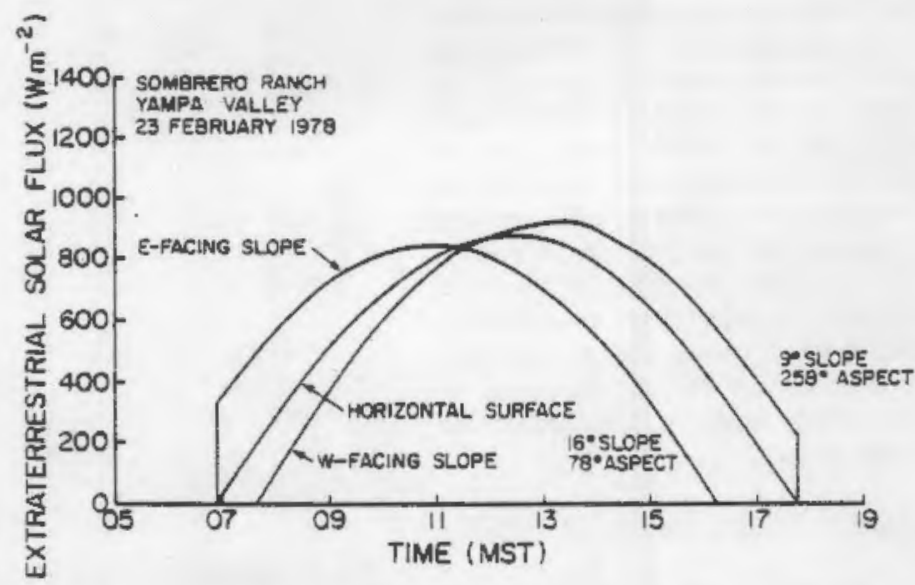

Fio. 9. Extraterreatrial solar flux calculated for yalley floor and sidewall surfaces of the Yampa Valley, 23 February 1978. 


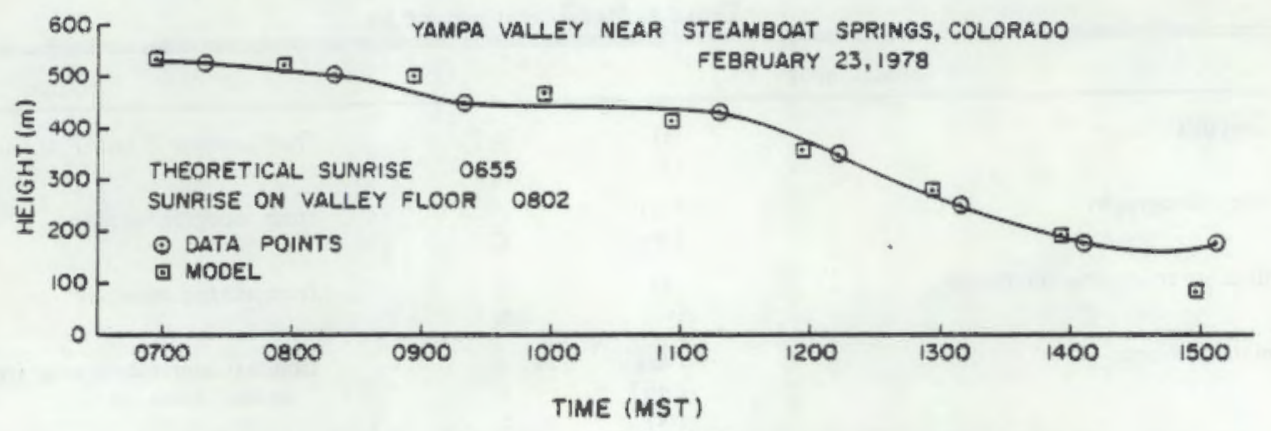

Fio. 10. Comparison of modei simulation of $h(t)$ with actual data for the Yampa Valley, 23 February 1978.

$\mathrm{s}^{-1}$. The best fit of the model output $h(t)$ to the inversion top data of Fig. 10 was obtained with $A_{0}$ $=0.19$ by a trial-and-error procedure. Using this value, the simulation of the height of the top of the inversion agrees to within $25 \mathrm{~m}$ of the data over a $7 \mathrm{~h}$ period. In mid-afternoon, however, the simulation continues to call for the descent of the inversion top, when the actual data indicate that the descent stopped. This is probably due to afternoon shading of the valley by a mountain peak southwest of the site. The model, using a simpie sine function to simulate solar flux, does not account for this shading. In Fig. 11 the potential temperature profile simulations are compared to actual sounding data. The sounding data consist of eight consecutive potential temperature soundings taken at $\sim 1 \mathrm{~h}$ intervals throughout the day. The characteristics of the initial inversion were obtained from the 0714 MST sounding and are indicated by the straight line fit to the sounding in the figure. The slow neutral layer warming is also apparent in the figure. The excellent fit of the model simulations to the data in the stable core above the $50 \mathrm{~m}$ deep surface layer is shown for soundings 4 and 6 . The value of $A_{0}$ required to obtain these results seems reasonable for the snow-covered valley with evergreen forests covering much of the valley sidewail above the observation site. It is particularly interesting that the model assumption of constant potential temperature gradient was satisfied well during the long period of inversion destruction in the complicated topography of the Yampa Valley. The case study is an excellent exampie of the effect of enhanced albedo due to snow cover in retarding the normal breakup of an inversion. Despite the fact that the temperature inversion was not destroyed on this clear day, the diurnal range of temperature at the ground was quite large.

\section{b. Pattern 3 simulation-Eagle Valley, 16 October 1977}

Pattern 3 inversion breakup in the Eagle Valley is remarkably consistent in all seasons when snow cover is not present in the valley. To test the mathematical model, the Pattern 3 breakup on the clear day of 16 October 1977 is chosen for simulation. The input parameters to the model are obtained as for the Pattern 2 simulation above. Thus, values of the constants $\theta T^{-1}(1.08)$ and $\rho c_{p}\left(990 \mathrm{~J} \mathrm{~m}^{-3} \mathrm{~K}^{-1}\right)$ are determined from the approximate mean pressure $(768 \mathrm{mb})$ and temperature $\left(0^{\circ} \mathrm{C}\right)$ of the valley inversion. The valley topographic parameters $(l=1450$ $\left.\mathrm{m}, \alpha_{1}=21^{\circ}, \alpha_{2}=10^{\circ}, C=8.28\right)$ are determined from topographic maps. The initial values of the inversion parameters $\left(h_{i}=650 \mathrm{~m}\right.$ and $\gamma=0.0269 \mathrm{~K}$ $\mathrm{m}^{-1}$ ) were taken from the $0650-0719$ MST sounding since the pre-sunrise sounding was of insufficient height to determine $h_{i}$. A solar irradiance modei was used to determine the parameters $A_{1}=906 \mathrm{~W} \mathrm{~m}^{-2}$, $t_{i}=0621 \mathrm{MST}$ and $\tau=11 \mathrm{~h}$ (Fig. 12). The value of $\beta\left(8.3 \times 10^{-5} \mathrm{~K} \mathrm{~s}^{-1}\right)$ was taken from valley temperature sounding data.

The fitting of the model output to the data on Fig. 13 was accomplished first by choosing the value of

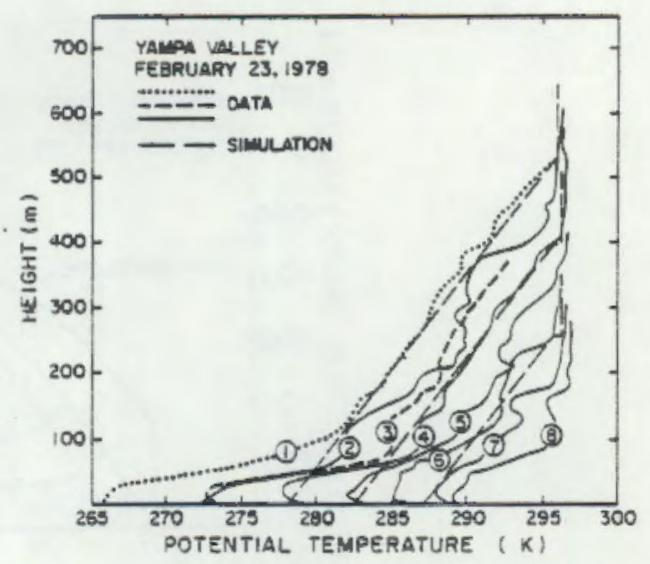

FIG. 11. Comparison of model simulation of potential temperature structure with data for the Yampa Valley, 23 February 1978. Upsoundings 1-8 were initiated at 0714, 0905, 0959, 1100, 1202. 1259,1359 and 1508 MST, respectively. 


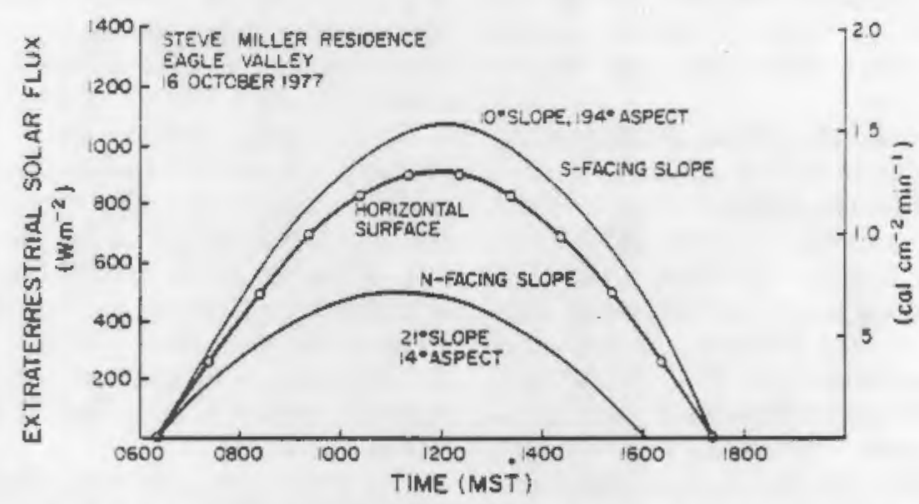

FIG. 12. Extraterrestrial solar flux ealculated for valley floor and sidewail surfaces of Eagie Valley, 16 October 1977.

$k$ so that the ascending CBL and descending inversion top met at the proper observed height at the time of inversion destruction. The value of $A_{0}$ was then varied until the model outputs $h(t)$ and $H(t)$ fit the data weil. The fit in Fig. 13 was obtained with $k=0.14$ and $A_{0}=0.45$. The value of $A_{0}$ seems realistic considering the dry nature of the valley surface on this date. The equations were integrated from the initial conditions of $h=650 \mathrm{~m}$ and $H=10 \mathrm{~m}$ at $t=0705 \mathrm{MST}$ using a time step of $10 \mathrm{~min}$. From Fig. 13 it is clear that a good fit to the data is obtained with the chosen values of the two parameters $A_{0}$ and $k$. The simulation of CBL height and inversion top height agrees with the data within $50 \mathrm{~m}$ over most of the period of inversion destruction. The CBL height was overpredicted early in the inversion period, due to the bulk nature of the model. Following sunrise the CBL develops first over the illuminated sidewall or sidewalls, and somewhat later over the valley floor when it is sunlit. The bulk model, however, does not differentiate between CBL growth over the three different valley surfaces. All energy going into CBL growth is attributed, in the model, to growth of the valley floor CBL. Thus, the initial

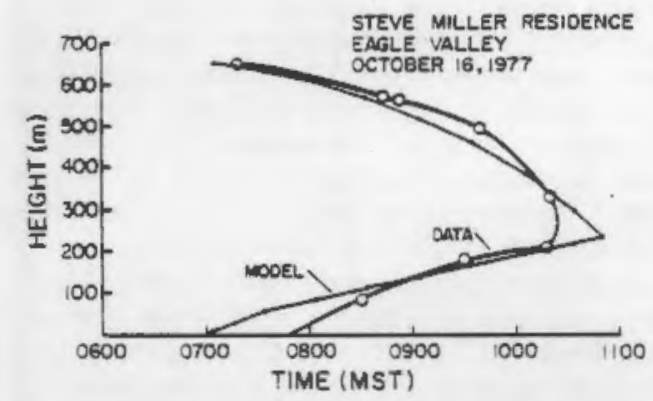

FIC. 13. Comparison of modei simulation of $H(t)$ and $h(t)$ with actual data for the Eagle Valley, 16 October 1977. overprediction of CBL growth over the valley floor is a characteristic feature of the model equations. The behavior of the simulation at mid-levels of the valley atmosphere near the time of inversion destruc. tion should also be mentioned. The data typically show a more sudden inversion breakup is to be expected in nature since the final remnants of the stable core will break up in convective overturning, once the stable core becomes thin enough and the convective plumes rising from the valley floor become vigorous enough. Due to the chaotic nature of the breakup, actual soundings taken during this time will often show deformations in the vertical potentiai temperature profiles. Estimates of heights $h$ and $H$ from soundings are difficult to make during this time. A continued flux of energy into this region is nec-

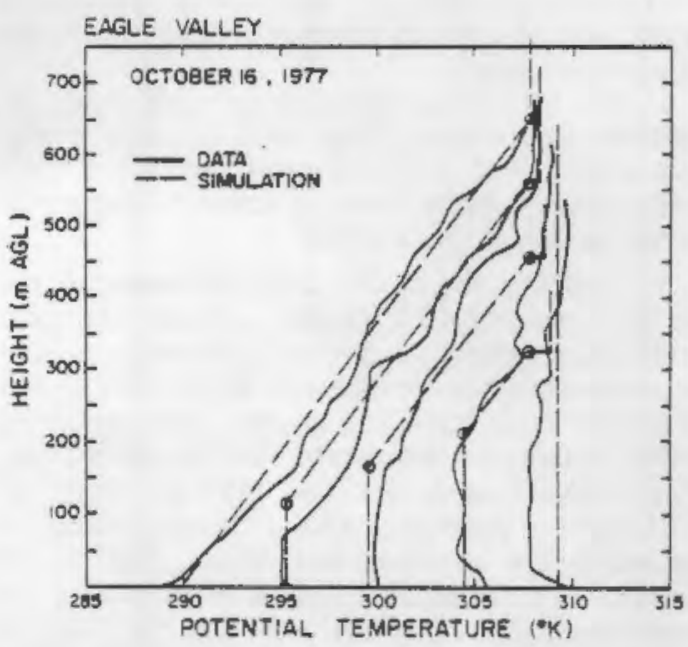

Fic. 14. Comparison of model simulation of potential temperature structure with data from the Eagle Valiey, 16 October 1977. 
essary before the deformations in the profiles are destroyed and well-organized convection through the entire depth of the valley results in smooth neutral profiles. When this occurs, the breakup can be considered as finished.

The potential temperature profiles corresponding to the data and simulation of Fig. 13 are presented in Fig. 14. The potential temperature data are from the tethersonde up-soundings taken at 0650-0719, 0829-0848, 0924-0948, 1013-1033 and 1106-1121 MST. The corresponding potential temperature simulations are plotted for the approximate midtimes of the tethersonde up-soundings at 0840, 0935, 1025 and 1115. Again, the model provides a good simulation of the actual data, reproducing the warming and growth of the CBL, the warming of the stable core, and the descent of the inversion top.

\section{Summary and conclusions}

A thermodynamic model of valley temperature structure evolution has been developed. By differentiating the first law of thermodynamics, the rate of energy input into the valley atmosphere is equated to the rate of descent of the inversion top and the rate of ascent of the CBL under the following assumptions:

1) The potential temperature gradient in the stabie core is constant during the period of inversion breakup.

2) The temperature structure is horizontally homogeneous in the cross-yalley direction.

3) The valley topography can be adequately represented by a horizontal valley floor of arbitrary width and two linear sidewalls of arbitrary slope.

4) The initial inversion at sunrise can be adequateiy represented by a constant potential temperature gradient layer of arbitrary depth.

5) Convective boundary layers can be adequately represented as constant potential temperature layers of arbitrary beight.

6) The rate of energy input into the valley atmosphere is a constant fraction of the solar energy flux (assumed to be a sinusoidal function of time from sunrise to sunset) coming across the horizontal upper surface of the inversion.

To complete the model, the partitioning of the energy input into CBL growth and mass transport must be estimated. As a first approximation, it is assumed that a constant fraction of the energy input is used to cause the CBLs to grow. The remaining energy is used for mass transport in the upslope flows. Energy going into the growth of the CBL causes the CBL depth to increase with time. Energy causing air parceis to flow up the sidewall CBLs resuits in the descent of the top of the inversion. When most of the available energy drives the growth of the CBLs, a temperature structure evolves in which the inversion is destroyed predominantly by the upward growth of a CBL from the ground. When most of the available energy drives mass up the sidewalls, a temperature structure evolves in which the inversion is destroyed by the descent of the inversion top.

The inputs to the model are 1) the initial inversion characteristics (depth and average potential temperature gradient); 2) valley topography (floor width and inclination angies of the two sidewalls); 3) the rate of energy input; and 4) the fraction of energy available to increase the depth of the CBL. The effect on inversion evolution of warm air advection above the inversion layer can be investigated by using a modified version of the model in which the warming rate is input.

The model simulates the changes with time of the height of the inversion top and the depth of the CBL during the inversion breakup period. From these simulations potential temperature profiles of the valley atmosphere can be constructed for any time during the period.

Sensitivity analyses were conducted for the limiting cases of the model. The results indicate that the time required to destroy an inversion depends primarily on the initial height of the inversion, on its potential temperature gradient, and on the amount of energy available to destroy it. Using a reference simulation in which model parameters were given values typical of valley inversions, inversion destruction took approximately $3 \frac{1 / 2}{2}$ to $4 \frac{1}{2} \mathrm{~h}$ after sunrise. These times correspond well with actual observations. Less time is required to destroy a valley inversion than an inversion of like dimensions over the plains, because the available energy is used to warm a smaller volume of air. For the dry valleys of western Colorado, the amount of energy available depends to a large extent on the presence or absence of snow cover or surface moisture in the valley. Valley inversions were destroyed sooner by the growth of a CBL than by the descent of the inversion top. Valley width and inclination angies of the sidewalls had only a limited effect on the time required to destroy an inversion. Increased valley width and steeper sidewalls both increased slightly the time required.

The thermodynamic model was used to simulate two specific sets of inversion breakup data for Pattern 2 and 3 temperature structure evolution in the topographically diverse Eagle and Yampa Valleys. Simulations were obtained by fitting two constants in the model (relating to the surface energy budget and energy partitioning) to the data. The model output fit the Pattern 2 inversion breakup in the snowcovered Yampa Valley very well using an energy input equal to $19 \%$ of the extraterrestrial solar flux on a horizontal surface, and assuming that all of this energy was used to drive the slope flows. A good fit to the Eagle Valley data was obtained using an energy input equal to $45 \%$ of the extraterrestrial solar 
flux and assuming that $14 \%$ of this energy was used to cause the valley floor CBL to grow. The remaining energy was used to remove mass from the valley in the slope flows.

Resuits of the present study provide new insights into the evolution of valley temperature structure and quantify the influence of the various parameters affecting temperature inversion breakup. The model explains the importance of the initial sunrise inversion characteristics; the observed timing of the beginning of inversion destruction; the mean time required to destroy typical inversions in the deep valleys of western Colorado; the weak seasonal dependence of the time period required to destroy the inversions; the effects of snow cover and ground moisture and of valley topography; the patterns of warming observed in the various layers of the temperature structure; the typical observed inversion top descent rates of $40-150 \mathrm{~m} \mathrm{~h}^{-1}$; and the retarded growth of the valley CBL's relative to the flat plains case. The thermodynamic model, while implicitly incorporating up-slope mass transport, is able to simulate tem- perature structure evolution in a wide range of valley topography without taking account of along-yalley wind systems.

Acknowledgments. The research was accomplished at the Department of Atmospheric Science, Colorado State University, under funding from Grant ATM76-84405, Atmospheric Sciences Section, National Science Foundation. The manuscript was prepared under funding from the Environmental Protection Agency through Interagency Agreement AD-89-F-0-097-0, with the U.S. Department of Energy.

\section{REFERENCES}

Leahey, D. M., and J. P. Friend, 1971: A model for predicting the depth of the mixing laver over an urban heat island with applications to New York City. J. Appl. Meteor., 10, 11621173.

Seilers, W. D., 1965: Physical Climatology. University of Chicago Press. 272 pp.

Whiteman. C. D.. 1982: Breakup of temperature inversions in deep mountain valleys: Part I. Observations. J. Appl. Meteor., 21, 270-289. 
